\title{
ANÁLISE EXPERIMENTAL DE PILARES DE CONCRETO ARMADO DE ALTA RESISTÊNCIA SOB FLEXO COMPRESSÃO RETA
}

\author{
Romel Dias Vanderlei
}

Dissertação apresentada à Escola de Engenharia de São Carlos, da Universidade de São Paulo, como parte dos requisitos para obtenção do título de Mestre em Engenharia de Estruturas

José Samuel Giongo

Orientador 
é com prazer que dedico este trabalho a meus pais, por acreditar no meu sucesso e pela confiança em meus atos. 


\section{AGRADECIMENTOS}

Ao vencer mais uma etapa da minha vida, agradeço primeiramente a Deus, por ter me concedido sabedoria, tranqüilidade, força de vontade e oportunidade de realizar este trabalho.

Aos meus pais Pedro e Lourdes, a quem dedico este trabalho.

Ao meu orientador José Samuel Giongo, pelo apoio, dedicação e compreensão indispensável para conclusão deste trabalho.

Ao professor Toshiaki Takeya, pela colaboração na execução deste trabalho.

Aos professores João Bento de Hanai e Luiz Roberto Sobreira de Agostini, pela participação na banca de defesa.

A minha namorada Paula Sardeiro, pelo amor, amizade, cumplicidade, carinho e ajuda durante a conclusão deste trabalho. Se tornou a minha grande conquista durante o mestrado.

A minhas irmãs Karine, Mirna e Aleska pelo carinho e confiança.

Ao meu grande amigo Alexandre (Topó), pela amizade convívio, cumplicidade, farras e dificuldades que passamos juntos durante todo 0 mestrado, tornando este período mais agradável.

Aos amigos David, Júlio, Patrick, Renata e todos os colegas da PósGraduação, pela amizade e convívio.

À família Sardeiro, em especial Paulo, Márcia e Camilla, pelo apoio, carinho e tranqüilidade que me deram, tornando a minha passagem pelo mestrado mais agradável.

Agradecimentos especiais aos técnicos Amauri, Jorge, Mário, Mauri, Valdir e ao engenheiro Luiz, funcionários do Laboratório de Estruturas indispensáveis na realização da experimentação.

À Bibliotecária Maria Nadir e à secretária da Pós-graduação Rosi, pela ajuda e amizade.

Aos demais funcionários do Departamento de Engenharia de Estruturas da EESC - USP, pelo apoio. 


\section{CRÉDITOS}

A realização deste trabalho foi possível devido ao apoio de instituições e empresas, ao qual são dignos de créditos:

Universidade Federal de Alagoas - UFAL, através dos professores do curso de Engenharia Civil, principalmente o professor Severino Pereira Cavalcanti Marques, que me forneceram conhecimentos e apoio para iniciar o mestrado.

Universidade de São Paulo

- Escola de Engenharia de São Carlos

- Departamento de Engenharia de Estruturas

Programa Especial de Treinamento - PET, Curso de Engenharia Civil da UFAL,

através dos amigos e professores colaboradores, principalmente 0 professor tutor Roberaldo Carvalho de Sousa.

CAPES - Coordenação de Aperfeiçoamento de Pessoal de Nível Superior, pela concessão de bolsa de estudo durante a graduação e no primeiro ano do mestrado.

FAPESP - Fundação de Amparo à Pesquisa do Estado de São Paulo, pela concessão de bolsa de mestrado durante o segundo ano, processo 97/12850-4.

CAMARGO CORRÊA INDUSTRIAL S. A., através dos engenheiros Christovam S. C. e João Paulo, pela doação de cimento.

\section{REAX INDÚSTRIA E COMÉRCIO LTDA,} através do Engenheiro Mauro M. Movikawa, pela doação de aditivo superplastifiante.

\section{PROFIP LTDA,}

pela doação de aparelho de apoio, fundamental para desenvolvimento desse trabalho. 
LISTA DE FIGURAS _ _

LISTA DE TABELAS___ iii

LISTA DE ABREVIATURAS E SIGLAS _ _ $v$

LISTA DE SÍMBOLOS _ _ vi

RESUMO —

ABSTRACT

CAPÍTULO 1- INTRODUÇÃO___ 1

1.1- Considerações Iniciais ___ 1

1.2- Concretos de Alto Desempenho __ 8

1.3- Justificativa da Pesquisa __ 11

1.4- Objetivos da Pesquisa

1.5- Metodologia da Pesquisa___ 14

CAPÍTULO 2- FUNDAMENTOS DO CONCRETO DE ALTA RESISTÊNCIA ___ 16

2.1- Considerações Iniciais __ 16

2.2- Materiais Componentes do Concreto___ 16

2.2.1- Cimento _ 17

2.2.2- Sílica ativa __ 18

2.2.3- Agregados_ 20

2.2.4- Água _ 22

2.2.5- Aditivo superplastificante___ 23

2.3- Procedimentos de Dosagem e Mistura___ 24

2.4- Propriedades Mecânicas do Concreto no Estado Endurecido ___ 25

2.4.1- Resistência à compressão___ 25

2.4.2- Resistência à tração _ـ 27

2.4.3- Módulo de deformação longitudinal___ 29

2.4.4- Coeficiente de Poisson ___ 31

2.5- Considerações Finais __ 32

CAPÍTULO 3- CONSIDERAÇÕES TEÓRICAS PARA ANÁLISE DE PILARES DE CONCRETO DE ALTA RESISTÊNCIA _ 33

3.1- Considerações Iniciais _ـ 33

3.2- Coeficiente de Ajuste da Resistência à Compressão do Concreto___ 34

3.3- Análise das Deformações___ 35

3.4- Relação Tensão x Deformação _ـ 37

3.5- Esforços Resistentes __ 45

3.6- Estudos de Casos de Pilares de CAD sob Compressão Excêntrica___ 45

3.7-Considerações Finais _ 58 


\section{CAPÍTULO 4- ANÁLISE EXPERIMENTAL DE PILARES DE CONCRETO DE ALTA}

RESISTÊNCIA

4.1- Considerações Iniciais _ـ 59

4.2- Sistema de Aplicação de Força e de Vinculação ___ 60

4.3- Materiais Utilizados__ 62

4.3.1- Cimento — 63

4.3.2- Sílica ativa _ 63

4.3.3- Aditivo superplastificante___ 63

4.3.4- Água _ 63

4.3.5- Agregados_ 64

4.3.5.1- Agregados miúdo__ 64

4.3.5.2- Agregados graúdo _ـ 65

4.4- Estudo de Dosagem __ 65

4.4.1- Ensaios de dosagem para determinação do traço ___ 66

4.5- Caracterização das Armaduras___ 68

4.6- Experimentação em Pilares __ 70

4.6.1- Programa experimental___ 71

4.6.2- Arranjos das armaduras dos modelos __ 72

4.6.3- Detalhes do Consolo___ 73

4.6.4- Aparelho de Apoio _ 74

4.6.5- Fôrmas 75

4.6.6- Estrutura de reação ___ 76

4.6.7- Moldagem, adensamento e cura ___ 76

4.6.8- Instrumentação e procedimentos de ensaio____ 79

4.7- Descrição dos Ensaios Realizados___ 81

4.7.1- Ensaio piloto___ 81

4.7.2- Ensaios da série 1

4.7.2.1- Ensaio do pilar P1/1__ 85

4.7.2.2- Ensaio do pilar P1/1R _ 86

4.7.2.3- Ensaio do pilar P1/2__ 87

4.7.2.4- Ensaio do pilar P1/3__ 88

4.7.3- Ensaios da série $2 \ldots 89$

4.7.3.1- Ensaio do pilar P2/1_ 90

4.7.3.2- Ensaio do pilar P2/2__ 90

4.7.4- Ensaio da série 3

4.7.4.1- Ensaio do pilar P3/1__ 92

4.8- Considerações Finais __ 93

CAPÍTULO 5- RESULTADOS OBTIDOS __ 94

5.1- Considerações Iniciais ___ 94

5.2- Determinação das Características Mecânicas do Concreto ___ 94

5.2.1- Resistência à compressão___ 94

5.2.2- Resistência à tração _— 95

5.2.3- Módulo de deformação longitudinal____ 96

5.3- Resultados dos Ensaios dos Pilares ___ 97

5.3.1- Ensaios da série $1 \ldots 99$

5.3.1.1- Ensaio do pilar P1/1R __ 99

5.3.1.2- Ensaio do pilar P1/2 102

5.3.1.3- Ensaio do pilar P1/3 102

5.3.2- Ensaios da série $2 \ldots 105$

5.3.2.1- Ensaio do pilar P2/1_ 105

5.3.2.2- Ensaio do pilar P2/2 105

5.3.3- Ensaio da série 3

5.3.3.1- Ensaio do pilar P3/1__ 109

5.4- Considerações Finais _ 109 
6.1- Considerações Iniciais __ 110

6.2- Análise das Características Mecânicas do Concreto ___ 110

6.2.1- Resistência à tração ___ 111

6.2.2- Módulo de deformação longitudinal___ 113

6.3- Avaliação das Relações Tensão x Deformação Propostas por

LIMA (1997) e COLLINS et al. (1993).__ 115

6.4- Análise dos Resultados dos Modelos__ 117

6.4.1- Análise das deformações ___ 118

6.4.2- Esforços resistentes__ 119

6.4.2.1- Relação tensão x deformação proposta por LIMA (1997)___ 120

6.4.2.2- Relação tensão x deformação proposta por COLLINS et al. (1993) ___ 121

6.4.2.3- Relação tensão x deformação proposta pelo Código Modelo - MC90

CEB-FIP (1991)

6.4.2.4 Relação tensão x deformação proposta pelo ACI 318 - M89__ 125

6.4.2.5- Relação tensão x deformação proposta por DINIZ (1997) __ 126

6.5- Ductilidade126

6.6- Considerações Finais __ 127

CAPÍTULO 7- CONCLUS̃̃O___ 129

Sugestões para Continuidade da Pesquisa___ 131

CAPÍTULO 8- REFERÊNCIAS BIBLIOGRÁFICAS E BIBLIOGRAFIA COMPLEMENTAR — 132

8.1- Referências Bibliográficas___ 132

8.2- Bibliografia Complementar _ 137

APÊNDICE — 1

Gráficos do Pilar P1/1R __ 2

Gráficos do Pilar P1/2_ 6

Gráficos do Pilar P1/3 10

Gráficos do Pilar P2/1_ 14

Gráficos do Pilar P2/2_ 18

Gráficos do Pilar P3/1_ 22 
FIGURA 1.1 - Petronas Towers, Kuala Lumpur - Malásia [SOUSA (1997)] ___ 4

FIGURA 1.2 - Edifício do MASP, São Paulo - SP [ROCHA (1997)] ___ 5

FIGURA 1.3 - Centro Empresarial Nações Unidas, São Paulo - SP

[ROCHA (1997)] 5

FIGURA 1.4 - Centro Empresarial PREVINOR, Salvador - BA. [LEITE \& MIRANDA (1997)] 6

FIGURA 1.5 - Estrutura do Edifício Suarez Trade Center, Salvador - BA. [LEITE \& MIRANDA (1997)] 6

FIGURA 1.6 - Edifício Banco de Tokyo, Salvador - BA. [LEITE \& MIRANDA (1997)]

FIGURA 1.7 - Edifício Arthur Moreira Lima, Salvador - BA. [LEITE \& MIRANDA (1997)]

FIGURA 1.8 - Estádio do Pacaembú, São Paulo - SP. [CORBIOLI (1997)]___ 7

FIGURA 1.9 - Ponte sobre o rio Maranhão, Goiás. [ROCHA (1997)] ____ 8

FIGURA 1.10 - Sistema de aplicação de forças utilizado por LIMA (1997) __ 13

FIGURA 2.1 - Produção de sílica ativa [ROCHA (1997)]____ 18

FIGURA 3.1 - Hipótese de distribuição de deformações e de tensões na seção de concreto submetidas a flexão. 36

FIGURA 3.2 - Influência da resistência do concreto na relação tensão x deformação 39

FIGURA 3.3 - Aproximação para o diagrama tensão x deformação experimental 40

FIGURA 3.4 - Diagrama tensão x deformação simplificada segundo MC90 CEB(1991)

FIGURA 3.5 - Diagrama tensão x deformação segundo a NS3473E(1992) ___ 42

FIGURA 3.6 - Bloco retangular de tensão segundo o ACI318 - M89 ___ 43

FIGURA 3.7 - Diagrama retangular de tensões proposto por DINIZ___ 44

FIGURA 3.8 - Sistema de aplicação de forcas utilizado por LIMA $\left(\overline{1997)} \_47\right.$

FIGURA 3.9 - Pilares ensaiados por CUSSON \& PAULTRE (1994) ____ 49

FIGURA 3.10 - Efeito das armaduras no confinamento [CUSSON \& PAULTRE (1994)]

FIGURA 3.11 - Dimensões e tipos de configurações de estribos usados por AZIZINAMINI \& KEBRAEI (1996)

FIGURA 3.12 - Modelos ensaiados por IBRAHIM \& MAC GREGOR (1996) _ 57

FIGURA 4.1 - Modelo teórico de aplicação de força excêntrica em pilares ___ 60

FIGURA 4.2 - Sistema de ensaio utilizado___ 61

FIGURA 4.3 - Mecanismo de ensaio adotado ___ 62

FIGURA 4.4 - Moldagem dos corpos-de-prova ___ 67

FIGURA 4.5 - Crescimento da resistência com o tempo ___ 68

FIGURA 4.6 - Diagramas tensão x deformação das barras da armadura___ 69

FIGURA 4.7 - Detalhes do modelo P1/1 72

FIGURA 4.8 - Detalhes da armadura do pilar P1/1_ 72

FIGURA 4.9 - Armadura do pilar P1/2__ 73 
FIGURA 4.10 - Detalhes da armadura de fretagem __ 73

FIGURA 4.11 - Detalhamento do consolo ___ 74

FIGURA 4.12 - Aparelho de apoio utilizado para liberar as rotações na base e topo do pilar 75

FIGURA 4.13 - Fôrma usada para concretagem dos pilares ___ 75

FIGURA 4.14 - Pórtico de reação___ 76

FIGURA 4.15 - Misturador de capacidade de $2401 \_77$

FIGURA 4.16 - Concretagem do pilar e adensamento em mesa vibratória ___ 77

FIGURA 4.17 - Disposição da armadura na fôrma___ 77

FIGURA 4.18 - Pilar após a concretagem ___ 78

FIGURA 4.19 - Detalhamento da instrumentação do pilar___ 80

FIGURA 4.20 - Instrumentação do pilar____ 80

FIGURA 4.21 - Perfil metálico interposto entre a rótula e a célula de carga ___ 85

FIGURA 4.22 - Transporte do pilar até o pórtico de reação_____ 87

FIGURA 4.23 - Forma de ruptura do pilar P1/1R ___ 87

FIGURA 4.24 - Forma de ruptura do pilar P1/2___ 88

FIGURA 4.25 - Forma de ruptura do pilar P1/3__ 89

FIGURA 4.26 - Forma de ruptura do pilar P2/1__ 90

FIGURA 4.27 - Forma de ruptura do pilar P2/2__ 91

FIGURA 4.28 - Forma de ruptura do pilar P3/1_ 92

FIGURA 5.1 - Crescimento da resistência à compressão___ 95

FIGURA 5.2 - Ensaio de compressão axial com deformação controlada___ 96

FIGURA 5.3 - Posições dos pontos instrumentados___ 99

FIGURA 5.4 - Diagramas experimentais do pilar P1/1R 101

FIGURA 5.5 - Diagramas experimentais do pilar P1/2_ 103

FIGURA 5.6 - Diagramas experimentais do pilar P1/3 104

FIGURA 5.7 - Diagramas experimentais do pilar P2/1_ 106

FIGURA 5.8 - Diagramas experimentais do pilar P2/2 _ 107

FIGURA 5.9 - Diagramas experimentais do pilar P3/1 _ 108

FIGURA 6.1 - Valores teóricos e experimentais da resistência à tração do concreto

FIGURA 6.2 - Valores teóricos e experimentais do módulo de deformação longitudinal

FIGURA 6.3 - Exemplo da saída gráfica do ensaio com deformação controlada 116

FIGURA 6.4 - Relações tensão x deformação propostas por LIMA (1996) e COLLINS et al.(1993) 116 
TABELA 1.1 - Classificação do concreto quanto à resistência, AMARAL FILHO(1993) 10

TABELA 1.2 - Pilares sob compressão excêntrica ensaiados por LIMA (1997) _ 12

TABELA 1.3 - Análise dos resultados de LIMA (1997) considerando o modelo apresentado por COLLINS et al. (1993)

TABELA 2.1 - Efeito do tipo de agregado no módulo de deformação longitudinal segundo o Código Modelo - MC90 CEB-FIP (1991)

TABELA 3.1 - Coeficiente de modificação utilizado para o CRU e CAR 35

TABELA 3.2 - Valores para $\varepsilon_{\mathrm{cu}}$ e para os parâmetros $\alpha$ e $\beta$ sugeridos por DINIZ (1997)

TABELA 3.3 - Pilares sob compressão centrada ensaiados por LIMA (1997) __ 46

TABELA 3.4 - Pilares sob flexão normal composta ensaiados por LIMA (1997)_ 46

TABELA 3.5 - Análise dos resultados de LIMA (1997) considerando o modelo apresentado por COLLINS et al. (1993)

TABELA 4.1 - Análise Granulométrica do Agregado Miúdo ___ 64

TABELA 4.2 - Análise Granulométrica do Agregado Graúdo___ 65

TABELA 4.3 - Estudo de dosagem___ 66

TABELA 4.4 - Resultados dos ensaios de compressão axial ___ 68

TABELA 4.5 - Caracterização das armaduras __ 69

TABELA 4.6 - Características do modelo piloto __ 71

TABELA 4.7 - Ensaio dos corpos-de-prova___ 78

TABELA 4.8 - Ensaio dos corpos-de-prova__ 82

TABELA 5.1 - Resistência à compressão do concreto___ 94

TABELA 5.2 - Resistência à compressão do concreto usado no reforço___ 95

TABELA 5.3 - Resistência à tração do concreto ___ 95

TABELA 5.4 - Módulo de deformação longitudinal e deformação correspondente a tensão máxima do concreto___ 97

TABELA 5.5 - Características mecânicas do concreto_____ 97

TABELA 5.6 - Deformações, força centrada e excêntrica de ruptura e momento experimental de ruptura __ 98

TABELA 6.1 - Valores da resistência à tração experimental e sugeridos pelas bibliografias.

TABELA 6.2 - Relação entre os valores experimentais e teóricos da resistência à tração do concreto.

TABELA 6.3 - Módulos de deformação longitudinal experimental e propostos por bibliografias

TABELA 6.4 - Relação entre os valores experimentais e teóricos do módulo de deformação longitudinal

TABELA 6.5 - Características dos modelos analisados __ 118

TABELA 6.6 - Variação das deformações ___ 119

TABELA 6.7 - Análise dos esforços resistentes para a relação tensão x deformação proposta por LIMA (1997), para a ação última 
TABELA 6.8 - Análise dos esforços resistentes para a relação tensão x deformação proposta por LIMA (1997), para 80\% da ação última

TABELA 6.9 - Análise dos esforços resistentes para a relação tensão x deformação proposta por Collins et al. (1993), para a ação última 122

TABELA 6.10 - Análise dos esforços resistentes para a relação tensão x deformação proposta por Collins et al. (1993), para 80\% da ação última

TABELA 6.11- Análise dos esforços resistentes para as relações tensão x deformação proposta LIMA (1997 e COLLINS et al. (1993)

TABELA 6.12 - Correção do momento fletor experimental, proveniente de excentricidade acidental, relação de Collins, para a ação última _ 123

TABELA 6.13 - Análise dos esforços resistentes para a relação tensão x deformação sugerida pelo MC90 CEB-FIP (1991), para a ação última

TABELA 6.14- Análise dos esforços resistentes para a relação tensão x deformação sugerida pelo ACI 318 - M89, para a ação última

TABELA 6.15- Análise dos esforços resistentes para a relação tensão x deformação proposta por DINIZ (1997), para a ação última 


\section{LISTA DE ABREVEATURAS E SIGLAS}

$\begin{array}{ll}\text { ABNT } & \text { - Associação Brasileira de Normas Técnicas } \\ \text { ABCP } & \text { - Associação Brasileira de Cimento Portland } \\ \text { ACI } & \text { - American Concrete Institute } \\ \text { ARI } & \text { - Alta Resistência Inicial } \\ \text { ASCE } & \text { - American Society of Civil Engineering } \\ \text { ASTM } & \text { - American Society for Testing and Materials } \\ \text { CAD } & \text { - Concreto de Alto Desempenho } \\ \text { CAR } & \text { - Concreto de Alta Resistência } \\ \text { CARs } & \text { - Concretos de Alta Resistência } \\ \text { CEB } & \text { - Comite Euro-Internacional du Beton } \\ \text { CERF } & \text { - Civil Engineering Research Foundation } \\ \text { CUR } & \text { - Concreto de Resistência Usual } \\ \text { EESC } & \text { - Escola de Engenharia de São Carlos } \\ \text { FIP } & \text { - Féderation Internationale de la Précontrainte } \\ \text { IBRACON } & \text { - Instituto Brasileiro do Concreto } \\ \text { MC } & \text { - Model Code } \\ \text { MF } & \text { - Módulo de Finura } \\ \text { NBR } & \text { - Norma Brasileira Registrada } \\ \text { NS } & \text { - Norwergian Standard } \\ \text { USP } & \text { - Universidade de São Paulo }\end{array}$


$A_{c} \quad-\quad$ Área de concreto da seção transversal do pilar

$A_{g}$

- Área da seção transversal total do pilar

$A_{s t}$

- Área da seção transversal das barras da armadura longitudinal

$A_{s 1}$

- Área da seção transversal das barras da armadura longitudinal menos comprimida

As2 - Área da seção transversal das barras da armadura longitudinal mais comprimida

$\mathrm{A}_{s}$

- Área da seção transversal das barras da armadura longitudinal

b

- Largura da seção transversal do pilar

d

- Altura útil da seção transversal do pilar

d'

- Distância do eixo da armadura longitudinal à face do pilar

eacid

- Excentricidade acidental

$\mathrm{e}_{\text {geom }}$

- Excentricidade geométrica

$E_{c}$

- Modulo de deformação longitudinal do concreto

$E_{s}$

- Modulo de deformação longitudinal do aço

$F_{\text {exp }}$

- Força experimental

$F_{\text {exp, cent }}$

- Força aplicada resultante da soma da força aplicada no eixo longitudinal do pilar e das forças aplicadas excentricamente

$F_{\text {exp, exc }} \quad$ - Força excêntrica aplicada na extremidade do consolo do pilar

Flong, cent - Força aplicada no eixo longitudinal do pilar

$F_{\text {teo }} \quad$ - Esforço normal teórico

$f_{c}$

- Resistência à compressão do concreto

$f_{c}^{\prime} \quad$ - Tensão máxima de compressão do concreto

$f_{c d}$

- Valor de cálculo da resistência à tração do concreto

$f_{c k}$

- Resistência característica à compressão do concreto

$f_{\mathrm{tk}}$

- Resistência característica à tração do concreto

$f_{t D}$

- Resistência à tração por compressão diametral 


\begin{tabular}{|c|c|}
\hline $\mathrm{f}_{\mathrm{ctk}}$ & - Resistência característica cúbica à tração \\
\hline h & - Altura da seção transversal do pilar \\
\hline $\mathrm{k}$ & $\begin{array}{l}\text { - Fator que considera o declínio da curva tensão x deformação } \\
\text { no concreto, após o pico segundo COLLINS et al. (1993) }\end{array}$ \\
\hline mod & $\begin{array}{l}\text { - Coeficiente de modificação da resistência de cálculo do } \\
\text { concreto }\end{array}$ \\
\hline $\bmod 1$ & $\begin{array}{l}\text { - Coeficiente que leva em conta o acréscimo da resistência } \\
\text { após } 28 \text { dias de idade }\end{array}$ \\
\hline $\bmod 2$ & $\begin{array}{l}\text { - Coeficiente que considera a resistência medida em corpos- } \\
\text { de-prova cilíndricos de } 15 \mathrm{~cm} \times 30 \mathrm{~cm}\end{array}$ \\
\hline $\bmod 3$ & $\begin{array}{l}\text { - Coeficiente que leva em conta o efeito deletério da ação de } \\
\text { longa duração }\end{array}$ \\
\hline$M_{\exp }$ & - Momento experimental \\
\hline$M_{\text {teo }}$ & - Momento teórico \\
\hline $\mathrm{M}_{\mathrm{u}, \mathrm{teo}}$ & - Momento último teórico \\
\hline$n$ & $\begin{array}{l}\text { - Fator de adequação da curva tensão x deformação segundo } \\
\text { COLLINS et al. (1993) }\end{array}$ \\
\hline $\mathrm{N}_{\mathrm{u}}$ & - Força última \\
\hline$N_{\text {teo }}$ & - Esforço normal teórico \\
\hline $\mathrm{N}_{\mathrm{u}, \mathrm{teo}}$ & - Esforço normal último teórico \\
\hline$P_{0}$ & - Força última no pilar com compressão centrada \\
\hline$\alpha$ & - Coeficiente de intensidade de tensões para o concreto \\
\hline$\alpha_{1}$ & - Coeficiente de intensidade de tensões para o concreto \\
\hline$\alpha_{e}$ & $\begin{array}{l}\text { - Coeficiente para considerar o enfeito do tipo de agregado no } \\
\text { módulo de deformação longitudinal segundo o Código Modelo } \\
\text { - MC90(1991) }\end{array}$ \\
\hline$\beta$ & $\begin{array}{l}\text { - Coeficiente que define a profundidade do diagrama retangular } \\
\text { de tensões assumido por DINIZ (1997) }\end{array}$ \\
\hline$\beta_{1}$ & $\begin{array}{l}\text { - Coeficiente que define a profundidade do diagrama retangular } \\
\text { de tensões assumido pelo } \mathrm{ACl} 318 / 89\end{array}$ \\
\hline & - Deformação específica de compressão do concreto \\
\hline
\end{tabular}




\begin{tabular}{|c|c|}
\hline$\varepsilon_{\mathrm{co}}$ & $\begin{array}{l}\text { - Deformação específica correspondente a máxima compres- } \\
\text { são do concreto }\end{array}$ \\
\hline$\varepsilon_{c}^{\prime}$ & $\begin{array}{l}\text { - Deformação específica correspondente a resistência máxima } \\
\text { do concreto }\end{array}$ \\
\hline$\varepsilon_{\mathrm{c} 1}$ & - Deformação específica na face menos comprimida do pilar \\
\hline$\varepsilon_{\mathrm{c} 2}$ & - Deformação específica na face mais comprimida do pilar \\
\hline$\varepsilon_{\mathrm{s} 1}$ & - Deformação específica na armadura menos comprimida \\
\hline$\varepsilon_{\mathrm{s} 2}$ & - Deformação específica na armadura mais comprimida \\
\hline$\varepsilon_{\mathrm{cu}}$ & $\begin{array}{l}\text { - Valor último da deformação específica do concreto } \\
\text { comprimido }\end{array}$ \\
\hline$\varepsilon_{\mathrm{y}}$ & - Deformação específica de escoamento do aço a tração \\
\hline$\phi_{\text {máx }}$ & - Dimensão máxima característica do agregado graúdo \\
\hline$\phi$ & - Diâmetro das barras de aço \\
\hline$\phi_{\text {nominal }}$ & - Diâmetro nominal \\
\hline$\phi_{\text {efetivo }}$ & - Diâmetro efetivo \\
\hline$v$ & - Coeficiente de Poisson \\
\hline$\rho_{1}$ & - Taxa geométrica de armadura longitudinal \\
\hline$\rho_{\mathrm{w}}$ & - Taxa volumétrica de armadura transversal \\
\hline$\sigma_{\mathrm{c}}$ & - Tensão normal de compressão do concreto \\
\hline$\sigma_{\mathrm{cd}}$ & - Valor de cálculo da tensão normal de compressão do concreto \\
\hline$\sigma_{\mathrm{s} 1}$ & $\begin{array}{l}\text { - Tensão normal de compressão na armadura menos } \\
\text { comprimida }\end{array}$ \\
\hline$\sigma_{\mathrm{s} 2}$ & - Tensão normal de compressão na armadura mais comprimida \\
\hline
\end{tabular}


VANDERLEI, R. D. (1999). Análise experimental de pilares de concreto armado de alta resistência sob flexo compressão reta. São Carlos, 1999. 140p. Dissertação (Mestrado) - Escola de Engenharia de São Carlos, Universidade de São Paulo.

Com este projeto obteve-se informações sobre o comportamento de pilares submetidos à compressão excêntrica, executados com concreto de alta resistência, com resistência média à compressão de $80 \mathrm{MPa}$. Os pilares tinham seção transversal retangular de $15 \mathrm{~cm} \times 30 \mathrm{~cm}$, com altura livre de $174 \mathrm{~cm}$. A excentricidade da força foi de $38 \mathrm{~cm}$ com plano de ação do momento paralelo ao menor lado. Foram ensaiados seis pilares, onde as variáveis foram as taxas de armaduras transversais e longitudinais. Os pilares foram ensaiados sob a ação de duas forças aplicadas de modos independentes, para maior precisão e controle do posicionamento da força excêntrica. Uma força era aplicada na direção do eixo longitudinal do pilar e outra, paralela a esse, com excentricidade definida. Foram montados dispositivos de vinculações e mecanismos de transferências de forças nos pilares, procurando aproximar as situações de ensaios às do modelo teórico pretendido. As rotações eram liberadas nas extremidades dos pilares, e a seção localizadas na meia altura comportava-se sob flexo compressão reta com pequena excentricidade. Os pilares com menor taxa de armadura transversal, tiveram ruptura frágil da seção transversal central com flambagem das barras das armaduras longitudinais. Os pilares com maior taxa de armadura transversal, apresentaram ruptura com boa ductilidade e esmagamento do concreto do lado mais comprimido. As deformações lidas nas barras das armaduras do lado mais comprimido, no instante da ruptura, ficaram entre $2,3 \%$ e $3 \%$. Utilizaram-se modelos teóricos propostos na literatura para obter os valores estimados das forças normais últimas e momentos fletores últimos, comparando-os com os encontrados experimentalmente.

Palavras-chaves: Concreto de alto desempenho; Pilares; Flexo compressão 
VANDERLEI, R. D. (1999). Experimental analysis of reinforced high strength concrete columns under eccentric compression. São Carlos, 1999. 140p. Dissertação (Mestrado) - Escola de Engenharia de São Carlos, Universidade de São Paulo.

This work presents a study of the behavior of high strength columns under eccentric compression, with concrete cylinder compressive strength of around $80 \mathrm{MPa}$. The columns studied had cross section area of $15 \mathrm{~cm} \times 30 \mathrm{~cm}$ at the test region, and an effective length of $174 \mathrm{~cm}$. The eccentricity of the load was $380 \mathrm{~mm}$ and the plan of action of the moment was parallel to the smallest side of the cross section. Six columns were tested. The main variables were the stirrup volumetric ratio and the longitudinal steel ratio. The columns were tested under the action of two independent loads, an axial load and an eccentric load, so that could be precise the positioning of the eccentric load and the control of this action. The axial load was applied on of the longitudinal axis of the columns and the eccentric load was applied with the defined eccentricity. Articulation devices and load application devices were mounted such as to approach the proposed theoretical model as much as possible. The rotations were liberated in the extremities of the columns, and the section behaved under eccentric compression. The columns with smaller stirrup volumetric ratio showed a brittle mode of failure occurring at the central cross section accompanied by the buckling of the longitudinal reinforcement. On the other hand, the columns with larger stirrup volumetric ratio presented ductile failure accompanied by crushing on the most compressed side of the column. The measured longitudinal reinforcement strain on the most compressed side of the columns at the instant of failure were between $2,3 \%$ and $3 \%$ o. Theoretical models proposed in literature were used to obtain values of the maximum axial load and ultimate flexural moment and the result compared with experimental results obtained in the tests.

Keywords: High performance concrete; Columns; Eccentric compression 


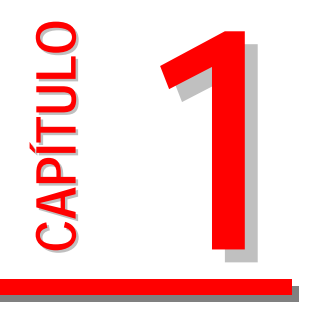

INTRODUÇÃO

\section{1- Considerações Iniciais}

A maioria das atividades dentro da Construção Civil estão direta ou indiretamente relacionadas com obras de concreto armado. Na construção de edifícios, em obras hidráulicas e de saneamento, construção de estradas, obras industriais e outras com fins diversos, mesmo que a estrutura não seja de concreto armado, alguns elementos o serão. Logo, fica evidente, portanto, a necessidade do engenheiro possuir conhecimentos básicos relativos a concreto armado.

O dinamismo da tecnologia face à evolução do conhecimento, tem imposto ao concreto um desempenho estrutural cada vez maior. Os notáveis progressos das técnicas de projeto estrutural, aliados ao maior conhecimento dos comportamentos mecânicos do concreto e do aço, têm feito surgir estruturas cada vez mais arrojadas em concreto armado e protendido. Nestas estruturas o concreto tem sido submetido a tensões mais elevadas, criando a necessidade do desenvolvimento de técnicas e estudos mais apurados e científicos que lhe permitia atender a estas solicitações.

As estruturas de concreto armado no Brasil são bastantes difundidas e fazem parte do padrão da construção brasileira. Logo, o estudo de novas técnicas e métodos de análises desse tipo de material, se torna de grande relevância para inovações relacionadas à sua eficiência. O Brasil não possui experiência suficiente com Concreto de Alto Desempenho - CAD, pois somente há poucos anos é que se iniciou a divulgação de algumas experiências, não havendo um número de pesquisas publicadas que propici- 
em bases teóricas seguras para produção e emprego deste material em obras. A verificação da aplicação das teorias dos concretos de resistências convencionais e o prosseguimento dos programas de pesquisa tornam-se indispensáveis para o conhecimento dos CAD.

Com isso surge o interesse do estudo do concreto de alto desempenho, que atualmente aparece como a recente novidade da construção civil, possibilitando a obtenção de um material onde todos os componentes são utilizados da melhor maneira, gerando assim o desenvolvimento de estruturas com maior durabilidade e alta resistência inicial, além do que, torna a edificação com elementos estruturais de menores dimensões e maior vida útil, sendo assim, mais econômica que a feita com concreto de resistência usual.

Os pilares se destacam nesse tipo de estudo, pois são elementos estruturais utilizados para transpor as ações dos pavimentos das estruturas para as fundações, solicitadas basicamente a tensões normais de compressão, sob ação de força centrada ou excêntrica. São de extrema importância na construção de edifícios, pois todas as ações nas lajes e vigas são sustentadas pelos pilares, tornando-se, quando muito solicitado, de grandes dimensões. O uso de Concreto de Alta Resistência - CAR - nesses elementos vieram solucionar essa questão, podendo-se construir elementos submetidos à compressão com pequenas dimensões otimizando o espaço arquitetônico.

Para vigas e lajes, a utilização do concreto de alto desempenho é vantajoso quanto à questão da durabilidade da estrutura, pois são elementos estruturais submetidos a flexão.

O uso do concreto armado de alto desempenho em substituição às estruturas metálicas na construção de edifícios altos, se dá devido à maior rigidez que o CAD confere à estrutura, melhor comportamento frente à ação do vento, e também, em função do seu melhor comportamento em relação ao fogo, segundo GONZALEZ-ISABEL (1993). Nas estruturas das plataformas offshore, o uso do CAD é justificado pela capacidade de suportar à ação contínua dos agentes agressivos, pelas condições de moldagem, 
reduzindo o custo de manutenção, melhor resistência à ações contínuas das águas geladas, choques e abrasão. Segundo ALMEIDA (1990), a aplicação dos concretos de alta resistência não se restringe aos edifícios altos, pois verificou-se que a economia obtida na execução de pilares também pode ser obtida na construção de edifícios médios e baixos.

As crescentes aplicações destes concretos, conduzem à necessidade de revisões nos parâmetros para implementação dos modelos de cálculo, e recomendações construtivas indicadas nas normas atuais ou, até mesmo, elaboração de novas normas que reflitam melhor o comportamento destes materiais. Segundo boletim 197 CEB(1990), houve uma rápida evolução na utilização dos concretos de alto desempenho, notadamente nos Estados Unidos, Canadá, Noruega, França, Japão e outros, enfatizando seu emprego na execução de: pilares de edifícios altos; obras-de-arte, como pontes e viadutos; estruturas offshore e, mais recentemente, nos pré-moldados além de pisos industriais e recuperação em obras de concreto.

As primeiras pesquisas sobre o CAD surgiram na Noruega e na Dinamarca em 1976 e atualmente estão sendo desenvolvidas em vários outros países. As aplicações do CAD tiveram início na execução de pilares. Em COLACO (1985), PACIOS et al. (1992), Boletim 197 CEB-FIP(1990) e $\mathrm{ACl} 363 \mathrm{R}(1992)$ observa-se o uso do concreto de alto desempenho na execução de edifícios altos, variando de 30 a 79 andares, como é o caso do Water Tower Place de 1979 e South Wacker Tower de 1989, ambos em Chicago com 79 andares, e do Texas Commerce Plaza em Houston 1981 com 57 andares. As resistências empregadas variam de $45 \mathrm{MPa}$ a $115 \mathrm{MPa}$, esta última usada no Two Union Saquare em Seattle com 58 andares.

Iniciadas em 1993 e concluídas em março de 1996, as Petronas Towers, mostradas na figura1.1, em Kuala Lumpur, capital da Malásia, com $452 \mathrm{~m}$ de altura, são as maiores torres do mundo e estão entre as maiores obras de Engenharia do planeta, conforme SOUSA (1997). Foram erguidas em estrutura mista, que combina concreto e aço, tomando partido das melhores características dos materiais. As torres são interligadas por uma ponte metálica nos $41 . .^{\circ}$ e $42 . .^{\circ}$ andares. Optou-se por uma estrutura em 
concreto de alto desempenho com $\mathrm{f}_{\mathrm{ck}}$ de $80 \mathrm{MPa}$ até o $60 .{ }^{\circ}$ andar, ponto de transição para uma estrutura em aço-carbono. Os pilares de concreto são dispostos em círculo e interligados por vigas de aço, sobre as quais repousam lajes de concreto moldadas em fôrmas metálicas incorporadas à estrutura. Essa mesma solução foi aplicada até o 88. pavimento. Nas fundações, foram usadas estacas-barrete sobre as quais se apoiaram blocos de concreto com $\mathrm{f}_{\mathrm{ck}}$ de $60 \mathrm{MPa}$.

$\mathrm{Na}$ aplicação do CAD no Brasil, pode-se citar exemplos como o do edifício Santo Amaro, e do edifício do CNEC, onde os pilares foram executados com resistência característica à compressão igual a $60 \mathrm{MPa}$.

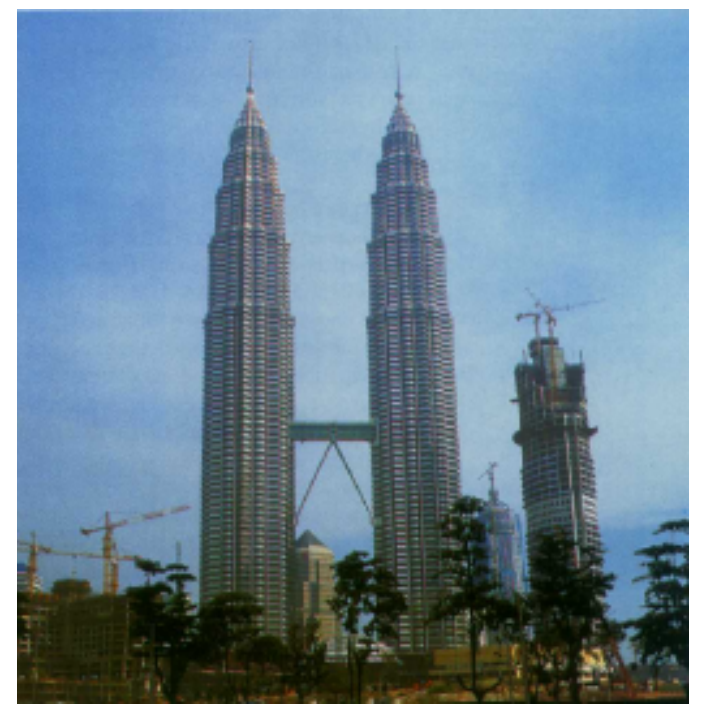

FIGURA 1.1 - Petronas Towers, Kuala Lumpur - Malásia. [SOUSA (1997)]

Segundo ROCHA (1997), o edifício do MASP, em São Paulo, figura 1.2, pode ser considerado o pioneiro em concreto de alta resistência, sem utilização de aditivos, sílica ativa ou superplastificantes. Com resistência média em torno de $45 \mathrm{MPa}$, exigiu um grande trabalho no estudo da dosagem e execução especial com relação à vibração e cura, com diversos operários vibrando o concreto ao mesmo tempo. A baixa relação água/cimento, em torno de 0,32 , ajudou a obter essa resistência; a obra teve consumo de cimento de $565 \mathrm{~kg} / \mathrm{m}^{3}$. 


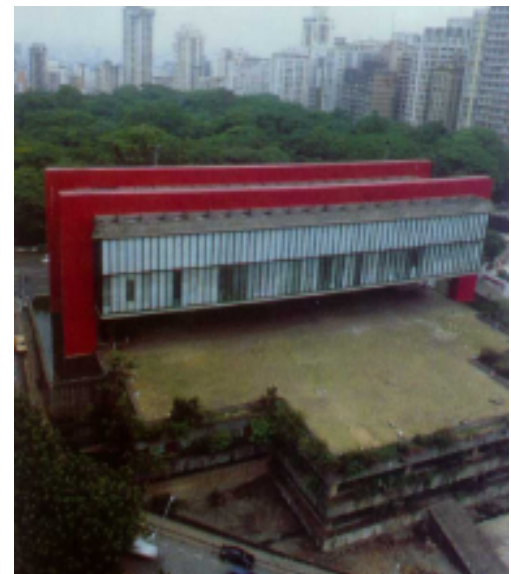

FIGURA 1.2 - Edifício do MASP, São Paulo [ROCHA (1997)]

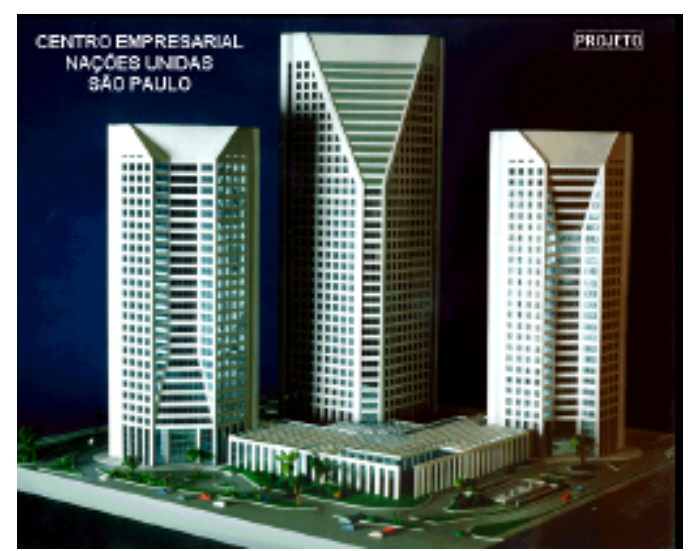

FIGURA 1.3 - Centro Empresarial Nações Unidas, São Paulo. [CD-ROM (1997) $\left.{ }^{1}\right]$

O Centro Empresarial Nações Unidas (Cenu), na cidade de São Paulo, mostrado na figura 1.3, com 41 andares é formado por três torres, denominadas torres Oeste, Leste e Norte, e formam o maior edifício do país. A torre Norte, atualmente em construção, é a maior das torres; tem $84 \mathrm{mil} \mathrm{m}^{2}$ de área construída e $158 \mathrm{~m}$ de altura distribuídos em 36 pavimentos. De acordo com o responsável pelo projeto estrutural da obra, engenheiro Mário Franco, através do informativo Cimento Hoje abcp (1998), foi utilizado CAD nos pilares com $f_{c k}$ igual a $60 \mathrm{MPa}$ e nas lajes de $35 \mathrm{MPa}$ possibilitando importantes ganhos no projeto. A torre Oeste já está pronta, mas, como sua construção foi a primeira a ser iniciada, ela não foi executada com CAD, pois essa tecnologia era pouco disseminada na época do projeto. Já a torre Leste, ainda em fase de fundação, vai usufruir da mesma tecnologia empregada na torre Norte, e como ela é gêmea no formato da torre Oeste, espera-se economizar muito no consumo de armadura, segundo Mário Franco.

O CAD teve, no Brasil, maior aplicação em Salvador - BA a partir de 1992. A primeira obra foi o Centro Empresarial PREVINOR, que pode ser visto na figura 1.4, formado por dois blocos de 18 andares cada, sendo que além dos pilares, o CAD foi usado nas lajes, na região dos pilares de canto, numa área de aproximadamente $1 \mathrm{~m}^{2}$, visando absorver as tensões de cisalhamento em torno dos pilares.

\footnotetext{
${ }^{1}$ Concreto de Alto Desempenho - CD-ROM versão 1.0 (1997) - Associação Brasileira de Cimento Portland.
} 


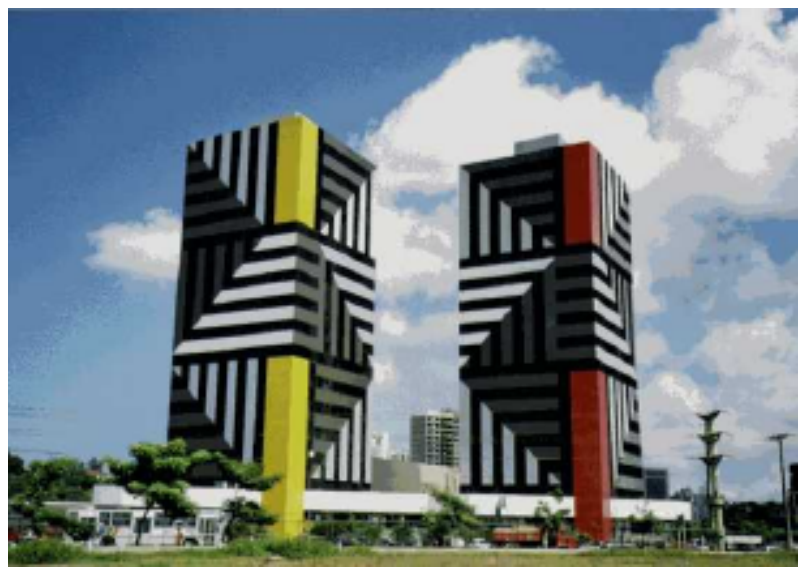

FIGURA 1.4 - Centro Empresarial PREVINOR, Salvador/BA. [LEITE \& MIRANDA (1997)] No edifício Suarez Trade Center, construído de 1992 a 1994 em Salvador, com 30 andares, utilizou-se CAD com resistência característica à compressão de $60 \mathrm{MPa}$ nos pilares centrais ao longo de 11 andares, enquanto que no resto da estrutura foi utilizado concreto com $f_{c k}$ igual a 30 $\mathrm{MPa}$, o esquema da estrutura é apresentado na figura 1.5. Os pilares com $\mathrm{f}_{\mathrm{ck}}$ de $60 \mathrm{MPa}$ tiveram 2 seções transversais; $(120 \mathrm{~cm} \times 120 \mathrm{~cm}$ e $60 \mathrm{~cm} \times 60 \mathrm{~cm}$ ). Os principais pilares centrais suportam uma ação acima de $50000 \mathrm{kN}$, com dimensões da seção transversal de $120 \mathrm{~cm}$ x $120 \mathrm{~cm}$. Caso fosse construído com concreto de $\mathrm{f}_{\mathrm{ck}}$ igual a $20 \mathrm{MPa}$, a seção transversal teria cerca de $200 \mathrm{~cm}$ x $200 \mathrm{~cm}$. O número de pilares e suas posições nos andares proporcionou aumento substancial no número de vagas para veículos.
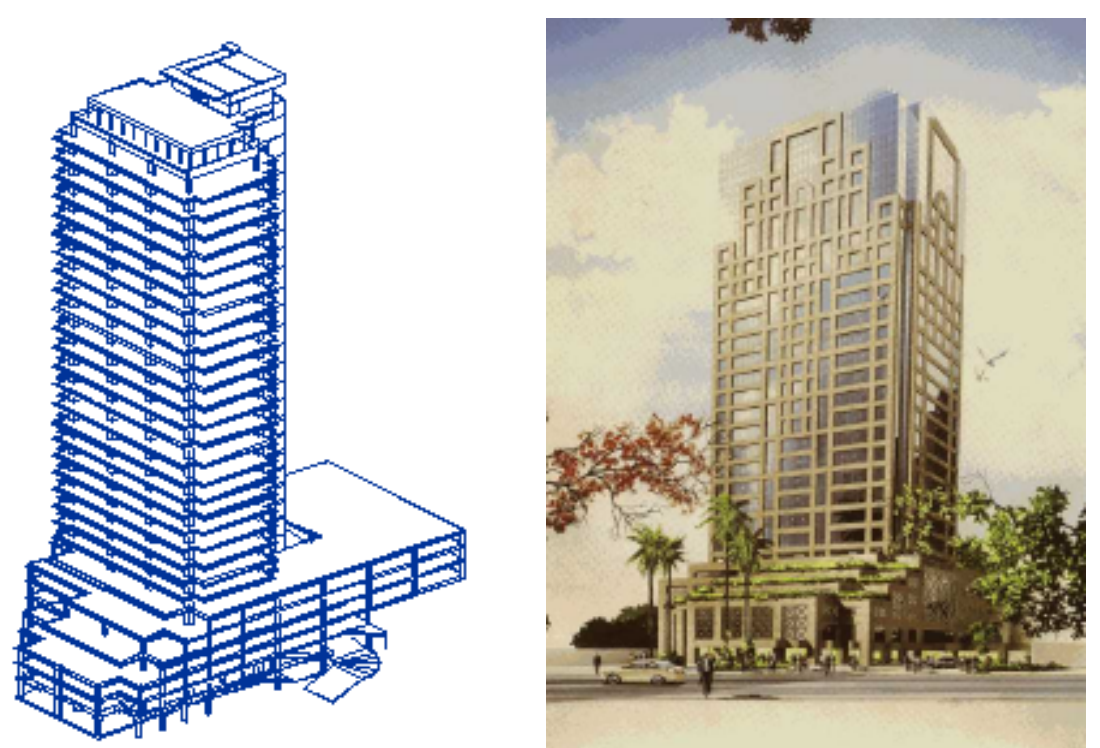

FIGURA 1.5 - Estrutura do Edifício Suarez Trade Center, Salvador - BA. [LEITE \& MIRANDA (1997)] 
Outro edifício foi o Banco de Tokyo com 16 andares, mostrado na figura 1.6, onde os pilares centrais, até o 5. andar, foram projetados com resistência característica à compressão igual a $30 \mathrm{MPa}$. Este procedimento permitiu dobrar o número de vagas nas garagens do prédio em relação ao projeto que previa resistência usual para o concreto.

Segundo LEITE \& MIRANDA (1997), o edifício residencial mais alto na cidade de Salvador é o Arthur Moreira Lima (figura 1.7). O prédio tem 33 andares e foi utilizado concreto com $\mathrm{f}_{\mathrm{ck}}$ igual a $60 \mathrm{MPa}$, obtendo-se redução da seção transversal dos pilares, melhores condições de durabilidade, já que a obra situa-se na orla marítima da cidade.

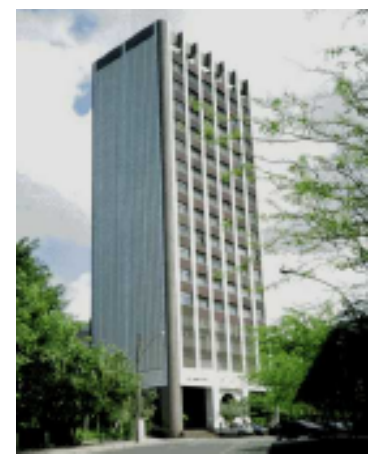

FIGURA 1.6 - Edifício Banco de Tokyo, Salvador - BA [LEITE \& MIRANDA (1997)]

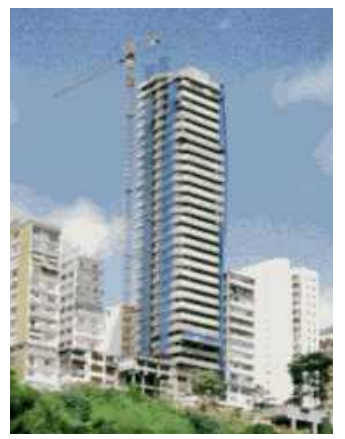

FIGURA 1.7 - Edifício Arthur Moreira Lima, Salvador - BA. [LEITE \& MIRANDA (1997)]

O CAD vem se destacando muito em serviços de restauração de edificações. Devido à sua maior capacidade de aderência e impermeabilidade, ele foi recentemente adotado na recuperação estrutural do setor conhecido como "Tobogã", no estádio do Pacaembú, em São Paulo (figura 1.8). Foi adotado, também recentemente, na recuperação da Ponte dos Remédios, nas Marginais Tietê, São Paulo, onde era preciso atender às especificações de alta resistência nas primeiras horas, com $f_{c k}$ igual a $18 \mathrm{MPa}$ em 24 horas.

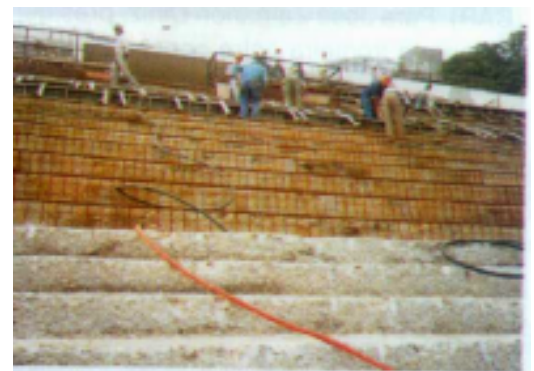


Outra grande aplicação do CAD no Brasil, foi na ponte do rio Maranhão, no Estado de Goiás, mostrado na figura1.9. Com 585m de extensão, a ponte tem $10,40 \mathrm{~m}$ de largura e duas faixas de tráfego com pavimento rígido em concreto com resistência à compressão de 30MPa. Ela é a primeira do País em que se empregou concreto de $\mathrm{f}_{\mathrm{ck}}$ superior a $50 \mathrm{MPa}$, conforme afirma José Zamarion Ferreira Diniz em CORBIOLI (1997). A princípio era proposto o uso de concreto convencional, no entanto, no decorrer das obras de fundação, foram feitos alguns estudos comparativos de custos, e os resultados demostraram que o concreto de alto desempenho no trecho em balanço significava uma boa economia: 2,4\% em fôrmas, 2,3\% em concreto, $21,3 \%$ em armadura passiva e $14,2 \%$ na protensão. Essa economia equivalia a $10 \%$ do total da obra. Há também, segundo ROCHA (1997), estudos para aplicação do CAD na recuperação do pavimento da ponte Rio-Niterói - RJ, com 12\% de sílica ativa, resistência de 92MPa aos 28 dias e deformação na ruptura em torno de $0,1 \%$.

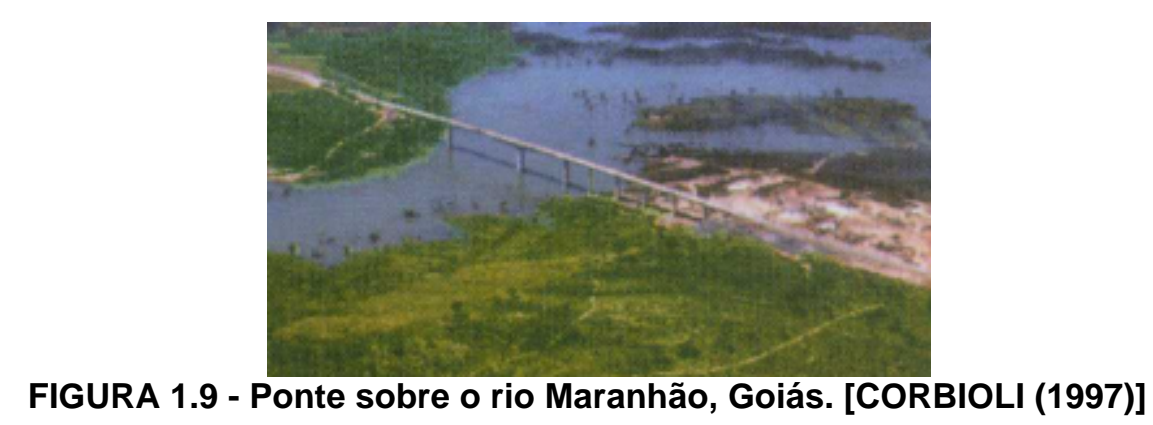

\section{2- Concretos de Alto Desempenho}

A designação "Concreto de Alto Desempenho - CAD" é atribuída ao concreto que reúna características especiais de desempenho, conforme CERF/ASCE(1993), as quais não poderiam ser obtidas comumente, usando apenas materiais convencionais, com procedimentos de misturas usuais. Estas características podem envolver por exemplo, as seguintes melhorias: facilidade de lançamento e adensamento sem segregação; resistências elevadas às pequenas idades; tenacidade; estabilidade de volume; durabilidade, alta densidade, baixa permeabilidade e resistência a agentes agressivos. 
O termo "Concreto de Alta Resistência - CAR", é correntemente utilizado por diversos autores, já que a resistência à compressão é utilizada como parâmetro de comparação entre o concreto usual e o de alto desempenho, porém, fica subtendido que além da alta resistência mecânica este possui outras qualidades, como citado anteriormente.

Nesta pesquisa, o atributo principal é a alta resistência à compressão, que pode ser obtida com uso de cimento Portland comum, porém tomadas medidas adequadas no controle de qualidade, nas baixas relações água/cimento, além do emprego de aditivos como: escória de alto forno, cinzas volante ou sílica ativa. Em função das baixas relações água/cimento, faz-se necessário o emprego de aditivos superplastificantes para fornecer trabalhabilidade ao concreto

Dentre as adições disponíveis, optou-se, nesta pesquisa, pelo uso da sílica ativa, em função de suas características e pelo potencial de produção no Brasil.

Isto posto, o concreto recebe também, entre outras, as denominações de concreto de alto desempenho mecânico, concreto com sílica ativa ou simplesmente concreto com alta resistência.

Pode-se dizer que a adição da sílica ativa, em percentuais que variam de $4 \%$ a $15 \%$ da massa de cimento, em combinação com aditivos químicos do tipo superplastificante, viabiliza a produção de concreto com alto desempenho que apresente características de: alta resistência mecânica, menor exudação e segregação, maior durabilidade, maior trabalhabilidade, alta coesão, alta impermeabilidade e alta resistência aos meios agressivos.

Os concretos de alta resistência também podem ser produzidos sem sílica ativa, porém, esta apresenta vantagens com relação a outras adições, principalmente pela maior reatividade em função da superfície específica e do alto teor de sílica amorfa. Um fato que merece destaque é que, o CAR com sílica ativa reúne características que aumentam a durabilidade das estruturas. VASCONCELOS (1994), considera que o CAR vai ser o material do futuro, pois os concretos feitos atualmente têm pequena durabilidade, não se tendo certeza que uma obra executada hoje dure 50 anos. 
O conceito de concreto de alta resistência tem variado ao longo dos anos, o que pode ser confirmado no boletim 197 CEB-FIP(1990), no qual consta uma evolução na máxima resistência de projeto, sendo recomendado como limite superior de resistência característica um concreto com $f_{c k}$ igual a $80 \mathrm{MPa}$, se bem que, os modelos de verificação da segurança apresentados são válidos para resistência de até 50MPa. Após o advento da sílica ativa, o cimento deixou de ser o fator limitante para a obtenção de maiores resistências, que passam a depender mais diretamente das propriedades dos agregados, que variam de região para região, em função da grande variabilidade das rochas existentes. Segundo AMARAL FILHO (1994) existe idéia de caracterizar as propriedades mecânicas dos agregados, disponíveis nas principais cidades do Brasil, auxiliando desta forma os tecnologistas, em cada região, com relação aos níveis de resistência possíveis de serem alcançados.

Nos Estados Unidos e países da Europa, considera-se um concreto como de alta resistência se apresentar uma resistência característica à compressão entre 40MPa e $85 \mathrm{MPa}$. No Brasil, conforme a NBR 8953/92, seriam os concretos C40 e C50 de Classe I, e Classe II ( C55 - C80). Segundo AMARAL FILHO (1993), parece ser razoável adotar-se a classificação apresentada na tabela 1.1.

TABELA 1.1 - Classificação do concreto quanto à resistência, AMARAL FILHO(1993)

\begin{tabular}{|l|lll|}
\hline \multicolumn{1}{|c|}{ Classificação } & \multicolumn{3}{|c|}{ Nível de resistência } \\
\hline Baixa resistência & & $\mathrm{f}_{\mathrm{ck}}$ & $<25 \mathrm{MPa}$ \\
\hline Média resistência & $25 \mathrm{MPa} \leq$ & $\mathrm{f}_{\mathrm{ck}}$ & $<50 \mathrm{MPa}$ \\
\hline Alta resistência & $50 \mathrm{MPa} \leq$ & $\mathrm{f}_{\mathrm{ck}}$ & $\leq 80 \mathrm{MPa}$ \\
\hline Ultra alta resistência & $90 \mathrm{MPa} \leq$ & $\mathrm{f}_{\mathrm{ck}}$ & $\leq 400 \mathrm{MPa}$ \\
\hline
\end{tabular}

A obtenção do CAD com tais níveis de resistência requer um programa rígido de qualidade que inclui a seleção prévia dos materiais, execução adequada e perfeito controle.

A crescente aplicação destes concretos conduz à necessidade de revisões nos modelos de cálculo, bem como recomendações construtivas das normas atuais ou, até mesmo, elaboração de novas normas que reflitam 
melhor o comportamento deste material, que, como pode ser visto no Boletim 197 do CEB-FIP(1990), apresenta uma evolução muito rápida na sua utilização.

Muitos são os benefícios decorrentes da utilização do CAD, hoje aplicado em edifícios altos, pontes e estruturas submetidas a condições de agressividades e ataques severos. Há ainda várias outras aplicações potenciais para o $C A D$, mas é indubitável que o uso não é feito por desconhecimento do meio técnico.

Importância deve ser dada ao fato de que parâmetros para a verificação da segurança não devem ser extrapolados para concretos destas resistências, principalmente por causa da redução da ductilidade do CAD.

\section{3- Justificativas da Pesquisa}

O Departamento de Engenharia de Estruturas da Escola de Engenharia de São Carlos - USP, vem desenvolvendo trabalhos em pilares com CAR sob compressão excêntrica e centrada com e sem adição de fibras; pilares mistos preenchidos com CAR; recuperação de pilares com utilização de CAD, tela soldada e fibras metálicas; lajes cogumelos utilizando o CAD com e sem adição de fibras; consolos para estruturas pré-moldadas, etc.. Com este trabalho, pretende-se dar continuidade à investigação do comportamento deste material nos pilares, para que se possa futuramente, chegar a conclusões que podem ser utilizadas na rotina de projetos estruturais que garantam confiabilidade e segurança às estruturas feitas com CAD.

Em trabalho desenvolvido neste Departamento, LIMA (1997) ensaiou alguns pilares sob compressão excêntrica, procurando dar continuidade, no Brasil, ao trabalho iniciado na EPUSP e UNICAMP por AGOSTINI (1992), no intuito de conhecer melhor o comportamento de pilares com CAD sob esforços oriundos da flexo compressão reta. Foi dado início à pesquisa, pois observou-se, a partir de uma análise bibliográfica, carência de estudo mais detalhado para a situação de flexão normal composta, avaliando por 
exemplo, a distribuição de tensões ao longo da seção transversal, para níveis diferentes de excentricidades e taxas de armadura. Existia também, necessidade de serem analisados pilares com dimensões que representassem os usados nos edifícios de concreto armado.

LIMA (1997) estudou o comportamento de pilares de concreto de alto desempenho solicitados à compressão centrada e excêntrica. Foram analisados pilares de seções transversais quadradas de $20 \mathrm{~cm} \times 20 \mathrm{~cm}$ e retangulares de $15 \mathrm{~cm} \times 30 \mathrm{~cm}$ e $12 \mathrm{~cm} \times 30 \mathrm{~cm}$, com concreto de resistência à compressão em torno de 80MPa.

Para os modelos solicitados à compressão excêntrica, foram estudados 10 pilares, sendo 5 séries com 2 modelos cada com as características mostradas na tabela 1.2.

TABELA 1.2 - Pilares sob compressão excêntrica ensaiados por LIMA (1997)

\begin{tabular}{|c|c|c|c|c|c|}
\hline Série & $\begin{array}{c}\text { Seção } \\
\text { cm }\end{array}$ & $\begin{array}{c}\text { Altura } \\
\text { Cm }\end{array}$ & Arm. Long. & Arm. trans. & $\begin{array}{c}\text { Excent. } \\
\text { cm }\end{array}$ \\
\hline 5 & $30 \times 15$ & 174 & $2,26 \%(8 \phi 12,5)$ & $1,56 \%(\phi 6,3 \mathrm{c} / 5)$ & 1,5 \\
\hline 6 & $30 \times 15$ & 174 & $3,45 \%(8 \phi 16)$ & $1,56 \%(\phi 6,3 \mathrm{c} / 5)$ & 1,5 \\
\hline 7 & $30 \times 15$ & 174 & $1,26 \%(8 \phi 10)$ & $1,56 \%(\phi 6,3 \mathrm{c} / 5)$ & 1,5 \\
\hline 8 & $30 \times 15$ & 174 & $1,26 \%(8 \phi 10)$ & $1,04 \%(\phi 6,3 \mathrm{c} / 7,5)$ & 2,5 \\
\hline 9 & $30 \times 12$ & 247 & $1,67 \%(8 \phi 10)$ & $0,82 \%(\phi 6,3 \mathrm{c} / 12)$ & 3 \\
\hline
\end{tabular}

O modelo de pilar utilizado por LIMA (1997), apresentava alargamento das seções do topo e da base na direção da excentricidade que se pretendia obter, fazendo com que a resultante da força aplicada nessas áreas, tivesse um deslocamento em relação ao eixo longitudinal do pilar, como mostra a figura 1.10 .

Para analisar os resultados de LIMA (1997), utilizou-se a relação tensão x deformação desenvolvida pelo mesmo, e outra proposta por COLLINS et al.(1993).

As relações entre a força experimental e a teórica obtida através dos modelos teóricos foram praticamente iguais a 1. Analisando as relações entre os momentos fletores, viu-se que a relação proposta por COLLINS et al.(1993) apresentou melhores resultados que os de LIMA (1997), no entanto, ambas relações foram muito acima da unidade. As médias entre 
todos os valores de $\mathrm{M}_{\text {exp }} / \mathrm{M}_{\text {teo }}$ resultaram iguais a 3,06 (LIMA) e 2,64 (COLLINS et al.).

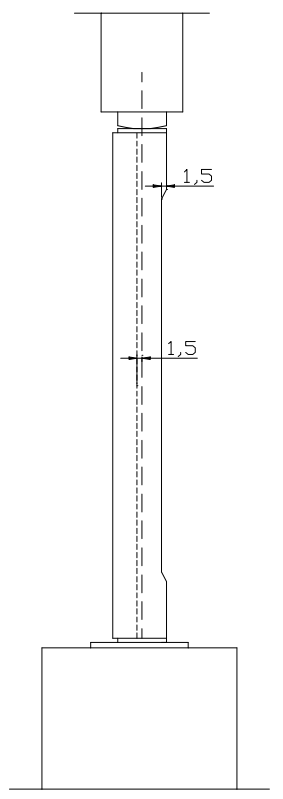

FIGURA 1.10 - Sistema de aplicação de forças utilizado por LIMA (1997)

$\mathrm{Na}$ análise dos pilares admitiu-se que o momento experimental era calculado por $M_{\text {exp }}=F_{\text {exp }}$. $e_{\text {inicial }}$. Pode-se concluir que 0 momento experimental, tal como admitido, não correspondia ao que atuava na seção a meia altura do pilar, o que dificultou a análise comparativa, cujo valores estão expressos na tabela 1.3. A principal causa da imprecisão do ensaio foi a vinculação na base e no topo do pilar, pois o modelo físico teórico considerava os dois pontos articulados, enquanto que o ensaio reproduziu uma situação de semi - engastamento tanto na base quanto no topo do pilar.

TABELA 1.3 - Análise dos resultados de LIMA (1997) considerando o modelo apresentado por COLLINS et al. (1993)

\begin{tabular}{|l|c|c|c|c|c|c|c|c|c|c|}
\hline Pilar & $\begin{array}{c}\mathbf{f}_{\mathbf{c}} \\
\mathbf{M P a}\end{array}$ & $\begin{array}{c}\mathbf{E}_{\mathbf{c}} \\
\mathbf{M P a}\end{array}$ & $\begin{array}{c}\mathbf{f}_{\mathbf{y}} \\
\mathbf{M P a}\end{array}$ & $\begin{array}{c}\mathbf{E}_{\mathbf{s}} \\
\mathbf{M P a}\end{array}$ & $\begin{array}{c}\mathbf{F}_{\text {exp }} \\
\mathbf{k N}\end{array}$ & $\begin{array}{c}\mathbf{M}_{\text {exp }} \\
\mathbf{k N . c m}\end{array}$ & $\begin{array}{c}\mathbf{F}_{\text {teo }} \\
\mathbf{k N}\end{array}$ & $\begin{array}{c}\mathbf{M}_{\text {teo }} \\
\mathbf{k N . c m}\end{array}$ & $\begin{array}{c}\mathbf{F}_{\text {exp }} / \\
\mathbf{F}_{\text {teo }}\end{array}$ & $\begin{array}{c}\mathbf{M}_{\text {exp }} / \\
\mathbf{M}_{\text {teo }}\end{array}$ \\
\hline $\mathrm{P} 5 / 1$ & 81,1 & 30836 & 543,3 & 205028 & 2842 & 4263 & 3110 & 2465 & 0,91 & 1,73 \\
\hline $\mathrm{P} 5 / 2$ & 79,5 & 30874 & 543,3 & 205028 & 2806 & 4209 & 2022 & 2808 & 1,39 & 1,50 \\
\hline $\mathrm{P} 6 / 1$ & 85,7 & 31876 & 710,5 & 201242 & 3227 & 4840 & 3226 & 2368 & 1,00 & 2,04 \\
\hline $\mathrm{P} 6 / 2$ & 83,7 & 31689 & 710,5 & 201242 & 3218 & 4827 & 3603 & 3210 & 0,89 & 1,50 \\
\hline $\mathrm{P} 7 / 1$ & 87,3 & 32615 & 681,2 & 200419 & 3012 & 4518 & 2969 & 1771 & 1,01 & 2,55 \\
\hline $\mathrm{P} 7 / 2$ & 93,5 & 34961 & 681,2 & 200419 & 3118 & 4677 & 3577 & 2074 & 0,87 & 2,26 \\
\hline $\mathrm{P} 8 / 1$ & 87,1 & 30263 & 681,2 & 200419 & 3252 & 8130 & 3156 & 2745 & 1,03 & 2,96 \\
\hline $\mathrm{P} 8 / 2$ & 92,8 & 35984 & 681,2 & 200419 & 3250 & 8125 & 3511 & 1809 & 0,93 & 4,49 \\
\hline $\mathrm{P} 9 / 1$ & 101,3 & 34195 & 676,4 & 203141 & 2388 & 7164 & 2385 & 6205 & 1,00 & 1,15 \\
\hline $\mathrm{P} 9 / 2$ & 83,3 & 27312 & 676,4 & 203141 & 2143 & 6438 & 2047 & 5061 & 1,05 & 1,27 \\
\hline
\end{tabular}




\section{4 - Objetivos da Pesquisa}

Este trabalho faz parte de um plano mais abrangente coordenado pelo orientador, e tem como objetivo analisar o comportamento de pilares construídos com concreto de alta resistência sujeitos à flexo compressão reta. Para isto, desenvolveu-se metodologia de ensaio adequada, no sentido de representar e controlar melhor as solicitações, para aferir modelo de cálculo teórico. Procurou-se também, estabelecer condições necessárias, como taxas de armaduras longitudinais e transversais, para obtenção de pilares que apresentassem comportamento suficientemente resistente e dúctil.

\section{5 - Metodologia da Pesquisa}

Tomaram-se por base os ensaios realizados por LIMA (1997) em pilares sob compressão excêntrica, projetando-se outras condições de vinculação e configuração geométrica, mantendo-se a mesma seção transversal, resistência característica à compressão do concreto e as taxas de armaduras transversais e longitudinais utilizadas.

Inicialmente, foi aperfeiçoado o método de ensaio utilizado por LIMA (1997), montando, para isso, dispositivo de ensaios de pilares que levassem a resultados experimentais que se aproximem mais dos obtidos com a idealização teórica. Procurou-se criar condições de vinculação dos modelos de pilares que se assemelhassem ao modelo teórico, tendo-se que mudar a configuração geométrica do pilar e o sistema de aplicação de força para melhor se adequar a situação de flexo compressão reta.

Pensou-se, para tanto, em prover os modelos com consolos no topo e base para facilitar a aplicação de força excêntrica e, ainda, escolher aparelhos de apoio que pudessem fornecer ao modelo, as condições de vinculação que se pretendia adotar no modelo teórico.

Com relação à análise teórica, o modelo de verificação de equilíbrio da seção transversal para pilares de CAR, é o mesmo adotado para concreto de resistência usual - CRU. A forma do diagrama tensão $x$ 
deformação para o CAR difere do CRU então, pretendia-se verificar a segurança da seção transversal, adotando os diagramas de tensões obtidos em ensaios de corpos-de-prova com o mesmo material dos modelos.

Foram analisados os comportamentos dos pilares durante os ensaios por meio de medidas de deformações e deslocamentos provenientes das aplicações das forças, centrada e excêntrica. Logo, adotando modelo que descreve a relação tensão $\mathrm{x}$ deformação indicada por LIMA (1997) e COLLINS et al. (1992), chegam-se a resultados teóricos para forças últimas e momentos fletores últimos dos pilares e comparam-se com os valores experimentalmente.

Sabe-se que os pilares em CAR podem, apresentar colapso frágil. Sendo conveniente que a ruína apresente características dúcteis, é necessário que se verifique os valores das taxas de armaduras longitudinais e transversais.

Foram também analisados os comportamentos dos pilares durante os ensaios através de gráficos que relacionam força aplicada com as deformações lidas nas armaduras e no concreto, e com os deslocamentos. Pretendeu-se também, relacionar as deformações últimas de ruptura do concreto e a forma de ruptura, com as taxas de armaduras transversais e longitudinais utilizadas. 


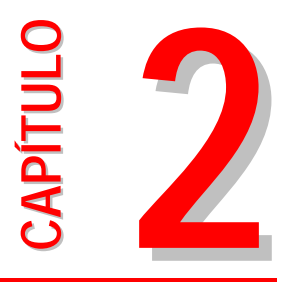

\section{FUNDAMENTOS DO CONCRETO DE ALTA RESISTÊNCIA}

\section{1- Considerações Iniciais}

Este capítulo procura dar melhor entendimento sobre a obtenção e as propriedades do concreto de alta resistência, onde são tratados os fatores que influenciam na obtenção de alta resistência à compressão, com considerações sobre os materiais componentes e sua importância na obtenção do CAR.

São abordados as várias características dos agregados, aglomerantes, água, aditivo superplastificante e sílica ativa, relacionando como cada característica influencia na obtenção do CAR e como otimizar a produção desse concreto partindo da análise dessas características.

É feita uma análise do processo de produção do CAR, comentando e descrevendo os procedimentos de mistura; lançamento; adensamento e cura. Também são abordadas algumas propriedades mecânicas: resistência à compressão e à tração, módulo de deformação longitudinal e coeficiente de Poisson.

\section{2- Materiais Componentes do Concreto}

Devido às grandes variações nas composições e propriedades dos cimentos e agregados, a seleção de materiais para produção de concreto de alta resistência - CAR - não é simples. A utilização simultânea de vários aditivos químicos e adições minerais dificulta ainda mais a escolha de materiais pela falta de correlações simples que facilitem a escolha dos materiais mais adequados. 
No entanto, é possível otimizar as propriedades mecânicas do concreto endurecido, fazendo escolhas de materiais pelas suas características e propriedades, melhorando assim o comportamento da mistura.

\subsection{1- Cimento}

O cimento mais adequado para a produção de CAR é, de acordo com ACI 363R (1992), aquele que apresenta menor variabilidade em termos de resistência àcompressão, não existindo critérios específicos para tal.

A escolha do tipo de cimento, segundo PINTO JUNIOR (1992), para produção dos concretos de alta resistência depende de critérios reológicos e critérios de resistência mecânica. METHA e AITCIN (1990), comentam que “... com qualquer tipo de cimento é possível produzir concretos de alta resistência, sendo preferível, no entanto, o cimento Portland comum e aqueles com elevados teores de $\mathrm{C}_{3} \mathrm{~S}$ e $\mathrm{C}_{2} \mathrm{~S}$."

O cimento $A R I$ requer mais água em comparação, por exemplo, com um cimento composto com cinza volante e para um mesmo abatimento.

O consumo, usualmente empregado na obtenção do CAR, varia de $400 \mathrm{~kg} / \mathrm{m}^{3}$ a $600 \mathrm{~kg} / \mathrm{m}^{3}$, conforme ACl 363R (1992), ALMEIDA(1990) e SHAH \& AHMAD (1994). O limite superior é estabelecido em função do aumento da quantidade de água que, para consumo acima de $550 \mathrm{~kg} / \mathrm{m}^{3}$ é da ordem de 10 litros para cada acréscimo de $30 \mathrm{~kg}$ de cimento, mantida fixa a trabalhabilidade do concreto. Esta preocupação esta diretamente relacionada com o objetivo de redução das deformações a longo prazo, provocadas por retração e fluência.

AGOSTINI (1992) ressalta que o aumento do consumo de cimento, desde que mantida as demais relações de materiais, proporciona aumentos sensíveis na resistência à compressão do concreto. 


\subsection{2- Sílica ativa}

Os concretos de alta resistência podem ser obtidos com as adições pozolânicas normalmente utilizadas, como cinza volante ou escória de alto forno. Entretanto, adições pozolânicas ultra-finas, como a sílica ativa e a cinza de casca de arroz, têm-se mostrado mais efetivas no aumento da resistência, pois, além do efeito químico, atuam fisicamente densificando a matriz e a zona de transição. A sílica ativa é conhecida no meio técnico como sílica, sílica volatizada, fumo de sílica condensada ou sílica fume, microssílica, entre outros.

Segundo a ASTM C1240/93, sílica ativa é um material pozolânico de alta finura composto basicamente de sílica amorfa, produzida a partir de fornos de arco voltaico, como subproduto decorrente da obtenção do ferro sílico ou silício metálico, que contem em sua composição química um percentual mínimo de $85 \%$ de dióxido de silício $\left(\mathrm{SiO}_{2}\right)$. A redução de quartzo a silício em temperaturas de até $2000^{\circ} \mathrm{C}$ produz vapor de $\mathrm{SiO}$, que oxida e condensa, em zonas de baixa temperatura, a partículas esféricas minúsculas consistindo de sílica não cristalina.

A figura 2.1 mostra como é realizada a produção da sílica ativa. Os gases de combustão passam por filtros onde a sílica ativa bruta é coletada. Logo após ela sofre tratamentos de aglomeração para evitar problemas no transporte e manuseio ocasionados por sua demasiada finura.

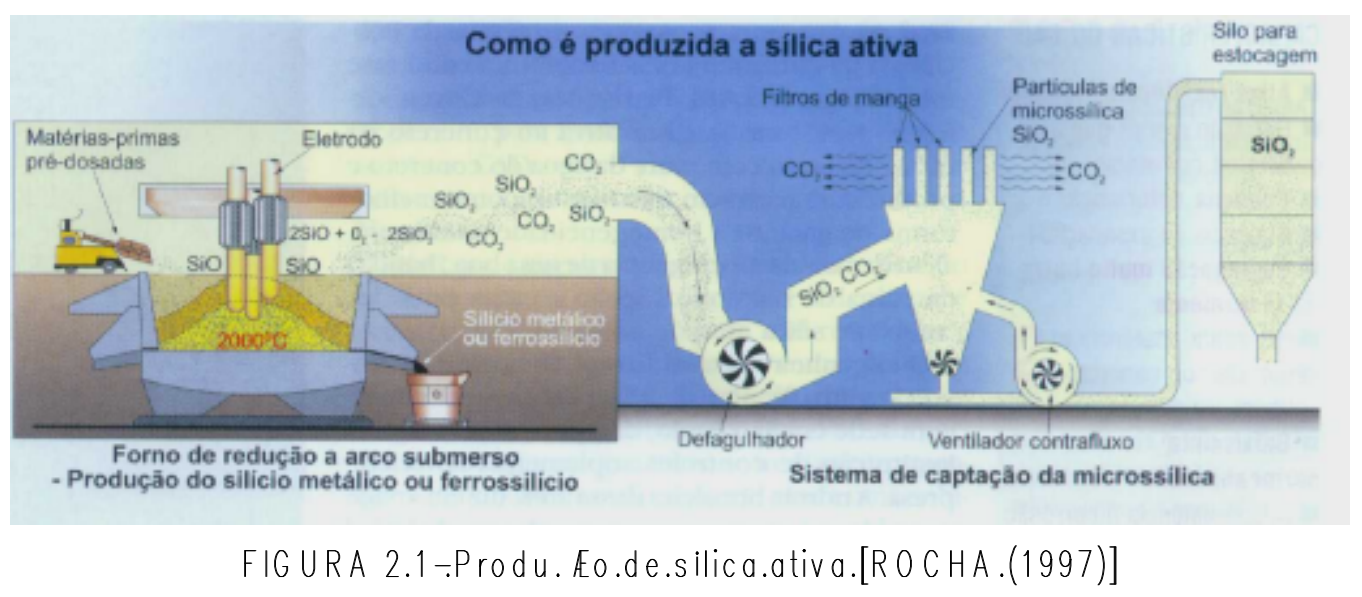


A zona de transição do concreto, que é a região entre os agregados graúdos e a pasta de cimento hidratada, apresenta uma espessura média entre $10 \mu \mathrm{m}$ a $50 \mu \mathrm{m}$, rica em hidróxido de cálcio $\mathrm{CH}$ e com maior concentração de poros. Esta zona é tida como a região mais fraca do concreto. A sílica ativa atua basicamente na zona de transição do concreto, apresentando dois efeitos: o efeito micro-filler e o efeito pozolânico.

Como as partículas de sílica ativa são extremamente pequenas e de forma esférica, sua superfície específica é muito grande, $20 \mathrm{~m}^{2} / \mathrm{g}$, isto faz com que haja uma rápida reação com o hidróxido de cálcio $\left(\mathrm{Ca}(\mathrm{OH})_{2}\right)$, produzindo um gel resistente de cálcio hidratado semelhante ao formado na hidratação do cimento.

Além do efeito pozolânico, há formação de produtos de hidratação secundários em volta das partículas de sílica ativa ocorrendo o preenchimento dos grandes vazios capilares com um material microporoso e portanto de baixa densidade, ocasionando um refinamento no tamanho dos poros. Existe também, um refinamento no tamanho dos grãos, causado pela nucleação do hidróxido de cálcio em volta das pequenas e bem distribuídas partículas de sílica ativa, que terá o efeito de substituir os grandes cristais orientados de hidróxido de cálcio por numerosos, pequenos e menos orientados produtos da reação mais pobremente cristalino.

Em resumo, pode-se dizer que a adição de sílica ativa em percentuais que variam de $4 \%$ a $15 \%$ da massa de cimento, em combinação com aditivos químicos do tipo superplastificantes, viabiliza a produção de concreto com alto desempenho que apresente características de: alta resistência mecânica, minimização da exudação e segregação, maior durabilidade, maior trabalhabilidade, alta coesão, alta impermeabilidade e alta resistência aos meios agressivos.

Para obtenção de concreto de alta resistência à compressão, não se tem um método que estabeleça o consumo adequado de sílica ativa para determinada resistência. Encontra-se, por exemplo, para resistência à compressão em torno de $80 \mathrm{MPa}$, consumos que variam de 10\% a $20 \%$ de sílica ativa em relação ao consumo de cimento. $O$ consumo ideal deve ser 
determinado experimentalmente de acordo com o projeto e a resistência do concreto.

\subsection{3- Agregados}

Os agregados usados em concretos de alta resistência podem ser materiais naturais (areia, pedregulho e pedra britada) ou artificiais (argila expandida).

Os agregados dividem-se em graúdo e miúdo, em função da dimensão máxima característica dos grãos, e ocupam $60 \%$ a $80 \%$ do volume de concreto. As características que mais influenciam na resistência à compressão dos concretos são: a resistência à compressão do agregado, módulo de deformação longitudinal da rocha mãe, granulometria, diâmetro máximo característico, módulo de finura, forma, textura superficial, natureza mineralógica e absorção.

Os agregados graúdos apresentam uma maior influência na resistência dos concretos de alta resistência, pois devido ao fortalecimento da zona de transição para resistências acima de $50 \mathrm{MPa}$, a ruptura do concreto se dá pela ruptura do agregado graúdo, havendo assim uma relação entre a resistência da rocha mãe do agregado e a resistência do concreto.

Os melhores resultados obtidos para a resistência à compressão acorrem quando se usam agregados graúdos de tamanho máximo entre $10 \mathrm{~mm}$ a $20 \mathrm{~mm}$, recomendado $12,5 \mathrm{~mm}$, areia com módulo de finura próximo de 3 , e com uma relação agregado graúdo / agregado miúdo em torno de 1,5 .

Existem várias razões pelas quais um agregado de menor dimensão máxima é capaz de produzir um concreto mais resistente. Como o agregado é britado, durante o processo de britagem podem ocorrer danos à microestrutura dos agregados, sendo, probabilisticamente, mais provável de remanescerem falhas e fissuras em agregados de maior dimensão, segundo 
JENNINGS ${ }^{1}$ apud DAL MOLIN (1995). Quanto menor o agregado, maior a superfície específica, ocasionando uma maior área de contato entre as partículas de agregado graúdo e a pasta, aumentando assim a homogeneidade da mistura, melhor transferência de ação entre pasta e agregado e redução do volume da pasta e do espaçamento entre os agregados.

Por outro lado, quanto maior é o agregado, maior é a espessura da zona de transição entre ele e a pasta, diminuindo a resistência do concreto pela criação de maior microfissuração e porosidade na zona de transição.

A natureza mineralógica dos agregados é fundamental para a resistência e elasticidade dos CARs. Neste tipo de concreto, os agregados graúdos participam efetivamente do processo de ruptura, visto que na maior parte dos ensaios a superfície de ruptura passa pelos grãos de agregados e alterações encontradas na estrutura e na composição mineralógica do agregado refletem na resistência do concreto.

MEHTA e AITCIN (1990), estudaram o efeito das características mineralógicas do agregado graúdo nas propriedades mecânicas do CAR, utilizando quatro tipos de agregados diferentes: diabásio britado, calcário britado, seixo rolado e granito britado. Observaram-se diferenças significativas no módulo de deformação e nas curvas de histeresse, comprovando a importância das características mineralógicas do agregado.

Em estudo feito por PEREIRA NETO (1994) sobre o efeito do agregado graúdo em algumas propriedades de CARs com adição de sílica ativa, observou-se que a evolução da resistência à compressão dos concretos de alta resistência é influenciada pelo tipo de agregado, não podendo a resistência à compressão dos CARs ser expressa somente em termos da Lei de Abrams.

O módulo de deformação longitudinal dos concretos é influenciado pelas propriedades elásticas dos agregados graúdos, havendo uma relação entre as deformações plásticas dos agregados e os módulos de deformação

\footnotetext{
${ }^{1}$ JENNINGS, H. M. (1988) Design of high strength cement based materials: Part 2-microstructure. Materials Science and Technology. v.4, n.4, p.285-290, April.
} 
longitudinal dos concretos. Os concretos que apresentam maiores módulos de deformação longitudinal não apresentam as maiores resistências.

Em relação àforma e textura superficial, é sabido que a forma angular e a superfície áspera, como a maioria das pedras britadas, geralmente resultam em maior aderência que a obtida em superfícies lisas e formas esféricas. A angulosidade excessiva deve ser evitada, pois provoca 0 aumento da quantidade de água necessária para obter a trabalhabilidade desejada. A forma ideal parece ser então a cúbica.

Logo para obtenção de CARs com relação ao agregado graúdo, estes devem apresentar alta resistência à compressão, módulo de deformação longitudinal maior ou igual ao da pasta de cimento, granulometria que minimize o consumo de água e/ou concentração de tensões, forma cúbica, textura superficial áspera e ausência de pó, que favoreçam a aderência com a pasta.

Quanto ao agregado miúdo, tanto as areias naturais quanto as artificiais podem ser utilizadas para obtenção de concreto de alta resistência. No entanto é preferível que se use uma granulometria descontínua, apresentando preferivelmente um módulo de finura entre 2,7 e 3,2 , ou seja, classificado como grosso. Segundo ALMEIDA (1990), isto é para que haja menor demanda de água de amassamento, e pelo fato deste tipo de concreto já apresentar grande quantidade de finos devido ao maior consumo de cimento e uso de sílica ativa.

Agregados miúdos com partículas arredondadas e lisas necessitam menos água de mistura e, por este motivo, são preferíveis para produção de concreto de alta resistência.

\subsection{4- Água}

A qualidade da água utilizada na produção de concreto de alto desempenho deve obedecer às mesmas especificações usadas nos concretos usuais, deve apresentar satisfatória isenção de matérias orgânicas e de substâncias estranhas e nocivas que possam provocar a deterioração do mesmo. 


\subsection{5- Aditivo superplastificante}

Aditivos são substâncias que modificam as propriedades do concreto quando incorporados a ele. No caso de CARs os aditivos fundamentais são os superplastificantes que são capazes de propiciar a obtenção conjunta de trabalhabilidade adequada com baixas relações água/cimento.

A maioria dos aditivos superplastificantes são obtidos através da polimerização por condesação do formaldeído com o naftaleno sulfonado ou com a melanina sulfonada, podendo ainda existir os formados por lignosulfonados modificados.

Os superplastificantes formados por melanina sulfonada ou naftaleno sulfonado são os mais utilizados, segundo BUCKER $^{2}$ (1988), por possuírem grande eficiência como redutor de água de amassamento, ações secundárias mínimas e efeitos colaterais indesejáveis praticamente desprezíveis. Isto se dá, pois estes surperplastificantes não existem em subprodultos industriais e nem no estado natural, precisando ser sintetizados em laboratório por processos complexos. Como o produto é fabricado especialmente para ser empregado como redutor de água, o comprimento da cadeia polimérica é dimensionado de modo a envolver os grãos de cimento o mais perfeitamente possível, e obtendo-se assim a máxima performance do produto, COLLEPARDI et al. ${ }^{3}$ apud DUCATTI (1993).

A ação dos superplastificantes é fundamentalmente de dispersão das partículas de cimento, as cadeias moleculares de alto massa se adsorvem às paredes dos grãos de cimento neutralizando suas cargas elétricas na periferia, causando a repulsão eletrostática entre os mesmos, e, atraindo ao mesmo tempo, através de suas ramificações aniônicas, moléculas de água que envolvem em todo o contorno o grão de cimento, DUCATTI (1993).

A grande quantidade de superplastificante e a baixa relação água/cimento no concreto de alta resistência são responsáveis pelo

\footnotetext{
${ }^{2}$ BUCKER, H. R. E. (1988) Desempenho de aditivos redutores de água de alta eficiência em pastas, argamassas ou concretos. In: REUNIÃO ANUAL DO IBRACON, 30. Rio de Janeiro. v.2, p.609-625. ${ }^{3}$ COLLEPARDI, M.; CORRADI, M.; VALENTI, M. (1983) Influência dos aditivos superplastificantes nas propriedades das argamassas e concretos. In: TECNOLOGIA DE ADITIVOS. 2v. Instituto de Pesquisas Tecnológicas IPT, São Paulo.
} 
retardamento de pega, retração plástica, incorporação de ar e perda da consistência inicial com o tempo.

A consistência obtida pelo superplastificante, dependendo das condições, se mantém apenas por um período de 30 a 60 minutos. A máxima trabalhabilidade alcançada normalmente permanece por 10 a 15 minutos. Os fatores que afetam a consistência inicial do concreto com superplastificantes, segundo DAL MOLIN (1995), são: tipo de aditivo, dosagem e momento de colocação na mistura, temperatura, umidade e tipo de cimento.

A quantidade de superplastificante é função da trabalhabilidade requerida, devendo-se optar por um consumo mínimo pensando na redução do custo do concreto. Os fornecedores indicam 3\% do consumo de cimento como máximo de quantidade de suerplastificante. Recomenda-se, também, que a parcela de água contida no superplastificante seja abatida da água utilizada, onde a quantidade de material sólido é em torno de $25 \%$ a $30 \%$.

\section{3- Procedimentos de Dosagem e Mistura}

Entre os vários métodos de dosagem do concreto, os fatores comuns entre eles são: resistência desejada, idade do ensaio, tipo de aplicação, durabilidade prevista, aspectos econômicos, ambiente, etc.. Para obter máxima resistência à compressão do concreto, deve-se otimizar 0 desempenho de cada um dos componentes, considerando-se os fatores de influência.

Para dosagem de um concreto, deve-se conhecer um método de dosagem e observar: menor relação água/cimento; características de finura do agregado miúdo; escolha do agregado graúdo que é função da sua mineralogia, resistência à compressão e módulo de deformação longitudinal; consumo de sílica ativa e aditivos. Em seguida, a partir de um primeiro ensaio feito para uma dosagem, fazem ajustes do fator água/cimento, agregados, e outros, até obter-se a resistência e a trabalhabilidade necessária e com menor consumo de cimento. 
Os mesmos equipamentos de mistura usados na produção dos concretos de resistências usuais podem ser adotados na obtenção dos CARs, observando-se que a eficiência da mistura é melhor quanto maior for o desempenho do equipamento utilizado.

Com relação a sequência de colocação dos materiais, LIMA (1997) usou a seguinte ordem: 1 - pedra britada $+20 \%$ da água; 2 - cimento $+30 \%$ da água; 3- sílica ativa; 4- restante da água + aditivo; 5- areia. O tempo total foi de 15 minutos. DUCATTI (1993), utilizando equipamento de pouca eficiência para a mistura dos materiais, seguiu a seguinte ordem de colocação dos materiais: 1- mistura de todo o agregado graúdo com o cimento, a sílica ativa, toda a água e um terço da solução do superplastificante durante mais ou menos 10 minutos; 2- colocação de toda a areia e os dois terços restante do aditivo, misturando por mais 5 minutos.

O tempo de mistura deve ser um pouco maior que o adotado para concreto de resistência usual, para se atingir a dispersão apropriada, principalmente dos materiais finos e a incorporação dos aditivos a mistura.

\section{4- Propriedades Mecânicas do Concreto no Estado Endurecido}

\subsection{1- Resistência à compressão}

A resistência à compressão é considerada geralmente a propriedade mais importante do concreto, pois fornece uma estimativa do desempenho do concreto no que diz respeito a resistência mecânica e indiretamente a sua durabilidade.

Essa resistência é obtida através da aplicação de forças em corposde-prova cilíndricos ou cúbicos de diferentes tamanhos, dependendo da normalização de cada país. No Brasil, a resistência à compressão do concreto é obtida através do ensaio padronizado pela NBR 5739/80, a partir de corpos-de-prova cilíndricos de $15 \mathrm{~cm} \times 30 \mathrm{~cm}$. Quando se trata de altas resistências, o uso destes geram dificuldades pela necessidade de grande capacidade da máquina de ensaio. A solução utilizada é a redução das 
dimensões dos corpos-de-prova, adotando-se $10 \mathrm{~cm} \times 20 \mathrm{~cm}$, mantendo-se a relação de duas vezes entre a altura e o diâmetro da base, e respeitando ainda a exigência do diâmetro do corpo-de-prova ser maior que quatro vezes o diâmetro máximo do agregado.

Os corpos-de-prova cilíndricos menores apresentam maior resistência se comparados com os maiores. METHA \& MONTEIRO (1994) e SHAH \& AHMAD (1994) indicam que essa correlação é em torno de 5\%. CARRASQUILLO et al. (1981), em estudo feito sobre esse efeito, indica correlação de $10 \%$.

Nos Estados Unidos e na França, adotam-se o cilindro com dimensões de $15 \mathrm{~cm} \times 30 \mathrm{~cm}$ e $16 \mathrm{~cm} \times 32 \mathrm{~cm}$, respectivamente. Na Alemanha e na Noruega são utilizados corpos-de-prova cúbicos com dimensões de $14 \mathrm{~cm}$ e $10 \mathrm{~cm}$ de aresta, respectivamente.

Um aspecto importante é a evolução da resistência com a idade. Para os CARs, as propriedades mecânicas se desenvolvem muito mais rapidamente do que os concretos de resistências usuais. Segundo DE LARRARD \& MALIER (1989), este rápido crescimento das resistências é provocado pela proximidade inicial dos grãos de cimento na mistura fresca, bem como pelo papel acelerador da sílica ativa. O Comitê 363 do ACl (1991) justifica tal comportamento em razão do calor de hidratação gerado em decorrência dos altos consumos de cimento dos CAR.

O efeito das condições de cura leva a variações na resistência à compressão. NEVILLE \& BROOKS (1987) relata que a cura inadequada em CAR provoca efeitos negativos mais pronunciados do que em concretos de resistência usual. CARRASQUILLO \& PETERMAN (1986) chamam a atenção para a importância da cura nas primeiras idades em CAR.

A curva tensão $x$ deformação, na compressão, tem uma forma dependente da resistência. Observam-se nas curvas que há encurtamentos diferentes para as tensões máximas, sendo que para os CAR estes alongamentos são da ordem de $2 \%$ e para os concretos de resistências usuais são de $3 \%$. O encurtamento de ruptura dos CARs fica em torno de $3,5 \%$, e dos concretos usuais varia entre $5 \%$ e $6 \%$. 
Outra diferença observada está no intervalo de resposta elástica linear, que nos concretos usuais é em torno de $50 \%$ da tensão máxima e nos concretos de alta resistência em torno de $80 \%$ da tensão máxima. Essa maior elasticidade deve ser atribuída ao CAR porque, diferentemente do concreto de resistência usual, ele se comporta como um verdadeiro material composto, com transferência efetiva de tensão entre a matriz de argamassa e o agregado graúdo, DUCATTI (1993).

O acabamento dado no topo do corpo-de-prova é de grande importância para os resultados esperados nos ensaios. A capacidade resistente do material utilizado para o capeamento dos corpos-de-prova de CAR pode afetar os resultados obtidos no ensaio. Se a resistência à compressão ou módulo de deformação do material de capeamento for menor que o do corpo-de-prova de concreto, as ações aplicadas através do capeamento não serão transmitidas uniformemente, resultando em uma grande variabilidade nos resultados.

Segundo ALMEIDA (1990), o emprego do capeamento, com argamassa de enxofre favorece a dispersão dos resultados obtidos em concretos com resistência superior a $55 \mathrm{MPa}$. Mas, tomando-se cuidado no acabamento quando da moldagem do corpo-de-prova, pode-se obter capeamento de enxofre com $2 \mathrm{~mm}$ de espessura o que não provoca diferença no valor da resistência em concreto com resistência à compressão até $80 \mathrm{MPa}$.

Várias soluções alternativas têm sido apresentadas como viáveis: anel metálico preenchido com um disco de poliuretano ou neoprene, planificação dos topos com serra, e outras.

\subsection{2- Resistência à tração}

A resistência àtração do concreto pode ser obtida por três maneiras:

$>$ resistência à tração por compressão diametral do corpo-deprova cilíndrico de concreto;

$>$ resistência à tração na flexão, onde aplica-se uma ação concentrada em uma viga padronizada de concreto, a ação pode 
ser aplicada no centro do vão ou com duas forças aplicadas nas seções transversais nos terços;

$>$ resistência àtração direta.

Segundo DE LARRARD \& MALIER (1992), o concreto atinge o valor máximo da resistência à tração por volta dos 14 dias de idade, ao contrário do valor da resistência à compressão, que pode crescer ainda $10 \%$ a $20 \%$ do seu valor aos 14 dias.

A resistência à tração apresenta uma relação com a resistência à compressão. Em geral aumentando-se a resistência à compressão, a resistência à tração também aumenta, mas a relação para CARs não é a mesma que para os concretos usuais.

A resistência à tração em corpos-de-prova cilíndricos por compressão diametral é calculada segundo a NBR 7222/1982 da seguinte forma:

$$
f_{t, D}=\frac{2 \cdot F}{\pi \cdot d \cdot L}
$$

onde: $\quad f_{t, D}=$ resistência àtração por compressão diametral, em MPa;

$\mathrm{F}$ = força máxima obtida no ensaio, em kN;

$\mathrm{d}$ = diâmetro do corpo-de-prova, em $\mathrm{mm}$;

$\mathrm{L}=$ altura do corpo-de-prova, em $\mathrm{mm}$.

$\mathrm{Na}$ ausência de resultados experimentais a NBR 6118 (1978), que ainda não foi ajustada para incorporar concretos de alta resistência, sugere que a resistência característica à tração seja calculada por:

$$
\begin{array}{lll}
f_{t k}=\frac{f_{c k}}{10} & \text { para } & \mathrm{f}_{\mathrm{ck}} \leq 18 \mathrm{MPa} \\
f_{t k}=0,06 f_{c k}+0,7 \mathrm{MPa} & \text { para } & \mathrm{f}_{\mathrm{ck}}>18 \mathrm{MPa}
\end{array}
$$

- O Código Modelo - MC90 CEB-FIP (1991), para concreto com resistência à compressão entre 12MPa e $80 \mathrm{MPa}$, em corpos-de-prova cilíndricos de $15 \mathrm{~cm} \times 30 \mathrm{~cm}$, indica a expressão 2.3 para determinar a resistência característica à tração.

$$
f_{c t k}=0,30 f_{c k}^{2 / 3} \quad(\mathrm{MPa})
$$


onde: $f_{c k}=$ resistência característica à compressão, obtida em ensaios de corpos-de-prova cilíndricos de $15 \mathrm{~cm} \times 30 \mathrm{~cm}$.

- A norma norueguesa NS 3473E (1992), que é válida para concreto com resistência à compressão entre $20 \mathrm{MPa}$ e $94 \mathrm{MPa}$, determinadas para corpos-de-prova cilíndrico de $15 \mathrm{~cm} \times 30 \mathrm{~cm}$, indica a expressão 2.4 para cálculo da resistência à tração característica limitando um valor nominal máximo de 4MPa.

$$
f_{t k}=0,30 f_{c k}^{0,6} \quad(\mathrm{MPa})
$$

onde: $f_{c k}=$ resistência característica à compressão, obtida em ensaios de corpos-de-prova cúbicos de $10 \mathrm{~cm}$ de aresta.

A resistência característica à tração axial é correspondente a 2/3 do valor obtido a partir do ensaio de compressão diametral.

- CARRASQUILLO et al. (1981), baseando-se em resultados de ensaios à flexão em corpos-de-prova prismático, e com resultados de ensaios à compressão diametral em corpos de prova cilíndricos, propõe para a resistência àtração no concreto, para $21 \mathrm{MPa} \leq \mathrm{f}_{\mathrm{ck}} \leq 83 \mathrm{MPa}$ :

$$
\begin{array}{ll}
\mathrm{f}_{\mathrm{tk}}=0,94 \sqrt{\mathrm{f}_{\mathrm{ck}}} & (\mathrm{MPa}), \quad \text { na flexão; } \\
\mathrm{f}_{\mathrm{tk}}=0,54 \sqrt{\mathrm{f}_{\mathrm{ck}}} \quad \text { (MPa), na compressão diametral. (2.5) }
\end{array}
$$

$\mathrm{f}_{\mathrm{ck}}=$ resistência à compressão medida em corpos de prova cilíndricos de $10 \mathrm{~cm} \times 20 \mathrm{~cm}$.

\subsection{3- Módulo de deformação longitudinal}

O aumento do módulo de deformação do CAR em relação ao concreto convencional, é, segundo DE LARRARD \& MALIER (1989), consequência da maior rigidez da argamassa e maior aderência pasta agregado. Entretanto, o aumento do módulo de deformação não se dá com a mesma intensidade do aumento da resistência à compressão.

O módulo de elasticidade do CAR é fortemente afetado pelas propriedades elásticas do agregado graúdo. A boa aderência na interface 
entre o agregado graúdo e a argamassa resulta em um material composto, cujos componentes são a pasta de cimento e o agregado graúdo, DUCATTI (1993).

O pesquisador indica que, as fórmulas das normas atuais relacionando $E_{c}$ com $f_{c k}$ não são válidas para os CAR. Logo, outras expressões relacionando $E_{c}$ e $f_{c k}$ serão necessárias para levar em conta 0 módulo de elasticidade da rocha-mãe da qual o agregado graúdo se originou.

$\mathrm{Na}$ falta de determinação experimental, a previsão do módulo de deformação pode ser feita segundo as seguintes normas técnicas:

a) A norma brasileira NBR 6118 (1978), que ainda não foi ajustada para incorporar concretos de alta resistência, sugere:

$$
E_{c}=6600 \sqrt{f_{c j}} \quad(\mathrm{MPa})
$$

b) O ACI 318 (1994), propõe:

$$
E_{c}=4730 \sqrt{f_{c k}} \quad(\mathrm{MPa})
$$

c) O Código Modelo do CEB-FIP (1991), indica:

$$
E_{c}=10^{4} \alpha_{e}\left(f_{c k}+8\right)^{1 / 3} \quad(\mathrm{MPa})
$$

onde: $\mathrm{f}_{\mathrm{ck}}=$ resistência característica à compressão obtida em corpos-deprova cilíndricos de $15 \mathrm{~cm} \times 30 \mathrm{~cm}$;

$\alpha_{e}=$ coeficiente para considerar o enfeito do tipo de agregado cujos valores estão apresentados na tabela 2.1.

TABELA.2.1.-Efeito.do.tipo.de.agregado.no.m $\$$ dulo.de.deforma. E0.longitudinal segundo.0.C $\$$ digo.Modelo.-M C 90.CEB FIP.(1991)

\begin{tabular}{|c|c|}
\hline Tipo de agregado & $\alpha_{\mathrm{e}}$ \\
\hline Basalto & 1,2 \\
\hline Quartzo & 1,0 \\
\hline Calcário & 0,9 \\
\hline Arenito & 0,7 \\
\hline
\end{tabular}


d) A norma norueguesa NS 3473 (1992), para concretos com resistências características à compressão entre $20 \mathrm{MPa}$ e $94 \mathrm{MPa}$, determinado em corpos-de-prova cilíndricos de $15 \mathrm{~cm} \times 30 \mathrm{~cm}$, o valor do módulo de deformação longitudianal pode ser determinado por:

$$
E_{c}=9500 f_{c k}^{0,3} \quad(\mathrm{MPa})
$$

onde: $\mathrm{f}_{\mathrm{ck}}=$ resistência característica à compressão obtido em corpo-deprova cilíndrico de $15 \mathrm{~cm} \times 30 \mathrm{~cm}$.

CARRASQUILLO et al. (1981) apresenta como adequada para os concretos com $21 \mathrm{MPa} \leq \mathrm{f}_{\mathrm{ck}} \leq 83 \mathrm{MPa}$ a equação:

$$
E_{c}=3320 \sqrt{f_{c k}}+6900 \quad(\mathrm{MPa})
$$

\subsection{4- Coeficiente de Poisson}

A relação entre a deformação transversal e longitudinal ainda não está bem definida para concretos de resistência à compressão superior a $50 \mathrm{MPa}$.

De acordo com NEVILLE (1997), não está bem estabelecido de que maneira a idade, resistência ou outras propriedades do concreto afetam o coeficiente de Poisson ( $v$ ).

Para os concretos de resistência usual, NEVILLE (1997) indica que o coeficiente de Poisson situa-se na faixa de 0,15 e 0,20. Os concretos de alta resistência apresentam valores, para os coeficientes de Poisson, menores que os adotados para os concretos de resistências usuais.

Segundo DUCATTI (1993), em se tratando de CARs, há queda no coeficiente de Poisson de 0,23 para 0,20. Provavelmente isto é consequência da densificação do material, àmedida que ele se aproxima de um sólido sem vazios.

ALMEIDA (1990), indica que, embora com grande dispersão de resultados, o coeficiente de Poisson apresentou variação inversamente proporcional àda resistência à compressão. 


\section{5- Considerações Finais}

O concreto de alta resistência envolve vários aspectos técnicos que não foram abordados nesse capítulo pois não dizem respeito a esta pesquisa, como por exemplo, mudanças com relação às propriedades reológicas, com comportamento diferente em relação à retração, fluência e deformação lenta, melhor comportamento em relação à aderência com a armadura, melhor comportamento ao ataque químico, reações expansivas com sulfatos e as reações álcali-agregados.

Observa-se que, em relação às propriedades mecânicas do CAR, necessita-se de mais pesquisas para a obtenção de equações que expressem valores mais confiáveis no tocante a resistência à compressão e à tração, módulo de deformação longitudinal e coeficiente de Poisson.

Outro parâmetro importantíssimo para o CAR é a relação tensão $x$ deformação que este concreto apresenta, pois esta relação se diferencia dos concreto de resistências usuais, e é essencial o seu conhecimento, pois tal relação é de grande importância na aplicação em projetos estruturais em concreto armado. Esta relação está ainda em estudo pelo meio técnico, e é o que vamos comentar no próximo capítulo. 


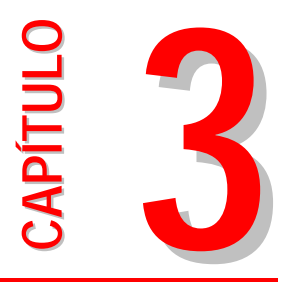

\section{CONSIDERAÇÕES TEÓRICAS PARA ANÁLISE DE PILARES DE CONCRETO DE ALTA RESISTÊNCIA}

\section{1- Considerações Iniciais}

Neste capítulo são abordados alguns conceitos com relação a ajustes na tensão de compressão do concreto e distribuição das deformações ao longo da altura da seção transversal, a partir de dados experimentais. São feitos comentários também sobre a relação tensão $x$ deformação para CAD, proposta por alguns pesquisadores e sugeridas por algumas normas internacionais, bem como, simplificações para projetos dessa relação em diagramas de tensão de compressão equivalentes, parametrizados por alguns coeficientes. Os esforços resistentes teóricos foram determinados pelas equações de equilíbrio das forças resultantes no concreto e barras da armadura, tanto para esforço normal quanto para momento fletor.

Foi realizado levantamento bibliográfico, onde se preocupou em identificar trabalhos semelhantes a este, ou seja, sobre pilares usuais de edifícios solicitados por compressão excêntrica. Apresentam-se os trabalhos identificados como de maior relevância em relação ao tema desta pesquisa, ou seja, de trabalhos experimentais de pilares carregados excentricamente. 


\section{2- Coeficiente de Ajuste da Resistência à Compressão do Concreto}

Considerando o estado limite último de ruptura do concreto comprimido, à tensão de compressão adotada na verificação da segurança dos pilares é $0,85 f_{\text {cdd }}$. O coeficiente 0,85 é explicado, segundo, FUSCO (1995), como coeficiente de modificação resultante do produto de três outros que reduz o valor da resistência de cálculo do concreto. O coeficiente de modificação pode ser escrito por:

$$
k_{\text {mod }}=k_{\text {mod.1. }} \cdot k_{\text {mod.2. }} \cdot k_{\text {mod. } 3}
$$

O coeficiente $k_{\text {mod. } 1}$ leva em conta 0 acréscimo de resistência do concreto após os 28 dias, o coeficiente $\mathrm{k}_{\text {mod.2 }}$ considera que a resistência medida em corpos-de-prova cilíndrico de $15 \mathrm{~cm} \times 30 \mathrm{~cm}$ é superestimada, pois se sabe que a resistência medida em corpos-de-prova de maior tamanho seria menor, por haver menor influência do atrito do corpo-de-prova com os pratos da prensa de ensaio e, o coeficiente $k_{\text {mod. } 3}$ leva em conta 0 efeito da ação de longa duração. Logo, para o concreto de resistência usual - $\mathrm{CRU}$, esses coeficientes assumem os seguintes valores: $k_{\text {mod. } 1}=1,2$, $\mathrm{k}_{\text {mod. } 2}=0,95$ e $\mathrm{k}_{\text {mod. } .3}=0,75$, cujo produto resulta no conhecido 0,85 , como mostrado na tabela 3.1 .

O concreto de alta resistência apresenta um pequeno crescimento da resistência à compressão após os 28 dias, provavelmente devido à menor quantidade de água livre que permite o prosseguimento da hidratação. Nos estudos feitos por LIMA (1997), para as idades de 63 e 92 dias houve pequeno crescimento cujas relações foram de 1,04 e 1,07, respectivamente, tomando por referência os 28 dias. Com isso o coeficiente $k_{\text {mod. } 1 \text { pode ser }}$ considerado igual a 1,0 para concretos de alta resistência. Análises feitas por PINTO JUNIOR (1992) confirmam essa teoria.

Os corpos-de-prova cilíndricos $10 \mathrm{~cm} \times 20 \mathrm{~cm}$ superestimam o valor da resistência à compressão do concreto, em relação aos cilindros padronizados $15 \mathrm{~cm} \times 30 \mathrm{~cm}$. Para as dosagem desenvolvida por LIMA (1997), observou-se uma relação de 0,96 entre resistências médias em 
corpos-de-prova cilíndricos $15 \mathrm{~cm}$ x $30 \mathrm{~cm}$ e $10 \mathrm{~cm}$ x $20 \mathrm{~cm}$. CARRASQUILIO et al. (1981), encontrou coeficiente próximo de 0,90 para resistências variando entre 20MPa e 80MPa. METHA \& MONTEIRO (1994) apresentaram uma relação de 0,95 . Desta forma, pode-se admitir uma redução de $5 \%$ no coeficiente $k_{\text {mod.2 }}$, passando a ser de 0,90.

Segundo PINTO JUNIOR (1992), a ação de longa duração em concretos de alta resistência reduz sua resistência na ordem de $15 \%$ a $20 \%$, assumindo o valor de $20 \%$ como feito em LIMA (1997), o coeficiente $k_{\text {mod.3 }}$ passa a ser 0,80 .

Portanto, o coeficiente de modificação para concreto de alta resistência passa a ser 0,72 como se mostra na tabela 3.1.

TABELA 3.1 - Coeficiente de modificação utilizado para o CRU e CAR
\begin{tabular}{|c|l|c|c|}
\hline Coef. & \multicolumn{1}{|c}{ Representa } & CRU & CAR \\
\hline $\mathrm{k}_{\text {mod.1. }}$ & Crescimento da resistência após 28 dias & 1,20 & 1,00 \\
\hline $\mathrm{k}_{\text {mod. } 2}$ & a resistência dos cp's é superestimada & 0,95 & 0,90 \\
\hline $\mathrm{k}_{\text {mod. } 3}$ & efeito da ação de longa duração & 0,75 & 0,80 \\
\hline $\mathrm{k}_{\text {mod. }}$ & $\mathrm{k}_{\text {mod.1 } 1} \times \mathrm{k}_{\text {mod.2 }} \times \mathrm{k}_{\text {mod.3 }}$ & 0,85 & 0,72 \\
\hline
\end{tabular}

\section{3- Análise das Deformações}

Admitindo-se a hipótese que as seções planas permanecem planas depois de deformadas, e sabendo-se o valor das deformações nas faces mais e menos comprimidas, pode-se calcular a deformação em qualquer ponto ao longo da altura da seção transversal do pilar.

Tomando-se como origem a face mais comprimida da seção, como mostra a figura 3.1, pode-se, através de relações geométricas, determinar a equação das deformações naquela seção, que genericamente pode ser dada pela expressão 3.2 .

$$
\varepsilon(x)=\left(\frac{\varepsilon_{c 1}-\varepsilon_{c 2}}{h}\right) x+\varepsilon_{c 2}
$$


onde: $\quad \varepsilon_{c 1}=$ deformação média medida na face menos comprimida, em valor absoluto;

$\varepsilon_{\mathrm{c} 2}=$ deformação média medida na face mais comprimida, em valor absoluto;

$\mathrm{h}=$ altura da seção transversal do pilar.

Ajustando a expressão 3.2 para considerar a medida das deformações médias tomada nas armaduras, que distam d' das faces mais e menos comprimidas, chega-se à expressão 3.3. Esta pode ser considerada mais precisa devido à maior confiança nas leituras feitas nas armaduras, pois o concreto apresenta microfissuras, que podem interferir na precisão dos resultados.

$$
\varepsilon(x)=\left(\frac{\varepsilon_{s 1}-\varepsilon_{s 2}}{d-d^{\prime}}\right) x+\frac{\varepsilon_{s 2} \cdot d-\varepsilon_{s 1} \cdot d^{\prime}}{d-d^{\prime}}
$$

onde: $\quad \varepsilon_{s 1}=$ deformação média medida na armadura menos comprimida, em valor absoluto;

$\varepsilon_{\mathrm{s} 2}=$ deformação média medida na armadura mais comprimida, em valor absoluto;

$\mathrm{d}=$ altura útil do pilar;

d' = altura da seção transversal menos a altura útil.

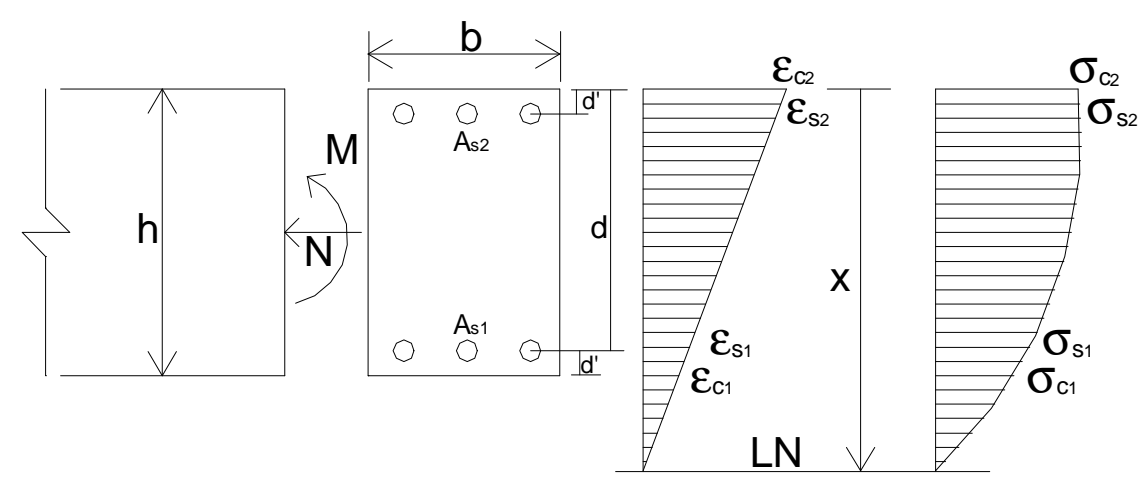

FIGURA 3.1 - Hipótese de distribuição de deformações e de tensões na seção de concreto submetidas a flexo compressão. 


\section{4- Relação Tensão x Deformação}

A relação tensão x deformação no concreto, é obtida a partir de compressão axial em corpos-de-prova com 0 controle do nível de deformação. Esta relação se diferencia dos concreto usuais e é essencial o seu profundo conhecimento, pois tal relação é de grande importância na aplicação em projetos estruturais em concreto armado.

Aqui, mostra-se algumas relações mais elaboradas propostas por COLLINIS et al. (1993) e LIMA (1997), e outras simplificações dessas relações que são indicadas por algumas normas internacionais e outros pesquisadores.

\section{a) Relação tensão x deformação proposta por COLLINS et al. (1993)}

Uma conveniente expressão que descreve a forma do ramo ascendente da curva tensão $x$ deformação medida em cilindros de concreto, foi proposta por Popovics'1 apud COLLINS et al. (1993), e é descrita pela equação 3.4 .

$$
\frac{\mathrm{f}_{\mathrm{c}}}{\mathrm{f}_{\mathrm{c}}^{\prime}}=\frac{\varepsilon_{\mathrm{c}}}{\varepsilon_{\mathrm{c}}^{\prime}} \frac{\mathrm{n}}{\mathrm{n}-1+\left(\frac{\varepsilon_{\mathrm{c}}}{\varepsilon_{\mathrm{c}}^{\prime}}\right)^{\mathrm{n}}}
$$

onde: $\mathrm{f}_{\mathrm{c}}=$ tensão de compressão;

$\mathrm{f}_{\mathrm{c}}{ }^{\prime}$ = tensão de compressão máxima em corpos de prova cilíndricos;

$\varepsilon_{\mathrm{c}}=$ deformação de compressão;

$\varepsilon_{\mathrm{c}}{ }^{\prime}=$ deformação onde $\mathrm{f}_{\mathrm{c}}$ atinge $\mathrm{f}_{\mathrm{c}}{ }^{\prime}$;

$\mathrm{n}$ = fator de ajuste da curva.

\footnotetext{
${ }^{1}$ POPOVICS, S. (1973) A Numerical Approach to the Complete Stress-Strain Curve of Concrete. Cement and Concrete Research, v.3, N. ${ }^{\circ}$ 5, May, pp. 583-599.
} 
Em 1987 Thorenfeldt, Tomaszewicz \& Jensen ${ }^{2}$ apud COLLINS (1993), publicaram que enquanto a expressão de Popovics descreve bem que 0 ramo ascendente da curva tensão $x$ deformação, o ramo descendente não cai rápido o suficiente após o pico para concretos de alta resistência. Para aumentar o declínio pós-pico eles sugerem a adição do fator $k$, logo a equação 3.4 torna-se:

$$
\frac{f_{c}}{f_{c}^{\prime}}=\frac{\varepsilon_{c}}{\varepsilon_{c}^{\prime}} \frac{n}{n-1+\left(\frac{\varepsilon_{c}}{\varepsilon_{c}^{\prime}}\right)^{n k}}
$$

onde $k$ é igual a 1 quando $\varepsilon_{d} / \varepsilon_{c}^{\prime}$ é menor que 1 , e $k$ é um número maior que 1 quando $\varepsilon_{c} / \varepsilon_{c}^{\prime}$ excede1. Collins e Parasz sugerem que para $\varepsilon_{d} / \varepsilon_{c}{ }^{\prime}>1$

$$
\begin{gathered}
n=0,8+\frac{f_{c}^{\prime}}{17} \quad(\mathrm{MPa}) \\
\mathrm{e} \\
k=0,67+\frac{f_{c}^{\prime}}{62} \quad(\mathrm{MPa})
\end{gathered}
$$

A equação 3.5 faz a relação entre $f_{c}$ e $\varepsilon_{c}$ uma função de quatro constantes: $f_{c}{ }^{\prime}, \varepsilon_{c}{ }^{\prime}, n$ e k. Essas quatro constantes podem ser determinadas a partir da curva tensão $x$ deformação de cilindros. Entretanto, em muitas situações de projeto apenas a resistência à compressão máxima do cilindro $\mathrm{f}_{\mathrm{c}}{ }^{\prime}$ é conhecida e é necessário estimar os outros três parâmetros.

Para concreto de densidade normal, $\mathrm{n}$ pode ser avaliado pela equação 3.6 e k pode ser obtida da equação 3.7. Se a inclinação inicial $E_{c}$ da curva tensão $x$ deformação é conhecida ou pode ser estimada, a deformação para a tensão de pico $\varepsilon_{c}^{\prime}$ pode ser encontrada a partir da equação 3.8 .

$$
\varepsilon_{c}^{\prime}=\frac{f_{c}^{\prime}}{E_{c}} \frac{n}{n-1}
$$

\footnotetext{
${ }^{2}$ THORENFELDT, E.; TOMASZEWICS, A.; JENSEN, J. J. (1987) Mechanical Properties of HighStrenght Concrete and Applications in Design, Proceedings of the Symposium Utilization of High Strenght Concrete, Tapir, Trondheim, pp. 149-159.
} 
Enquanto $E_{c}$ depende fortemente da rigidez dos agregados usados, uma sugestão para $E_{c}$ é:

$$
E_{c}=3320 \sqrt{f_{c}^{\prime}}+6900 \quad M P a
$$

As curvas tensão $x$ deformação que resultam das equações acima para uma certa resistência do concreto, são mostradas na figura 3.2.

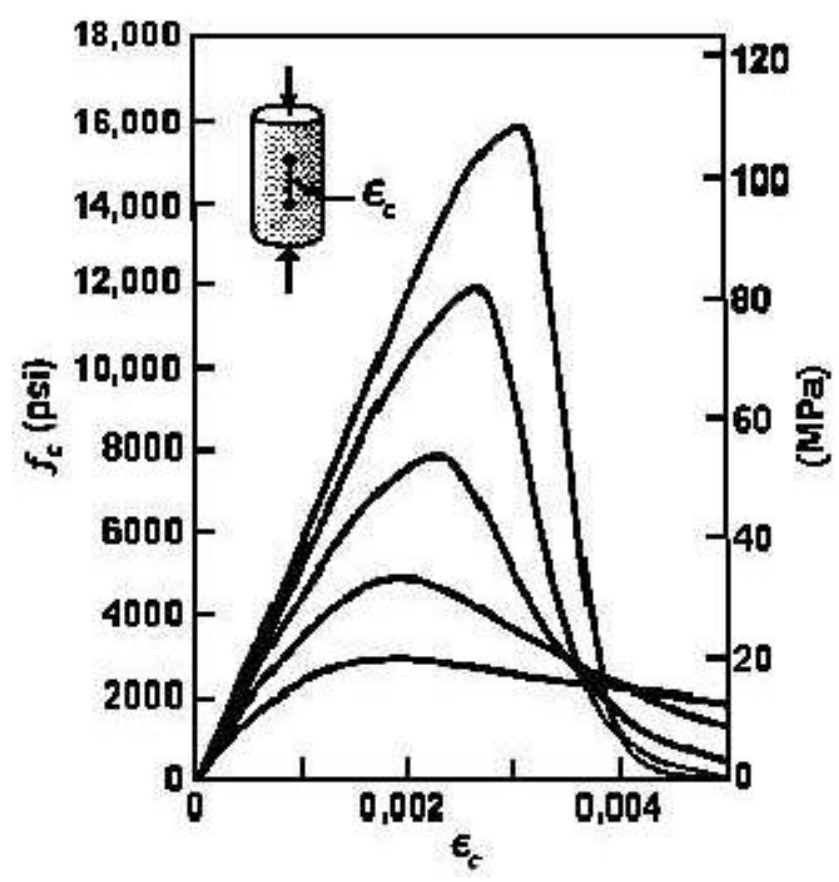

FIGURA 3.2 - Influência da resistência do concreto na relação tensão x deformação

Com o aumento da resistência do concreto, a parte ascendente da curva tensão $\mathrm{x}$ deformação passa a ser mais linear; a deformação correspondente à tensão máxima é maior; a parte descendente da curva é mais inclinada, ou seja, após o ponto de máxima tensão, a capacidade de carga cai mais bruscamente. Isto se deve à diferença entre as estruturas internas dos CADs em relação aos concretos Classe I.

Assim, COLLINS et al. (1993) propõem duas análises para o comportamento da curva tensão $x$ deformação, uma para quando se tem dados experimentais da tensão máxima e sua deformação correspondente, e outra para quando se sabe apenas a tensão máxima. 


\section{b) Relação tensão x deformação proposta por LIMA (1997)}

Em ensaios realizados com corpos-de-prova cilíndricos de $10 \mathrm{~cm} x$ $20 \mathrm{~cm}$ de concreto com resistência à compressão entre $70 \mathrm{MPa}$ e $80 \mathrm{MPa}$, tendo deformação axial controlada, LIMA (1997) observou grande dispersão nos resultados dos ensaios, onde os valores de tensão máxima eram sempre menores. A máquina de ensaio permitia o traçado de diagrama tensão $x$ deformação.

A proposta de relação tensão $x$ deformação, consistia em uma aproximação para a relação tensão $x$ deformação obtida no ensaio por uma função polinomial do $3 . .9$ grau apresentada na figura 3.3 .

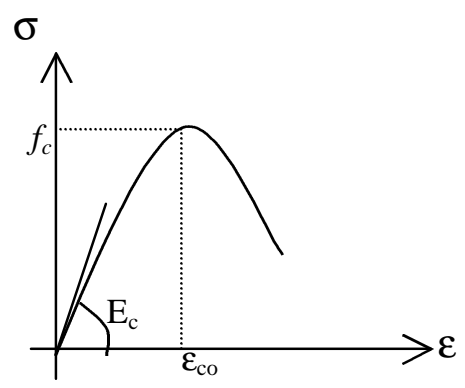

FIGURA 3.3 - Aproximação para o diagrama tensão x deformação experimental

A equação polinomial de $3 .^{\circ}$ grau, tem a seguinte forma:

$$
y=k_{1} x^{3}+k_{2} x^{2}+k_{3} x
$$

Aplicando as condições de contorno, determinam-se os valores das constantes $\mathrm{k}_{1}, \mathrm{k}_{2}$ e $\mathrm{k}_{3}$, encontrando-se:

$$
\begin{aligned}
& \text { para } \quad x=\varepsilon_{c o} \Rightarrow y=f_{c} \Leftrightarrow k_{1} \varepsilon_{c o}^{3}+k_{2} \varepsilon_{c o}^{2}+k_{3} \varepsilon_{c o}=f_{c} \\
& \text { para } \quad x=\varepsilon_{c o} \Rightarrow \frac{d y}{d x}=0 \Leftrightarrow 3 k_{1} \varepsilon_{c o}^{2}+2 k_{2} \varepsilon_{c o}+k_{3}=0 \\
& \text { para } \quad x=0 \Rightarrow \frac{d y}{d x}=E_{c} \Leftrightarrow k_{3}=E_{c}
\end{aligned}
$$

Resolvendo o sistema de equações têm-se:

$$
k_{1}=\frac{\left(-2 f_{c}+E_{c} \varepsilon_{c o}\right)}{\varepsilon_{c o}^{3}} \quad \text { e } \quad \mathrm{k}_{2}=\frac{\left(3 f_{c}-2 E_{c} \varepsilon_{c o}\right)}{\varepsilon_{c o}^{2}}
$$


Substituindo y por $\sigma_{\mathrm{c}}$ e x por $\varepsilon_{\mathrm{c}}$ na equação 3.10, tem-se como relação tensão $x$ deformação do concreto:

$$
\sigma_{c}=\frac{\left(-2 f_{c}+E_{c} \varepsilon_{c o}\right)}{\varepsilon_{c o}^{3}} \varepsilon_{c}^{3}+\frac{\left(3 f_{c}-2 E_{c} \varepsilon_{c o}\right)}{\varepsilon_{c o}^{2}} \varepsilon_{c}^{2}+E_{c} \varepsilon_{c}
$$

Assim, a função depende de três constantes: $f_{c}, \varepsilon_{c o}$ e $E_{c}$, que são determinadas através das curvas tensão x deformação de ensaios de resistência à compressão em corpos-de-prova cilíndricos com deformação axial controlada.

\section{c) Relação tensão x deformação indicada no Código Modelo - MC90} CEB (1991)

Em projetos estruturais, é mais conveniente utilizar relações constitutivas do concreto mais simplificadas. O Código Modelo - MC90 CEB (1991) apresenta a relação tensão x deformação da figura 3.4, para o concreto comprimido, onde o coeficiente 0,85 é indicado para considerar os efeitos de longa duração.

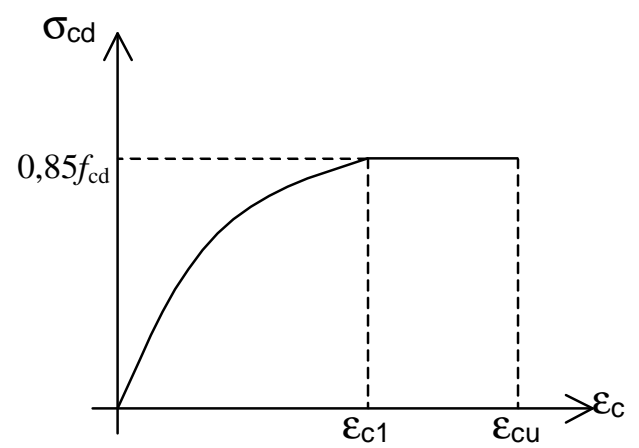

FIGURA 3.4- Diagrama tensão $x$ deformação simplificada segundo MC90 CEB(1991)

No trecho onde $\varepsilon_{\mathrm{c}}<\varepsilon_{\mathrm{c} 1}$ tem-se:

$$
\sigma_{c d}=0,85 f_{c d}\left[2 \cdot\left(\frac{\varepsilon_{c}}{\varepsilon_{c 1}}\right)-\left(\frac{\varepsilon_{c}}{\varepsilon_{c 1}}\right)^{2}\right]
$$

onde $\varepsilon_{\mathrm{c} 1}=0,002$ e $\varepsilon_{\mathrm{cu}}=0,0035$ para $\mathrm{f}_{\mathrm{ck}} \leq 50 \mathrm{MPa}$. 
Para 50MPa $<\mathrm{f}_{\mathrm{ck}} \leq 80 \mathrm{MPa}$ tem-se:

$$
\varepsilon_{c u}=0,0035 \cdot\left(\frac{50}{f_{c k}}\right) \quad(\mathrm{MPa})
$$

d) Relação tensão x deformação indicada pela norma norueguesa NS 3473E(1992)

A norma norueguesa indica uma versão simplificada da relação tensão x deformação do concreto. Recomenda-se o diagrama parábolaretângulo da figura 3.5, para concretos com 55MPa $<\mathrm{f}_{\mathrm{ck}} \leq 85 \mathrm{MPa}$ onde:

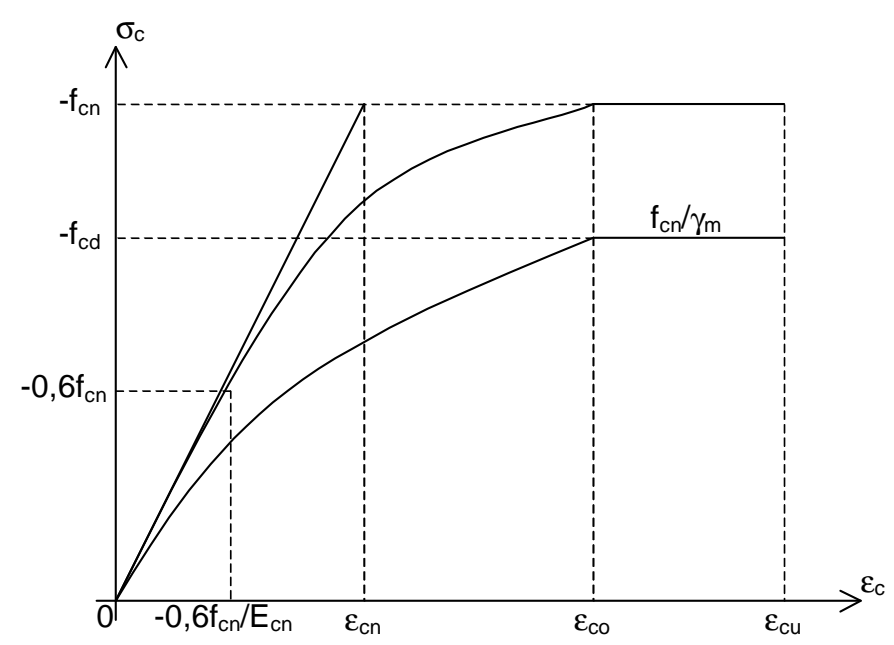

FIGURA 3.5- Diagrama tensão $x$ deformação segundo a NS3473E(1992)

$$
\begin{gathered}
\sigma_{\mathrm{cn}}=-\mathrm{f}_{\mathrm{cn}} \text {, para } \varepsilon_{\mathrm{co}}<\varepsilon_{\mathrm{c}} \leq \varepsilon_{\mathrm{cu}} \\
\sigma_{c n}=E_{c n}+(m-1) \cdot f_{c n} \cdot\left[\frac{E_{c n} \cdot \varepsilon+0,6 f_{c n}}{(0,6-m) f_{c n}}\right]^{\frac{m-0,6}{m-1}}
\end{gathered}
$$

para $-0,6 \frac{f_{c n}}{E_{c n}}<\varepsilon_{\mathrm{c}} \leq \varepsilon_{\mathrm{co}}$

$$
\sigma_{\mathrm{cn}}=\mathrm{E}_{\mathrm{cn}} \cdot \varepsilon_{\mathrm{c}}, \text { para } 0 \leq \varepsilon_{\mathrm{c}}<-0,6 \frac{f_{c n}}{E_{c n}}
$$

sendo:

$$
\begin{aligned}
& \varepsilon_{\mathrm{cu}}=(2,5 \mathrm{~m}-1,5) \varepsilon_{\mathrm{cn}} \quad ; \quad \varepsilon_{\mathrm{cn}}=-\mathrm{f}_{\mathrm{cn}} / \mathrm{E}_{\mathrm{cn}} \quad \text { e } m=\varepsilon_{\mathrm{co}} / \varepsilon_{\mathrm{cu}} \\
& \text { para } 50 \mathrm{MPa}<\mathrm{f}_{\mathrm{ck}} \leq 80 \mathrm{MPa}
\end{aligned}
$$


e) Relação tensão x deformação indicada pela norma americana $\mathrm{ACl}$ 318 - M89

$\mathrm{O}$ ACl 318 - M89 especifica a resistência à compressão no concreto usando corpos-de-prova cilíndricos de dimensões $15 \mathrm{~cm} \times 30 \mathrm{~cm}$ para representar o diagrama tensão. De acordo com os dados do ensaio, pode-se assumir diagramas retangular, trapezoidal, parabólico e outros que dão a distribuição da tensão de compressão em função da deformação do concreto.

O diagrama retangular de tensões assumido pelo $\mathrm{ACl}$, é definido por dois parâmetros $\alpha_{1}$ e $\beta_{1}$, como mostra a figura 3.6. O parâmetro $\alpha_{1}$ é assumido ter valor constante de 0,85. O parâmetro $\beta_{1}$ é igual a 0,85 para resistência do concreto até $30 \mathrm{MPa}$, e é reduzido continuamente a uma taxa de 0,08 , para cada $10 \mathrm{MPa}$ que excede $30 \mathrm{MPa}$. O parâmetro $\beta_{1}$ não pode ser menor que 0,65. A deformação de compressão máxima tem um valor constante de 0,003 .

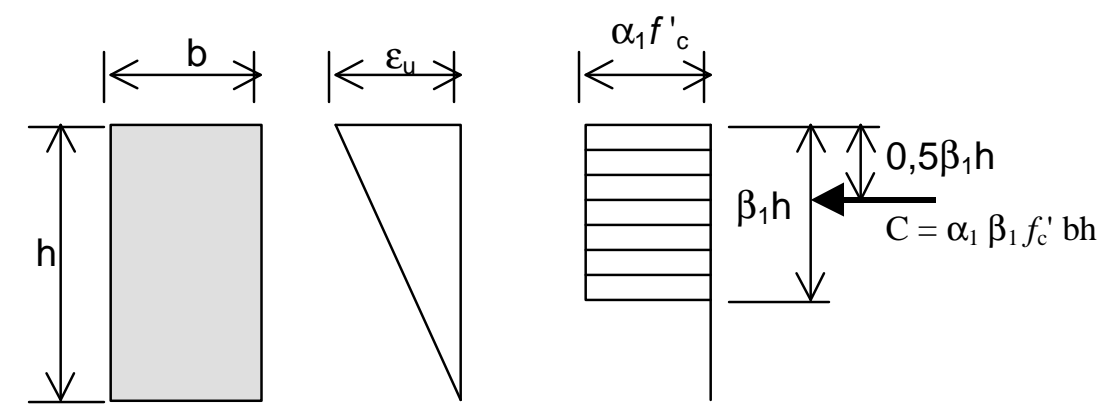

FIGURA 3.6- Bloco retangular de tensão segundo o ACI318 - M89

\section{f) Relação tensão $x$ deformação proposta por DINIZ apud VASCONCELOS (1998)}

DINIZ ${ }^{3}$ apud LIMA (1997), comenta que o diagrama tensão $x$ deformação deve estar de acordo com os dados experimentais, na falta de dados experimentais, a prática recomendada para cálculo e execução de CAD do IBRACON, indica um diagrama parábola - retângulo análogo ao apresentado na figura 3.4 do Código Modelo - MC90 CEB (1991), sendo que

\footnotetext{
${ }^{3}$ DINIZ, José Zamarion F. (1997) / Comunicação Pessoal à LIMA (1997)/, São Paulo, abr.
} 
os valores da deformação última do concreto estão apresentados na tabela 3.2.

Pode-se utilizar o diagrama da figura 3.7, preparado por DINIZ apud VASCONCELOS (1998), nos quais foi fixado para todas as classes em $0,2 \%$ o valor da deformação correspondente à máxima tensão de cálculo do concreto $\left(0,85 f_{c d}\right)$.

Para efeito de cálculo, o diagrama parábola-retângulo pode ser transformado em retângulo equivalente onde a tensão máxima varia de $0,85 f_{c d}$ até $0,76 f_{c d}$, o primeiro valor aplicando-se até C50 sem variação. $O$ valor $f_{c d}$ aqui indicado vale $f_{c k} / 1,4$.

A altura do retângulo equivalente é adotada como fração $\beta$ da profundidade " $x$ " da $L N$, que varia de acordo com a classe do concreto como mostra a tabela 3.2.

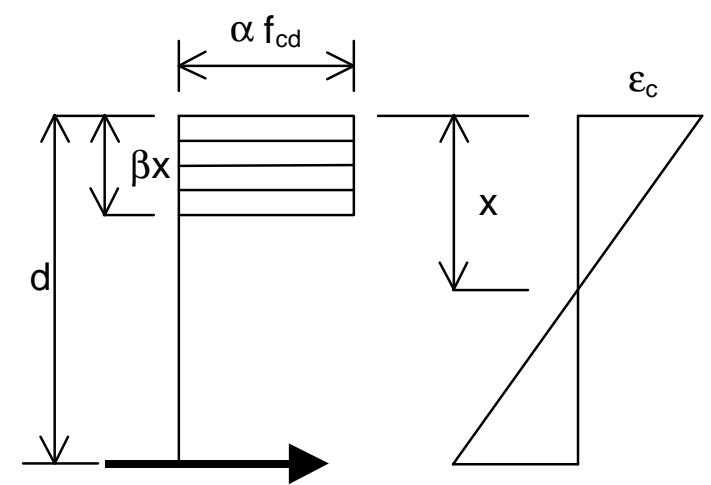

FIGURA 3.7- Diagrama retangular de tensões proposto por DINIZ apud VASCONCELOS (1998)

A tensão máxima de cálculo é considerada como fração $\alpha$ da resistência $\mathrm{f}_{\mathrm{cd}}$. Para concretos das classes até $\mathrm{C} 50$, este valor continua igual a 0,85 . À medida que a resistência aumenta, o valor de $\alpha$ diminui de acordo com a tabela 3.2.

TABELA 3.2- Valores para $\varepsilon_{c u}$ e para os parâmetros $\alpha$ e $\beta$ sugeridos por DINIZ apud VASCONCELOS (1998)

\begin{tabular}{|c|c|c|c|c|c|}
\hline Coef. & C20 a 50 & C55 & C60 & C70 & C80 \\
\hline$\varepsilon_{\text {cu }}(\%)$ & 3,5 & 2,9 & 2,8 & 2,6 & 2,4 \\
\hline$\alpha$ & 0,850 & 0,835 & 0,820 & 0,790 & 0,76 \\
\hline$\beta$ & 0,800 & 0,793 & 0,787 & 0,773 & 0,760 \\
\hline
\end{tabular}




\section{5- Esforços Resistentes}

Conhecendo-se a variação das deformações ao longo da altura da seção transversal de uma barra, e admitindo-se uma relação tensão $x$ deformação para o concreto, é estabelecida a variação da tensão normal ao longo da altura da seção, podendo-se, por integração, obter o esforço normal teórico e o respectivo momento fletor, usando as equações de equilíbrio 3.18 e 3.19, sendo a origem da variável $x$, a fibra mais comprimida da seção, como mostra a figura 3.1. Na equação 3.19, o momento fletor é calculado em relação ao eixo da seção.

$$
\begin{aligned}
& N_{\text {teo }}=\int_{A} \sigma_{c} d A+\sum_{i} A_{s i} \sigma_{s i} \\
& M_{\text {teo }}=\int_{A} \sigma_{c} x d A+\sum_{i} A_{s i} \sigma_{s i} x_{i}
\end{aligned}
$$

A figura 3.1 apresenta as hipóteses admitidas para a distribuição das deformações e das tensões na seção de concreto.

Sendo assim, para o estado limite último de ruptura, os esforços resistentes são expressos por:

$$
\begin{aligned}
& N_{u, \text { teo }}=b \int_{0}^{h} \sigma_{x}(x) d x+A_{s 1} \sigma_{\mathrm{s} 1}+A_{s 2} \sigma_{s 2} \\
& M_{u, \text { teo }}=b \int_{0}^{h} \sigma_{x}(x) \cdot\left(\frac{h}{2}-x\right) d x+\left(A_{s 2} \sigma_{s 2}-A_{s 1} \sigma_{s 1}\right) \cdot\left(\frac{h}{2}-d^{\prime}\right)
\end{aligned}
$$

\section{6- Estudos de Casos de Pilares de CAD sob Compressão Excêntrica}

O Boletim 197 CEB-FIP(1990) e o Estado-da-Arte do ACI 363R(1992), indicam que pesquisas têm sido desenvolvidas sobre o comportamento dos pilares executados com CAD. A resistência última é tida como parâmetro mais importante, seguida das condições de ductilidade, que podem ser resolvidas mediante uso de detalhamento adequado de armaduras, longitudinais e transversais. Da mesma forma que para os pilares de 
concreto de resistência usual, consideram-se as contribuições das resistências do concreto e do aço, sendo que a participação mais efetiva deste depende, por exemplo, da contribuição dos estribos ou outro tipo de armadura transversal no confinamento do núcleo de concreto.

LIMA (1997) fez estudo em tese de doutorado sobre o comportamento de pilares de concreto de alto desempenho solicitados à compressão centrada e flexão normal composta. Foram analisados pilares de seções transversais quadradas de $20 \mathrm{~cm} \times 20 \mathrm{~cm}$ e retangulares de $15 \mathrm{~cm} \times 30 \mathrm{~cm}$ e $12 \mathrm{~cm} \times 30 \mathrm{~cm}$, com concreto de resistências à compressão em torno de $80 \mathrm{MPa}$.

Para os modelos solicitados à compressão simples, foram estudados 18 pilares, sendo 4 séries com 3 modelos cada, além de 3 modelos pilotos para ajustes no pórtico de reação e repetição da primeira série de ensaios. As séries foram planejadas como mostra a tabela 3.3.

TABELA 3.3- Pilares sob compressão centrada ensaiados por LIMA (1997)

\begin{tabular}{|c|c|c|c|c|}
\hline Série & $\begin{array}{c}\text { Seção } \\
\text { cm }\end{array}$ & $\begin{array}{c}\text { Altura } \\
\text { cm }\end{array}$ & Arm. long. & Arm. Trans. \\
\hline 1 & $20 \times 20$ & 120 & $2,54 \%(8 \phi 12,5)$ & $1,03 \%(\phi 6,3 c / 5)$ \\
\hline 2 & $20 \times 20$ & 120 & $2,54 \%(8 \phi 12,5)$ & $0,51 \%(\phi 6,3 c / 010)$ \\
\hline 3 & $30 \times 15$ & 90 & $2,26 \%(8 \phi 12,5)$ & $1,01 \%(\phi 6,3 c / 5)$ \\
\hline 4 & $30 \times 15$ & 90 & $2,26 \%(8 \phi 12,5)$ & $2,02 \%(\phi 6,3 c / 10)$ \\
\hline
\end{tabular}

Foram estudados 10 modelos solicitados a flexão normal composta, sendo 5 séries de 2 modelos cada, com as características mostrada na tabela 3.4 .

TABELA 3.4- Pilares sob flexão normal composta ensaiados por LIMA (1997)

\begin{tabular}{|c|c|c|c|c|c|}
\hline Série & $\begin{array}{c}\text { Seção } \\
\text { cm }\end{array}$ & $\begin{array}{c}\text { Altura } \\
\text { cm }\end{array}$ & Arm. Long. & Arm. Trans. & $\begin{array}{c}\text { Excent. } \\
\text { cm }\end{array}$ \\
\hline 5 & $30 \times 15$ & 174 & $2,26 \%(8 \phi 12,5)$ & $1,56 \%(\phi 6,3 c / 5)$ & 1,5 \\
\hline 6 & $30 \times 15$ & 174 & $3,45 \%(8 \phi 16)$ & $1,56 \%(\phi 6,3 c / 5)$ & 1,5 \\
\hline 7 & $30 \times 15$ & 174 & $1,26 \%(8 \phi 10)$ & $1,56 \%(\phi 6,3 c / 5)$ & 1,5 \\
\hline 8 & $30 \times 15$ & 174 & $1,26 \%(8 \phi 10)$ & $1,04 \%(\phi 6,3 c / 7,5)$ & 2,5 \\
\hline 9 & $30 \times 12$ & 247 & $1,67 \%(8 \phi 10)$ & $0,82 \%(\phi 6,3 c / 12)$ & 3 \\
\hline
\end{tabular}


Os modelos de pilares ensaiados por LIMA (1997), tinham os topos e as bases alongados na distância da excentricidade que se pretendia, fazendo com que a resultante das forças aplicadas nessas áreas, tivessem um deslocamento em relação ao eixo longitudinal do pilar, como mostra a figura 3.8.

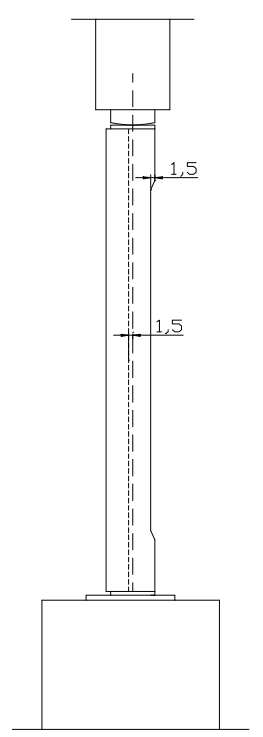

FIGURA 3.8 - Sistema de aplicação de forças utilizado por LIMA (1997)

Para analisar os resultados, foi utilizada relação tensão $x$ deformação desenvolvida para tese, e outra proposta por COLLINS et al.(1993).

Para os modelos ensaiados à compressão centrada, LIMA (1997) obteve relações média entre a força última experimental e a força última teórica de 1,12, considerando a seção do núcleo. Com isto pode-se afirmar que a seção resistente é formada pelo núcleo, ou seja, a região limitada pelo eixo da armadura transversal mais externa. E, quando se mudou a seção transversal de quadrada para retangular, não foram observadas grandes modificações nos comportamentos dos pilares.

Para os modelos submetidos a flexão normal composta, a relação entre a força experimental e a teórica, obtida através dos modelos teóricos, foram praticamente iguais a 1 . Analisando as relações entre os momentos fletores, viu-se que a relação proposta por COLLINS et al.(1993) apresentou melhores resultados que as de LIMA (1997), no entanto, os resultados experimentais e teóricos não apresentaram boa relação. As medidas entre 
todos os valores de $M_{\text {exp }} / M_{\text {teo }}$ resultaram iguais a 3,06 (LIMA) e 2,64 (COLLINS et al.).

$\mathrm{Na}$ análise dos pilares ensaiados sob flexão normal composta admitiuse que o momento experimental era calculado por $M_{\exp }=F_{\exp }$. e einicial. Podese concluir que o momento experimental, tal como admitido, não correspondia ao que atuava na seção à meia altura do pilar, o que dificultou a análise comparativa, conforme os dados mostrados na tabela 3.5. A principal causa da imprecisão do ensaio foi a vinculação na base e no topo do pilar, pois o modelo físico teórico considerava os dois pontos articulados, enquanto que o ensaio reproduziu uma situação de semi - engastamento tanto na base quanto no topo do pilar.

TABELA 3.5- Análise dos resultados de LIMA (1997) considerando o modelo apresentado por COLLINS et al. (1993)

\begin{tabular}{|l|c|c|c|c|c|c|c|c|c|c|}
\hline Pilar & $\begin{array}{c}\mathbf{f}_{\mathbf{c}} \\
\mathbf{M P a}\end{array}$ & $\begin{array}{c}\mathbf{E}_{\mathrm{c}} \\
\mathbf{M P a}\end{array}$ & $\begin{array}{c}\mathbf{f}_{\mathbf{y}} \\
\mathbf{M P a}\end{array}$ & $\begin{array}{c}\mathbf{E}_{\mathbf{s}} \\
\mathbf{M P a}\end{array}$ & $\begin{array}{c}\mathbf{F}_{\text {exp }} \\
\mathbf{k N}\end{array}$ & $\begin{array}{c}\mathbf{M}_{\text {exp }} \\
\mathbf{k N . c m}\end{array}$ & $\begin{array}{c}\mathbf{F}_{\text {teo }} \\
\mathbf{k N}\end{array}$ & $\begin{array}{c}\mathbf{M}_{\text {teo }} \\
\mathbf{k N . c m}\end{array}$ & $\begin{array}{c}\mathbf{F}_{\text {exp }} / \\
\mathbf{F}_{\text {teo }}\end{array}$ & $\begin{array}{c}\mathbf{M}_{\text {exp }} / \\
\mathbf{M}_{\text {teo }}\end{array}$ \\
\hline $\mathrm{P} 5 / 1$ & 81,1 & 30836 & 543,3 & 205028 & 2842 & 4263 & 3110 & 2465 & 0,91 & 1,73 \\
\hline $\mathrm{P} 5 / 2$ & 79,5 & 30874 & 543,3 & 205028 & 2806 & 4209 & 2022 & 2808 & 1,39 & 1,50 \\
\hline $\mathrm{P} 6 / 1$ & 85,7 & 31876 & 710,5 & 201242 & 3227 & 4840 & 3226 & 2368 & 1,00 & 2,04 \\
\hline $\mathrm{P} 6 / 2$ & 83,7 & 31689 & 710,5 & 201242 & 3218 & 4827 & 3603 & 3210 & 0,89 & 1,50 \\
\hline $\mathrm{P} 7 / 1$ & 87,3 & 32615 & 681,2 & 200419 & 3012 & 4518 & 2969 & 1771 & 1,01 & 2,55 \\
\hline $\mathrm{P} 8 / 2$ & 93,5 & 34961 & 681,2 & 200419 & 3118 & 4677 & 3577 & 2074 & 0,87 & 2,26 \\
\hline $\mathrm{P} 8 / 2$ & 87,1 & 30263 & 681,2 & 200419 & 3252 & 8130 & 3156 & 2745 & 1,03 & 2,96 \\
\hline $\mathrm{P} 9 / 1$ & 101,3 & 35984 & 681,2 & 200419 & 3250 & 8125 & 3511 & 1809 & 0,93 & 4,49 \\
\hline $\mathrm{P} 9 / 2$ & 83,3 & 27312 & 676,4 & 203141 & 2388 & 7164 & 2385 & 6205 & 1,00 & 1,15 \\
\hline
\end{tabular}

Segundo LIMA (1997), para aumentar a ductilidade deve-se aumentar tanto a taxa de armadura transversal quanto a longitudinal, como foi constatado nos ensaios dos modelos das série 1 e 2 , onde as deformações nas barras das armaduras longitudinais não variaram quando se dobrou a taxa de armadura transversal. Sugere-se também, que as hipóteses de distribuição de tensões indicada pela NBR 6118 (1978), para verificação teórica das seções transversais de pilares não são satisfatórias para os pilares em CAR.

CUSSON \& PAULTRE (1994), apresentaram estudo experimental sobre pilares executados com CAD, confinados por estribos retangulares. Foram ensaiados 27 pilares cujas dimensões podem ser vistas na figura 3.9. As resistências à compressão, de quatro modelos, aos 28 dias, foram 
inferiores a 90MPa e os demais de 93,1 MPa a 115,9MPa, determinadas em corpos-de-prova cilíndricos de $15 \mathrm{~cm} \times 30 \mathrm{~cm}$. Como variáveis tinham, a resistência de escoamento da armadura transversal, configuração e espaçamento entre estribos, taxas de armaduras transversais e longitudinais. Observou-se que, em geral, o comportamento era caracterizado pela ruptura brusca do cobrimento de concreto.

Neste trabalho, concluíram que, em compressão axial apenas a área do núcleo de concreto, delimitada pelas armaduras transversais, deve ser considerada no cálculo da resistência à compressão axial dos pilares de CAD, isto devido ao comportamento de tais pilares apresentarem rompimento brusco da camada de cobrimento, resultando em perda de capacidade resistente. Para 4 pilares o espaçamento entre estribos utilizados foi de $10 \mathrm{~cm}$ que, segundo CUSSON \& PAULTRE (1994), é adequado quando no projeto não se prevê ações sísmicas atuantes na estruturas.

Apesar da maior eficiência do confinamento do CAD comparado com concretos de resistência Classe I, o ganho maior de resistência e o comportamento dúctil de pilares confinados de CAD foram obtidos quando foi adotado um detalhamento de armaduras adequado, tanto longitudinal quanto transversal. A figura 3.10 mostra o efeito benéfico das armaduras longitudinais e transversais no confinamento do núcleo.

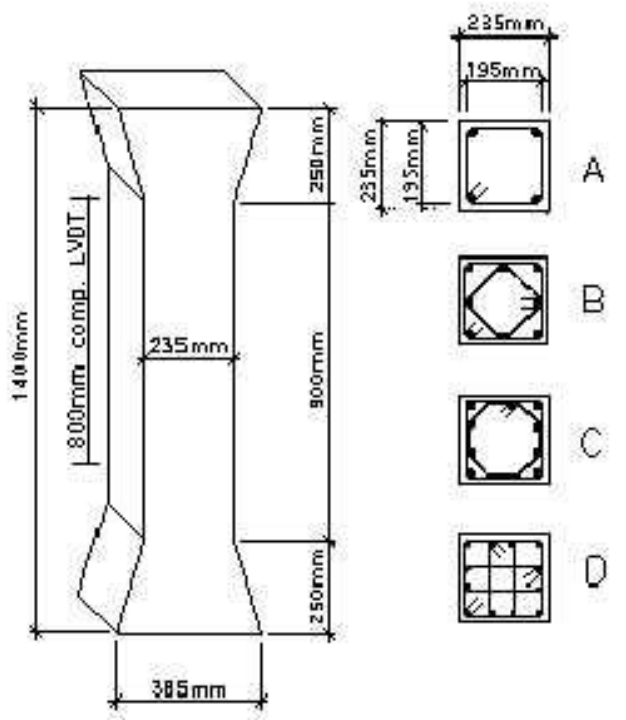

FIGURA 3.9 - Pilares ensaiados por CUSSON \& PAULTRE (1994) 


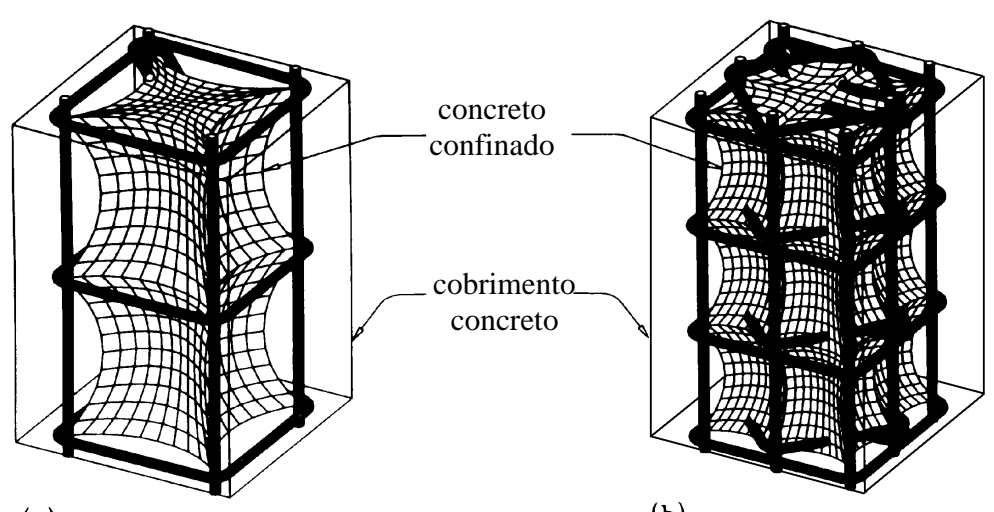

(a)

(b)

FIGURA 3.10 - Efeito das armaduras no confinamento [CUSSON \& PAULTRE (1994)]

O aumento na resistência à compressão resultou em decréscimo na resistência e na rigidez do concreto confinado, isto é, a razão não é proporcional entre estas variáveis. Por outro lado, aumentando significativamente a taxa de armadura transversal se acentuam os ganhos de resistência e rigidez, apenas para amostras bem confinadas com taxas elevadas de armadura lateral.

Para os níveis de resistência do concreto e da armadura utilizada, os resultados indicam que a configuração $A$, mostrada na figura 3.9 , não é efetiva no confinamento do núcleo e não deveria ser usada quando se exige um comportamento dúctil. Por outro lado, os resultados indicam que as configurações de estribos $B, C$ e $D$ são eficazes no confinamento do núcleo de concreto. A redução do espaçamento dos estribos resulta em acréscimo de resistência e de rigidez do concreto confinado, o aumento da taxa de armadura longitudinal também, mas apenas nos modelos bem confinados com altas taxas de armaduras transversais.

AGOSTINI (1992) desenvolveu um trabalho sobre pilares de concreto de alta resistência de seção transversal quadrada, com o objetivo de estudar a ductilização com o emprego de armadura helicoidal transversalmente na seção.

Foram feitos vários ensaios com pilares com variação da área da seção transversal, altura do pilar, resistência à compressão do concreto e taxa de armadura longitudinal e transversal. Tais modelos foram ensaiados submetidos à compressão axial e comparados com ensaios feitos com 
corpos-de-prova de $10 \mathrm{~cm} \times 20 \mathrm{~cm}$, também com armaduras longitudinais e transversais. Os resultados são os seguintes:

$>$ O diagrama de força $x$ deformação do concreto apresentou um trecho curvo para as forças próximas da ruptura, mostrando que a armadura de confinamento foi suficiente para garantir uma ruptura dúctil;

$>$ As deformações no concreto foram superiores aos valores obtidos nos ensaios de pilares sem armaduras, pois a seção resistente de concreto correspondeu ao núcleo de concreto confinado pelas armaduras. A deformação no instante da ruptura foi em torno de $0,35 \%$ sendo de $0,23 \%$ para pilares não - armados; > A relação entre a seção de concreto do núcleo e a seção transversal do pilar cresceu, para os pilares com dimensões maiores, ao mesmo tempo que aumentou a eficiência das armaduras de confinamento. As forças de ruptura foram até de $20 \%$ maiores que aquelas previstas. Este fato comprova a ocorrência de cintamento do núcleo de concreto pelas armaduras transversais;

$>$ Em alguns pilares ocorreu flexão oblíqua e flexão normal em outros devido a existência de uma excentricidade acidental, decorrente da heterogeneidade inevitável do concreto. Em pilares com 6 barras longitudinais, quase não existiu o efeito das excentricidades acidentais, que foi compensado pela homogeneidade da distribuição das armaduras.

Foram também realizados ensaios de 2 pilares submetidos a flexão normal composta para analisar a armadura de confinamento. Os resultados são os seguintes:

> Para garantir a ruptura dúctil, verificou-se que a taxa de armadura de confinamento de $1,5 \%$ foi suficiente. Todavia, observam-se também a necessidade de novos estudos para definição da armadura de confinamento. 
> A deformação máxima do concreto foi em torno de $0,35 \%$ no instante da ruptura, ocorrendo esmagamento do concreto.

Tais ensaios desenvolvidos por AGOSTINI (1992), indicaram que em termos de armadura mínima para pilares solicitados à compressão simples, seriam necessárias taxas de armadura longitudinal em torno de 3,2\% e transversal de $2,2 \%$.

LLOYD \& RAGAN (1996) desenvolveram pesquisas sobre o desempenho e resistência de pilares de concreto de alta resistência sob compressão excêntrica. Foram realizados 36 ensaios onde as variáveis foram a seção transversal dos pilares, excentricidade da ação, taxa de armadura longitudinal e resistência à compressão do concreto. A resistência à compressão dos corpos-de-prova cilíndricos no dia do ensaio variou entre $58 \mathrm{MPa}, 92 \mathrm{MPa}$ e $97 \mathrm{MPa}$. Os pilares tinham seção transversal de $30 \mathrm{~cm} \times$ $10 \mathrm{~cm}$ e $17,5 \mathrm{~cm} \times 17,5 \mathrm{~cm}$ com um comprimento teórico de $168 \mathrm{~cm}$. O índice de esbeltez foi 32 para pilares quadrados e 56 para os pilares retangulares. A excentricidade da força foi de $1,5 \mathrm{~cm}, 5,0 \mathrm{~cm}$ e $6,5 \mathrm{~cm}$ para pilares quadrados e $1,0 \mathrm{~cm}, 3,0 \mathrm{~cm}$ e $4,0 \mathrm{~cm}$ para pilares retangulares. Nos pilares retangulares, o plano de ação do momento ficou paralelo ao menor lado.

Foi desenvolvida também teoria para prever o comportamento força $x$ deformação e o carregamento de ruptura dos pilares de concreto de alta resistência sob compressão excêntrica. A teoria era baseada na análise simplificada de estabilidade e a relação tensão $x$ deformação de concreto de alto desempenho comprimido.

Como esperado, o aumento da resistência à compressão do concreto aumentou a força de ruptura do pilar. A força de ruptura foi também dependente da excentricidade da força e da taxa de armadura longitudinal. Um aumento na excentricidade resultou uma diminuição da força de ruptura e um aumento na deflexão de ruptura no meio do vão. Aumento de $50 \%$ na taxa de armadura longitudinal produziu aumento de $20 \%$ na força última.

Com os ensaios foram observados que: os pilares com pequena excentricidade na força exibiu pequena ou nenhuma deformação além da 
força de pico, o destacamento do cobrimento da armadura foi explosivo para vários pilares, o modo de ruptura não era significativamente diferente para quaisquer das dosagens de concreto; os pilares com grande excentricidade apresentaram maior deflexão na força de ruptura, foram observadas fissuras e deformações significativas antes da ruptura, depois da força de pico eles continuaram a se deformar indicando comportamento dúctil.

A teoria baseada em uma análise de estabilidade simplificada e uma relação tensão $x$ deformação para concreto de alta resistência previu bem a resistência dos pilares ensaiados. A relação média da resistência experimental e teórica era de 1,13, com coeficiente de variação de $10 \%$. A parte ascendente das curvas força $x$ deflexão teórica concordaram muito bem com as curvas experimentais. A teoria era de certo grau muito aproximada para prever a parte descendente da curva força $x$ deflexão.

AZIZINAMINI \& KEBRAEI (1996) dizem que evidências experimentais indicam que a capacidade da seção transversal de pilares de concreto de alta resistência submetidos à ação de força axial e momento fletor é superestimada, quando as recomendações do $\mathrm{ACl}$ 318-89 são utilizadas. Os Autores apresentam os resultados de ensaios realizados para avaliar modificações propostas para determinação da capacidade de pilares de concreto de alta resistência.

Foram ensaiados 6 pilares sob combinação de força axial e momento fletor. Os trechos além da região central de ensaio foram fortemente reforçados para prevenir ruptura nessas regiões. A armadura longitudinal de cada modelo consistiu de 8 barras de $16 \mathrm{~mm}$ de diâmetro com resistência de escoamento de 476,5MPa cada. Dois arranjos de armaduras transversais foram usados, com barras de diâmetro iguais a $9,5 \mathrm{~mm}$ e resistência de escoamento de $503,3 \mathrm{MPa}$. Na figura 3.11 podem ser observadas as dimensões dos modelos ensaiados e configuração de armaduras utilizadas. 


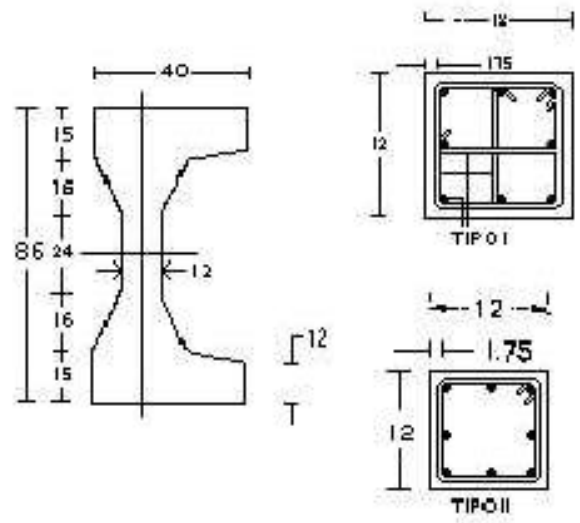

FIGURA 3.11 - Dimensões e tipos de configurações de estribos usados por AZIZINAMINI \& KEBRAEI (1996)

Os espaçamentos das armaduras transversais foram de $3,8 \mathrm{~cm}$ para um modelo e $30,5 \mathrm{~cm}$ para os demais, as resistências à compressão do concreto no dia do ensaio foram de $30,3 \mathrm{MPa}, 89,3 \mathrm{MPa}$ e $93,1 \mathrm{MPa}$. As idades dos modelos no dia do ensaio variou de 323 a 586 dias após a moldagem. $O$ ensaio consistia na aplicação de uma força centrada variável de $0,19 \mathrm{P}_{\circ}$ a $0,40 \mathrm{P}_{\circ}$ e outra com excentricidade de $40,6 \mathrm{~cm}$. AZIZINAMINI \& KEBRAEI (1996), calcularam as capacidades dos pilares solicitados por ação centrada com base na equação:

$$
P_{0}=0,85 f_{c}^{\prime}\left(A_{g}-A_{s t}\right)+A_{s t} f_{y}
$$

onde:

$\mathrm{P}_{\mathrm{o}}=$ força última no pilar com compressão centrada;

$f_{c}^{\prime}=$ resistência a compressão do concreto;

$A_{g}=$ área da seção transversal total do pilar;

$\mathrm{A}_{\mathrm{st}}=$ área de aço da armadura longitudinal;

$\mathrm{f}_{\mathrm{y}}=$ resistência de escoamento do aço da armadura longitudinal.

O esquema de ensaio permitia rotação de cada ponto de aplicação das ações, e os modelos foram instrumentados para se obter a deformação resultante na armadura longitudinal e transversal. Extensômetros foram também colocados na superfície da região de observação dos modelos para medirem as máximas deformações de compressão antes dos destacamentos dos cobrimentos de concreto. 
Geralmente, modelos com armadura transversal do tipo II romperam logo depois do destacamento do cobrimento, sem exibir qualquer nível significante de ductilidade. Nesses modelos, as forças que provocaram os destacamentos dos cobrimentos ficaram muito próximas das forças que provocaram flambagem das armaduras longitudinais e ruína. Um dos modelos em que se utilizou armadura transversal tipo I, apresentou um maior nível de ductilidade antes da ruptura.

A partir dos resultados obtidos nos ensaios de AZIZINAMINI \& KEBRAEI (1996) as seguintes conclusões foram observadas com relação à capacidade de flexão de pilares de concreto de alta resistência:

> A relação $\mathrm{M}_{\text {exp }} / \mathrm{M}_{\mathrm{ACl}}$ momento fletor experimental e teórico previstos com as indicações do $\mathrm{ACl} 318 / 89$ é menor que 1 , em geral, para os pilares de concreto de alta resistência. Para pilares de concreto de resistência usual, essa relação é maior do que 1;

$>$ Resultados, com relação a momentos fletores, previstos com as hipóteses do $\mathrm{ACl} 318 / 89$ superestimam a capacidade dos pilares de CAR com pequena quantidade de armadura transversal. Isto está baseado na comparação do comportamento dos pilares ensaiados com outros realizados em outra pesquisa do mesmo Autor.

Segundo AZIZINAMINI \& KEBRAEI (1996) a razão para superestimar a capacidade à flexão pelo $\mathrm{ACl} 318 / 89$ está no fato de que a relação tensão $x$ deformação para concreto de alta resistência na compressão é caracterizada por uma parte ascendente que é inicialmente linear, com resistência máxima alcançada para um valor de deformação variando aproximadamente entre 0,0024 e 0,003. Considerando isto, deve ser mais apropriado usar um diagrama triangular de tensões nos pilares, quando os concretos tiverem resistência superior a $70 \mathrm{MPa}$. No digrama triangular a tensão de pico é assumida igual a $0,85 f^{\prime}$ para deformação na fibra mais comprimida de 0,003. Um bloco retangular de tensões correspondendo a esse bloco triangular teria uma intensidade de tensão de $0,63 f_{c}^{\prime}$ e uma profundidade de $0,67 \mathrm{c}$. 
Baseado nestas observações, AZIZINAMINI et al. ${ }^{4}$ apud AZIZINAMINI \& KEBRAEI (1996), recomendam o uso do coeficiente de intensidade de tensões $\alpha_{1}$ para concreto com resistência superior a $70 \mathrm{MPa}$, sendo:

$$
\begin{aligned}
& \alpha_{1}=0,85-0,007\left(f_{c}^{\prime}-70\right) \geq 0,6 \\
& \text { onde } f_{c}{ }_{c} \text { é expresso em MPa }
\end{aligned}
$$

Em relação ao momento último experimental, AZIZINAMINI \& KEBRAEI (1996) indicam que aqueles previstos usando as novas recomendações das Normas Canadense e da Nova Zelândia ainda resultam em valores superestimados para a capacidade à flexão dos pilares ensaiados. Por outro lado, previsões feitas usando a equação 3.23 geralmente resultam em valores conservativos para a capacidade à flexão de pilares de CAR submetidos a combinação de forças axiais com momentos fletores. Modificações propostas por AZIZINAMINI et al. ${ }^{6}$ apud AZIZINAMINI \& KEBRAEI (1996), resultam aproximadamente nos mesmos níveis de segurança para pilares de CAR como ocorre com o ACl 318/89 para pilares de concreto com resistência equivalentes a Classe I.

IBRAHIM \& MAC GREGOR (1996), dizem que a maioria das normas de projeto estrutural utiliza equações com constantes empíricas baseadas em ensaios para concreto com resistência usual. Nos últimos anos extensos trabalhos experimentais e analíticos têm possibilitado um melhor entendimento do comportamento do concreto de alta resistência. São apresentados os resultados de 20 ensaios de pilares com resistência de $60 \mathrm{MPa}$ a $130 \mathrm{MPa}$, solicitados por forças com pequenas excentricidades. Os ensaios foram semelhantes aos de AZIZINAMINI et al. (1996). Os pilares foram ensaiados sob a ação de duas forças aplicadas de tal forma que, em uma das faces a deformação seja nula numa determinada seção transversal durante cada ensaio. $O$ estudo desenvolvido foi para pilares de concreto simples e com pequenas taxas de armadura longitudinal e de confinamento, visando contribuir para um melhor entendimento do comportamento à flexão

\footnotetext{
${ }^{4}$ AZIZINAMINI, A.; KUSKA, S.; BRUNGARDT, P.; HATFIELD, E. (1994). Seismic behavior of square high-strength concrete columns. ACI Structural Journal, p. 336-345.
} 
de seções de concreto de alta resistência sem confinamento ou com menos confinamento que os necessários para ações sísmicas.

O programa experimental desenvolvido incluiu uma primeira fase com 14 modelos de seções transversais retangulares nas regiões de observação dos pilares. Três desses não tinham armadura, 11 eram armados longitudinalmente e transversalmente e todos os modelos tinham seção transversal de $20,0 \mathrm{~cm} \times 30,0 \mathrm{~cm}$. Na segunda fase foram ensaiados 6 modelos com seção transversal triangular sendo 2 sem armaduras e 4 armados; na figura 3.12 podem ser vistos detalhes dos modelos ensaiados nas duas fases.
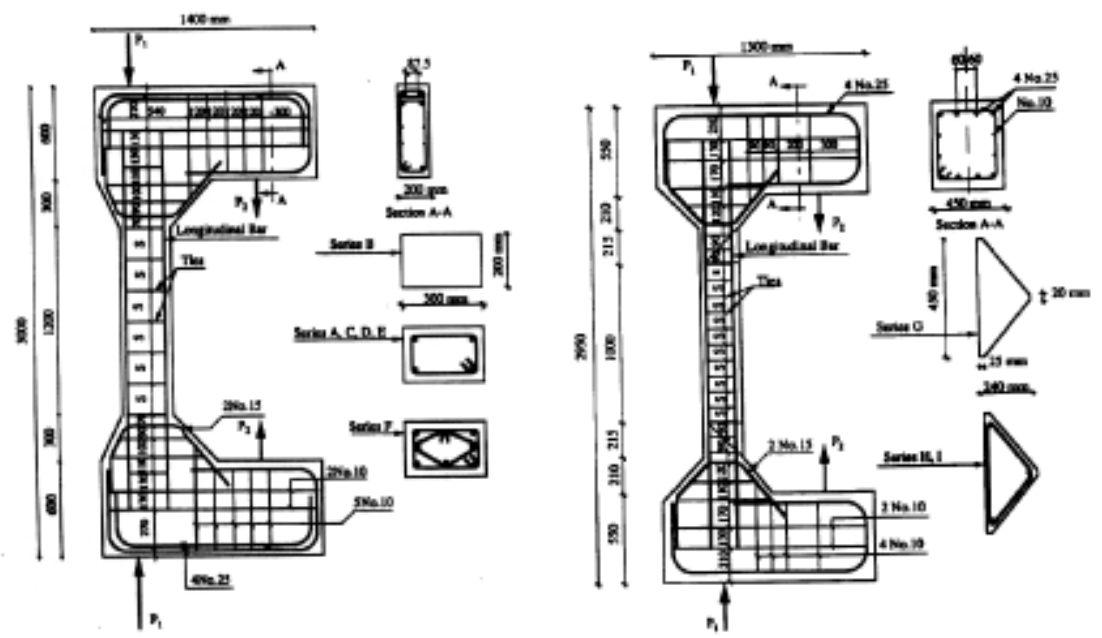

FIGURA 3.12 - Modelos ensaiados por IBRAHIM \& MAC GREGOR (1996)

Os resultados dos ensaios indicaram que a ruptura das seções de concreto simples e pouco armadas são muito frágeis. Pilares com espaçamentos de estribos igual à menor dimensão do pilar romperam subitamente quando houve o destacamento do cobrimento de concreto. Uma seção bem confinada pode apresentar um comportamento dúctil, mantendo a força aplicada para grandes deformações. A forma da zona comprimida é um importante parâmetro na determinação da ductilidade da seção, e as seções com zonas de compressão triangulares exibiram um comportamento mais dúctil em relação às retangulares. 


\section{7-Considerações Finais}

Observou-se neste capítulo, as várias propostas para a relação tensão $\mathrm{x}$ deformação do CAD. Como as relações indicadas foram baseadas em dados experimentais, notou-se a divergência de resultados que se justifica pela grande quantidade de parâmetros que envolvem esta relação, principalmente no que se refere as propriedades dos agregados graúdos, que, em se tratando de CAD, influenciam bastante nesta relação.

Assim, o diagrama tensão $\mathrm{x}$ deformação mais calibrado, é aquele desenvolvido em pesquisas locais, baseados em dados experimentais com materiais da região. Por isso, há necessidade de pesquisas sobre esta relação, para se ter maior segurança sobre o comportamento desse material.

A intensa pesquisa bibliográfica revelou a escassez de trabalhos em pilares submetidos à compressão excêntrica, isto se dá principalmente no Brasil. No entanto, verificou-se que nos últimos anos houve maior quantidade de publicações internacionais sobre este assunto, confirmandose assim a recente preocupação e interesse pelos pesquisadores neste tema. 


\section{ANÁLISE EXPERIMENTAL DE PILARES DE CONCRETO DE ALTA RESISTÊNCIA}

\section{1- Considerações Iniciais}

Este capítulo apresenta a metodologia adotada no desenvolvimento experimental da pesquisa. São abordados todos os procedimentos envolvidos na experimentação que pode ser resumida da seguinte maneira:

$>$ Sistema de aplicação de força e de vinculação:

Elaboração do sistema de ensaio que apresente comportamento próximo dos modelos teóricos.

> Obtenção de um concreto de alta resistência:

Escolha e caracterização dos agregados e materiais utilizados; estudo de dosagem.

> Caracterização das barras de aço que foram utilizadas nas armaduras dos pilares.

$>$ Ensaio dos pilares:

Projeto e execução das fôrmas de madeira; projeto do consolo que foi adaptado nas extremidades do pilar; montagem das armaduras, instrumentação e posicionamento na fôrma; moldagem do pilar e desforma; execução dos ensaios; ensaios dos corpos-de-prova de compressão axial, diametral e deformação controlada. 


\section{2- Sistema de Aplicação de Força e de Vinculação}

Este trabalho visa apresentar um sistema de ensaio viável para as condições do Laboratório de Estruturas da Escola de Engenharia de São Carlos EESC - USP, em que eram aplicados, em uma seção de pilar, esforços de compressão e flexão, de forma que se caracterizasse na seção estudada, situação de flexo compressão reta.

O modelo físico teórico que se pretendeu atingir, era o de um pilar com força excêntrica aplicada na direção do seu eixo longitudinal, provocando, na região central, situação de flexo compressão reta, como mostra a figura 4.1.

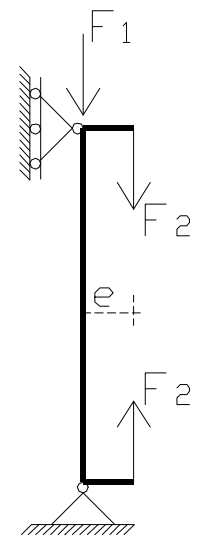

FIGURA 4.1 - Modelo teórico de aplicação de força excêntrica em pilares

Baseados nos ensaios realizados por IBRAHIM \& MAC GREGOR (1996) e AZIZINAMINI \& KEBRAEI (1996), adaptaram-se os modelos de pilares ensaiados por LIMA (1997) para projeto geométrico apresentado por aqueles Autores, conforme indicado na figura 4.2. Tal configuração possibilitou a aplicação de duas forças independentes com excentricidade bem definida em relação ao eixo longitudinal do pilar, facilitando assim a aplicação e o controle das forças para que a distribuição de tensões fosse de acordo com o esperado no modelo teórico adotado. 


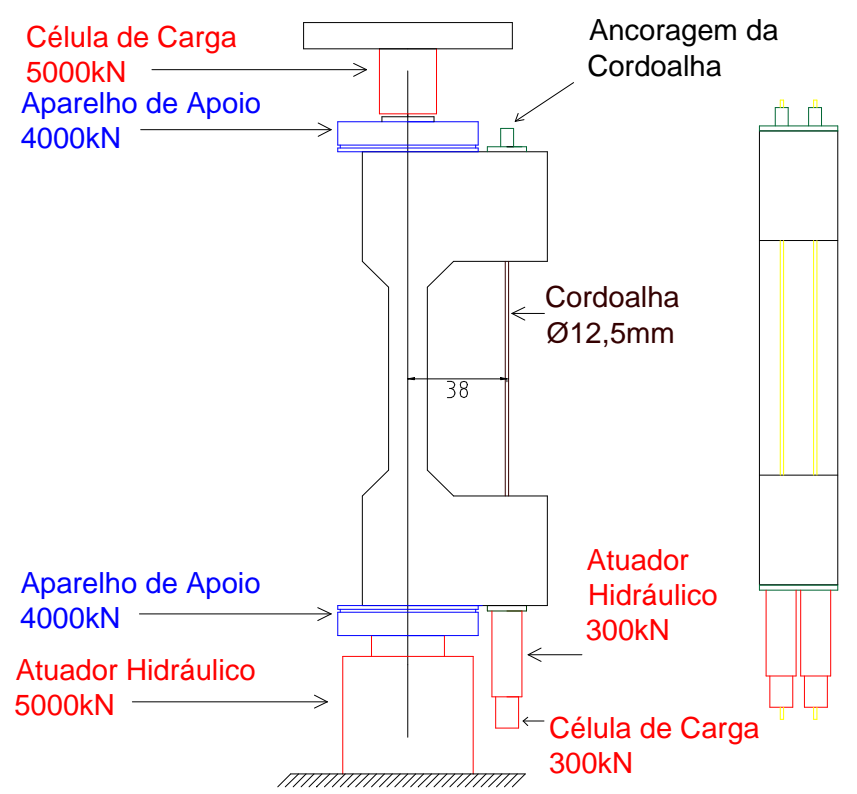

FIGURA 4.2 - Sistema de ensaio utilizado

Para a aplicação das forças foram criados dois consolos, um no topo e outro na base do pilar, idéia indicada em IBRAHIM \& MAC GREGOR (1996) e AZIZINAMINI \& KEBRAEI (1996).

A força centrada foi aplicada no eixo longitudinal do pilar, através de um atuador hidráulico com capacidade de $5000 \mathrm{kN}$ agindo na base do pilar. A sua reação era dada por uma estrutura metálica de reação na qual os modelos eram posicionados. A força excêntrica era aplicada nos consolos por dois atuadores hidráulicos de $300 \mathrm{kN}$ cada, e a ação era transmitida de um consolo para o outro por duas cordoalhas de aço para elementos estruturais protendidos de $12,5 \mathrm{~mm}$ de diâmetro cada. Estas, atravessavam os consolos por meio de furos deixados no modelo utilizando tubos de plático - PVC de diâmetro de 19mm, como mostra a figura 4.17. Para facilitar o transporte do modelo foi deixado um furo na parte superior, localizado próximo ao centro de massa do pilar, para que se pudesse passar uma barra de aço por esse e assim içá-lo pela ponte rolante do Laboratório, como mostrado na figura 4.22 .

Em se tratando da vinculação, era considerado no modelo teórico pilar rotulado na base e no topo. Para se ter isto em laboratório, foram adotados aparelhos de apoio usados comumente para apoio de pontes, com 
capacidade de $4000 \mathrm{kN}$, posicionados na base e no topo do pilar, como mostrado na figura 4.2 .

As aplicações das forças foram feitas por duas bombas, uma para 0 atuador hidráulico de $5000 \mathrm{kN}$ e a outra para os outros dois atuadores de $300 \mathrm{kN}$. As forças foram aplicadas em etapas onde a força excêntrica era $5 \%$ da força centrada. O pilar recebia ações conjuntas de modo que os esforços de flexão atuavam desde o início do ensaio procurando-se, assim, reproduzir situação real de edifícios onde os esforços normais e os momentos fletores atuavam simultaneamente e de forma gradual.

Com isso chegou-se ao sistema de ensaio mostrado na figura 4.3.
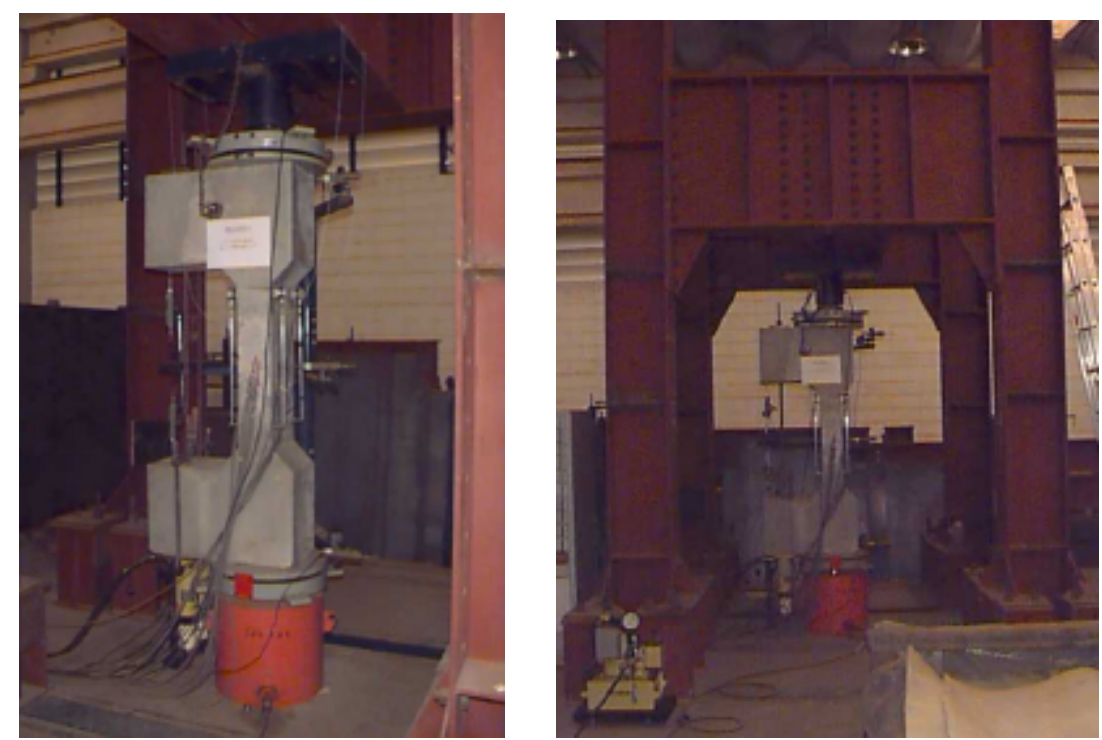

FIGURA 4.3 - Mecanismo de ensaio adotado

\section{3- Materiais Utilizados}

Os materiais utilizados nos pilares foram caracterizados segundo as normas da ABNT. Para isso, utilizaram-se recursos do Laboratório de Construção Civil e do Laboratório de Madeiras e Estruturas de Madeira EESC-USP. Para alguns materiais foram seguidas as especificações dos fabricantes. 


\subsection{1- Cimento}

Foi utilizado o cimento Portland de alta resistência inicial CP V ARI, por ser um material cimentício sem adições, e pela possibilidade de realização de ensaios dos elementos com idades menores.

O cimento empregado nos ensaios foi recebido como doação, em convênio estabelecido com a Camargo Corrêa Industrial S.A. - Cimento Eldorado, tendo sido caracterizado pelo fabricante, segundo a NBR-6474/84, com uma massa específica de $3120 \mathrm{~kg} / \mathrm{m}^{3}$.

Após o recebimento, os sacos eram envolvidos em embalagens plásticas e armazenados em pilhas sobre lastro de madeira, afastados do piso e da parede, evitando dessa forma interferência da umidade nas propriedades do concreto.

\subsection{2- Sílica ativa}

A sílica ativa utilizada foi a não densificada, SILMIX ND, fornecida por doação em convênio com a empresa Camargo Corrêa Industrial S.A.. Para fins de dosagem, seguindo indicação do fabricante, a massa específica é de $2222 \mathrm{~kg} / \mathrm{m}^{3}$.

\subsection{3- Aditivo superplastificante}

O aditivo superplastificante usado foi o $\mathrm{RX} 3000$, da REAX Indústria e Comércio Ltda., com densidade de $1,160 \mathrm{~g} / \mathrm{cm}^{3}$, obedecendo, segundo a empresa, as normas ASTM C 494 e NBR11768/92. Este material fez parte de doação feita ao Laboratório de Estruturas - EESC - USP.

\subsection{4- Água}

Para o amassamento do concreto foi utilizada água proveniente da rede pública de abastecimento de cidade de São Carlos. 


\subsection{5- Agregados}

Foi feita a escolha dos agregados, miúdo e graúdo, disponíveis na região de São Carlos, através de ensaios de granulometria, massa específica e massa unitária.

\subsubsection{1- Agregado miúdo}

Na dosagem do concreto foi utilizado como agregado miúdo, areia do tipo quartozita proveniente do rio Mogi-Guaçu - Município de São Carlos SP. A análise granulométrica, foi feita segundo a NBR 7217/87, no Laboratório de Construção Civil - EESC - USP, com os resultados mostrados na tabela 4.1. Segundo a NBR 7211/83, a areia pôde ser classificada como média.

Para ensaios de caracterização efetuados, foram tomados sempre como média de duas determinações: a massa específica, segundo a NBR $9776 / 87$ foi de $2,682 \mathrm{~kg} / \mathrm{dm}^{3}$ e a massa unitária, segundo a NBR 7251/82 foi de $1,435 \mathrm{~kg} / \mathrm{dm}^{3}$.

TABELA 4.1 - Análise Granulométrica do Agregado Miúdo

\begin{tabular}{|c|c|c|c|}
\hline Peneira & Massa (g) & $\%$ Retida & $\%$ Acumulada \\
\hline 6,3 & 0 & 0 & 0 \\
\hline 4,8 & 0,5 & 0,1 & 0,1 \\
\hline 2,4 & 7,0 & 1,4 & 1,5 \\
\hline 1,2 & 51,5 & 10,3 & 11,8 \\
\hline 0,6 & 165,0 & 33,0 & 44,8 \\
\hline 0,3 & 199,0 & 39,8 & 84,6 \\
\hline 0,15 & 65,5 & 13,1 & 97,7 \\
\hline Resíduo & 2,5 & 0,5 & 98,2 \\
\hline \multicolumn{4}{|c|}{$\begin{array}{l}\text { Dimensão máxima característica: } \phi_{\text {máx }}=2,4 \mathrm{~mm} \\
\text { Módulo de finura: MF }=2,405 \\
\text { Classificação : areia média }\end{array}$} \\
\hline
\end{tabular}




\subsubsection{2- Agregado graúdo}

O agregado graúdo usado foi pedra britada de origem basáltica, da região de Araraquara-SP. A massa específica obtida foi de $2,864 \mathrm{~kg} / \mathrm{dm}^{3}$, utilizando-se a NBR 9776/87, e a massa unitária foi de $1,485 \mathrm{~kg} / \mathrm{dm}^{3}$, conforme a NBR 7251/82. A análise granulométrica, cujos resultados apresentam-se na tabela 4.2, foi feita conforme a NBR 7217/87.

TABELA 4.2 - Análise Granulométrica do Agregado Graúdo

\begin{tabular}{|c|c|c|c|}
\hline Peneira & Massa (g) & \% Retida & \% Acumulada \\
\hline 25 & 0 & 0 & 0 \\
\hline 19 & 26,5 & 0,53 & 0,53 \\
\hline${ }^{*} 12,5$ & 1750 & 35 & 35,53 \\
\hline 9,5 & 2250 & 45 & 80,53 \\
\hline${ }^{*} 6,3$ & 920 & 18,4 & 98,93 \\
\hline 4,8 & 87,5 & 1,75 & 100,68 \\
\hline 015 & 19 & 0,38 & 101,06 \\
\hline \multicolumn{4}{|c|}{$\begin{array}{l}\text { Dimensão máxima característica: } \phi_{\text {máx }}=19 \mathrm{~mm} \\
\text { Módulo de finura: MF }=1,82\end{array}$} \\
\hline
\end{tabular}

\section{4- Estudo de Dosagem}

Inicialmente adotou-se o traço utilizado por LIMA (1997), que consistia em dosagem para concreto de alta resistência com a resistência média à compressão de $80 \mathrm{MPa}$. Na tabela 4.3 podem ser vistas as quantidades de materiais usados na mistura.

Como o concreto apresentou características diferentes dos de LIMA (1997), não foi possível chegar aos $80 \mathrm{MPa}$ de resistência média à compressão, então, procurou-se ajustá-lo, mas obtiveram-se grandes variações de trabalhabilidade e resistência.

Tomou-se então como segunda referência, o traço utilizado na pesquisa desenvolvida por GIONGO et al. (1998), onde se obteve concreto com resistência média à compressão de $80 \mathrm{MPa}$, aos 15 dias, com adição de fibras metálicas. O ponto comum foi a utilização de material com as mesmas características que o utilizado nesta pesquisa. Na tabela 4.3 podem ser 
vistas as quantidades de materiais usados na mistura, tendo como diferença fator água/cimento que era de 0,37 e foi adotado 0,35.

TABELA 4.3 - Estudo de dosagem

\begin{tabular}{|c|c|c|c|}
\hline \multirow{2}{*}{ Material } & \multicolumn{3}{|c|}{ Consumo $\left(\mathrm{kg} / \mathrm{m}^{3}\right)$} \\
\hline & Dosagem inicial & Segunda dosagem & Dosagem adotada \\
\hline Cimento & 480,000 & 492,500 & 495,000 \\
\hline Sílica ativa (10\%) & 48,000 & 49,250 & 49,500 \\
\hline Areia & 577,920 & 715,000 & 715,000 \\
\hline Pedra britada & 1198,090 & $1.025,000$ & $1.025,000$ \\
\hline Superplastificante (3\%) & 17,430 & 17,140 & 17,226 \\
\hline Água & 160,600 & 160,380 & 146,342 \\
\hline Massa Total & $2.560,540$ & $2.459,270$ & $2.448,068$ \\
\hline
\end{tabular}

Comparou-se então a dosagem inicial com a segunda, aumentou-se um pouco o consumo de cimento para $495,0 \mathrm{~kg} / \mathrm{m}^{3}$ e foi reduzido o fator água/cimento para 0,32 , chegando-se àdosagem que forneceu um resultado bem próximo de $80 \mathrm{MPa}$, como era o procurado, tabela 4.4.

$\mathrm{Na}$ tabela 4.3, encontram-se as quantidades de materiais usados na dosagem modificada.

O consumo de sílica ativa foi de $10 \%$, valor recomendado por outros autores. O teor de superplastificante usado foi de $3 \%$ do consumo de cimento, e é considerado um valor muito alto, o dobro do recomendado. Com a densidade do superplastificante, fornecida pelo fabricante, determinou-se o consumo do aditivo em massa. Do consumo de água, está descontado o volume de água contido no aditivo, admitido ser de $70 \%$ da massa. A relação água / cimento foi de 0,32 , e considerando-se a relação água / material cimentante, tem-se 0,29.

\subsection{1- Ensaios de Dosagem para Determinação do Traço}

Para moldagem dos corpos-de-prova, foram utilizadas fôrmas metálica cilíndricas de $10 \mathrm{~cm} \times 20 \mathrm{~cm}$. Este tamanho de corpo-de-prova foi adotado devido a menor força para execução do ensaio, já que é um concreto de alta resistência, e também devido ao menor volume de concreto. 
O adensamento dos corpos-de-prova foi realizado utilizando mesa vibratória, como pode ser visto na figura 4.4. Foi utilizado mesa vibratória, pois o vibrador de agulha orienta a posição dos agregados graúdos, podendo descaracterizar o material.

Para mistura do material, seguiu-se a indicada por DAL MOLIN (1995). Para que, pelo menos uma parcela do pó de pedra fosse retirada, deixou-se a betoneira girando com o agregado graúdo a seco por 3 minutos, em seguida adicionou-se $20 \%$ da água, deixando a betoneira virar por 2 minutos. Depois foram acrescentados o cimento, a sílica ativa e 50\% da água, fechando a boca da betoneira com saco plástico para que a sílica ativa não saísse, e deixou-se a máquina rodar por 2 minutos. Por último, foram acrescentados a areia e o superplastificante com o restante da água (30\%), deixando a massa bater por mais 3 minutos. O tempo de mistura foi de mais de 10 minutos.
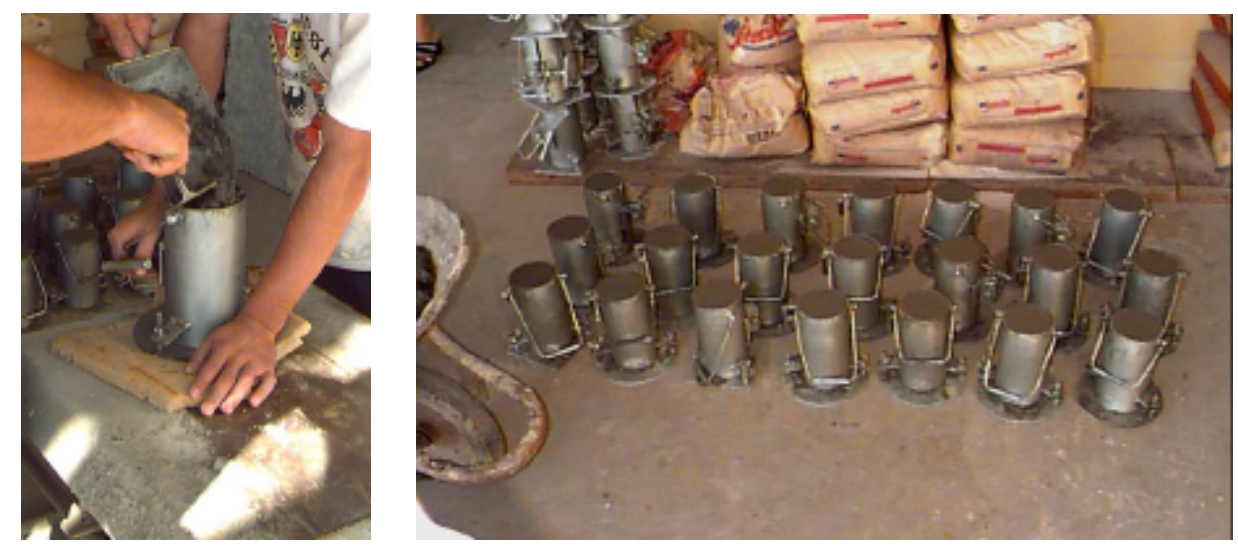

FIGURA 4.4 - Moldagem dos corpos-de-prova

Para realizar os ensaios, foram moldados 9 corpos-de-prova para cada tentativa, com o objetivo de determinar a resistência à compressão aos 3, 7 e 15 dias de idade. O 15. dia foi escolhido apenas pela conveniência do cronograma de ensaios acontecerem de 15 em 15 dias. Dos 9 corpos-deprova, eram ensaiados 3 a cada data, onde se obtinha a média dos resultados.

Os resultados das resistências médias à compressão estão na tabela 4.4. 
TABELA 4.4 - Resultados dos ensaios de compressão axial

\begin{tabular}{|c|c|c|c|}
\hline \multirow{2}{*}{$\begin{array}{c}\text { Idade } \\
\text { (dias) }\end{array}$} & \multicolumn{3}{|c|}{ Tensão de Ruptura (MPa) } \\
\cline { 2 - 4 } & Dosagem inicial & Segunda dosagem & Dosagem adotada \\
\hline 3 & 51,18 & 59,63 & 67,81 \\
\hline 7 & 59,62 & 66,36 & 67,89 \\
\hline 15 & 69,84 & 65,92 & 79,09 \\
\hline
\end{tabular}

O crescimento da resistência com o tempo, foi acompanhado como mostra a figura 4.5 .

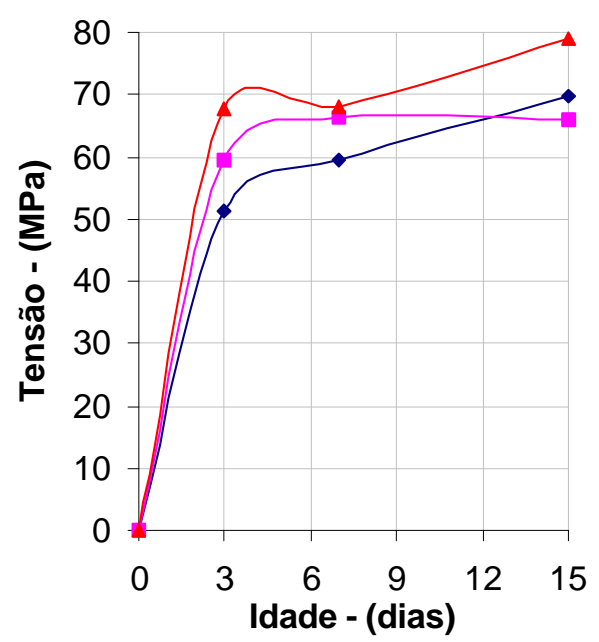

$\multimap$ Dosagem inicial $\longrightarrow$ Segunda dosagem $\multimap$ Dosagem adotada

FIGURA 4.5 - Crescimento da resistência com o tempo

\section{5- Caracterização das Armaduras}

Utilizou-se como armadura longitudinal, barras de aço de diâmetro nominal de $10 \mathrm{~mm}, 12,5 \mathrm{~mm}$ e $16 \mathrm{~mm}$. Como armadura transversal, foi usada barras de $6,3 \mathrm{~mm}$ de diâmetro. $\mathrm{Na}$ figura 4.6 , observam-se os diagramas tensão $x$ deformação, obtidos em ensaios de tração em amostras retiradas das barras de aço utilizadas. 


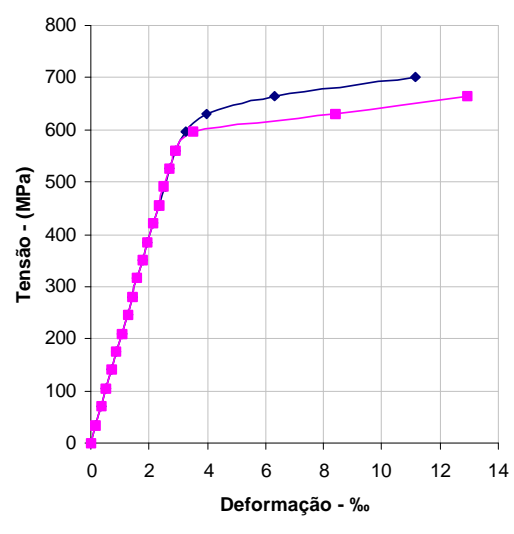

- Amostra $1 \rightarrow$ Amostra 2

$(\phi 6,3 \mathrm{~mm})$

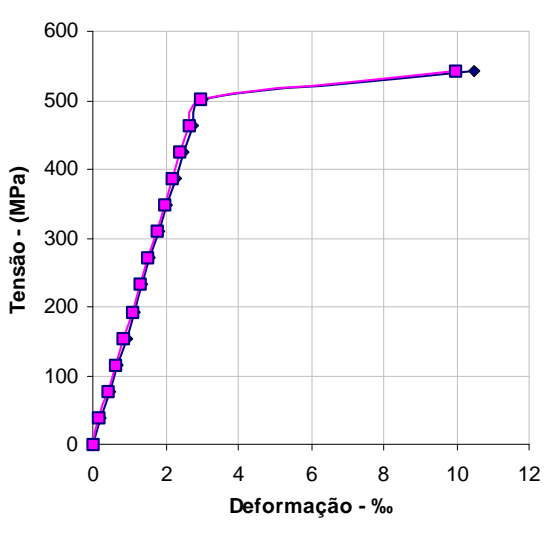

$(\phi 12,5 \mathrm{~mm})$

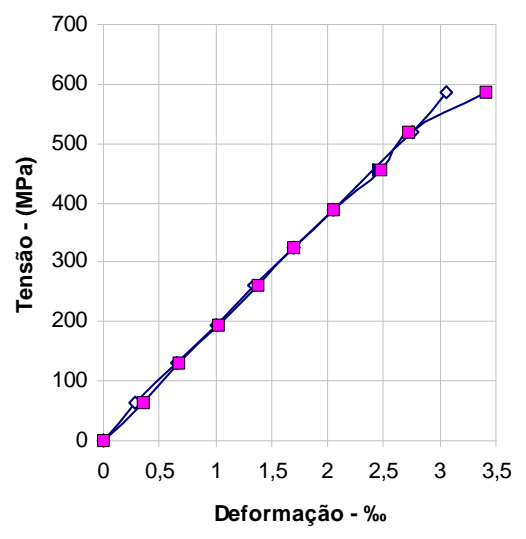

$\longrightarrow$ Amostra $1 \rightarrow-$ Amostra 2

$(\phi 10 \mathrm{~mm})$

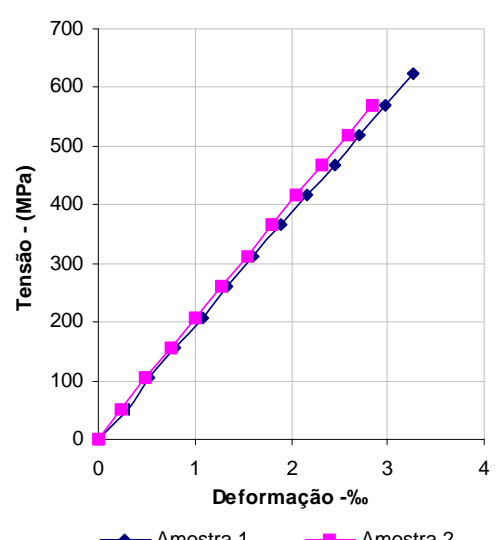

( $\phi 16 \mathrm{~mm})$

FIGURA 4.6 - Diagramas tensão x deformação das barras da armadura

A tabela 4.5 apresenta a caracterização das barras das armaduras utilizadas nos pilares.

TABELA 4.5 - Caracterização das armaduras

\begin{tabular}{|c|c|c|c|c|c|}
\hline $\begin{array}{c}\phi_{\text {nominal }} \\
\mathbf{m m}\end{array}$ & $\begin{array}{c}\mathbf{A}_{\mathbf{s}} \\
\mathbf{c m}^{\mathbf{2}}\end{array}$ & $\begin{array}{c}\mathbf{E}_{\mathbf{s}} \\
\mathbf{M P a}\end{array}$ & $\begin{array}{c}\boldsymbol{f}_{\boldsymbol{y}} \\
\mathbf{M P a}\end{array}$ & $\begin{array}{c}\boldsymbol{\varepsilon}_{\mathbf{y}} \\
\%\end{array}$ & $\begin{array}{c}\boldsymbol{f}_{\boldsymbol{u}} \\
\mathbf{M P a}\end{array}$ \\
\hline 6,3 & 0,31 & 194.674 & 595,61 & 3,37 & 877,68 \\
\hline 10 & 0,785 & 194.060 & 623,00 & 3,47 & 725,74 \\
\hline 12,5 & 1,23 & 168.841 & 502,13 & 2,99 & 826,54 \\
\hline 16 & 2,01 & 194.388 & 622,85 & 3,26 & 851,22 \\
\hline
\end{tabular}




\section{6- Experimentação em Pilares}

A metodologia para o desenvolvimento experimental do trabalho compreende a dosagem para obtenção de concreto com resistência média à compressão de $80 \mathrm{MPa}$ aos 15 dias, como mencionado no item anterior, e ensaios de pilares para obtenção dos resultados experimentais sobre 0 comportamento àflexo compressão reta.

Para elaboração e execução do programa experimental seguiram-se as seguintes etapas:

a- Construção de fôrmas de madeira;

b- Montagem da armadura, instrumentação de barras e posicionamento na fôrma;

c- Moldagem, envolvendo o lançamento, adensamento, cura;

d- Desmoldagem dos pilares e posicionamento no pórtico de ensaio.;

e- Instrumentação e execução dos ensaios;

f - Ensaios dos pilares até se caracterizar a ruína;

g- Ensaios de compressão axial em corpos-de-prova cilíndricos de $100 \mathrm{~mm} \times 200 \mathrm{~mm}$, para controle da resistência do concreto no dia do ensaio, obtendo-se também o módulo de elasticidade;

h- Ensaios de compressão com deformação controlada para obter o comportamento pós-pico do concreto no dia do ensaio, usando, também, corpos-de-prova cilíndricos de $10 \mathrm{~cm}$ x $20 \mathrm{~cm}$;

i- A partir dos dados obtidos pelo sistema de aquisição, elaboração de planilhas e, em seguida, de diagramas força $x$ deformação e força $x$ deslocamento.

Baseados nos ensaios realizados por LIMA (1997), definiram-se as características dos modelos, onde todos os pilares tinham dimensões da seção transversal fixa de $15 \mathrm{~cm} \times 30 \mathrm{~cm}$, altura livre igual a $174 \mathrm{~cm}$, resistência à compressão do concreto de $80 \mathrm{MPa}$, excentricidade constante de $38 \mathrm{~cm}$; e foram variadas as taxas de armaduras transversais e longitudinais. 


\subsection{1 - Programa experimental}

A tabela 4.6 traz as características dos modelos de pilares que se executou nesse trabalho, com as respectivas resistência à compressão média do concreto, taxas de armadura longitudinais e transversais, quantidade e diâmetro das barras das armaduras longitudinais e o diâmetro e espaçamento dos estribos. Os modelos são identificados pela sigla Pilj, onde $i=$ número da série, e $j=$ número do pilar na série.

TABELA 4.6 - Características dos modelos

\begin{tabular}{|c|c|c|c|c|c|c|c|c|}
\hline Pilar & $\begin{array}{c}\mathbf{b} \\
\mathbf{c m}\end{array}$ & $\begin{array}{c}\mathbf{h} \\
\mathbf{c m}\end{array}$ & $\begin{array}{c}\mathbf{L} \\
\mathbf{c m}\end{array}$ & $\begin{array}{c}\boldsymbol{f}_{\mathbf{c}} \text { (nominal) } \\
\mathbf{M P a}\end{array}$ & $\begin{array}{c}\rho_{\mathrm{L}} \\
\%\end{array}$ & $\begin{array}{c}\text { Arm. } \\
\text { longit. }\end{array}$ & $\begin{array}{c}\rho_{\mathbf{t}} \\
\%\end{array}$ & Estribo \\
\hline Piloto & 30 & 15 & 174 & 80 & 2,26 & $8 \phi 12,5$ & 1,58 & $\phi 6,3 \mathrm{c} / 5$ \\
\hline $\mathrm{P} 1 / 1$ & 30 & 15 & 174 & 80 & 2,26 & $8 \phi 12,5$ & 1,58 & $\phi 6,3 \mathrm{c} / 5$ \\
\hline $\mathrm{P} 1 / 2$ & 30 & 15 & 174 & 80 & 2,26 & $8 \phi 12,5$ & 0,79 & $\phi 6,3 \mathrm{c} / 10$ \\
\hline $\mathrm{P} 1 / 3$ & 30 & 15 & 174 & 80 & 2,26 & $8 \phi 12,5$ & 0,53 & $\phi 6,3 \mathrm{c} / 15$ \\
\hline $\mathrm{P} 2 / 1$ & 30 & 15 & 174 & 80 & 1,26 & $8 \phi 10$ & 0,79 & $\phi 6,3 \mathrm{c} / 10$ \\
\hline $\mathrm{P} 2 / 2$ & 30 & 15 & 174 & 80 & 1,26 & $8 \phi 10$ & 1,58 & $\phi 6,3 \mathrm{c} / 5$ \\
\hline $\mathrm{P} 3 / 1$ & 30 & 15 & 174 & 80 & 3,45 & $8 \phi 16$ & 0,79 & $\phi 6,3 \mathrm{c} / 10$ \\
\hline
\end{tabular}

Inicialmente foi feito um modelo piloto para se ter idéia de como seria seu comportamento com relação às deformações das barras de aço, do concreto e os deslocamentos, além de se verificar as dificuldades que se teria na construção, moldagem, montagem no pórtico de reação e instrumentação do modelo.

Com a série 1 teve-se o objetivo de definir taxa de armadura transversal que promovia confinamento do núcleo; com isso pretendia-se realizar três modelos com três níveis de taxa de confinamento.

Na série 2, utilizou-se a taxa de confinamento encontrada na série 1 e verificou-se a sua eficiência com a diminuição da taxa de armadura longitudinal, sendo, para isto, ensaiados dois modelos com taxas de armaduras transversais diferentes.

Na série 3 aumentou-se a taxa de armadura longitudinal, e usou-se a melhor taxa de armadura transversal encontrada para as séries 1 e 2 . 
4.6.2 - Arranjos das armaduras do modelo

Como exemplo, o detalhamento da armadura e do pilar P1/1 é mostrado na figura 4.7 .

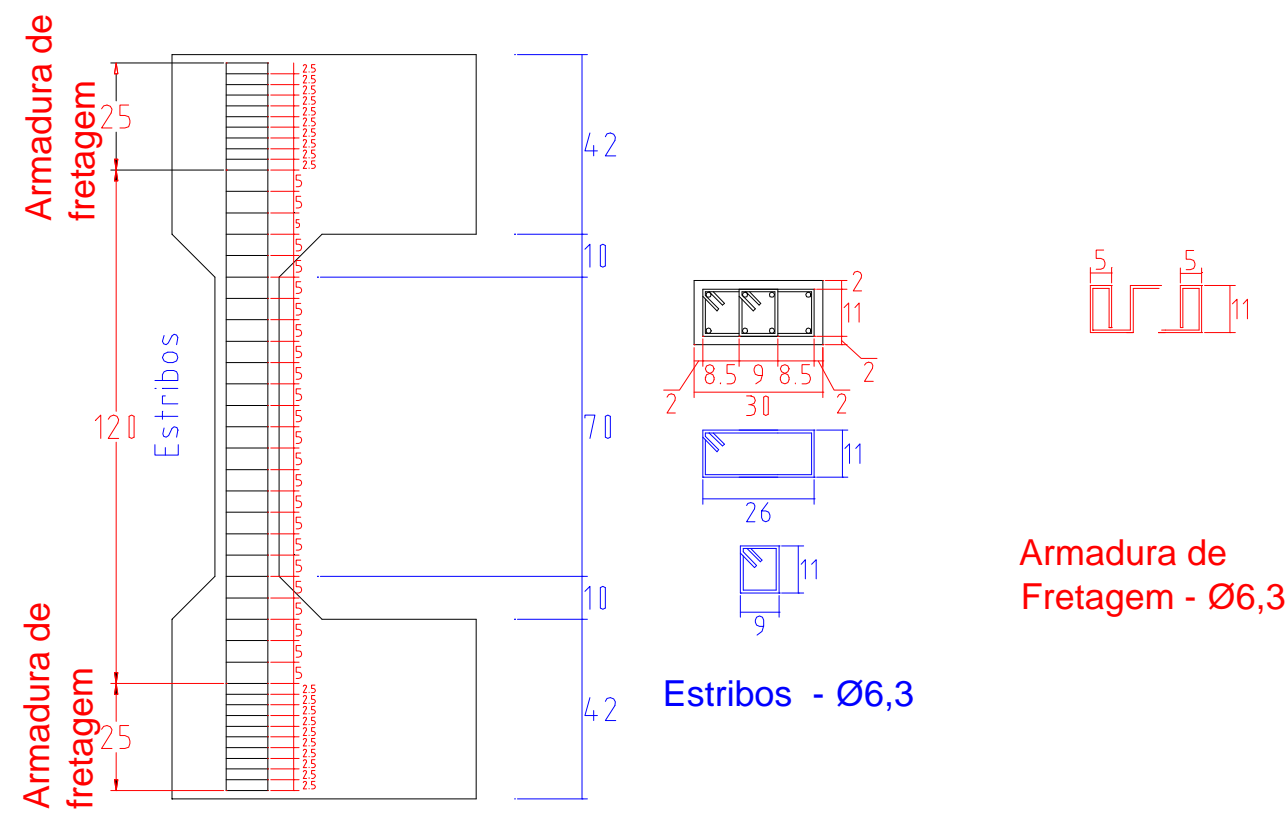

FIGURA 4.7 - Detalhes do modelo P1/1

Como armadura transversal, foi feita a superposição de dois estribos para melhorar o confinamento do núcleo dos pilares, como mostra a figura 4.7 e 4.8.
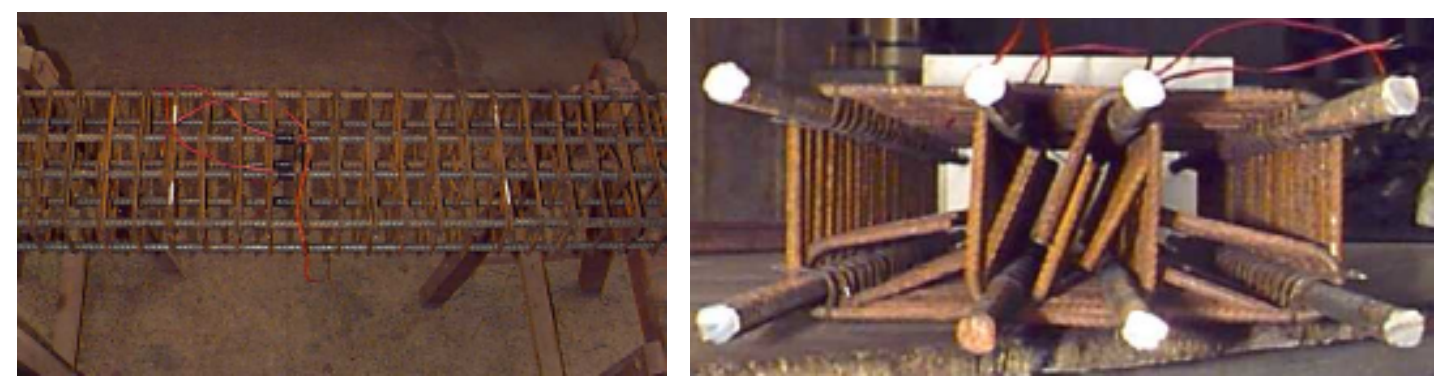

FIGURA 4.8 - Detalhes da armadura do pilar P1/1

A armadura de fretagem foi usada nas extremidades dos pilares, devido à grande concentração de tensões nessas regiões. Foi adotado arranjo de armadura proposto por LIMA (1997), figura 4.7 e 4.10 , que 
mostrou grande eficiência, ou seja, não houve ruptura ou fissuração excessiva nas extremidades dos modelos.

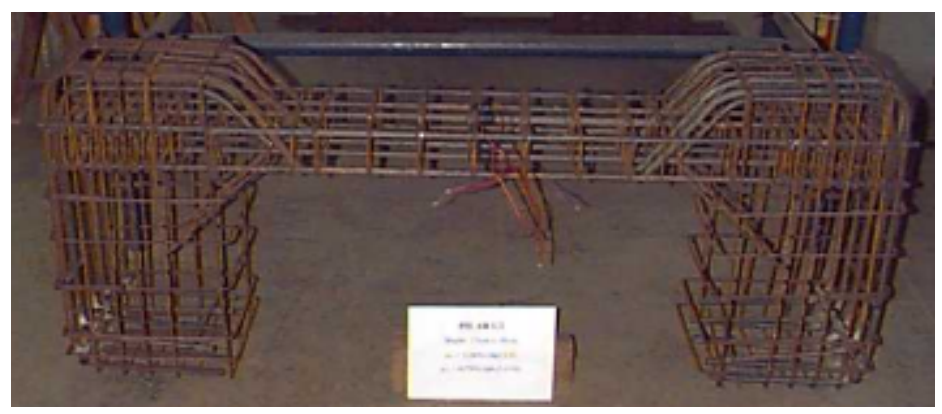

FIGURA 4.9 - Armadura do pilar P1/2
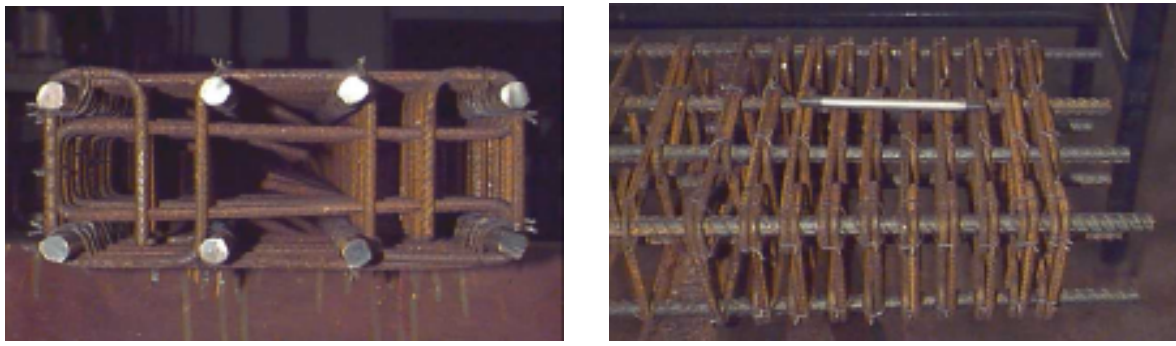

FIGURA 4.10 - Detalhes da armadura de fretagem

\subsection{3 - Detalhes do consolo}

Como foi dito, o modelo era composto por dois consolos, um na base e outro no topo. As funções desses consolos eram transmitir as forças excêntricas para o pilar e provocar, com isto, momento fletor na região central. Para isso, o consolo teve que ser projetado de modo que não ocorresse ruptura em hipótese alguma, pois o elemento que seria ensaiado éra o pilar e não o consolo. Logo, seguiram-se as recomendações da NBR 9062 (1985) e de LEONHARDT \& MONNIG (1978) como critérios de dimensionamento, tendo maiores cuidados nos coeficientes de segurança para garantir o correto dimensionamento do consolo.

O detalhamento é mostrado nas figuras 4.9 e 4.11 . 




FIGURA 4.11 - Detalhamento do consolo

\subsection{4 - Aparelho de apoio}

O aparelho de apoio usado para liberar a rotação no topo e na base do pilar, foi o modelo VASOFLON fixo com capacidade para $4000 \mathrm{kN}$, da empresa PROFIP, figura 4.12.

Esse aparelho, segundo catálogo entregue pelo fornecedor, era do tipo "pot bearing", nos quais as rotações ocorriam através da deformação de um disco de neoprene contido em um prato de aço, no qual a parte superior atuava como um êmbolo. Com isso o neoprene se mantinha como um fluido viscoso, ou seja, ele não alterava o volume e oferecia baixa resistência à deformação, desta forma, pode ser obtida perfeita articulação para rotações de $\pm 1 \%$, com alta rigidez vertical.

A escolha por esse tipo de aparelho de apoio ocorreu pela dificuldade que se teria de construir eficazes aparelhos de apoios em aço para as ações previstas. Então, para agilizar a pesquisa procurou-se em catálogos de fabricantes, onde foi levado em consideração as dimensões, o material utilizado na confecção e o custo do aparelho, chegando-se assim ao VASOFLON fixo 400. 
A empresa PROFIP colaborou com a pesquisa, fazendo a doação de um aparelho de apoio VASOFLON fixo 400, dos dois que seriam necessários. A compra pôde ser realizada com os recursos de Reserva Técnica fornecida pela Fundação de Amparo à Pesquisa do Estado de São Paulo - FAPESP.
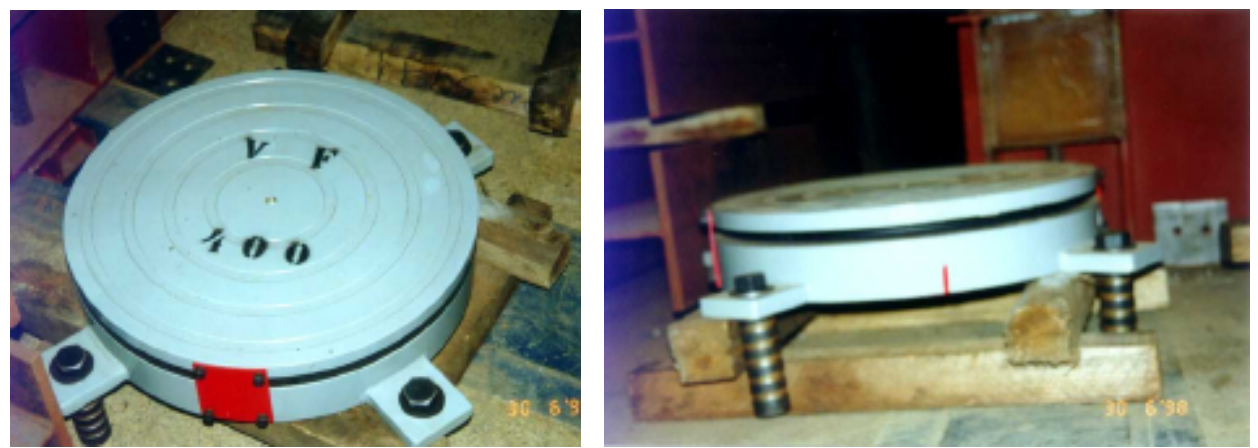

FIGURA 4.12 - Aparelho de apoio utilizado para liberar as rotações na base e topo do pilar

\subsection{5- Fôrmas}

As fôrmas foram projetadas e em seguida executadas em madeira compensada plastificada de $14 \mathrm{~mm}$, de acordo com a forma do pilar. Nas figuras 4.13, podem ser observados detalhes da fôrma.
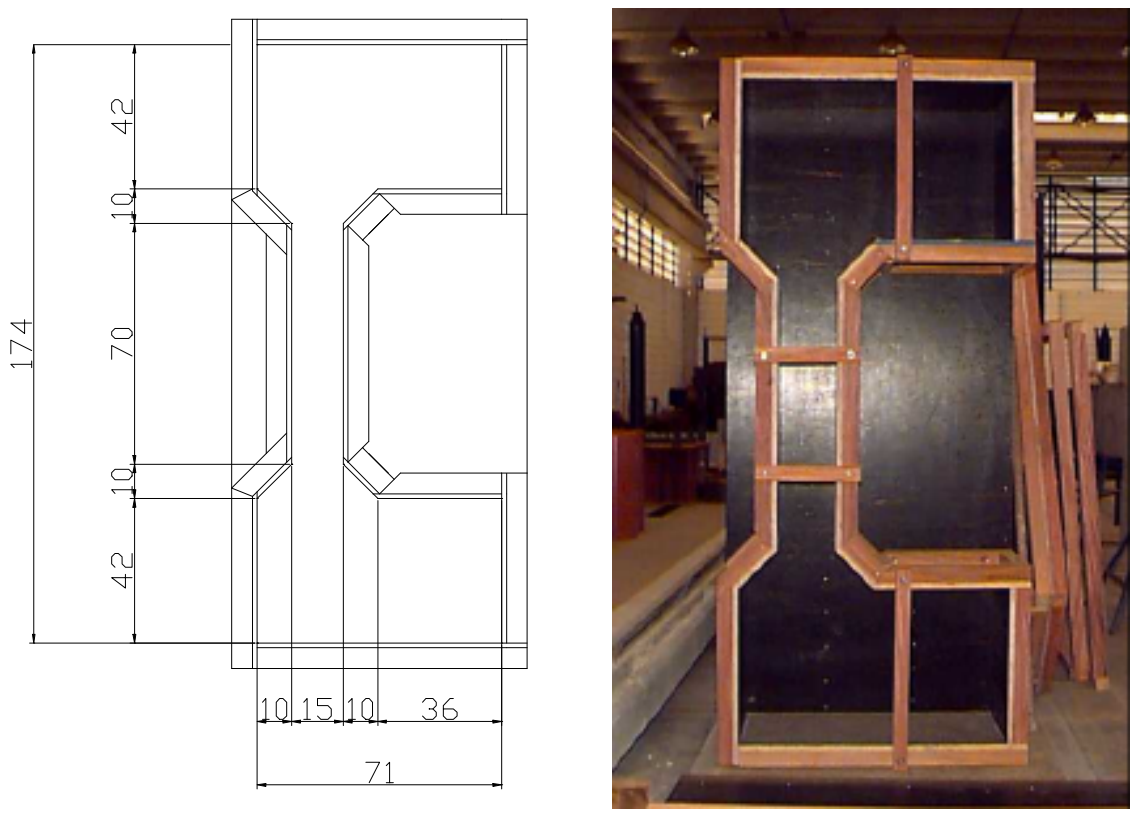

FIGURA 4.13 - Fôrma usada para concretagem dos pilares 


\subsection{6 - Estrutura de reação}

Para aplicação das forças previstas, foi utilizado o pórtico espacial e laje de reação do Laboratório de Estruturas do Departamento de Engenharia de Estruturas da EESC-USP.

O pórtico é composto por 4 colunas e uma grelha horizontal fixada por meio de parafusos, e convenientemente ancorado por meio de tirantes na laje de reação do Laboratório de Estruturas da EESC-USP. A capacidade nominal é de $5000 \mathrm{kN}$. O projeto permite a movimentação da grelha ao longo da altura das colunas, possibilitando a variação da altura dos modelos estudados.

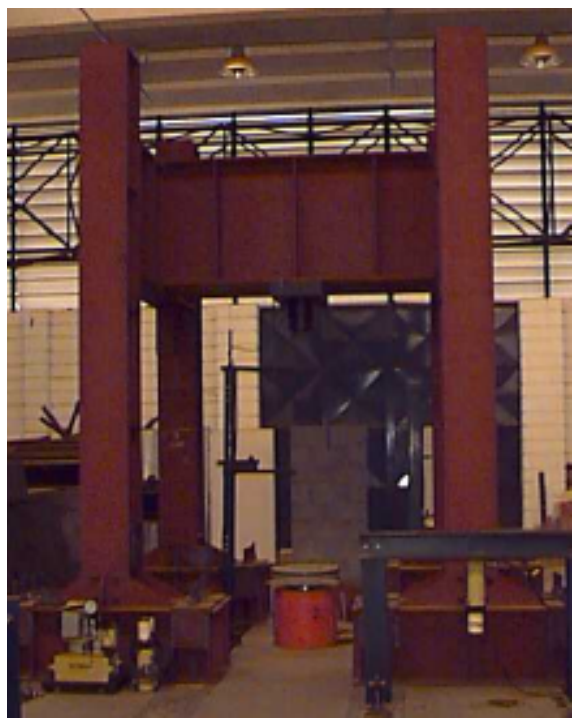

FIGURA 4.14 - Pórtico de reação

\subsection{7 - Moldagem, adensamento e cura}

O modelo piloto foi concretado horizontalmente para maior facilidade de moldagem, devido à grande concentração de armadura de fretagem nas extremidades. A mistura do material foi feita no misturador planetário do Laboratório de Estruturas - EESC, figura 4.15, e foram necessárias duas operações de mistura devido ao volume de concreto. O adensamento foi feito usando vibrador de imersão para o modelo piloto, e mesa vibratória para os demais modelos, figura 4.16. 


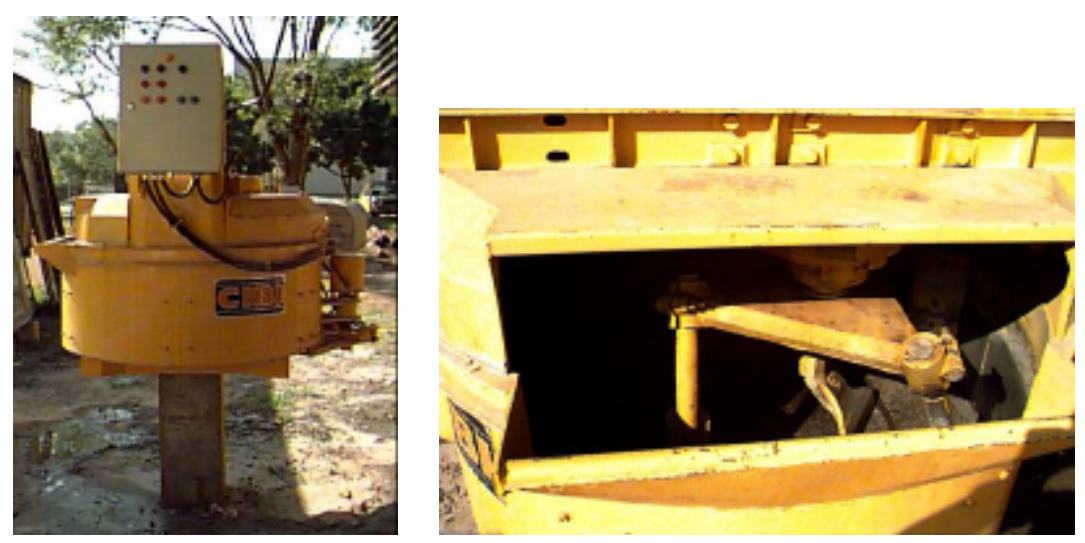

FIGURA 4.15 - Misturador de capacidade de 2401

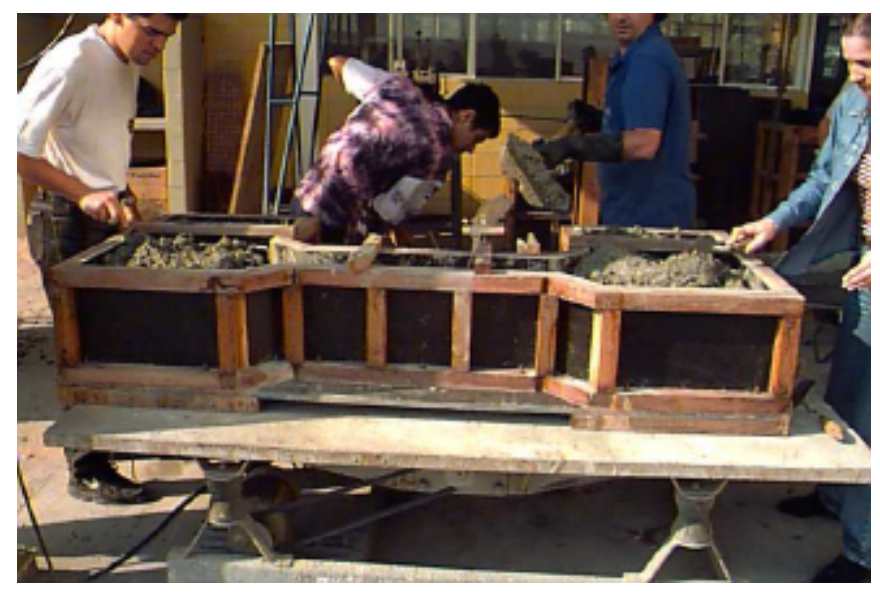

FIGURA 4.16 - Concretagem do pilar e adensamento em mesa vibratória

Para o posicionamento da armadura na fôrma, foram utilizados espaçadores plásticos comumente encontrados no mercado da construção civil.
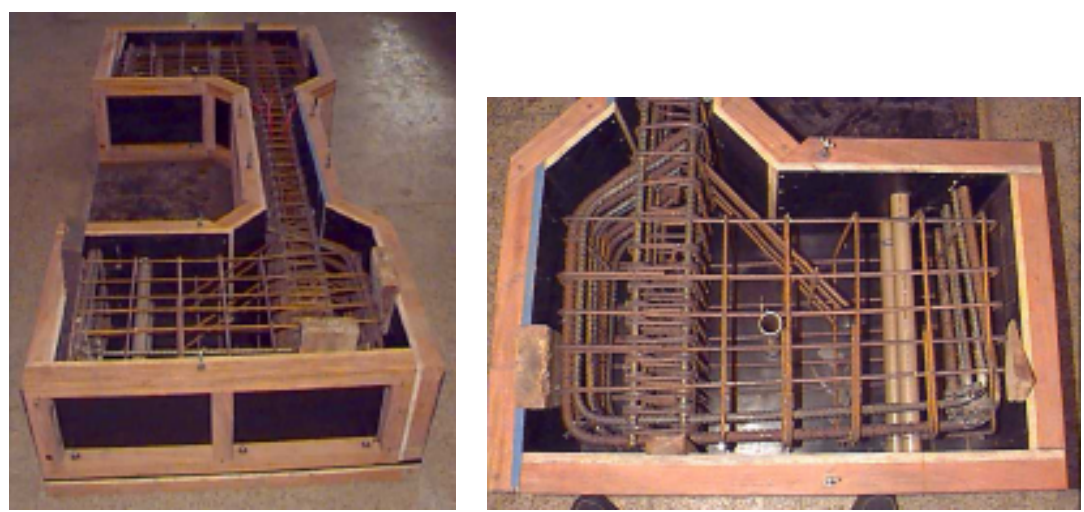

FIGURA 4.17 - Disposição da armadura na fôrma 
De cada mistura foram moldados 11 corpos-de-prova cilíndricos $(10 \mathrm{~cm} \times 20 \mathrm{~cm})$, adensados na mesa vibratória, para serem ensaiados como mostra a tabela 4.7 .

TABELA 4.7 - Ensaio dos corpos-de-prova

\begin{tabular}{|c|c|c|c|}
\hline № $\mathbf{C P}$ & № $\mathbf{C P}$ & Idade (dias) & Tipo de Ensaio \\
\hline 1 & 12 & 7 & Compressão \\
\hline 2 & 13 & 7 & Compressão \\
\hline 3 & 14 & 7 & Compressão \\
\hline 4 & 15 & 15 & Compressão \\
\hline 5 & 16 & 15 & Compressão \\
\hline 6 & 17 & 15 & Compressão \\
\hline 7 & 18 & 15 & Tração \\
\hline 8 & 19 & 15 & Tração \\
\hline 9 & 20 & 15 & Tração \\
\hline 10 & 21 & 15 & deformação controlada \\
\hline 11 & 22 & 15 & deformação controlada \\
\hline
\end{tabular}

Após a moldagem, o pilar permaneceu na fôrma durante 7 dias e a cura se deu com uso de manta de espuma embebida em água colocada sobre o pilar. Em seguida era desmoldado e colocado no ambiente do Laboratório até a data do ensaio. A figura 4.18 mostra o pilar após a moldagem.
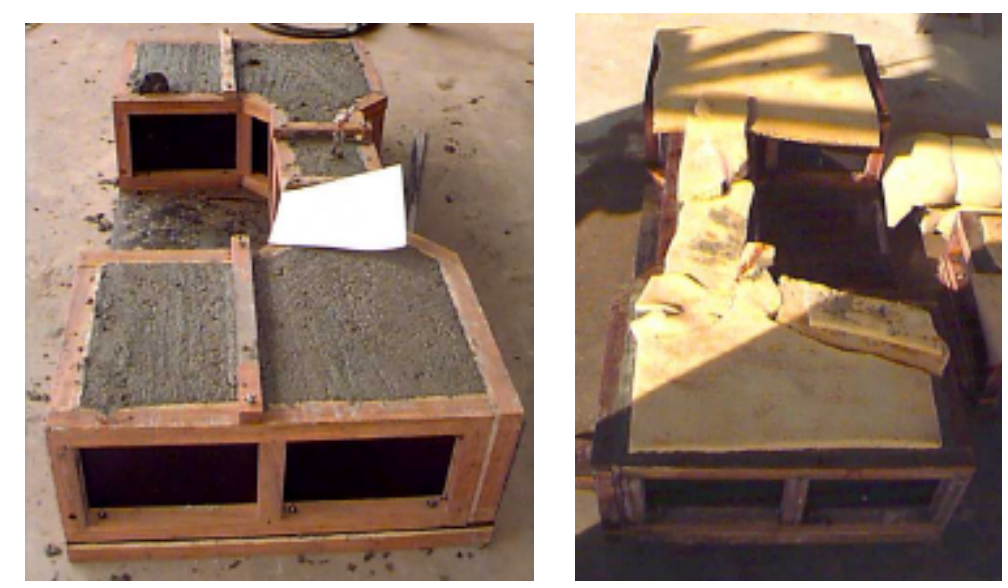

FIGURA 4.18 - Pilar após a concretagem 


\subsection{8 - Instrumentação e procedimentos de ensaio}

A aplicação das forças foi feita por meio de três atuadores hidráulicos, um com capacidade nominal de $5000 \mathrm{kN}$ acionado por bomba elétrica, e os outros dois com capacidade nominal de $300 \mathrm{kN}$ acionados por bomba manual.

As forças foram controladas por células de carga, uma com capacidade de $5000 \mathrm{kN}$ e outras duas com capacidade de $300 \mathrm{kN}$ para medirem as forças aplicadas pelos atuadores de mesma capacidade.

As medidas das deformações e deslocamentos foram feitas por extensômetros elétricos de resistência, e transdutores de deslocamentos à base de extensômetros elétricos de resistência.

As barras das armaduras longitudinal e transversal foram instrumentadas com extensômetro elétrico de resistência KFG 5, onde as barras longitudinais escolhidas foram as quatro centrais e os estribos eram os dois que ficavam na metade da altura do pilar. Inicialmente foram instrumentados os dois estribos na metade da altura do pilar, para se saber o comportamento de um com relação ao outro. Após o ensaio piloto, passouse a instrumentar apenas um estribo, pois percebeu-se que 0 comportamento dos dois eram bem semelhantes, figura 4.19. As quatro barras longitudinais foram escolhidas na região central da seção transversal, pois esperava-se melhor distribuição das tensões nessa região, não se preocupando com eventuais excentricidades que causariam flexão oblíqua.

As deformações no concreto foram medidas com extensômetros elétricos de resistência do tipo KFG 10, posicionados na seção central do pilar, nas faces mais e menos comprimidas. Em cada face foram colocados dois extensômetros no sentido longitudinal do pilar, na mesma posição dos colados nas barras longitudinais, para que se pudessem comparar os resultados. Foram colocados também extensômetros no sentido transversal, para o modelo piloto utilizaram-se dois na face menos comprimida e um na face mais comprimida, nas mesmas posições dos instalados nos estribos. $\mathrm{O}$ motivo de colocar-se dois extensômetros de um lado e um do outro, foi 
comparar os resultados de ambos e definir se seria usado um ou dois extensômetros no sentido transversal do pilar em cada face instrumentada. Após o ensaio do modelo piloto, adotou-se apenas um extensômetro no sentido transversal de cada lado do pilar, como mostra a figura 4.19.

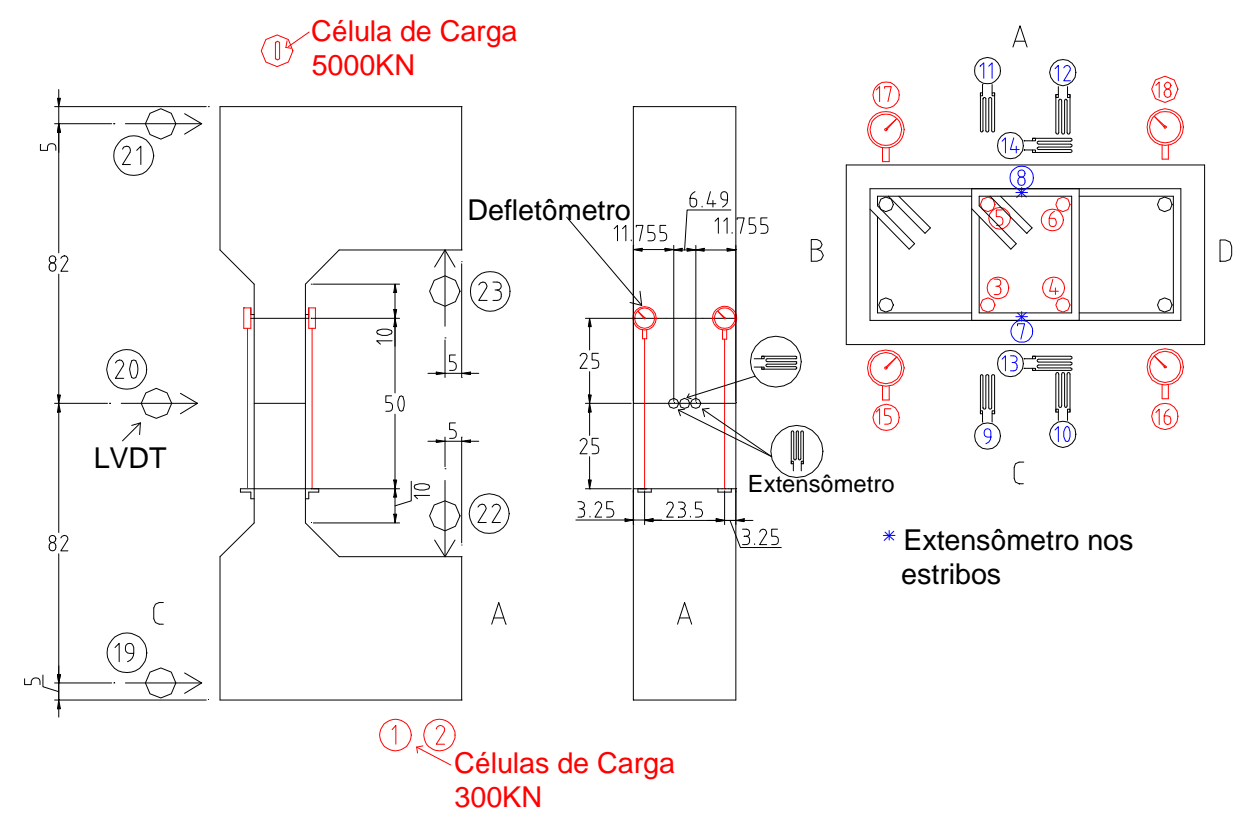

FIGURA 4.19 - Detalhamento da instrumentação do pilar
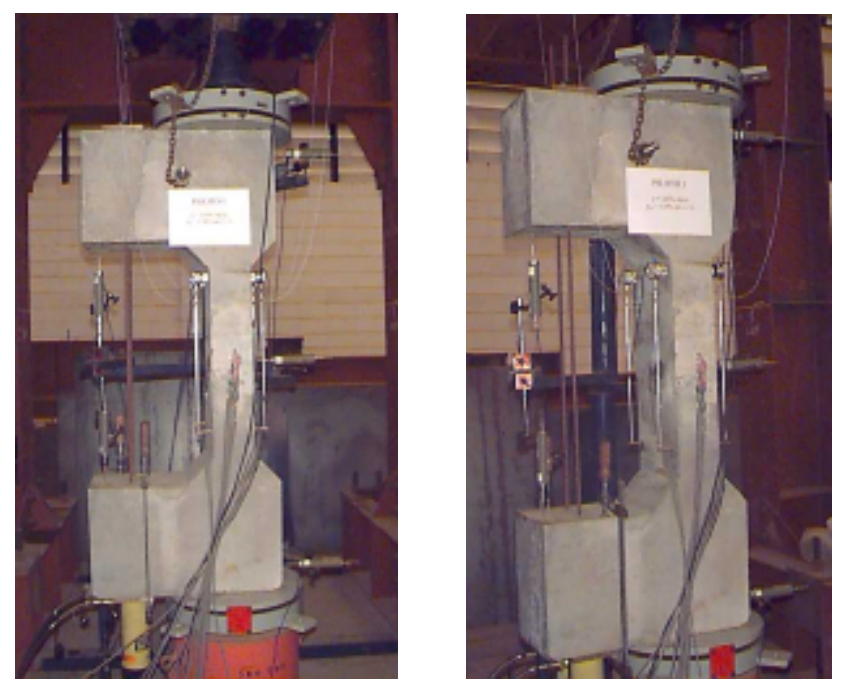

FIGURA 4.20 - Instrumentação do pilar

O deformação do pilar foi medida através de defletômetros com curso de $10 \mathrm{~mm}$, onde a região de estudo foi de $57 \mathrm{~cm}$ no meio do pilar, como mostram as figuras 4.19 e 4.20 . 
Os deslocamentos horizontais na região superior, inferior e no meio do pilar; e os verticais nas extremidades dos consolos foram medidos com transdutores de deslocamentos à base de extensômetros elétricos de resistência, como mostram as figuras 4.19 e 4.20 .

Todas as leituras, em cada etapa do ensaio, foram feitas automaticamente através de um sistema de aquisição de dados, que registrava, em disquete e por meio de impressora, os valores das ações, dos deslocamentos e das deformações. O sistema era controlado por computador e após a execução dos ensaios, os dados gerados eram convertidos em planilha que, posteriormente, era lida e manipulada pelo "software Excel da Microsoft" versão 97, para geração de relatórios e diagramas.

\section{7 - Descrição dos Ensaios Realizados}

Todos os modelos foram submetidos à flexo compressão reta, com dimensões da seção transversal de $15 \mathrm{~cm} \times 30 \mathrm{~cm}$ e altura igual a $174 \mathrm{~cm}$, caracterizando índice de esbeltez igual a 40, excentricidade geométrica constante de $38 \mathrm{~cm}$, resistência à compressão do concreto em torno de $80 \mathrm{MPa}$, e variando as taxas de armaduras longitudinais e transversais.

\subsection{1 - Ensaio piloto}

Após definição da concepção do ensaio, geometria do pilar, armadura do pilar e consolos, equipamentos de vinculação, equipamentos de aplicação de ações e de leitura de dados, moldou-se um modelo piloto para averiguar o seu comportamento e dos equipamentos utilizados.

Para o modelo piloto, escolheu-se o pilar P1/1, que foi moldado no dia 17/06/1998 com previsão de ensaio 15 dias mais tarde. No entanto, houve atraso na programação do Laboratório e o ensaio do modelo foi feito no dia 14/07/1998, com 27 dias de moldagem. 
Devido ao atraso houve mudança na programação dos ensaios dos corpos-de-prova, ficando da seguinte maneira: de cada mistura na betoneira ensaiaram 11 corpos-de-prova de acordo como a tabela 4.8.

TABELA 4.8 - Ensaio dos corpos-de-prova

\begin{tabular}{|c|c|c|c|}
\hline № $\mathbf{C P}$ & № $\mathbf{C P}$ & Idade (dias) & Tipo de Ensaio \\
\hline 1 & 12 & 7 & Compressão \\
\hline 2 & 13 & 7 & Compressão \\
\hline 3 & 14 & 7 & Compressão \\
\hline 4 & 15 & 15 & Compressão \\
\hline 5 & 16 & 15 & Compressão \\
\hline 6 & 17 & 15 & Compressão \\
\hline 7 & 18 & 15 & Tração \\
\hline 8 & 19 & 15 & Tração \\
\hline 9 & 20 & 27 & Compressão \\
\hline 10 & 21 & 27 & Compressão \\
\hline 11 & 22 & 27 & compressão (instrumentado) \\
\hline
\end{tabular}

Assim, foram ensaiados apenas 2 corpos-de-prova à compressão diametral, o terceiro foi transferido para ser ensaiado à compressão no dia do ensaio do pilar; os ensaios com deformação controlada foram suspensos e tais corpos-de-prova foram rompidos no dia do ensaio do pilar, totalizando 3 corpos-de-prova por mistura de concreto, onde um de cada mistura foi instrumentado.

Os corpos-de-prova número 11 e 22 (um de cada mistura na betoneira), foram instrumentados com dois extensômetros colocados diametralmente opostos, para se medir as deformações dos corpos-deprova, e assim, calcular o módulo de elasticidade.

A trabalhabilidade da primeira mistura foi boa, resultando abatimento médio do tronco de cone de $13,2 \mathrm{~cm}$. Para a segunda mistura, o abatimento médio do tronco de cone foi de $18,7 \mathrm{~cm}$, sendo o concreto considerado com boa trabalhabilidade. No entanto, devido à alta quantidade de superplastificante houve uma rápida perda de trabalhabilidade.

Aos 7 dias foi feito a desforma do modelo, onde detectou-se vazios em dois pontos do pilar. O maior problema estava em um vazio de grande 
volume localizado na região central do pilar, pois era a região de observação e onde estavam localizados os extensômetros. Então optou-se por aproveitar o modelo fazendo um enchimento nas regiões de falha com concreto composto por pedrisco, com resistência semelhante à do concreto do pilar. Para isso utilizou-se para dosagem do concreto da restauração, o mesmo estudado na pesquisa que estava em andamento do Departamento de Engenharia de Estruturas, intitulada "Encamisamento com Concreto de Alta Resistência", realizada pelo Eng. Adilson Roberto Takeuti, orientado pelo Professor Titular João Bento de Hanai. O concreto era com pedrisco e previsto para obter resistência de $60 \mathrm{MPa}$ aos 7 dias. Para aumentar a resistência obtida com essa dosagem, modificou-se o fator água/cimento de 0,42 para 0,38 .

O enchimento dos vazios foi feito no mesmo dia da desforma, e foram moldados 6 corpos-de-prova para serem ensaiados à compressão aos 3 e 7 dias e no dia do ensaio, para se ter idéia da resistência do concreto de recuperação. A cura da restauração foi feita com espuma umedecida com água até os 3 dias; depois retirou-se a espuma para instrumentar o pilar.

O pilar piloto foi ensaiado com 27 dias de idade, com resistência média à compressão do concreto de $89,61 \mathrm{MPa}$, sendo que, a resistência média do concreto com pedrisco usado no reforço foi $72,08 \mathrm{MPa}$.

O ensaio foi planejado para aplicação das forças em etapas de $50 \mathrm{kN}$, para a força centrada e $5 \mathrm{kN}$ para a força excêntrica (equivalente a 10\% da força centrada) de forma simultânea, fazendo-se a leitura dos dados a cada etapa, assim que os valores das deformações se apresentassem estáveis. A aplicação simultânea das forças tinham o objetivo de fazer com que o pilar recebesse forças conjuntas e o momento fletor atuasse desde o início do ensaio, procurando-se, assim, reproduzir situação onde as ações atuam simultaneamente e de forma gradual.

Antes do início do ensaio, levou-se a força centrada a $300 \mathrm{kN}$ e a força excêntrica a $30 \mathrm{kN}$ ( $15 \mathrm{kN}$ em cada atuador hidráulico), descarregando os atuadores em seguida para que pudesse ser feito o "escorvamento" do pilar. Nesta etapa, observou-se o comportamento inicial do pilar através das 
leituras dos aparelhos de medição, e constatou-se inicialmente o comportamento esperado, ou seja, uma face mais comprimida que a outra e similar ordem de grandeza das deformações.

Durante a aplicação das forças, observou-se que quando a força centrada alcançou $1450 \mathrm{kN}$ as leituras demoravam a se estabilizarem, e a força centrada sofria um grande decréscimo. Isso pode ser caracterizado como início da ruptura da seção, no entanto, como se trata de uma região recuperada com preenchimento do vazio que existia, não se pode ter a certeza desse comportamento, pois pode ter ocorrido mal adensamento desse preenchimento e isso pode ter provocado perda de aderência da armadura com o concreto.

A ruptura se deu na seção central do pilar, e a força última foi identificada como a soma da força centrada e das forças excêntricas, correspondente às últimas leituras de deformações, resultando $1620 \mathrm{kN}$, $1520 \mathrm{kN}$ da força centrada e $78,3 \mathrm{kN}$ e $75,4 \mathrm{kN}$ para cada força excêntrica.

As armaduras de confinamento colocadas nas extremidades do pilar, bem como os consolos funcionaram perfeitamente, pois não ocorreu ruptura nessas regiões, apenas fissuração do concreto na região de contato da base do pilar.

\subsection{2 - Ensaios da série 1}

Esta série era composta por três pilares e foram denominados $\mathrm{P} 1 / 1$, $\mathrm{P} 1 / 2$ e $\mathrm{P} 1 / 3$. Estes pilares tinham taxa de armadura longitudinal constante de $2,26 \%(8 \phi 12,5 \mathrm{~mm})$, e o objetivo era definir uma taxa de armadura transversal que promoveria confinamento do núcleo para a taxa de armadura longitudinal adotada. Com isso pretendia-se realizar três modelos com três níveis de taxa de confinamento. 


\subsubsection{1 - Ensaio do pilar P1/1}

No pilar P1/1, adotou-se taxa de armadura longitudinal de 2,26\% $(8 \phi 12,5 \mathrm{~mm})$, e transversal de $1,58 \%(\phi 6,3$ cada $5 \mathrm{~cm})$. A concretagem foi feita em 29/07/1998, a temperatura ambiente estava em $26^{\circ} \mathrm{C}$ e a umidade em $35 \%$. Devido à baixa umidade, o concreto apresentou grande dificuldade no adensamento do modelo e dos corpos-de-prova.

Aos 7 dias, o pilar foi desformado e transportado para o pórtico, onde foram colados os extensômetros no concreto e feita toda a instrumentação prevista.

O ensaio foi feito em 13/08/1998. Durante a aplicação das forças, observou-se que após ultrapassar $1600 \mathrm{kN}$, a rótula superior começou a se deformar e o ensaio foi cancelado. Concluiu-se que estava acontecendo uma grande concentração de tensões no centro da rótula, pois a célula de carga tinha um diâmetro de $20 \mathrm{~cm}$ e o diâmetro da rótula era de $57 \mathrm{~cm}$. De imediato, colocou-se uma placa de $5 \mathrm{~cm}$ de espessura entre a rótula e a célula de carga, procurando-se assim distribuir a tensão por espraiamento, mas a espessura da placa era muito pequena e não suportou, deformandose junto com a rótula.

Assim, o ensaio foi cancelado e optou-se por fabricar uma peça com perfis metálicos em forma de cruz e interpô-la entre a rótula e a célula de carga, como mostra a figura 4.21 .

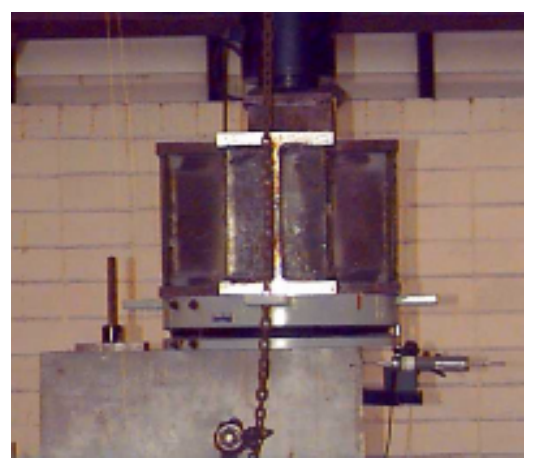

FIGURA 4.21 - Perfil metálico interposto entre a rótula e a célula de carga 
Em 10/09/1998, foi refeito o ensaio, mas quando a força centrada estava em torno de $1800 \mathrm{kN}$, ocorreu vazamento de óleo na mangueira da bomba elétrica, ocasionando perda de pressão e consequentemente de força. Descarregou-se, mais uma vez, o modelo e efetuou-se a troca da mangueira e iniciou-se o ensaio novamente.

Por decorrência da aplicação de forças com grandes intensidade no modelo, ocorreram perdas de alguns extensômetros localizados nas barras das armaduras longitudinais e no concreto, tornando o ensaio do modelo $\mathrm{P} 1 / 1$ prejudicado e descartado da análise efetuada neste trabalho.

Mas, mesmo assim, levou-se o modelo à ruína, que aconteceu a uma força resultante de $3020 \mathrm{kN}$. O concreto no dia do ensaio teve resistência média à compressão de $81 \mathrm{MPa}$. $\mathrm{O}$ modelo teve ruptura pouco dúctil com esmagamento do concreto do lado mais comprimido.

O modelo P1/1 foi refeito com as mesmas características, e denominado P1/1R. Como os outros modelos estavam sendo preparados de acordo com o cronograma experimental, deixou-se esta repetição para o fim dos ensaios.

\subsubsection{2 - Ensaio do pilar P1/1R}

$O$ pilar $\mathrm{P} 1 / 1 \mathrm{R}$, é a repetição do pilar $\mathrm{P} 1 / 1$. Foi o último a ser ensaiado, a concretagem foi em 01/12/1998, quando a temperatura estava em $23^{\circ} \mathrm{C}$ e a umidade do ar estava em $68 \%$. O concreto apresentou boa trabalhabilidade, com abatimento do tronco de cone de $9,5 \mathrm{~cm}$ para a primeira mistura, e $10,5 \mathrm{~cm}$ para a segunda.

Aos 7 dias, o pilar foi desformado e transportado para o pórtico de reação, onde foram colados os extensômetros no concreto e feita toda a instrumentação prevista. $\mathrm{O}$ transporte dos pilares foi feito por meio de uma barra metálica, encaixada no furo previamente deixado na parte superior do pilar, e transportado pela ponte rolante do Laboratório, como mostra a figura 4.22 . 


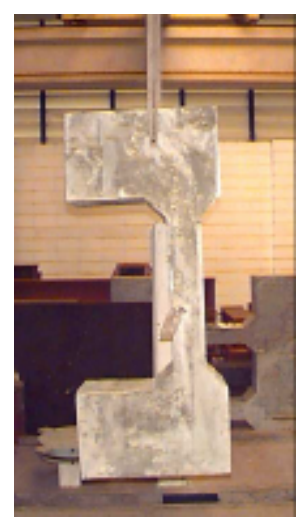

FIGURA 4.22 - Transporte do pilar até o pórtico de reação

O ensaio foi feito em 16/12/1998. Depois de feito o "escorvamento", iniciou-se a aplicação das forças em etapas como descritos para o pilar piloto.

No dia do ensaio, o concreto apresentou resistência característica à compressão de $88,89 \mathrm{MPa}$. A ruptura se deu na seção central do pilar com destacamento do cobrimento de concreto do lado mais comprimido, como mostra a figura 4.23. A ação resultante foi de $3.157 \mathrm{kN}$, onde $156 \mathrm{kN}$ eram provenientes das forças excêntricas.

As armaduras de confinamento colocadas nas extremidades do pilar, mostraram novamente perfeita eficiência.
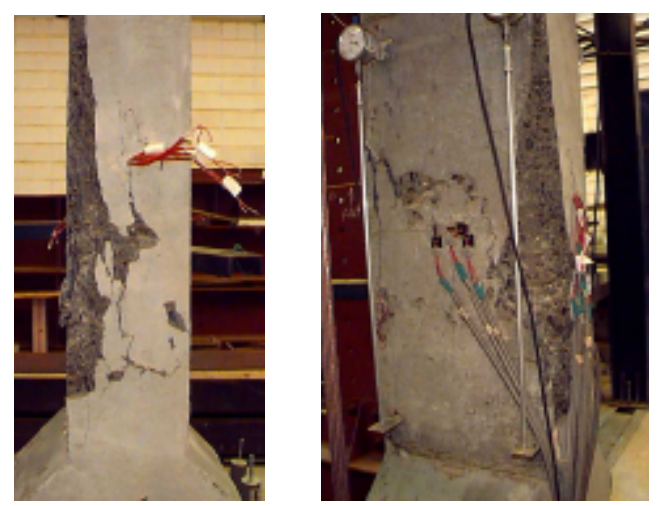

FIGURA 4.23 - Forma de ruptura do pilar P1/1R

\subsubsection{3 - Ensaio do pilar P1/2}

No pilar P1/2, diminuiu-se a taxa da armadura transversal em relação ao $\mathrm{P} 1 / 1$, adotaram-se as seguintes características: taxa de armadura 
longitudinal de $2,26 \%(8 \phi 12,5 \mathrm{~mm})$, e transversal de $0,79 \%(\phi 6,3$ cada $10 \mathrm{~cm})$.

A concretagem foi feita em 09/09/1998, com temperatura ambiente de $18^{\circ} \mathrm{C}$ e umidade do ar de $83 \%$. O concreto apresentou boa trabalhabilidade, com abatimento do tronco de cone de $14,5 \mathrm{~cm}$ para a primeira mistura, e de $14,3 \mathrm{~cm}$ para a segunda.

O pilar foi desformado aos 7 dias e posicionado no pórtico de reação para instrumentação.

O ensaio foi feito em 24/09/1998, quando o concreto tinha resistência média à compressão de 85,68MPa.

As forças conjuntas foram aplicadas simultaneamente até a ruptura, que se deu na seção central do pilar, com destacamento do cobrimento de concreto na face mais comprimida, como mostra a figura 4.24. A ruptura aconteceu com ação resultante de $2.825,8 \mathrm{kN}$, onde $125,8 \mathrm{kN}$ são provenientes das forças excêntricas.
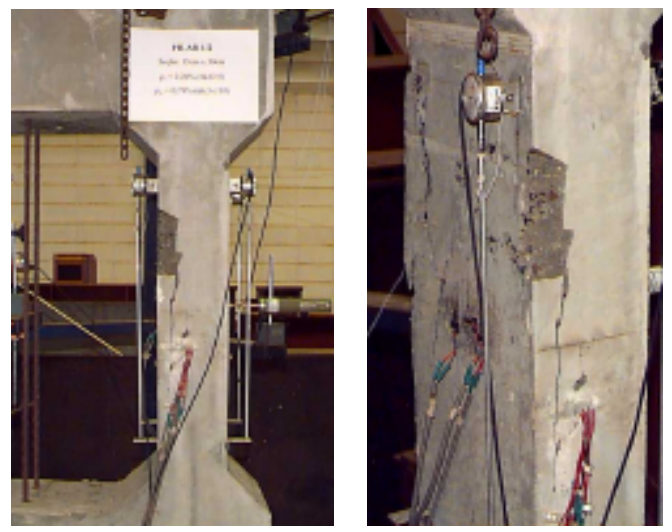

FIGURA 4.24 - Forma de ruptura do pilar P1/2

\subsubsection{4 - Ensaio do pilar P1/3}

O pilar $\mathrm{P} 1 / 3$, teve aumentado ainda mais o espaçamento dos estribos, diminuindo assim a taxa da armadura transversal em relação ao modelo $\mathrm{P} 1 / 1$, tendo as seguintes características: taxa de armadura longitudinal de $2,26 \%(8 \phi 12,5 \mathrm{~mm})$, e transversal de $0,53 \%$ ( $\phi 6,3$ cada $15 \mathrm{~cm})$. 
A concretagem foi feita em 17/09/1998, com temperatura ambiente de $25^{\circ} \mathrm{C}$ e umidade do ar de $74 \%$. O concreto apresentou boa trabalhabilidade, com abatimento do tronco de cone de $12 \mathrm{~cm}$ para a primeira mistura, e de $10 \mathrm{~cm}$ para a segunda.

O ensaio foi feito em 02/10/1998, quando o concreto tinha resistência média à compressão de 82,61MPa.

As forças foram aplicadas até a ruptura, que se deu na seção central do pilar. Com esta taxa de armadura transversal, teve-se ruptura frágil da seção transversal e ruptura do estribo central maior, não sendo suficiente para provocar o confinamento do núcleo do pilar figura 4.25. A ruptura aconteceu com ação resultante de $2.967,8 \mathrm{kN}$, das quais $117,8 \mathrm{kN}$ provém das forças excêntricas.
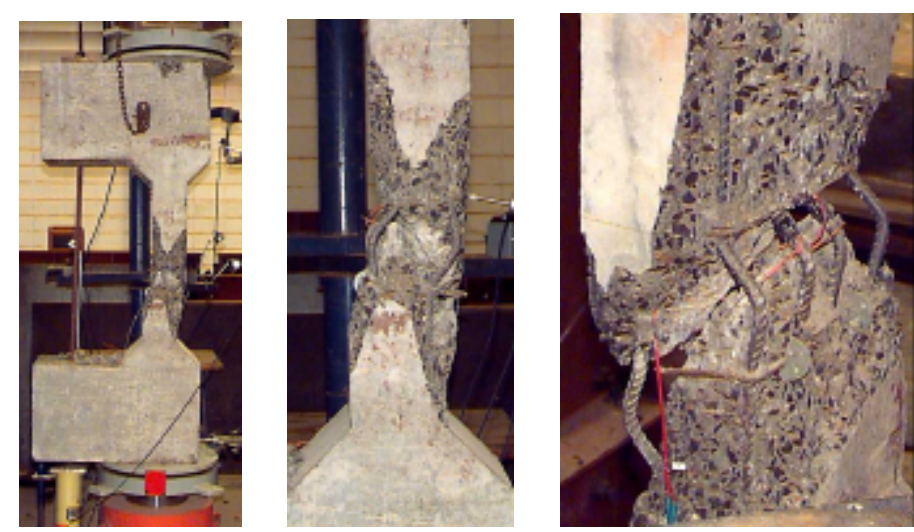

FIGURA 4.25 - Forma de ruptura do pilar P1/3

\subsection{3 - Ensaios da série 2}

A série 2 era composta por dois pilares e foram denominados $\mathrm{P} 2 / 1 \mathrm{e}$ $\mathrm{P} 2 / 2$. Estes pilares apresentavam taxa de armadura longitudinal constante de $1,26 \%(8 \phi 10 \mathrm{~mm})$. Esta série tinha o objetivo de diminuir a taxa de armadura longitudinal utilizada na série 1, e testar as taxas de armaduras transversais que apresentaram melhor desempenho, no que se refere ao confinamento do núcleo, obtidas nos ensaios da série 1. Com isso pretendiase realizar dois modelos com duas taxas de confinamento. 


\subsubsection{1 - Ensaio do pilar P2/1}

No pilar P2/1, adotaram-se as seguintes características: taxa de armadura longitudinal de $1,26 \%(8 \phi 10 \mathrm{~mm})$, e transversal de $0,79 \%(\phi 6,3$ cada $10 \mathrm{~cm})$.

A concretagem foi feita em 15/10/1998, com temperatura ambiente de $21^{\circ} \mathrm{C}$ e umidade do ar de $77 \%$. O concreto apresentou boa trabalhabilidade, com abatimento do tronco de cone de $12 \mathrm{~cm}$ para a primeira mistura, e de $14,5 \mathrm{~cm}$ para a segunda.

O ensaio foi feito em 30/10/1998, onde o concreto teve resistência média à compressão de 90,07MPa.

As forças foram aplicadas até a ruptura, que se deu na seção central do pilar. Com esta taxa de armadura transversal não se teve confinamento suficiente do núcleo do pilar, ocasionando ruptura frágil com destruição da seção transversal, como mostra a figura 4.26. Logo, comparando-se com o pilar $\mathrm{P} 1 / 2$, para uma taxa de armadura longitudinal menor, era necessário uma maior taxa de confinamento. A ruptura aconteceu com ação resultante de $2.788,9 \mathrm{kN}$, das quais $189,9 \mathrm{kN}$ provém das forças excêntricas.
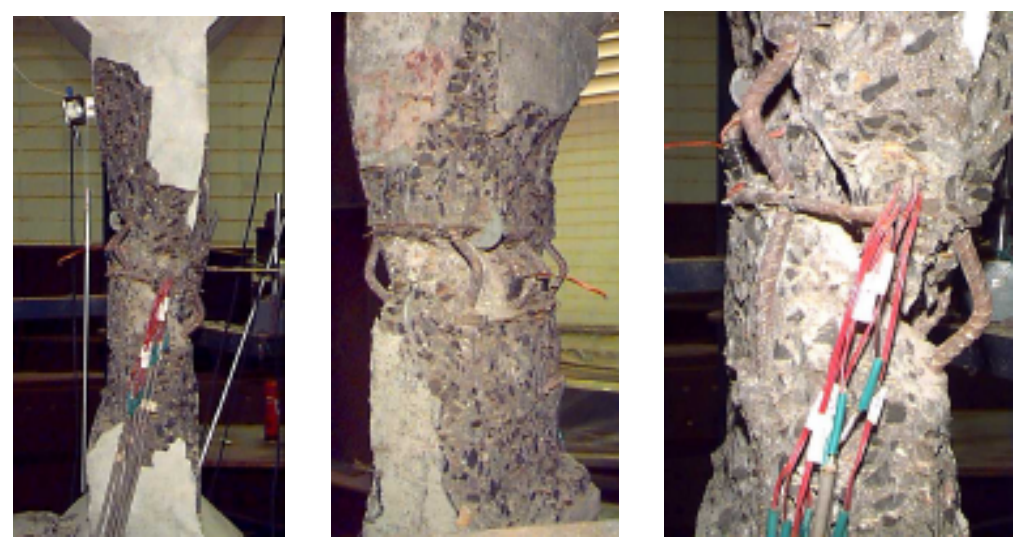

FIGURA 4.26 - Forma de ruptura do pilar P2/1

\subsubsection{2 - Ensaio do pilar P2/2}

Como o pilar P2/1 não apresentou bom confinamento do núcleo, adotou-se uma maior taxa de confinamento para o pilar P2/2, que tinham as 
seguintes características: taxa de armadura longitudinal de 1,26\% (8ф10mm), e transversal de 1,58\% ( $\phi 6,3$ cada $5 \mathrm{~cm})$.

A concretagem foi feita em 12/11/1998, com temperatura ambiente de $20^{\circ} \mathrm{C}$ e umidade do ar de $57 \%$. O concreto apresentou boa trabalhabilidade, com abatimento do tronco de cone de $12 \mathrm{~cm}$ para a primeira mistura, e de $17 \mathrm{~cm}$ para a segunda.

O ensaio foi feito em $27 / 11 / 1998$, quando o concreto tinha resistência média à compressão de 89,61MPa.

As forças foram aplicadas até a ruptura, que se deu na seção central do pilar com destacamento do cobrimento de concreto na face mais comprimida, figura 4.27. Logo, comparando-se com o pilar P2/2, a taxa de confinamento de 1,58\% combinada com a taxa de armadura longitudinal de $1,26 \%$, foi suficiente para oferecer um confinamento do núcleo do pilar. A ruptura aconteceu com ação resultante de $2.902,2 \mathrm{kN}$, das quais $153,2 \mathrm{kN}$ provém das forças excêntricas.
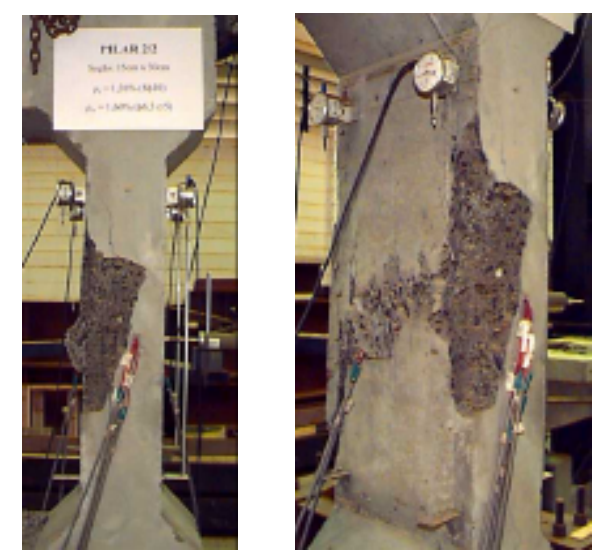

FIGURA 4.27 - Forma de ruptura do pilar P2/2

\subsection{4 - Ensaios da série 3}

A série 3 era composta por apenas um pilar e foi denominado P3/1. Este pilar apresentava taxa de armadura longitudinal de 3,45\% (8ф16mm). Esta série teve o objetivo de aumentar a taxa de armadura longitudinal utilizada na série 1, e testar as taxas de confinamento que apresentaram melhor desempenho, obtidas nos ensaios das séries 1 e 2. 


\subsubsection{1 - Ensaio do pilar P3/1}

No pilar P2/1, adotaram-se as seguintes características: taxa de armadura longitudinal de 3,45\% ( $8 \phi 16 \mathrm{~mm})$, e transversal de 0,79\% $(\phi 6,3$ cada $10 \mathrm{~cm})$.

A concretagem foi feita em 22/10/1998, com temperatura ambiente de $22^{\circ} \mathrm{C}$ e umidade do ar de $60 \%$. O concreto apresentou boa trabalhabilidade, com abatimento do tronco de cone de $12,33 \mathrm{~cm}$ para a primeira mistura, e de $14,5 \mathrm{~cm}$ para a segunda.

O ensaio foi feito em 09/11/1998, onde o concreto teve resistência média à compressão de 87,41MPa.

As forças foram aplicadas até a ruptura, que se deu na seção central do pilar com destacamento do cobrimento de concreto na face mais comprimida, como mostra a figura 4.28. A ruptura aconteceu com ação resultante de $3.307,6 \mathrm{kN}$, das quais $157,6 \mathrm{kN}$ advém das forças excêntricas.
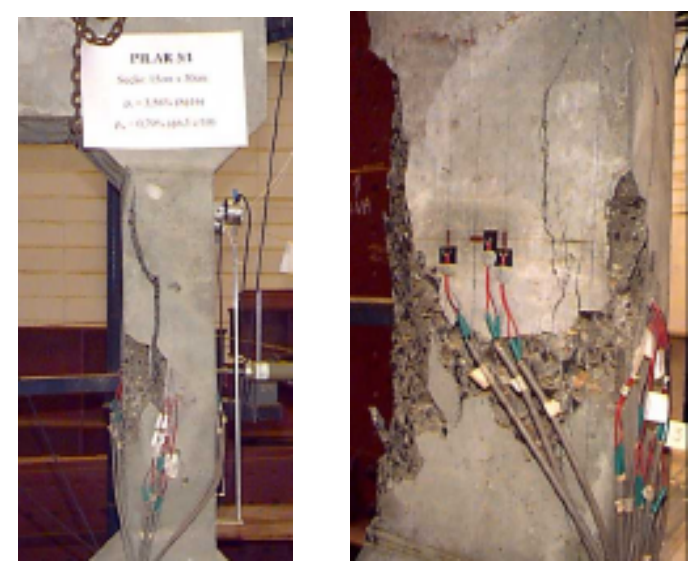

FIGURA 4.28 - Forma de ruptura do pilar P3/1 


\section{8 - Considerações Finais}

Este capítulo mostrou todo o procedimento utilizado para realizar os ensaios dos modelos, como: a concepção do ensaio, materiais utilizados, instrumentação, detalhes de execução do ensaio, etc.

Foram encontradas varias dificuldades para realizar estes ensaios, como:

> Preparo da mistura de concreto, que além do grande volume, depois de pronta perdia com rapidez a trabalhabilidade, tendo que ter boa agilidade na concretagem para não perder o material. Tinhase também variação da trabalhabilidade em função da temperatura e umidade relativa do ar;

> Preparo da armadura, que em principio era muito trabalhosa, levando-se próximo de uma semana para concluir um modelo. Com o tempo, teve-se mais facilidade para preparar a amadura, devido experiência adquirida com os primeiros modelos, levando-se três dias para conclusão desta etapa;

> Colocação do modelo na estrutura de reação, que necessitava grande mão-de-obra e cuidado;

> Ocorreram problemas com o modelo piloto com moldagem, aparecendo vazio na região de estudo do pilar;

> O aparelho de apoio apresentou grandes deformações quando a força foi aplicada diretamente sobre ele, sendo necessário a fabricação de uma peça metálica que servia para distribuir a força por toda a área do apoio, levando-se 20 dias para conclusão desta etapa. 
RESULTADOS OBTIDOS

\section{1- Considerações Iniciais}

São apresentadas, neste capítulo, as características mecânicas de todos os pilares ensaiados. Em seguida, são relacionados para cada pilar, os valores das forças últimas experimentais, centradas e excêntricas, e as deformações correspondentes às forças últimas. Foram desenhadas, a partir dos dados obtidos através do sistema de aquisição de dados, diagramas que relacionam as forças aplicadas nos pilares com as deformações e os deslocamentos.

\section{2- Determinação das Características Mecânicas do Concreto}

\subsection{1- Resistência à compressão}

A resistência média à compressão dos corpos-de-prova de concreto correspondentes a todos os pilares ensaiados, são mostrados na tabela 5.1.

TABELA 5.1 - Resistência à compressão do concreto

\begin{tabular}{|c|c|c|}
\hline Pilar & $\begin{array}{c}\text { Idade } \\
\text { (dias) }\end{array}$ & $\begin{array}{c}\text { Tensão de Ruptura } \\
\text { (MPa) }\end{array}$ \\
\hline \multirow{3}{*}{ Piloto } & 7 & 71,03 \\
\cline { 2 - 3 } & 15 & 75,28 \\
\cline { 2 - 3 } & 27 & 89,61 \\
\hline \multirow{2}{*}{ P1/1 } & 7 & 59,59 \\
\cline { 2 - 3 } & 15 & 81,00 \\
\hline \multirow{2}{*}{ P1/1R } & 7 & 75,86 \\
\cline { 2 - 3 } & 15 & 88,89 \\
\hline \multirow{2}{*}{ P1/2 } & 7 & 77,71 \\
\cline { 2 - 3 } & 15 & 85,68 \\
\hline
\end{tabular}

\begin{tabular}{|c|c|c|}
\hline Pilar & $\begin{array}{c}\text { Idade } \\
\text { (dias) }\end{array}$ & $\begin{array}{c}\text { Tensão de Ruptura } \\
\text { (MPa) }\end{array}$ \\
\hline \multirow{2}{*}{ P1/3 } & 7 & 73,25 \\
\cline { 2 - 3 } & 15 & 82,61 \\
\hline \multirow{2}{*}{ P2/1 } & 7 & 74,82 \\
\cline { 2 - 3 } & 15 & 90,07 \\
\hline \multirow{2}{*}{ P2/2 } & 7 & 76,84 \\
\cline { 2 - 3 } & 15 & 89,61 \\
\hline \multirow{2}{*}{ P3/1 } & 7 & 73,17 \\
\cline { 2 - 3 } & 15 & 87,41 \\
\hline
\end{tabular}


O crescimento da resistência à compressão do concreto com o tempo, pode ser visto na figura 5.1 .

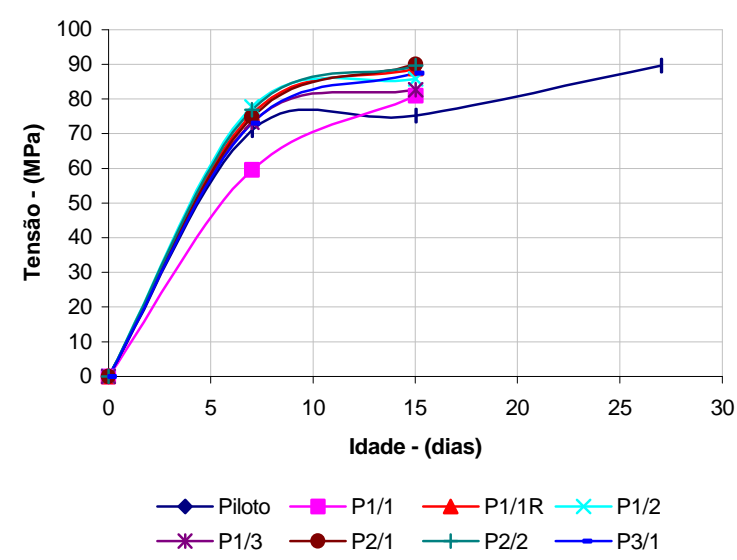

FIGURA 5.1 - Crescimento da resistência à compressão

Os resultados das resistências à compressão do concreto usado na recuperação feita no pilar piloto foi:

TABELA 5.2 - Resistência à compressão do concreto usado no reforço

\begin{tabular}{|c|c|}
\hline $\begin{array}{c}\text { Idade } \\
\text { (dias) }\end{array}$ & $\begin{array}{c}\text { Tensão de Ruptura } \\
\text { (MPa) }\end{array}$ \\
\hline 3 & 56,67 \\
\hline 7 & 67,17 \\
\hline 15 & 72,09 \\
\hline
\end{tabular}

\subsection{2- Resistência àtração}

A resistência à tração foi determinada pelo ensaio de compressão diametral dos corpos-de-prova cilíndricos moldados durante a concretagem dos pilares.

O ensaio dos corpos-de-prova das duas misturas, foram feito com 15 dias de idade, onde a média dos resultados de cada pilar estão na tabela 5.3 .

TABELA 5.3 - Resistência à tração do concreto

\begin{tabular}{|c|c|}
\hline Pilar & $\begin{array}{c}\text { Tensão de Ruptura } \\
\text { (MPa) }\end{array}$ \\
\hline Piloto & 5,25 \\
\hline $\mathrm{P} 1 / 1$ & 5,17 \\
\hline $\mathrm{P} 1 / 1 \mathrm{R}$ & 4,52 \\
\hline $\mathrm{P} 1 / 2$ & 5,42 \\
\hline $\mathrm{P} 1 / 3$ & 4,75 \\
\hline $\mathrm{P} 2 / 1$ & 4,72 \\
\hline $\mathrm{P} 2 / 2$ & 5,20 \\
\hline $\mathrm{P} 3 / 1$ & 4,64 \\
\hline
\end{tabular}




\subsection{3- Módulo de deformação longitudinal}

O módulo de deformação longitudinal, foi obtido a partir dos ensaios feitos em corpos-de-prova cilíndricos submetidos à compressão axial, com deformação controlada. Exceto para dois modelos, o piloto e o P1/1R, onde seus corpos-de-prova foram ensaiados na prensa com controle apenas da força. Estes foram instrumentados com dois extensômetros de resistência, diametralmente opostos no sentido longitudinal, e as deformações nos extensômetros foram lidas por meio de equipamento de aquisição de dados.

Os ensaios de compressão axial com deformação controlada foram feitos no Laboratório de Mecânica das Rochas do Departamento de Geotecnia, onde foram ensaiados os corpos-de-prova dos pilares P1/1, P1/2 e P1/3, e no Laboratório de Estruturas do Departamento de Engenharia de Estruturas, onde ensaiavam-se os dos pilares P2/1, P2/2 e P3/1.

Primeiramente dava-se preferência aos ensaios feitos no Laboratório de Mecânica das Rochas, pela precisão do equipamento. No caso de algum empecilho, optava-se pelo uso da máquina INSTRON, do Laboratório de Estruturas, que também apresentava boa precisão, figura 5.2. Caso as duas máquinas estivessem indisponíveis, fazia-se o ensaio apenas com controle da força, que foi o que aconteceu com os corpos-de-prova dos pilares Piloto e P1/1R.
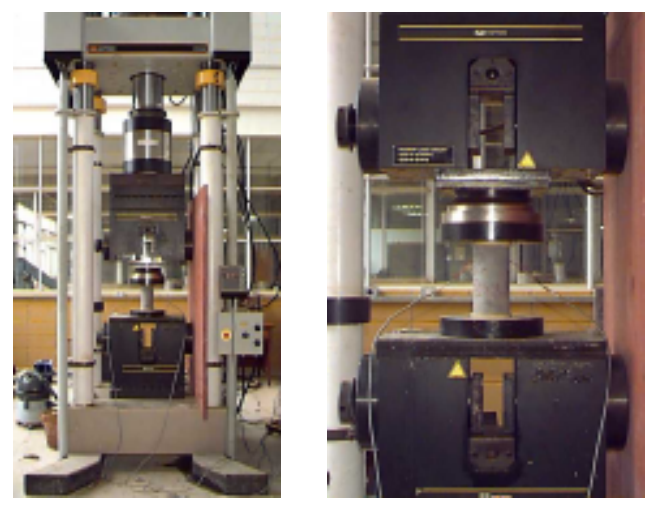

FIGURA 5.2 - Ensaio de compressão axial com deformação controlada 
Com os ensaios de compressão axial dos corpos-de-prova com deformação controlada, foi possível definir também a deformação correspondente a tensão máxima alcançada.

Para traçar o gráfico tensão $x$ deformação do concreto nas faces do pilar, tomou-se a média dos resultados obtidos com a leitura das deformações de dois corpos-de-prova ensaiados. O módulo de deformação longitudinal foi tomado pela inclinação da semi-reta que passava pela origem do gráfico e por um ponto do diagrama relativo a $40 \%$ da resistência última do corpo-de-prova. Os resultados são mostrados na tabela 5.4.

\section{TABELA 5.4 - Módulo de deformação longitudinal e deformação correspondente a tensão máxima do concreto

\begin{tabular}{|c|c|c|}
\hline Pilar & $\begin{array}{c}\varepsilon_{\mathrm{c}} \\
(\%)\end{array}$ & $\begin{array}{c}\mathbf{E}_{\mathbf{c}} \\
(\mathbf{M P a})\end{array}$ \\
\hline Piloto & 2,73 & $43.017,0$ \\
\hline $\mathrm{P} 1 / 1$ & 2,51 & $36.492,0$ \\
\hline $\mathrm{P} 1 / 1 \mathrm{R}$ & 2,61 & $39.728,0$ \\
\hline $\mathrm{P} 1 / 2$ & 2,32 & $41.915,0$ \\
\hline $\mathrm{P} 1 / 3$ & 2,31 & $41.797,0$ \\
\hline $\mathrm{P} 2 / 1$ & 2,35 & $41.931,0$ \\
\hline $\mathrm{P} 2 / 2$ & 2,49 & $45.988,0$ \\
\hline $\mathrm{P} 3 / 1$ & 2,39 & $41.645,0$ \\
\hline
\end{tabular}

Em resumo, as características mecânicas do concreto utilizados nos pilares ensaiados podem ser vistas na tabela 5.5.

TABELA 5.5 - Características mecânicas do concreto

\begin{tabular}{|c|c|c|c|c|}
\hline Pilar & $\begin{array}{c}\mathbf{f}_{\mathrm{c} 15} \\
(\mathbf{M P a})\end{array}$ & $\begin{array}{c}\mathbf{f}_{\text {t15 }} \\
(\mathbf{M P a})\end{array}$ & $\begin{array}{c}\boldsymbol{\varepsilon}_{\mathrm{c}} \\
(\%)\end{array}$ & $\begin{array}{c}\mathbf{E}_{\mathrm{c}} \\
(\mathbf{M P a})\end{array}$ \\
\hline Piloto & 89,61 & 5,25 & 2,73 & $43.017,0$ \\
\hline $\mathrm{P} 1 / 1$ & 81,00 & 5,17 & 2,51 & $36.492,0$ \\
\hline $\mathrm{P} 1 / 1 \mathrm{R}$ & 88,89 & 4,52 & 2,61 & $39.728,0$ \\
\hline $\mathrm{P} 1 / 2$ & 85,68 & 5,42 & 2,32 & $41.915,0$ \\
\hline $\mathrm{P} 1 / 3$ & 82,61 & 4,75 & 2,31 & $41.797,0$ \\
\hline $\mathrm{P} 2 / 1$ & 90,07 & 4,72 & 2,35 & $41.931,0$ \\
\hline $\mathrm{P} 2 / 2$ & 89,61 & 5,20 & 2,49 & $45.988,0$ \\
\hline $\mathrm{P} 3 / 1$ & 87,41 & 4,64 & 2,39 & $41.645,0$ \\
\hline
\end{tabular}

\section{3- Resultados dos Ensaios dos Pilares}

A tabela 5.6 apresenta os valores das forças máximas centradas e excêntricas, bem como as deformações correspondentes a tais força, lidas nas armaduras longitudinais. 
O momento experimental $\left(M_{\text {exp. }}\right)$ foi tomado igual à força máxima excêntrica vezes a excentricidade geométrica de $38 \mathrm{~cm}$. A força máxima excêntrica $\left(F_{\text {exc. }}\right)$, resulta da soma das duas forças aplicadas na extremidade do consolo no momento da ruptura.

A força máxima centrada $\left(F_{\text {exp. }}\right)$, resulta da soma da força máxima excêntrica com a força máxima aplicada no eixo longitudinal do pilar. Considerou-se que a força aplicada excentricamente, encaminhou-se para o segmento de pilar de $70 \mathrm{~cm}$ de altura, atuando de forma conjunta com a força aplicada no eixo longitudinal.

Os pilares Piloto e P1/1 foram excluídos da análise dos resultados em função da grande quantidade de problemas que aconteceram durante sua execução (comentado no capítulo 4), não sendo possível aquisição de dados confiáveis para este modelo.

TABELA 5.6 - Deformações, força centrada e excêntrica de ruptura e momento experimental de ruptura

\begin{tabular}{|c|c|c|c|c|c|}
\hline Pilar & $\begin{array}{c}\varepsilon_{\text {s1 }} \\
(\% \circ)\end{array}$ & $\begin{array}{c}\varepsilon_{\text {s2 }} \\
(\%)\end{array}$ & $\begin{array}{c}\mathbf{F}_{\text {exp. }} \\
(\mathbf{M P a})\end{array}$ & $\begin{array}{c}\mathbf{F}_{\text {exc. }} \\
(\mathbf{M P a})\end{array}$ & $\begin{array}{c}\mathbf{M}_{\text {exp. }} \\
(\mathbf{M P a})\end{array}$ \\
\hline $\mathrm{P} 1 / 1 \mathrm{R}$ & 1,402 & 2,983 & $3.157,0$ & 156,0 & $5.928,0$ \\
\hline $\mathrm{P} 1 / 2$ & 1,374 & 2,354 & $2.825,8$ & 125,8 & $4.780,4$ \\
\hline $\mathrm{P} 1 / 3$ & 2,481 & 2,481 & $2.967,8$ & 117,8 & $4.476,4$ \\
\hline $\mathrm{P} 2 / 1$ & 1,2905 & 2,524 & $2.788,9$ & 189,9 & $7.216,2$ \\
\hline $\mathrm{P} 2 / 2$ & 1,407 & 2,292 & $2.902,2$ & 153,2 & $5.821,6$ \\
\hline $\mathrm{P} 3 / 1$ & 1,3705 & 2,922 & $3.307,6$ & 157,6 & $5.988,8$ \\
\hline
\end{tabular}

A partir dos dados adquiridos através do sistema de aquisição de dados durante o ensaio do pilar, foram montados diagramas relacionando a força total aplicada, ou seja, a soma da força aplicada no eixo longitudinal e a força aplicada excentricamente, com as deformações lidas nas armaduras longitudinais e transversais, no concreto, e no pilar; também foi relacionada com os deslocamentos do pilar.

As posições dos pontos instrumentados dos pilares são mostrados na figura 5.3. Os diagramas dos gráficos são identificados nas respectivas legendas. 

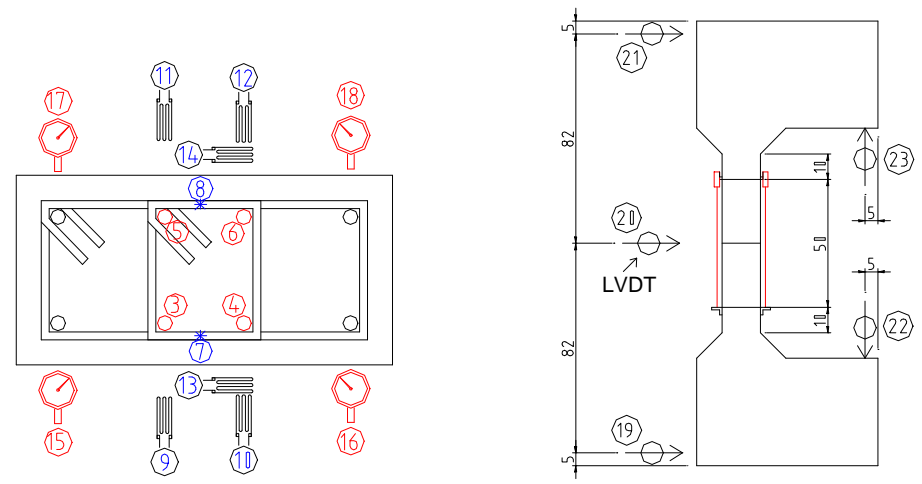

FIGURA 5.3 - Posições dos pontos instrumentados

Para facilitar, ressalta-se que para todos os gráficos que relacionam força $x$ deformação, as cores lilás e azul escuro representam os pontos instrumentados do lado menos comprimido, enquanto que as cores vermelha e azul claro representam pontos instrumentados do lado mais comprimido.

Os gráficos expostos neste capítulo, foram apresentados de forma mais reduzida, para melhor organização e facilidade de leitura do texto. $\mathrm{Na}$ necessidade de melhor visualização dos gráficos, todos estão apresentados em maior escala no apêndice desta dissertação.

\subsection{1- Ensaios da série 1}

\subsubsection{1- Ensaio do pilar P1/1R}

Os comportamentos das barras das armaduras longitudinais podem ser vistos com o diagrama força $x$ deformação apresentado na figura 5.4. Os canais 3 e 4 mediam as deformações nas armaduras do lado menos comprimido, enquanto que os canais 5 e 6 mediam as deformações nas armaduras do lado mais comprimido.

Observou-se que as deformações das armaduras foram de acordo com o esperado, onde as duas barras instrumentadas, do lado menos comprimido, apresentaram deformações bem próximas e de pequena intensidade, enquanto que as barras instrumentadas do lado mais comprimido, apresentaram deformações bem próximas mas com grande intensidade, caracterizando assim, caso de flexo compressão reta com 
pequena excentricidade. Observou-se também que os canais 3 e 4 apresentaram leituras quase que idênticas, o mesmo aconteceu com os canais 5 e 6, notando-se assim um efeito muito pequeno, ou quase nulo, de flexão oblíqua.

A deformação média das barras da armadura, do lado mais comprimido do pilar P1/1R, correspondente a força última, foi 2,98\%.

O diagrama força $x$ deformação medida nas faces do pilar, ou seja no concreto, estão coerentes pois os dois pontos instrumentados do lado menos comprimido apresentaram deformações quase idênticas e de pequena intensidade, enquanto que os dois pontos instrumentados do lado mais comprimido apresentaram deformações similares mas com grande intensidade, caracterizando assim caso de flexo compressão reta com pequena excentricidade, concordando com o que apresentou as armaduras longitudinais.

Foi instrumentado também o estribo maior localizado na metade da altura do pilar. Os resultados das deformações estão apresentados pelos diagramas força $x$ deformação das armaduras transversais mostrados na figura 5.4 .

As deformações do pilar foram medidas através de defletômetros para comprimentos de $57 \mathrm{~cm}$. Os resultados podem ser vistos no diagrama força $x$ deformação do pilar, figura 5.4, onde pelo exposto, o canal 18 apresentou uma acomodação no início do ensaio, deslocando as deformações para esquerda, tornando o diagrama com falha em comparação com o canal 17.

Os deslocamentos horizontais da parte inferior, central e superior do pilar, foram lidas pelos canais 19, 20 e 21 respectivamente, de acordo com 0 esquema da figura 5.3. O diagrama força $x$ deslocamentos é mostrado na figura 5.4 .

Em todos os diagramas do pilar P1/1R, detectou-se uma mudança na inclinação da curva quando a força estava próxima de $1800 \mathrm{kN}$, que correspondia a aproximadamente $57 \%$ da força máxima alcançada pelo pilar. 


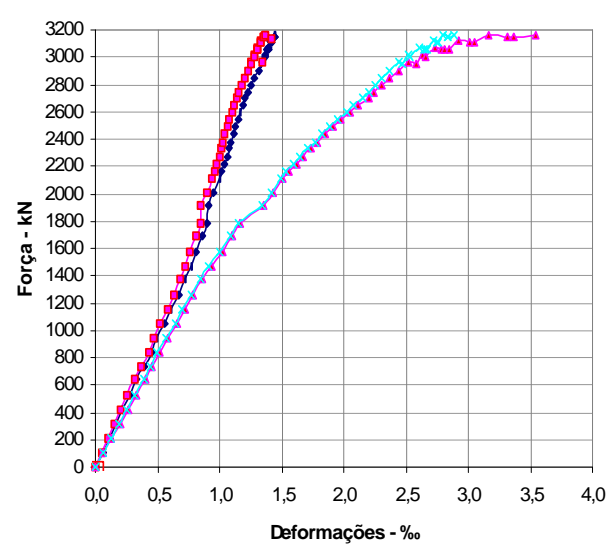

Diagrama força $x$ deformação na armadura longitudinal

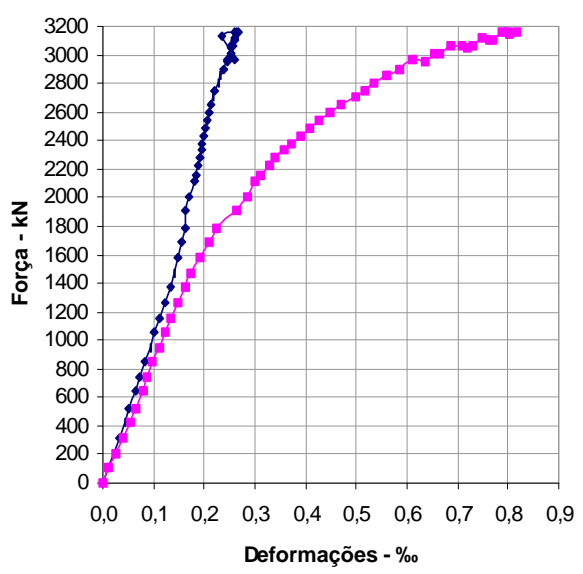

Diagrama força $x$ deformação na armadura transversal

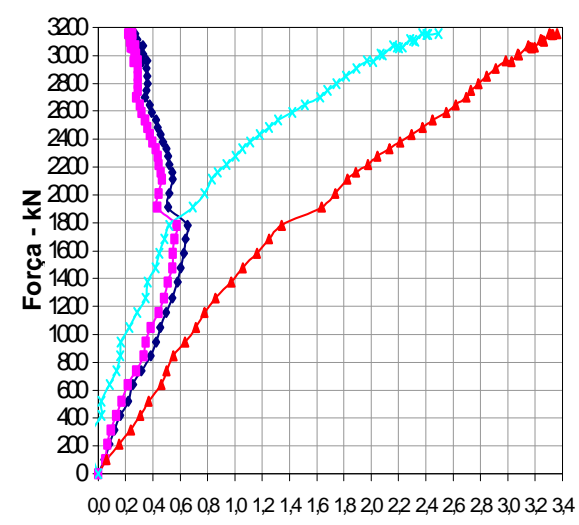

Deformeção-\%。

Diagrama força $\mathbf{x}$ deformação do pilar

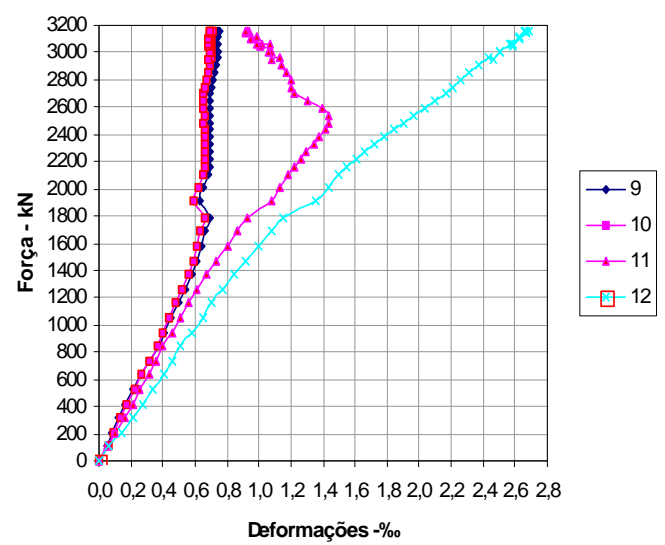

Diagrama força $x$ deformação longitudinal no concreto

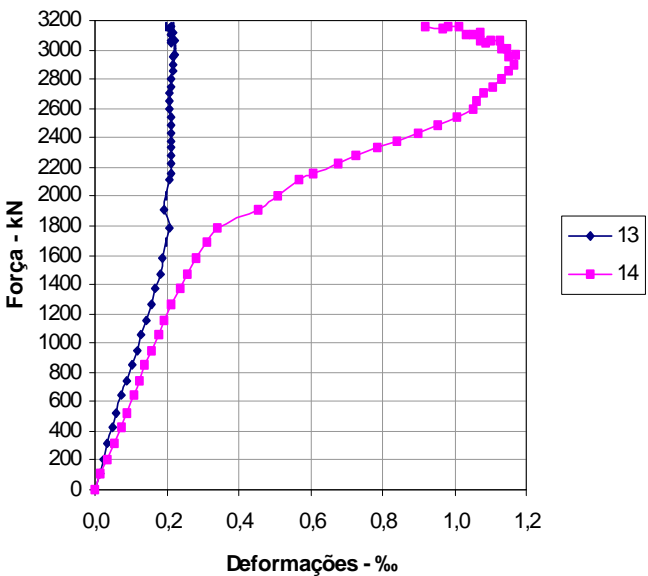

Diagrama força $x$ deformação transversal no concreto

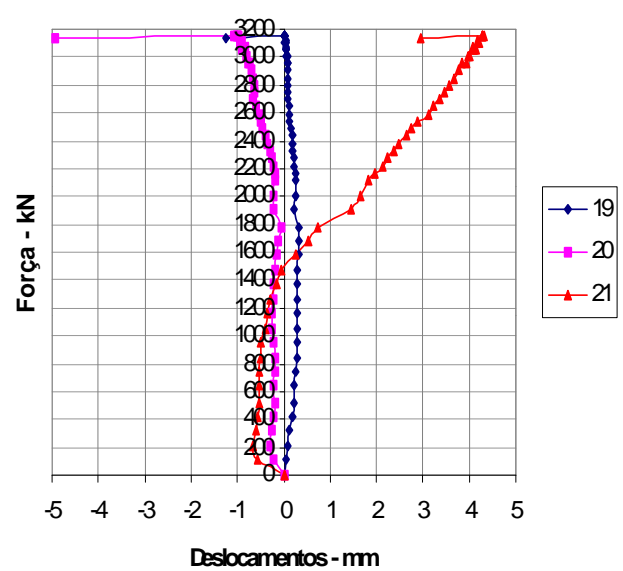

Diagrama força $\mathrm{x}$ deslocamento do pilar 


\subsubsection{2- Ensaio do pilar P1/2}

A figura 5.5 traz o diagrama força x deformação das barras da armadura longitudinal. Observou-se que o comportamento das barras da armadura foi semelhante ao diagrama do pilar P1/1R.

A deformação média das barras da armadura, do lado mais comprimido do pilar $\mathrm{P} 1 / 2$, correspondente a força última, foi $2,35 \%$.

O diagrama força $\mathrm{x}$ deformação medida no concreto das faces do pilar, apresentou deformações coerentes com as deformações das barras da armadura. Os dois extensômetros apresentaram deformações compatíveis até o fim do ensaio.

Os diagramas do pilar P1/2, também apresentaram uma pequena descontinuidade na curva quando a força estava próxima de $1400 \mathrm{kN}$, que correspondia a aproximadamente $50 \%$ da força máxima alcançada pelo pilar.

\subsubsection{3- Ensaio do pilar P1/3}

A figura 5.6 apresenta o diagrama força $x$ deformação das barras da armadura longitudinal. Observou-se que a flexão oblíqua, esperada neste tipo de ensaio, teve efeito mínimo, como aconteceu nos pilares anteriores.

A deformação média das barras da armadura, do lado mais comprimido do pilar $\mathrm{P} 1 / 3$, correspondente a força última, foi $2,48 \%$.

O diagrama força $x$ deformação medida no concreto das faces do pilar, apresentou pequena excentricidade acidental, evidenciando pequenos efeitos da flexão oblíqua, o que não foi observado no diagrama das barras da armadura. Neste caso, foi preferível confiar nas leituras das deformações das barras, devido aos vários problemas aos quais os extensômetros colados nas faces do pilar estão propensos.

Os diagramas das deformações do lado mais comprimido, apresentaram um pequeno decréscimo na inclinação da curva quando a força estava próxima de $1600 \mathrm{kN}$, que corresponde a aproximadamente $54 \%$ da força máxima alcançada pelo pilar. 

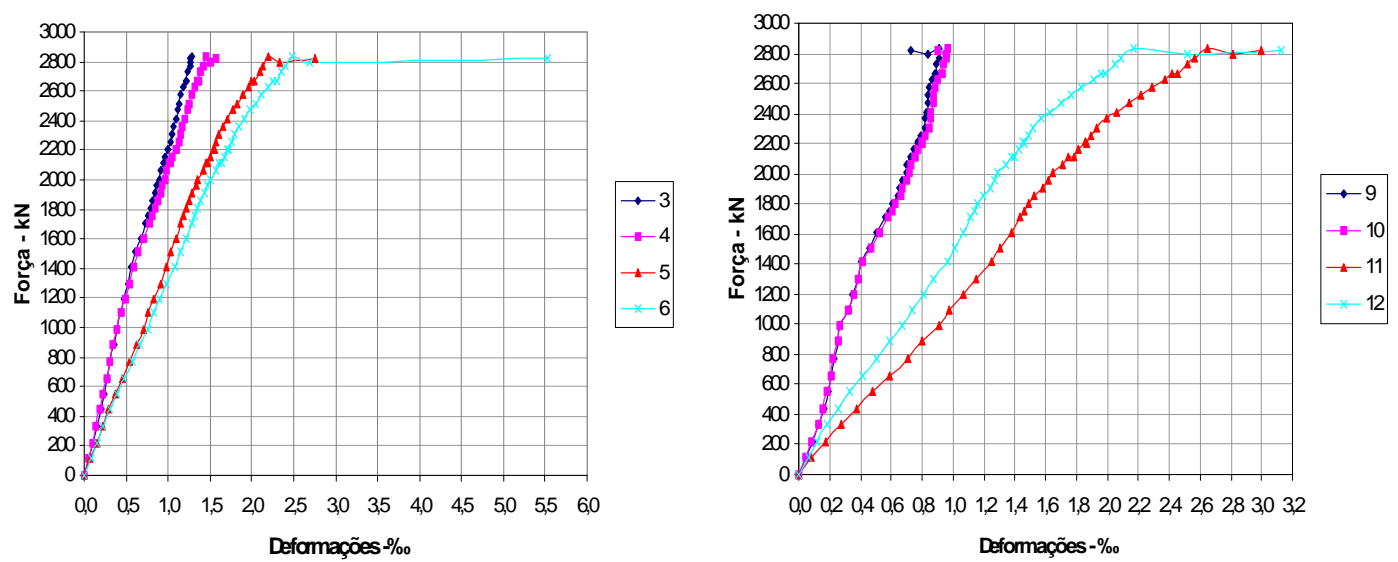

Diagrama força $x$ deformação na armadura longitudinal

Diagrama força $x$ deformação longitudinal no concreto
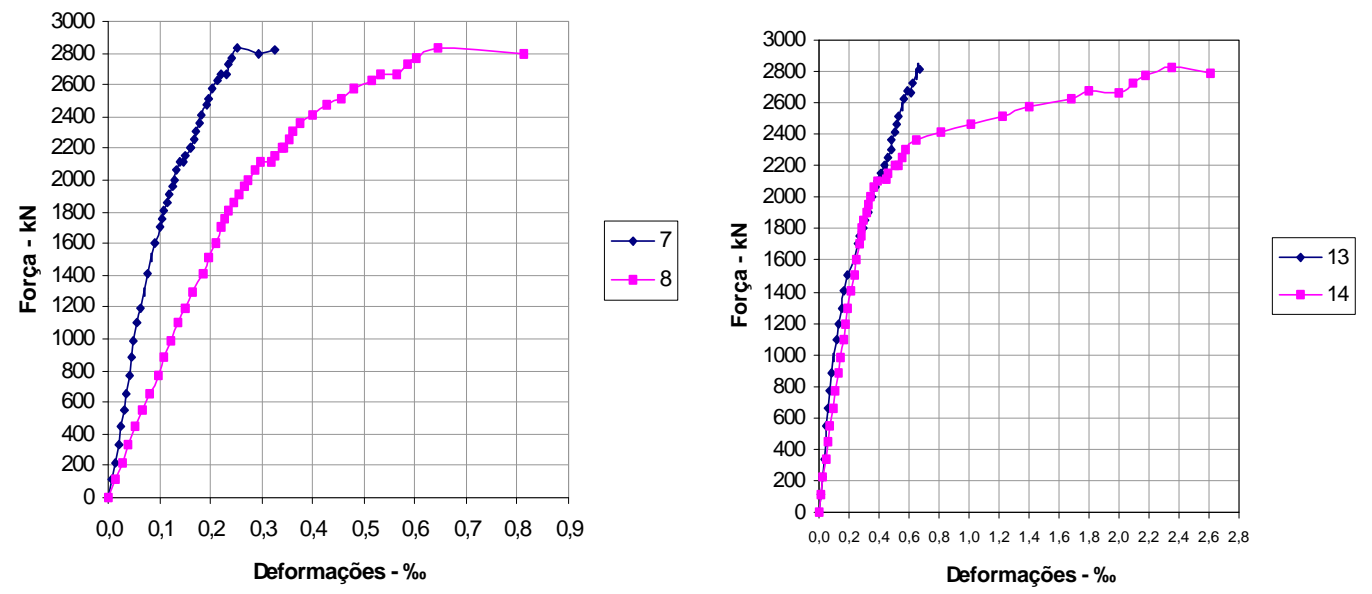

Diagrama força $x$ deformação na armadura transversal

Diagrama força $\mathrm{x}$ deformação transversal no concreto

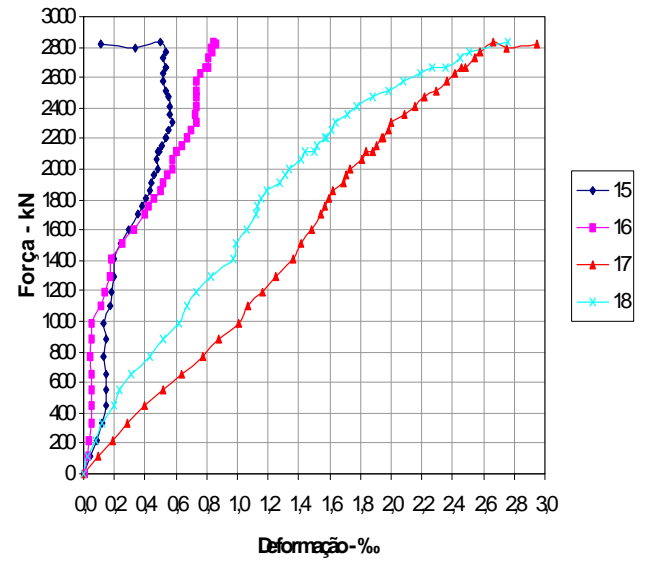

Diagrama força $\mathrm{x}$ deformação do pilar

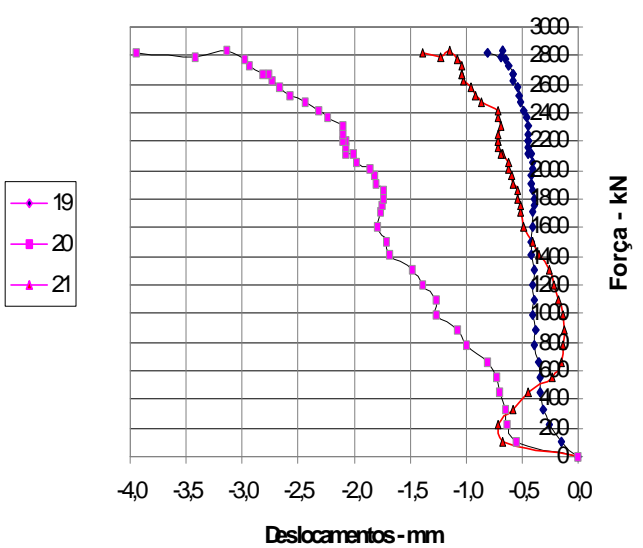

Diagrama força $\mathrm{x}$ deslocamento do pilar 


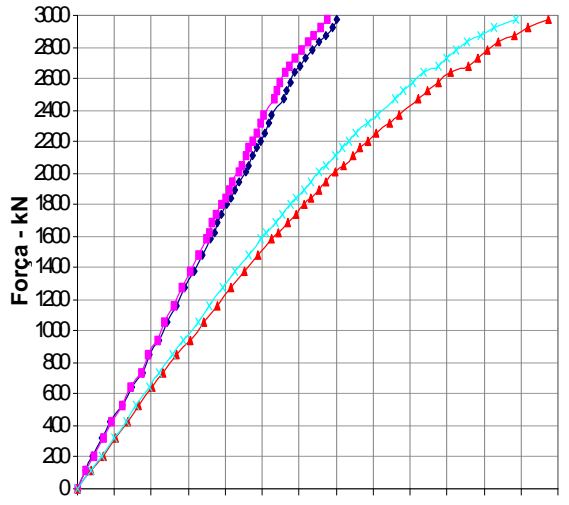

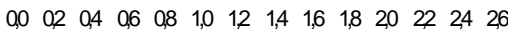
Deformações-\%。

Diagrama força $x$ deformação na armadura longitudinal

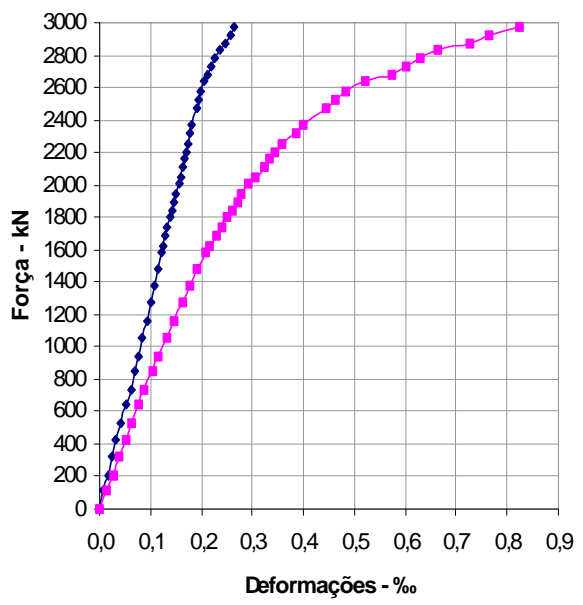

Diagrama força $\mathrm{x}$ deformação na armadura transversal

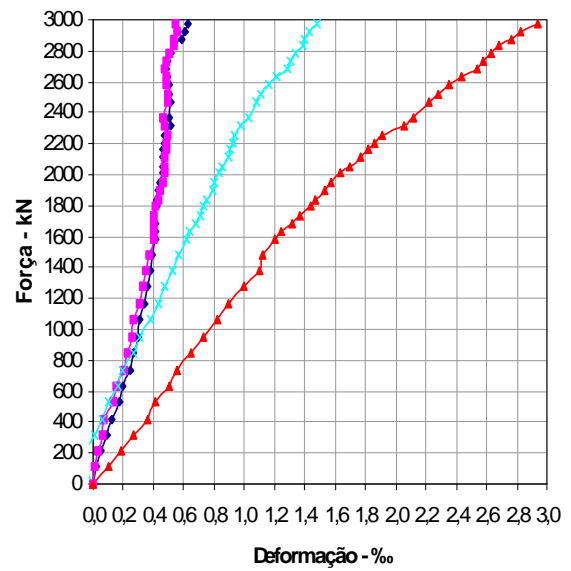

Diagrama força $\mathrm{x}$ deformação do pilar

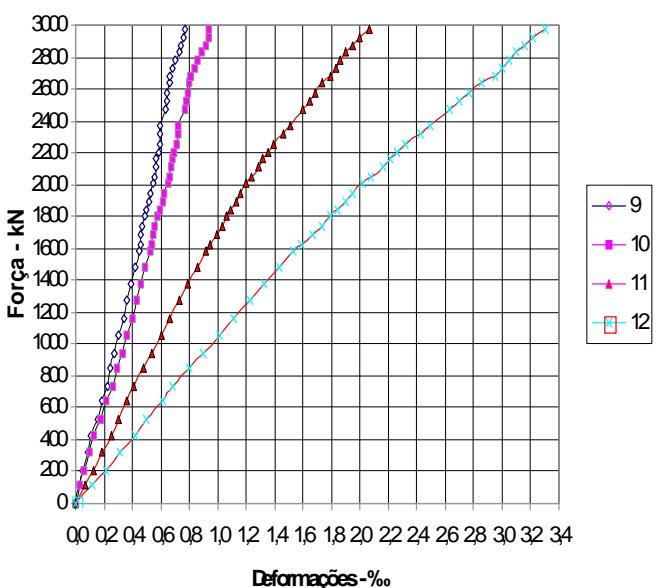

Diagrama força $x$ deformação longitudinal no concreto

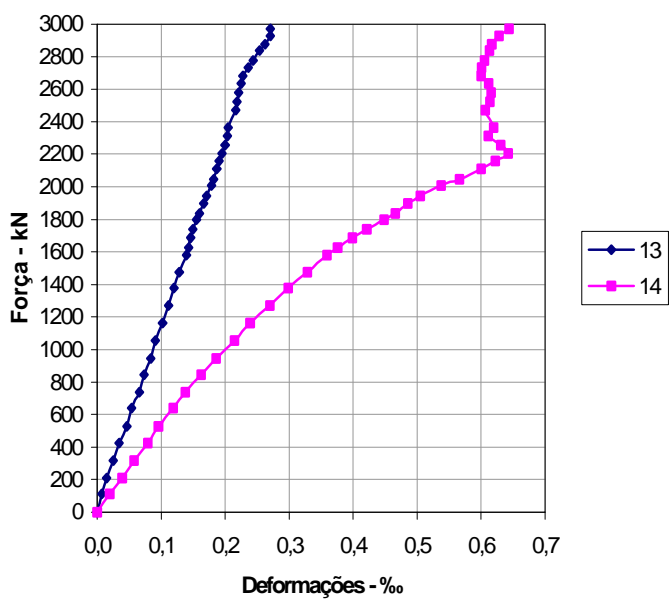

\section{Diagrama força $\mathrm{x}$ deformação transversal no concreto}

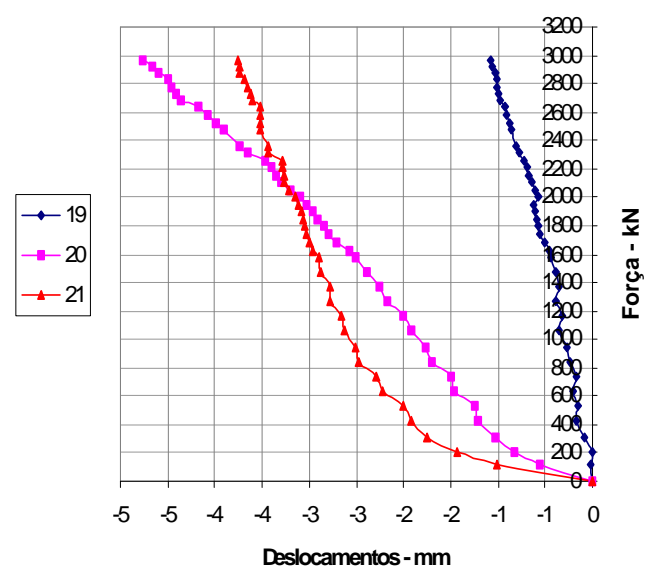

Diagrama força $\mathbf{x}$ deslocamento do pilar

FIGURA 5.6 - Gráficos do pilar P1/3 


\subsection{2- Ensaios da série 2}

\subsubsection{1- Ensaio do pilar P2/1}

$\mathrm{Na}$ figura 5.7, estão todos os diagramas que relacionam a força aplicada no pilar P2/1, com as deformações e deslocamentos lidos durante a aquisição de dados.

A deformação média das barras da armadura, do lado mais comprimido do pilar P2/1, correspondente a força última, foi 2,52\%o.

Os diagramas das deformações do lado mais comprimido, apresentaram uma descontinuidade na curva quando a força estava próxima de $1800 \mathrm{kN}$, que correspondia a aproximadamente $65 \%$ da força máxima alcançada pelo pilar.

\subsubsection{2- Ensaio do pilar P2/2}

$\mathrm{Na}$ figura 5.8, estão todos os diagramas que relacionam a força aplicada no pilar P2/2, com as deformações e deslocamentos lidos durante a aquisição de dados.

A deformação média das barras da armadura, do lado mais comprimido do pilar $\mathrm{P} 2 / 2$, correspondente a força última, foi $2,30 \%$.

Os diagramas das deformações do lado mais comprimido, apresentaram um pequeno decréscimo na inclinação da curva quando a força estava próxima de $1600 \mathrm{kN}$, que correspondia a aproximadamente 55\% da força máxima alcançada pelo pilar. 


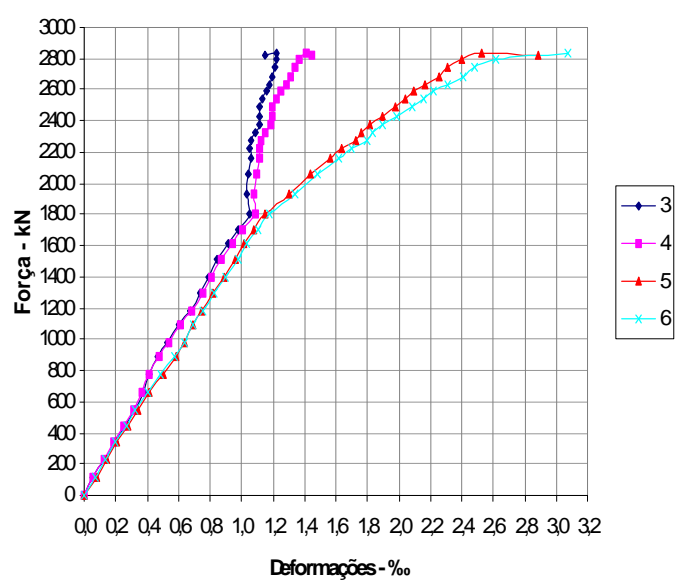

Diagrama força $\mathrm{x}$ deformação na armadura longitudinal

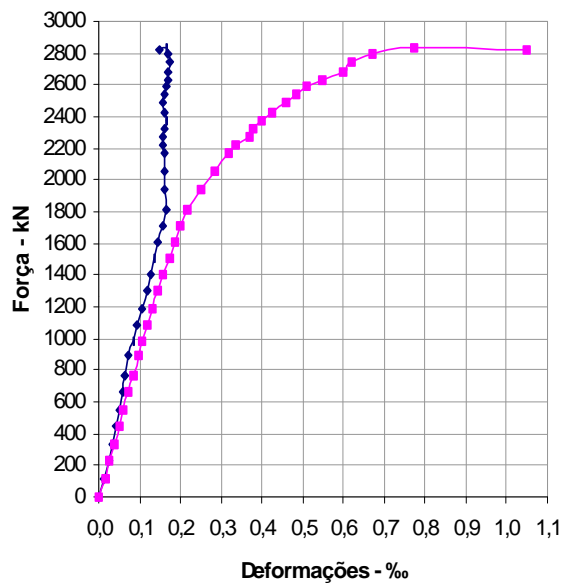

Diagrama força $x$ deformação na armadura transversal

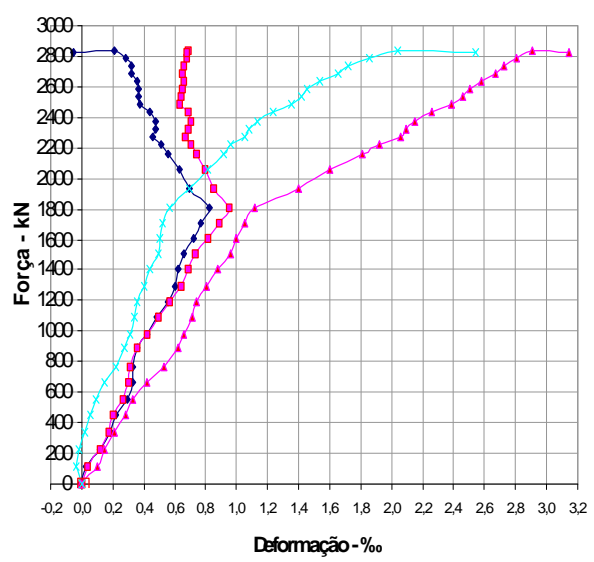

Diagrama força $\mathrm{x}$ deformação do pilar

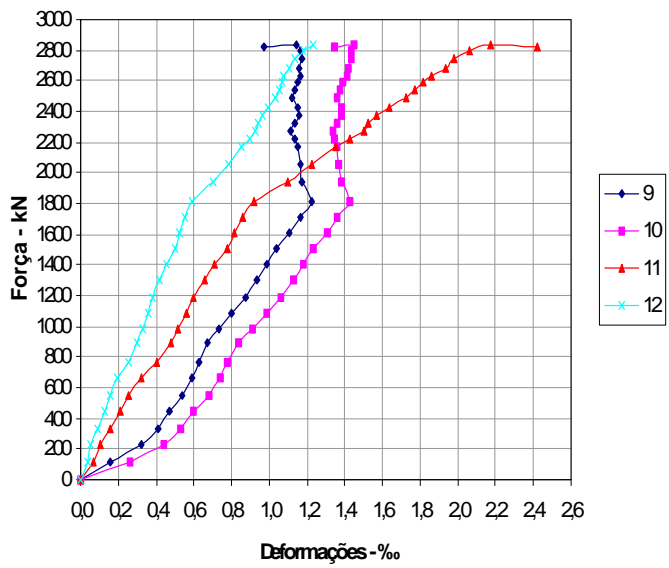

Diagrama força $\mathrm{x}$ deformação longitudinal no concreto

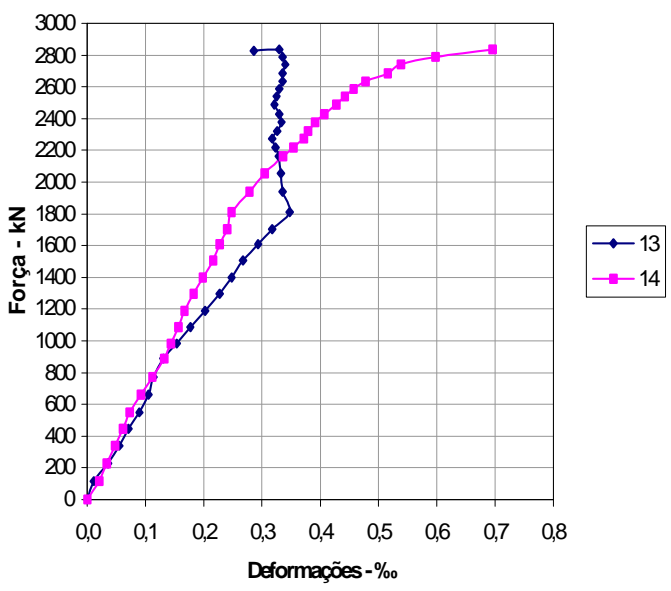

Diagrama força $x$ deformação transversal no concreto

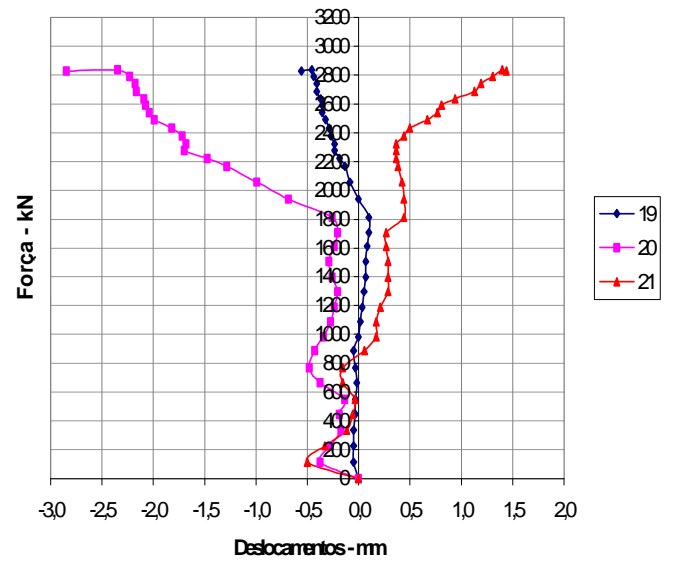

Diagrama força $\mathrm{x}$ deslocamento do pilar

FIGURA 5.7 - Gráficos do pilar P2/1 


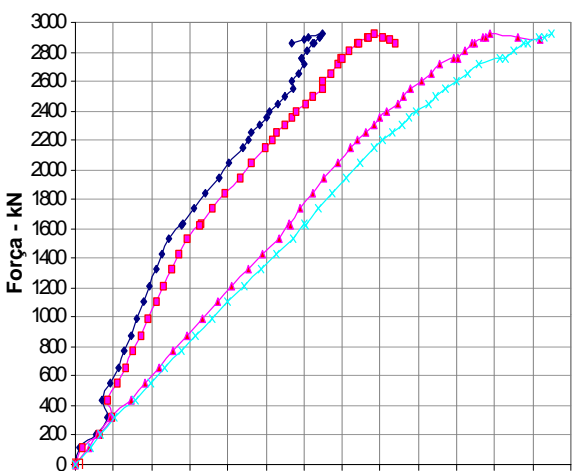

$\begin{array}{llllllllllllll}0,0 & 0,2 & 0,4 & 0,6 & 0,8 & 1,0 & 1,2 & 1,4 & 1,6 & 1,8 & 2,0 & 2,2 & 24 & 2,6\end{array}$ Deformações $\%$ 。

Diagrama força $x$ deformação na armadura longitudinal

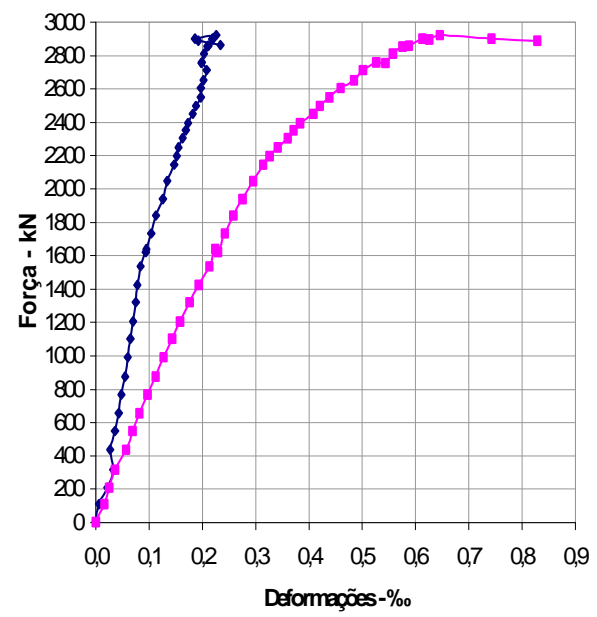

Diagrama força $x$ deformação na armadura transversal

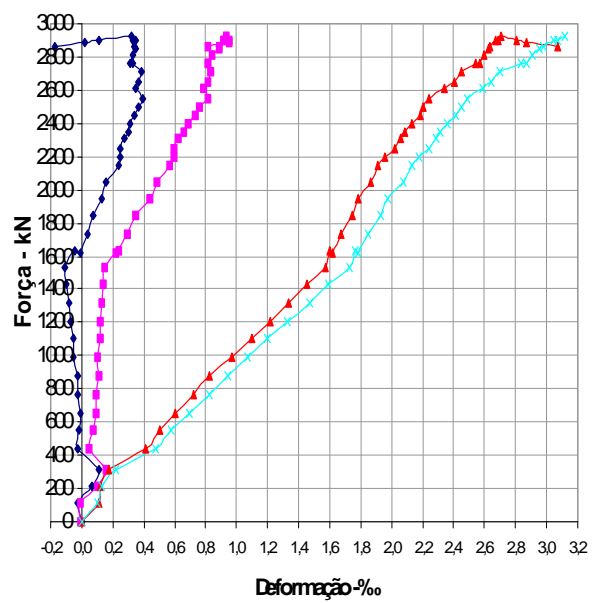

Diagrama força $\mathrm{x}$ deformação do pilar

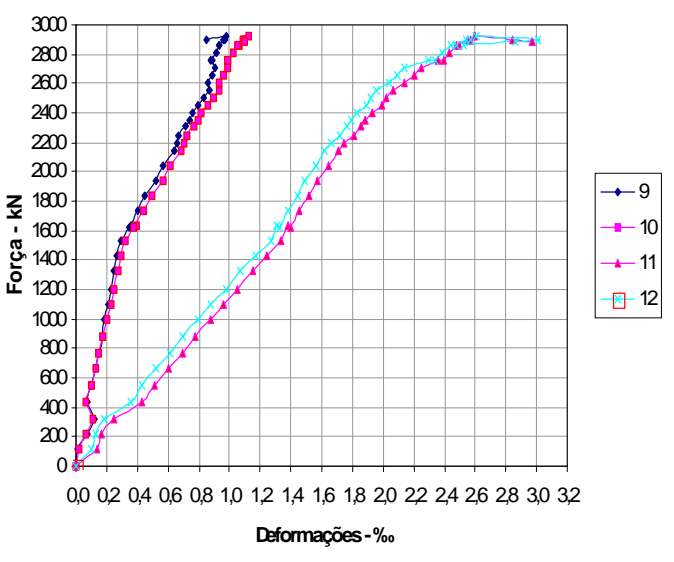

Diagrama força $x$ deformação longitudinal no concreto

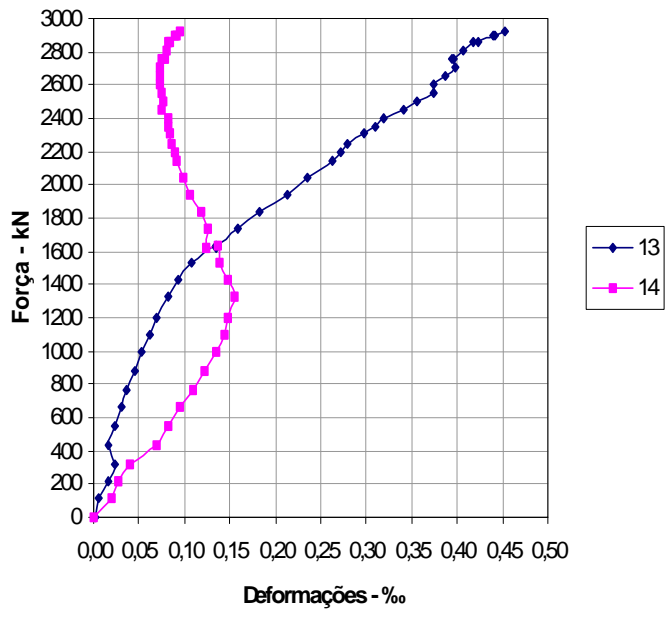

Diagrama força $x$ deformação transversal no concreto

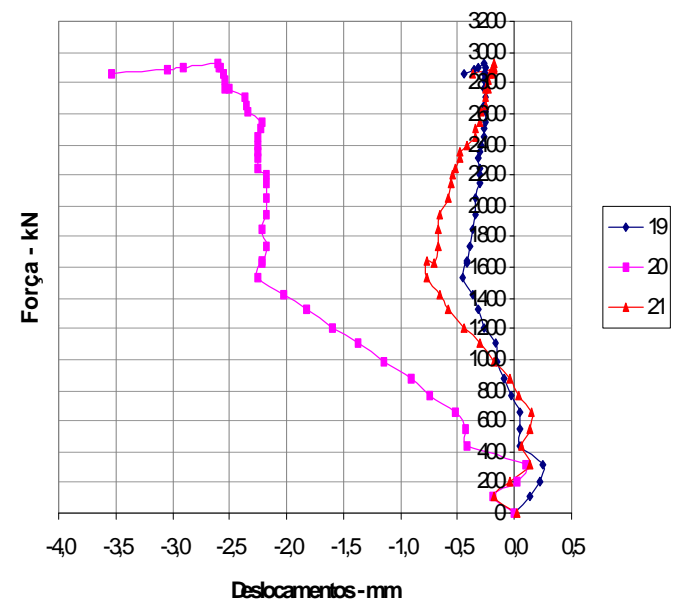

Diagrama força $\mathrm{x}$ deslocamento do pilar

FIGURA 5.8 - Gráficos do pilar P2/2 


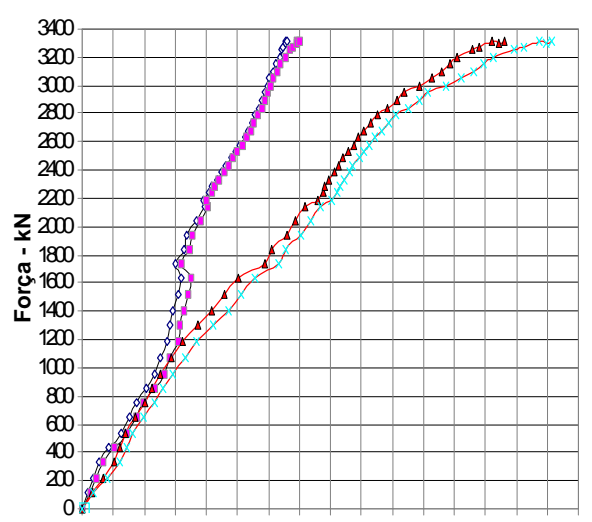

$0,0020,40,60,81,01,21,41,61,820222,4262,83,032$ Deformações-\%。

Diagrama força $x$ deformação na armadura longitudinal

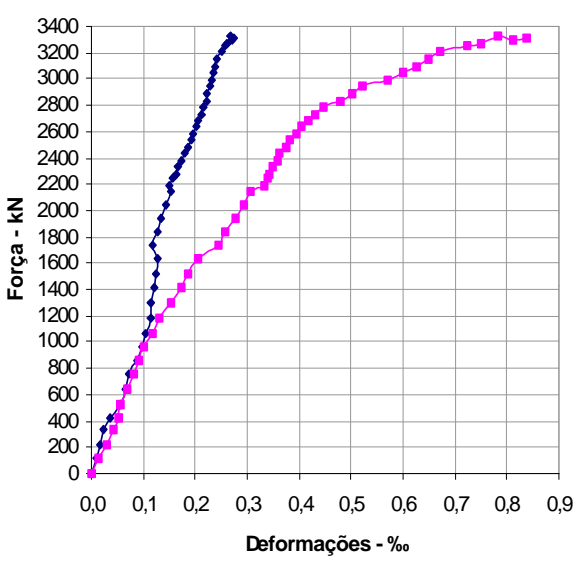

Diagrama força $x$ deformação na armadura transversal

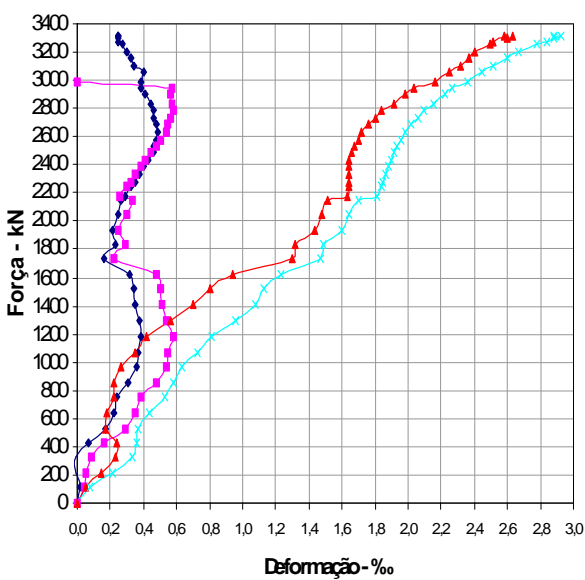

Diagrama força $\mathrm{x}$ deformação do pilar

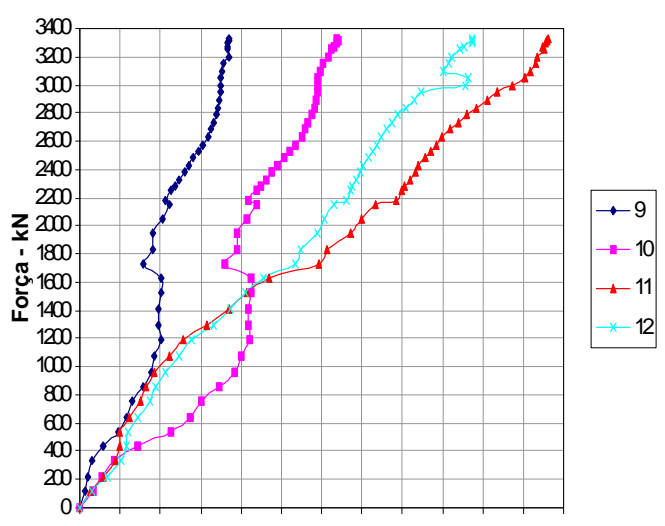

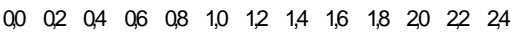
Deformações-\%。

Diagrama força $x$ deformação longitudinal no concreto

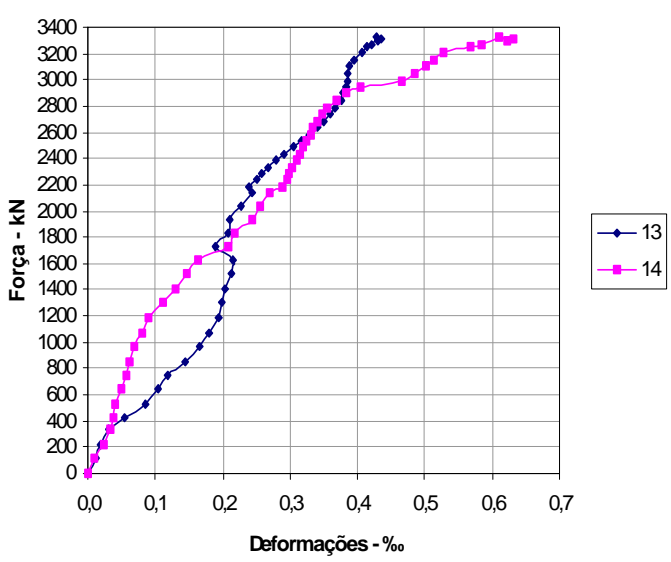

Diagrama força $\mathrm{x}$ deformação transversal no concreto

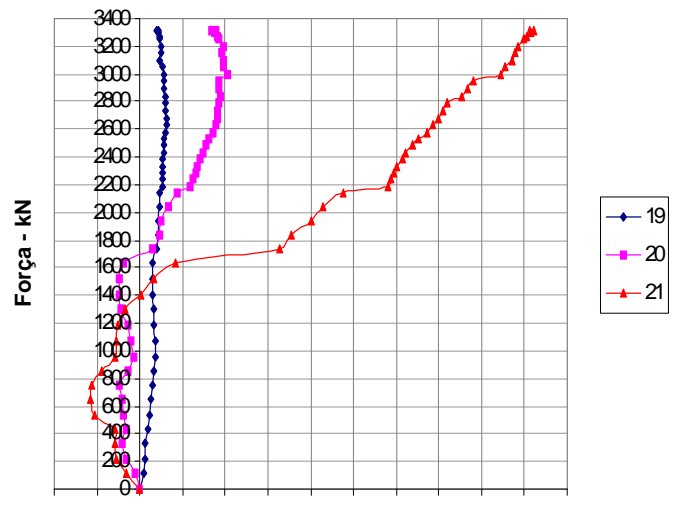

$\begin{array}{lllllllllllll}-2,0 & -1,0 & 0,0 & 1,0 & 2,0 & 3,0 & 4,0 & 5,0 & 6,0 & 7,0 & 8,0 & 9,0 & 10,0\end{array}$ Deslocamentos-mm

Diagrama força $x$ deslocamento do pilar

FIGURA 5.9 - Gráficos do pilar P3/1 


\subsection{3- Ensaios da série 3}

\subsubsection{1- Ensaio do pilar P3/1}

Todos os diagramas que relacionam a força aplicada no pilar P3/1, com as deformações e deslocamentos lidos durante o ensaio, estão na figura 5.9.

A deformação média das barras da armadura, do lado mais comprimido do pilar P3/1, correspondente a força última, foi 2,92\%o.

Os diagramas das deformações do lado mais comprimido, apresentaram um pequeno decréscimo na inclinação da curva quando a força estava próxima de $1800 \mathrm{kN}$, que corresponde a aproximadamente $55 \%$ da força máxima alcançada pelo pilar.

\section{4- Considerações Finais}

Neste capítulo, pode-se observar que as resistências à compressão dos concretos utilizados nos pilares, ficaram acima de $80 \mathrm{MPa}$, que era 0 pretendido. Mas isso não compromete os objetivos da pesquisa, pois a diferença entre as características mecânicas do concretos de resistência entre $80 \mathrm{MPa}$ e 90MPa são mínimas.

Os diagramas que relacionaram as forças aplicadas com as deformações e deslocamentos do pilar, apresentaram, de maneira geral, resultados coerentes com os esperados em ensaios deste tipo.

Os efeitos da flexão oblíqua provavelmente não foram sentidos nos ensaios devido à proximidade dos pontos onde se fazia a leitura das deformações longitudinais. Para isso, seria necessário instrumentar as barras da armadura longitudinal dos cantos da seção do pilar, tendo assim, uma provável diferença de deformações e uma situação mais real do que estava acontecendo na seção.

As deformações últimas de compressão do concreto, na face mais comprimida do pilar, variaram entre $2,3 \%$ e $3 \%$.

O fato de haver uma variação da inclinação da curva quando se alcançou entre $50 \%$ e $60 \%$ da força última, é analisado no capítulo seguinte, bem como as relações entre o valores experimentais e teóricos. 


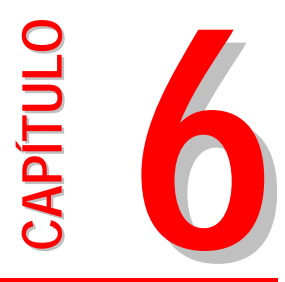

\section{ANÁLISE DOS RESULTADOS}

\section{1- Considerações Iniciais}

Neste capítulo, são feitas as análises dos resultados experimentais obtidos na pesquisa e os previstos em expressões propostas na literatura técnica.

São comparados resultados referentes đ̀s características mecânicas do concreto, como a resistência à tração e o módulo de elasticidade. Também são feitas análises dos valores dos esforços normais e momentos fletores obtidos com os ensaios dos modelos experimentais, e comparados com valores teóricos através de expressões de equilíbrio, utilizando relações tensão $\mathrm{x}$ deformação propostas por alguns pesquisadores e algumas normas internacionais.

São comparados dois diagramas de tensões simplificados, propostos no ACI 318 (1994) e por DINIZ, para avaliar a precisão desses diagramas, pois são de uso simples e de grande utilidades em projetos estruturais.

\section{2- Análise das Características Mecânicas do Concreto}

As características mecânicas do concreto utilizado nos modelos, foram analisadas para se ter um comparativo com os resultados obtidos com as expressões indicadas em artigos e normas técnicas internacionais, já descritas no capítulo 2. 
A resistência média à compressão do concreto $\left(\mathrm{f}_{\mathrm{c}}\right)$ dos modelos, foi tomada como média de 6 corpos-de-prova, três de cada mistura, para a idade de 15 dias, como descrito no capítulo 4.

\subsection{1- Resistência àtração}

A resistência à tração experimental $\left(f_{t}\right)$, foi obtida com corpos-deprova cilíndricos de $10 \mathrm{~cm}$ x $20 \mathrm{~cm}$, ensaiados à compressão diametral como mostrado no capítulo 4 .

As normas técnicas NBR 6118/78, MC90 CEB-FIP/91, NS 3473E/92 e o artigo publicado por CARRASQUILLO et al. (1981), trazem expressões que estimam a resistência à tração na falta de dados experimentais. As expressões foram expostas no capítulo 2 de acordo com os números 2.2, 2.3, 2.4 e 2.5, respectivamente.

Apesar da resistência à tração não ter sido usado nesta pesquisa, procurou-se fazer uma análise entre os valores obtidos experimentalmente, e os encontrados nas expressões das referências citadas. Os resultados das resistências àtração estão expostos na tabela 6.1.

TABELA 6.1 - Valores da resistência à tração experimental e sugeridos pelas bibliografias.

\begin{tabular}{|c|c|c|c|c|c|c|}
\hline Modelos & $\begin{array}{c}\boldsymbol{f}_{c} \\
(\mathbf{M P a})\end{array}$ & $\begin{array}{c}\boldsymbol{f}_{\boldsymbol{t}} \\
(\mathbf{M P a})\end{array}$ & $\begin{array}{c}\text { NBR } \\
(\mathbf{M P a})\end{array}$ & $\begin{array}{c}\mathbf{C E B} \\
(\mathbf{M P a})\end{array}$ & $\begin{array}{c}\text { NS } \\
(\mathbf{M P a})\end{array}$ & $\begin{array}{c}\text { Carrasquillo } \\
(\mathbf{M P a})\end{array}$ \\
\hline Piloto & 89,61 & 5,25 & 6,08 & 6,01 & 4,45 & 5,11 \\
\hline P1/1 & 81,00 & 5,17 & 5,56 & 5,62 & 4,19 & 4,86 \\
\hline P1/1R & 88,89 & 4,52 & 6,03 & 5,98 & 4,43 & 5,09 \\
\hline P1/2 & 85,68 & 5,42 & 5,84 & 5,83 & 4,33 & 5,00 \\
\hline P1/3 & 82,61 & 4,75 & 5,66 & 5,69 & 4,24 & 4,91 \\
\hline P2/1 & 90,07 & 4,72 & 6,10 & 6,03 & 4,47 & 5,12 \\
\hline P2/2 & 89,61 & 5,2 & 6,08 & 6,01 & 4,45 & 5,11 \\
\hline P3/1 & 87,41 & 4,64 & 5,94 & 5,91 & 4,39 & 5,05 \\
\hline
\end{tabular}

Para melhor avaliar a precisão dos valores teóricos fornecidos pelas expressões indicadas pelos vários Autores consultados, fez-se a relação entre o valor experimental e o teórico, onde está exposto na tabela 6.2. 
TABELA 6.2 - Relação entre os valores experimentais e teóricos da resistência à tração do concreto.

\begin{tabular}{|c|c|c|c|c|}
\hline Modelos & NBR & CEB & NS & Carrasquillo \\
\hline Piloto & 0,86 & 0,87 & 1,18 & 1,03 \\
\hline $\mathrm{P} 1 / 1$ & 0,93 & 0,92 & 1,23 & 1,06 \\
\hline $\mathrm{P} 1 / 1 \mathrm{R}$ & 0,75 & 0,76 & 1,02 & 0,89 \\
\hline $\mathrm{P} 1 / 2$ & 0,93 & 0,93 & 1,25 & 1,08 \\
\hline $\mathrm{P} 1 / 3$ & 0,84 & 0,83 & 1,12 & 0,97 \\
\hline $\mathrm{P} 2 / 1$ & 0,77 & 0,78 & 1,06 & 0,92 \\
\hline $\mathrm{P} 2 / 2$ & 0,86 & 0,87 & 1,17 & 1,02 \\
\hline $\mathrm{P} 3 / 1$ & 0,78 & 0,79 & 1,06 & 0,92 \\
\hline
\end{tabular}

A comparação dos valores da resistência à tração, também podem ser feita pela figura 6.1.

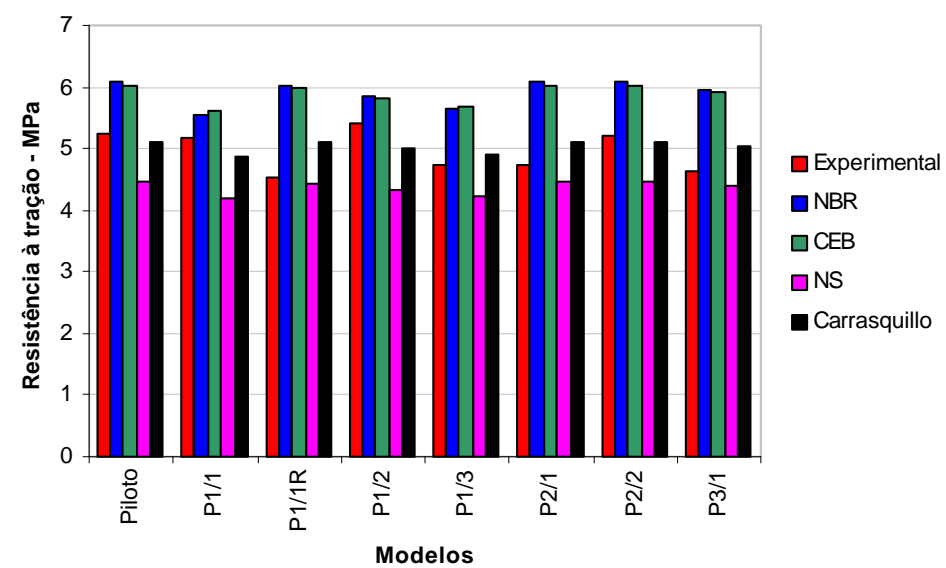

FIGURA 6.1 - Valores teóricos e experimentais da resistência à tração do concreto

De acordo com os valores da tabela 6.2 e a figura 6.1, pode-se avaliar a precisão das expressões propostas. Observa-se que as expressões da NBR 6118/78 e do MC90 CEB-FIP/91 apresentam a mesma precisão, com valores bem próximos um do outro, entretanto, um pouco acima dos valores obtidos experimentalmente. A NBR 6118/78 ainda não foi revisada, e sua expressão não foi elaborada para concretos de alta resistência, por isso, a diferença encontrada. No entanto, o CEB-FIP/91 está atualizado, e a expressão para a resistência à tração é válida para concretos de alta resistência até $f_{c}=80 \mathrm{MPa}$, logo, sua expressão não apresentou, em nossa pesquisa, bons valores para a resistência àtração, sendo de baixa precisão.

Os valores da expressão proposta pela NS 3473E/92 foram, em sua maioria, menores que os valores encontrados experimentalmente. Esta 
norma é bem atualizada e mostrou-se um pouco conservativas para os resultados encontrados nesta pesquisa.

A expressão proposta por CARRASQUILLO et al. (1981), apresentou boa precisão em relação aos valores experimentais. Pode ser indicada, como a melhor expressão para se prever valores da resistência à tração, quando utilizados os procedimentos de mistura e materiais com características semelhantes ao adotados nesta pesquisa. A expressão que prevê a resistência àtração do concreto proposto por CARRASQUILLO et al. (1981) é :

$$
\mathrm{f}_{\mathrm{tk}}=0,54 \sqrt{\mathrm{f}_{\mathrm{ck}}} \quad(\mathrm{MPa})
$$

\subsection{2- Módulo de deformação longitudinal}

O módulo de deformação longitudinal $\left(E_{c}\right)$, foi obtido através dos ensaios de compressão axial, com deformação controlada, em corpos-deprova cilíndricos de $10 \mathrm{~cm} \times 20 \mathrm{~cm}$, como mostrado no capítulo 4 .

As normas técnicas NBR 6118/78, ACI 318/94, MC90 CEB-FIP/91, NS 3473E/92 e o artigo publicado de CARRASQUILLO et al (1981), trazem expressões que estimam o módulo de deformação longitudinal, na falta de dados experimentais. As expressões foram expostas no capítulo 2 pelos números 2.6, 2.7, 2.8, 2.9 e 2.10, respectivamente.

Procurou-se analisar a eficiência das expressões das referências bibliográficas, comparando-se com os valores obtidos experimentalmente. Os resultados dos módulos de deformação longitudinal estão expostos na tabela 6.3.

TABELA 6.3 - Módulos de deformação longitudinal experimental e propostos nas bibliografias

\begin{tabular}{|c|c|c|c|c|c|c|c|}
\hline Modelos & $\begin{array}{c}\boldsymbol{f}_{\boldsymbol{c}} \\
(\mathbf{M P a})\end{array}$ & $\begin{array}{c}\text { Ec } \\
(\mathbf{M P a})\end{array}$ & $\begin{array}{c}\text { NBR } \\
(\mathbf{M P a})\end{array}$ & $\begin{array}{c}\text { ACl } \\
(\mathbf{M P a})\end{array}$ & $\begin{array}{c}\text { CEB } \\
(\mathbf{M P a})\end{array}$ & $\begin{array}{c}\text { NS } \\
(\mathbf{M P a})\end{array}$ & $\begin{array}{c}\text { Carrasquillo } \\
(\mathbf{M P a})\end{array}$ \\
\hline Piloto & 89,61 & $43.017,00$ & $63.685,73$ & $44.775,39$ & $55.251,75$ & $36.595,74$ & $38.327,97$ \\
\hline P1/1 & 81,00 & $36.492,00$ & $60.669,76$ & $42.570,00$ & $53.576,94$ & $35.503,33$ & $36.780,00$ \\
\hline P1/1R & 88,89 & $39.728,00$ & $63.439,01$ & $44.595,15$ & $55.115,56$ & $36.507,28$ & $38.201,46$ \\
\hline P1/2 & 85,68 & $41.915,00$ & $62.327,21$ & $43.782,53$ & $54.500,05$ & $36.106,67$ & $37.631,08$ \\
\hline P1/3 & 82,61 & $41.797,00$ & $61.245,01$ & $42.990,99$ & $53.898,08$ & $35.713,58$ & $37.075,49$ \\
\hline P2/1 & 90,07 & $41.931,00$ & $63.842,85$ & $44.890,17$ & $55.338,41$ & $36.652,00$ & $38.408,53$ \\
\hline P2/2 & 89,61 & $45.988,00$ & $63.685,73$ & $44.775,39$ & $55.251,75$ & $36.595,74$ & $38.327,97$ \\
\hline P3/1 & 87,41 & $41.645,00$ & $62.928,85$ & $44.222,34$ & $54.833,49$ & $36.323,86$ & $37.939,78$ \\
\hline
\end{tabular}


Os resultados teóricos provenientes das expressões das referências citadas, foram avaliados através da relação entre o valor experimental e o teórico, tabela 6.4, como feito para as expressões da resistência à tração.

TABELA 6.4 - Relação entre os valores experimentais e teóricos do módulo de deformação longitudinal

\begin{tabular}{|c|c|c|c|c|c|}
\hline Modelos & NBR & ACl & CEB & NS & Carrasquillo \\
\hline Piloto & 0,68 & 0,96 & 0,78 & 1,18 & 1,12 \\
\hline P1/1 & 0,60 & 0,86 & 0,68 & 1,03 & 0,99 \\
\hline P1/1R & 0,63 & 0,89 & 0,72 & 1,09 & 1,04 \\
\hline P1/2 & 0,67 & 0,96 & 0,77 & 1,16 & 1,11 \\
\hline P1/3 & 0,68 & 0,97 & 0,78 & 1,17 & 1,13 \\
\hline P2/1 & 0,66 & 0,93 & 0,76 & 1,14 & 1,09 \\
\hline P2/2 & 0,72 & 1,03 & 0,83 & 1,26 & 1,20 \\
\hline P3/1 & 0,66 & 0,94 & 0,76 & 1,15 & 1,10 \\
\hline
\end{tabular}

A comparação dos valores da resistência à tração, também podem ser feita pela figura 6.2.

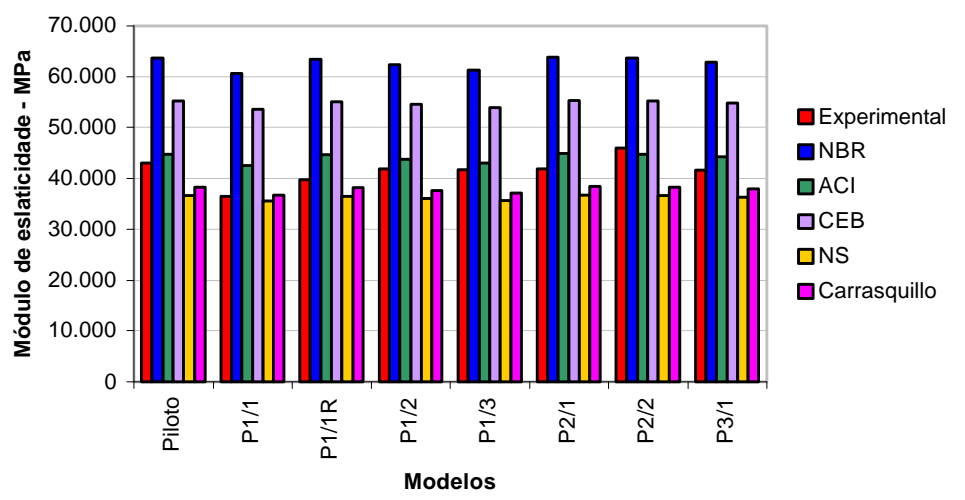

FIGURA 6.2 - Valores teóricos e experimentais do módulo de deformação longitudinal

De acordo com os valores da tabela 6.4 e da figura 6.2, pode-se avaliar a precisão das expressões propostas.

Constatou-se que a expressão da NBR 6118/78, apresentou valores bem acima dos obtidos experimentalmente, cerca de 30\% a 40\%. Isto se dá, pois esta norma ainda não foi revisada, e sua expressão não foi elaborada para concretos de alta resistência.

Os valores resultantes da expressão proposta pelo MC90 CEBFIP/91, não apresentaram boa precisão, com valores superando o experimental em torno de $30 \%$. Logo, sua expressão não apresentou, em nossa pesquisa, bons valores para o módulo de deformação longitudinal, sendo de baixa precisão. 
Os valores das expressões propostas pela NS 3473E/92 e por CARRASQUILLO et al. (1981), tiveram boa precisão e apresentaram valores bem próximos entre si. Estas expressões apresentaram valores ligeiramente menores que os valores encontrados experimentalmente, sendo consideradas satisfatória, para pesquisas feitas com procedimentos de mistura e materiais com características semelhantes aos adotados nesta pesquisa.

A expressão proposta pelo ACI 318/94, apresentou boa precisão em relação aos valores experimentais. Esta pode ser indicada como a melhor expressão para se prever valores do módulo de deformação longitudinal, quando utilizados os procedimentos de mistura e materiais com características semelhantes aos adotados nesta pesquisa. A expressão prevê o módulo de deformação longitudinal do concreto proposto pelo $\mathrm{ACI}$ 318 é:

$$
E_{c}=4730 \sqrt{f_{c k}} \quad(\mathrm{MPa})
$$

\section{3- Avaliação das Relações Tensão x Deformação Propostas por LIMA (1997) e COLLINS et al. (1993).}

Para comparação das relações tensão $x$ deformação propostas por LIMA (1997) e COLLINS et al.(1993), descritas no capítulo 3, utilizaram-se resultados dos ensaios realizados por LIMA (1997) para determinação da resistência à compressão e sua correspondente deformação, e o módulo de elasticidade, em corpos-de-prova cilíndricos de $10 \mathrm{~cm} \times 20 \mathrm{~cm}$ com deformação axial controlada com velocidade de $0,035 \mathrm{~mm} / \mathrm{min}$. Os ensaios foram realizados no Laboratório de Mecânica das Rochas do Departamento de Geotecnia. A máquina de ensaio permitia o traçado de diagramas tensão x deformação, como pode ser visto na figura 6.3.

Os resultados teóricos e experimentais foram comparados através do comportamento das curvas de cada modelo. A comparação foi feita tomando como base a curva experimental. 


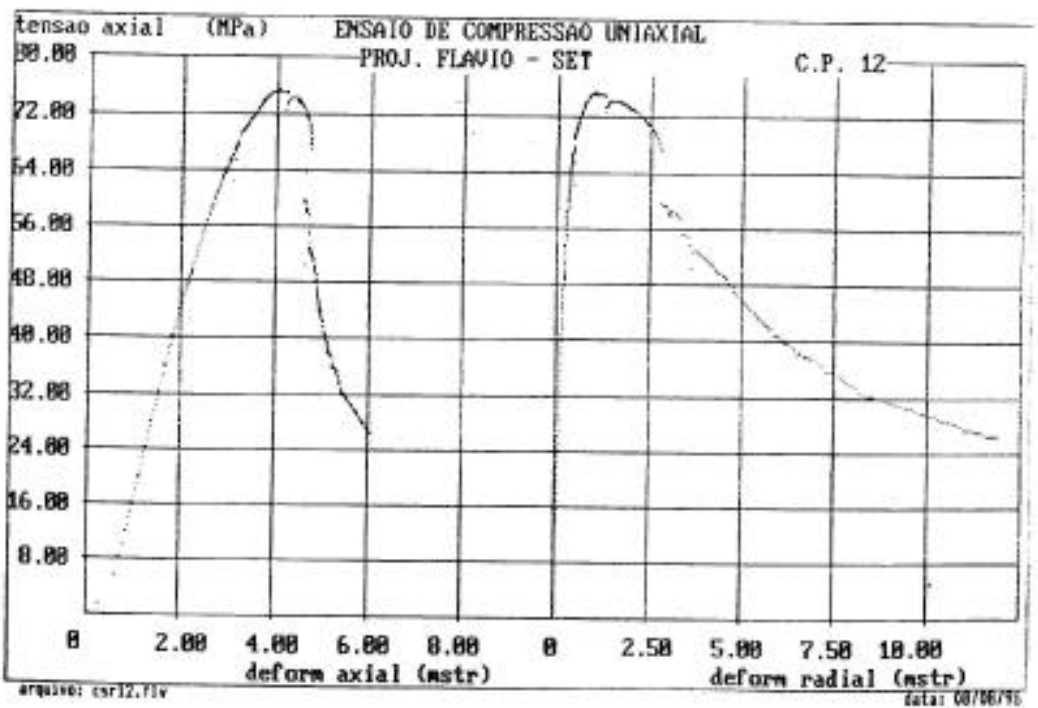

FIGURA 6.3 - Exemplo da saída gráfica do ensaio com deformação controlada

A curva que representa a relação teórica proposta por LIMA (1997), expressão 3.12, é denominada LIMA. As que representam as duas formas de análise das relações propostas por COLLINS et al. (1993), expressão 3.5, são denominados de COLLINS 1, quando se utiliza os dados experimentais para $\varepsilon_{\mathrm{c}}$ e $\mathrm{E}_{\mathrm{c}}$, e COLLINS 2 quando se utiliza para $\varepsilon_{\mathrm{c}}$ e $\mathrm{E}_{\mathrm{c}}$ os valores provenientes das expressões 3.8 e 3.9.

Como exemplo tem-se o resultado mostrado pela figura 6.2.

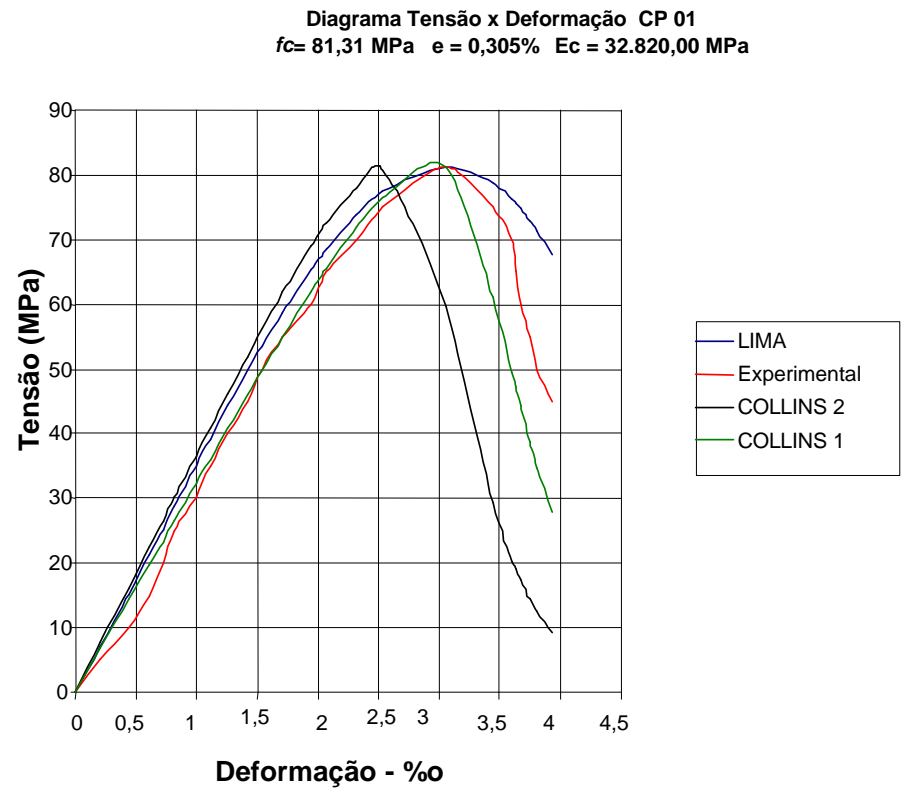

FIGURA 6.4 - Relações tensão x deformação propostas por LIMA (1996) e COLLINS et al.(1993) 
Podem-se obter da análise do comportamento dos relações estudadas as seguintes conclusões:

- A proposta de LIMA (1997) se aproxima bem da curva experimental no ramo ascendente, mas se comporta de modo insatisfatório na parte descendente, fugindo um pouco da curva experimental.

- A primeira proposta de COLLINS et al. (1993), representada pela curva COLLINS 1, apresenta um ótimo comportamento na parte ascendente da curva, quanto a parte descendente, é a que se aproxima mais da curva experimental.

- O segundo modelo de COLLINS et al. (1993), mais simplificado e representado pela curva COLLINS 2, é o que menos se aproxima da curva experimental tanto no ramo ascendente quanto no descendente. Isto se deve à aproximação feita para o módulo de elasticidade e para a deformação correspondente àtensão máxima.

Com isso vê-se que o modelo proposto por COLLINS et al. (1993), considerando os dados experimentais de tensão máxima e sua deformação correspondente, é o modelo que se aproxima mais dos resultados experimentais. No entanto optou-se por fazer a análise dos modelo utilizando as relações propostas por LIMA (1997) e COLLINS et al. (1993) para se comparar as duas relações com relação aos esforços resistentes.

\section{4- Análise dos Resultados dos Modelos}

Inicialmente, foram adotados valores para os coeficientes de modificação da resistência do concreto. Como o ensaio foi realizado com 15 dias, e com ação de curta duração, consideraram-se os coeficientes $\mathbf{k}_{\bmod .1} \mathrm{e}$ $\mathrm{k}_{\text {mod.3 }}$ iguais a unidade, levando-se em conta apenas a relação entre a resistência do concreto, medida nos corpos-de-prova cilíndricos de $10 \mathrm{~cm} x$ $20 \mathrm{~cm}$, e do concreto dos pilares, dado pelo coeficiente $\mathrm{k}_{\text {mod.2 }}=0,90$.

Então, para análise dos valores últimos experimentais, a resistência à compressão do concreto foi assumida como $0,90 f_{c}$, sendo $f_{c}$ a resistência 
média à compressão do concreto medida no dia do ensaio através de corpos-de-prova cilíndricos de $10 \mathrm{~cm}$ de diâmetro e $20 \mathrm{~cm}$ de altura.

As características dos modelos ensaiados e analisados estão apresentadas na tabela 6.5 .

TABELA 6.5 - Características dos modelos analisados

\begin{tabular}{|c|c|c|c|c|c|c|c|c|c|c|c|c|}
\hline Pilar & $\begin{array}{c}\text { b } \\
\text { cm }\end{array}$ & $\begin{array}{c}\mathrm{h} \\
\mathrm{cm}\end{array}$ & $\begin{array}{l}A_{c} \\
\mathrm{~cm}^{2}\end{array}$ & $\begin{array}{c}f_{c} \\
\mathrm{MPa}\end{array}$ & $\begin{array}{c}0,90 f_{c} \\
\mathrm{MPa}\end{array}$ & $\begin{array}{c}\varepsilon_{\mathrm{c}} \\
(\% \circ)\end{array}$ & $\begin{array}{c}\mathrm{E}_{\mathrm{c}} \\
\mathrm{MPa}\end{array}$ & $\begin{array}{l}A_{s} \\
\mathrm{~cm}^{2}\end{array}$ & $\begin{array}{c}\boldsymbol{f}_{\boldsymbol{y}} \\
\mathrm{MPa}\end{array}$ & $\begin{array}{c}\mathrm{E}_{\mathrm{s}} \\
\mathrm{MPa}\end{array}$ & $\begin{array}{l}\rho_{\mathrm{L}} \\
\%\end{array}$ & $\begin{array}{l}\rho_{\mathrm{t}} \\
\%\end{array}$ \\
\hline $\mathrm{P} 1 / 1 \mathrm{R}$ & 30 & 15 & 450 & 88,89 & 80,00 & 2,61 & $39.728,0$ & 9,84 & 502,13 & 168.841 & 2,26 & 1,58 \\
\hline $\mathrm{P} 1 / 2$ & 30 & 15 & 450 & 85,68 & 77,11 & 2,32 & $41.915,0$ & 9,84 & 502,13 & 168.841 & 2,26 & 0,79 \\
\hline $\mathrm{P} 1 / 3$ & 30 & 15 & 450 & 82,61 & 74,35 & 2,31 & $41.797,0$ & 9,84 & 502,13 & 168.841 & 2,26 & 0,53 \\
\hline $\mathrm{P} 2 / 1$ & 30 & 15 & 450 & 90,07 & 81,06 & 2,35 & $41.931,0$ & 6,28 & 623,00 & 194.060 & 1,26 & 0,79 \\
\hline $\mathrm{P} 2 / 2$ & 30 & 15 & 450 & 89,61 & 80,65 & 2,49 & $45.988,0$ & 6,28 & 623,00 & 194.060 & 1,26 & 1,58 \\
\hline P3/1 & 30 & 15 & 450 & 87,41 & 78,67 & 2,39 & $41.645,0$ & 16,08 & 622,85 & 194.388 & 3,45 & 0,79 \\
\hline
\end{tabular}

Para análise dos resultados, foi determinada a força e momento fletor resistentes a partir dos valores das deformações medidas em uma determinada seção, e das características mecânicas do aço da armadura e do concreto, também determinados experimentalmente.

A análise teórica do modelo foi feita em duas fases de carregamento, uma considerando a ação última, onde foi possível se medirem as deformações próximo ao colapso, e outra considerando cerca de $80 \%$ da força última, onde a estrutura encontrava-se em serviço.

\subsection{1- Análise das deformações}

Admitiu-se hipótese de que as seções planas permaneciam planas depois de deformadas, e seguindo-se raciocínio descrito no capítulo 3, item 3.3, pôde-se determinar a variação da deformação ao longo da altura $h$ da seção transversal do pilar. Para isso, foi preciso saber o valor das deformações nas barras da armadura das faces 1 (face menos comprimida) e 2 (face mais comprimida) e utilizar a expressão 3.3 que é repetida abaixo:

$$
\varepsilon(x)=\left(\frac{\varepsilon_{s 1}-\varepsilon_{s 2}}{d-d^{\prime}}\right) x+\frac{\varepsilon_{s 2} \cdot d-\varepsilon_{s 1} \cdot d^{\prime}}{d-d^{\prime}}
$$


onde: $\quad \varepsilon_{\mathrm{s} 1}=$ deformação média medida na armadura menos comprimida, em valor absoluto;

$\varepsilon_{\mathrm{s} 2}=$ deformação média medida na armadura mais comprimida, em valor absoluto;

$\mathrm{d}=$ altura útil do pilar;

d' = altura da seção transversal menos a altura útil.

As deformações médias obtidas em cada ensaio, e sua respectiva variação a partir da equação 3.3 , tanto para a força última quanto para $80 \%$ da força última, podem ser vistas nas tabelas 6.6.

Tabela 6.6 - Variação das deformações

\begin{tabular}{|c|c|c|c|c|c|c|}
\hline \multirow{3}{*}{ Modelo } & \multicolumn{4}{|c|}{ Força última } & \multicolumn{3}{|c|}{$\mathbf{8 0 \%}$ força última } \\
\cline { 2 - 7 } & $\begin{array}{c}\boldsymbol{\varepsilon}_{\mathbf{s} 1} \\
(\%)\end{array}$ & $\begin{array}{c}\boldsymbol{\varepsilon}_{\mathbf{s} 2} \\
(\%)\end{array}$ & $\varepsilon(\mathbf{x})$ & $\begin{array}{c}\boldsymbol{\varepsilon}_{\mathbf{s} 1} \\
(\%)\end{array}$ & $\begin{array}{c}\boldsymbol{\varepsilon}_{\mathbf{s} 2} \\
(\% \circ\end{array}$ & $\varepsilon(\mathbf{x})$ \\
\hline $\mathrm{P} 1 / 1 \mathrm{R}$ & 1,402 & 2,983 & $-0,014373 \mathrm{x}+0,003270$ & 1,117 & 1,963 & $-0,007695 \mathrm{x}+0,002117$ \\
\hline $\mathrm{P} 1 / 2$ & 1,374 & 2,354 & $-0,008909 \mathrm{x}+0,002532$ & 1,075 & 1,665 & $-0,005364 \mathrm{x}+0,001772$ \\
\hline $\mathrm{P} 1 / 3$ & 2,481 & 2,968 & $-0,010036 \mathrm{x}+0,002682$ & 1,680 & 2,364 & $-0,005941 \mathrm{x}+0,001799$ \\
\hline $\mathrm{P} 2 / 1$ & 1,291 & 2,524 & $-0,011214 \mathrm{x}+0,002748$ & 1,084 & 1,595 & $-0,004641 \mathrm{x}+0,001688$ \\
\hline $\mathrm{P} 2 / 2$ & 1,407 & 2,292 & $-0,008050 \mathrm{x}+0,002454$ & 1,068 & 1,673 & $-0,005500 \mathrm{x}+0,001783$ \\
\hline $\mathrm{P} 3 / 1$ & 1,371 & 2,922 & $-0,014109 \mathrm{x}+0,003205$ & 1,077 & 1,878 & $-0,007277 \mathrm{x}+0,002024$ \\
\hline
\end{tabular}

\subsection{2- Esforços resistentes}

Conhecendo-se as variações das deformações ao longo da altura da seção transversal do pilar, mostrada nas tabelas 6.6 e 6.7, as características da seção do pilar, do concreto e da armadura, mostradas na tabela 6.5, e admitindo-se uma relação tensão x deformação para o concreto, pode-se utilizar as expressões 3.20 e 3.21, comentadas no capítulo 3, para calcular os esforços normais resistentes teóricos e os respectivos momentos fletores, das seções dos modelos ensaiados.

As expressões 3.20 e 3.21 são mostradas abaixo:

$$
\begin{aligned}
& N_{u, \text { teo }}=b \int_{0}^{h} \sigma_{x}(x) d x+A_{s 1} \sigma_{\mathrm{s} 1}+A_{s 2} \sigma_{s 2} \\
& M_{u, \text { teo }}=b \int_{0}^{h} \sigma_{x}(x) \cdot\left(\frac{h}{2}-x\right) d x+\left(A_{s 2} \sigma_{\mathrm{s} 2}-A_{s 1} \sigma_{s 1}\right) \cdot\left(\frac{h}{2}-d^{\prime}\right)
\end{aligned}
$$


As análises foram feitas considerando-se as variações das tensões nas seções transversais dos pilares com as expressões propostas por LIMA (1997) e por COLLINS et al. (1993). Também, utilizavam-se os diagramas simplificados sugeridos pelo MC90 CEB-FIP (1991), pelo ACI 318 e por DINIZ (1997).

Para cálculo dos esforços resistentes teóricos, foi utilizado software "Mathcad Plus 6.0".

6.4.2.1- Relação tensão x deformação proposta por LIMA (1997)

Relação tensão x deformação:

$$
\sigma_{c}=\frac{\left(-2 f_{c}+E_{c} \varepsilon_{c o}\right)}{\varepsilon_{c o}^{3}} \varepsilon_{c}^{3}+\frac{\left(3 f_{c}-2 E_{c} \varepsilon_{c o}\right)}{\varepsilon_{c o}^{2}} \varepsilon_{c}^{2}+E_{c} \varepsilon_{c}
$$

Os esforços resistentes relativos à força última são mostrados na tabela 6.7.

TABELA 6.7 - Análise dos esforços resistentes para a relação tensão $x$ deformação proposta por LIMA (1997), para a ação última

\begin{tabular}{|c|c|c|c|c|c|c|c|}
\hline Modelo & $\begin{array}{c}\mathbf{F}_{\text {exp, cent }} \mathbf{k N} \\
\mathbf{k}\end{array}$ & $\begin{array}{c}\mathbf{F}_{\text {exp, exc }} \\
\mathbf{k N}\end{array}$ & $\begin{array}{c}\mathbf{M}_{\text {exp }} \\
\mathbf{k N . . c m}\end{array}$ & $\begin{array}{c}\mathbf{F}_{\text {teo }} \\
\mathbf{k N}\end{array}$ & $\begin{array}{c}\mathbf{M}_{\text {teo }} \\
\mathbf{k N . c m}\end{array}$ & $\begin{array}{c}\mathbf{F}_{\text {exp }} / \\
\mathbf{F}_{\text {teo }}\end{array}$ & $\begin{array}{c}\mathbf{M}_{\text {exp }} / \\
\mathbf{M}_{\text {teo }}\end{array}$ \\
\hline $\mathrm{P} 1 / 1 \mathrm{R}$ & $3.157,0$ & 156,0 & $5.928,0$ & $3.538,0$ & $2.282,0$ & 0,89 & 2,60 \\
\hline $\mathrm{P} 1 / 2$ & $2.825,8$ & 125,8 & $4.780,4$ & $2.821,0$ & $1.850,0$ & 1,00 & 2,58 \\
\hline $\mathrm{P} 1 / 3$ & $2.967,8$ & 117,8 & $4.476,4$ & $3.020,0$ & $2.054,0$ & 0,98 & 2,18 \\
\hline $\mathrm{P} 2 / 2$ & $2.788,9$ & 189,9 & $7.216,2$ & $2.994,0$ & $2.140,0$ & 0,93 & 3,35 \\
\hline $\mathrm{P} 3 / 1$ & $2.902,2$ & 153,2 & $5.821,6$ & $2.980,0$ & $1.785,0$ & 0,97 & 3,24 \\
\hline
\end{tabular}

Os esforços resistentes calculados para $80 \%$ da força última são mostrados na tabela 6.8 .

TABELA 6.8 - Análise dos esforços resistentes para a relação tensão $x$ deformação proposta por LIMA (1997), para $80 \%$ da ação última

\begin{tabular}{|c|c|c|c|c|c|c|c|}
\hline Modelo & $\begin{array}{c}\mathbf{F}_{\text {exp, cent }} \\
\mathbf{k N}\end{array}$ & $\begin{array}{c}\mathbf{F}_{\text {exp, exc }} \\
\mathbf{k N}\end{array}$ & $\begin{array}{c}\mathbf{M}_{\text {exp }} \\
\mathbf{k N . c m}\end{array}$ & $\begin{array}{c}\mathbf{F}_{\text {teo }} \\
\mathbf{k N}\end{array}$ & $\begin{array}{c}\mathbf{M}_{\text {teo }} \\
\mathbf{k N . c m}\end{array}$ & $\begin{array}{c}\mathbf{F}_{\text {exp }} / \\
\mathbf{F}_{\text {teo }}\end{array}$ & $\begin{array}{c}\mathbf{M}_{\text {exp }} / \\
\mathbf{M}_{\text {teo }}\end{array}$ \\
\hline $\mathrm{P} 1 / 1 \mathrm{R}$ & $2.539,0$ & 138,0 & $5.244,0$ & $2.438,0$ & $2.420,0$ & 1,04 & 2,17 \\
\hline $\mathrm{P} 1 / 2$ & $2.253,9$ & 106,9 & $4.062,2$ & $2.377,0$ & $1.833,0$ & 0,95 & 2,21 \\
\hline $\mathrm{P} 1 / 3$ & $2.364,1$ & 116,1 & $4.411,8$ & $2.751,0$ & $1.764,0$ & 0,86 & 2,50 \\
\hline $\mathrm{P} 2 / 1$ & $2.165,5$ & 161,5 & $6.137,0$ & $2.489,0$ & $1.642,0$ & 0,87 & 3,72 \\
\hline $\mathrm{P} 3 / 1$ & $2.350,3$ & 146,3 & $5.559,4$ & $2.468,0$ & $1.795,0$ & 0,95 & 3,08 \\
\hline
\end{tabular}


Analisando as tabelas 6.7 e 6.8, pode-se perceber que os valores das relações $F_{\text {exp }} / F_{\text {teo }}$, para as duas situações de etapas de aplicação de forças, ficaram próximo da unidade, indicando que os valores teóricos fornecidos pela equação de equilíbrio dos esforços normais resistentes, utilizando a relação tensão x deformação proposta por LIMA (1997), representam, com boa precisão, os valores obtidos experimentalmente.

As relações $M_{\text {exp }} / M_{\text {teo }}$, ficaram acima da unidade. Com isto, pode-se concluir que a excentricidade responsável pelos momentos experimentais atuantes nas seções transversais de meia altura dos pilares, não ocorreram na sua integridade, podendo existir também excentricidades acidentais que geravam momentos fletores contrários aos aplicados pelas forças excêntricas.

6.4.2.2- Relação tensão x deformação proposta por COLLINS et al. (1993)

Relação tensão $x$ deformação:

$$
\frac{\mathrm{f}_{\mathrm{c}}}{\mathrm{f}_{\mathrm{c}}^{\prime}}=\frac{\varepsilon_{\mathrm{c}}}{\varepsilon_{\mathrm{c}}^{\prime}} \frac{\mathrm{n}}{\mathrm{n}-1+\left(\frac{\varepsilon_{\mathrm{c}}}{\varepsilon_{\mathrm{c}}^{\prime}}\right)^{\mathrm{nk}}}
$$

Para a relação proposta por COLLINS et al. (1993), a análise foi feita usando os valores experimentais do módulo de deformação longitudinal do concreto $\left(E_{c}\right)$, e da deformação do concreto $\left(\varepsilon_{c}\right)$ correspondente à força máxima nos corpos-de-prova, tabela 6.5 .

Os valores dos esforços resistentes para a força última são mostrados na tabela 6.9.

TABELA 6.9 - Análise dos esforços resistentes para a relação tensão x deformação proposta por Collins et al. (1993), para a ação última

\begin{tabular}{|c|c|c|c|c|c|c|c|}
\hline Modelo & $\begin{array}{c}\mathbf{F}_{\text {exp, cent }} \\
\mathbf{k N}\end{array}$ & $\begin{array}{c}\mathbf{F}_{\text {exp, exc }} \mathbf{k N} \\
\text { kN }\end{array}$ & $\begin{array}{c}\mathbf{M}_{\text {exp }} \\
\mathbf{k N . c m}\end{array}$ & $\begin{array}{c}\mathbf{F}_{\text {teo }} \\
\mathbf{k N}\end{array}$ & $\begin{array}{c}\mathbf{M}_{\text {teo }} \\
\mathbf{k N . c m}\end{array}$ & $\begin{array}{c}\mathbf{F}_{\text {exp }} / \\
\mathbf{F}_{\text {teo }}\end{array}$ & $\begin{array}{c}\mathbf{M}_{\text {exp }} / \\
\mathbf{M}_{\text {teo }}\end{array}$ \\
\hline $\mathrm{P} 1 / 1 \mathrm{R}$ & $3.157,0$ & 156,0 & $5.928,0$ & 3226,0 & 4625,0 & 0,98 & 1,28 \\
\hline $\mathrm{P} 1 / 2$ & $2.825,8$ & 125,8 & $4.780,4$ & 2725,0 & 1888,0 & 1,04 & 2,53 \\
\hline $\mathrm{P} 1 / 3$ & $2.967,8$ & 117,8 & $4.476,4$ & 2483,0 & 3749,0 & 1,19 & 1,19 \\
\hline $\mathrm{P} 2 / 1$ & $2.788,9$ & 189,9 & $7.216,2$ & 2806,0 & 1670,0 & 0,99 & 4,28 \\
\hline $\mathrm{P} 2 / 2$ & $2.902,2$ & 153,2 & $5.821,6$ & 2852,0 & 2158,0 & 1,02 & 2,70 \\
\hline $\mathrm{P} 3 / 1$ & $3.307,6$ & 157,6 & $5.988,8$ & 3370,0 & 2196,0 & 0,98 & 2,72 \\
\hline
\end{tabular}


Para o caso de etapa de força relativa a $80 \%$ da força última os valores são mostrados na tabela 6.10 .

TABELA 6.10 - Análise dos esforços resistentes para a relação tensão $x$ deformação proposta por Collins et al. (1993), para $80 \%$ da ação última

\begin{tabular}{|c|c|c|c|c|c|c|c|}
\hline Modelo & $\begin{array}{c}\mathbf{F}_{\text {exp, cent }} \\
\mathbf{k N}\end{array}$ & $\begin{array}{c}\mathbf{F}_{\text {exp, exc }} \\
\mathbf{k N}\end{array}$ & $\begin{array}{c}\mathbf{M}_{\text {exp }} \\
\mathbf{k N . c m}\end{array}$ & $\begin{array}{c}\mathbf{F}_{\text {teo }} \\
\mathbf{k N}\end{array}$ & $\begin{array}{c}\mathbf{M}_{\text {teo }} \\
\mathbf{k N . c m}\end{array}$ & $\begin{array}{c}\mathbf{F}_{\text {exp }} / \\
\mathbf{F}_{\text {teo }}\end{array}$ & $\begin{array}{c}\mathbf{M}_{\text {exp }} / \\
\mathbf{M}_{\text {teo }}\end{array}$ \\
\hline $\mathrm{P} 1 / 1 \mathrm{R}$ & $2.539,0$ & 138,0 & $5.244,0$ & 2793,0 & 2569,0 & 0,91 & 2,04 \\
\hline $\mathrm{P} 1 / 2$ & $2.253,9$ & 106,9 & $4.062,2$ & 2160,0 & 2111,0 & 1,04 & 1,92 \\
\hline $\mathrm{P} 1 / 3$ & $2.364,1$ & 116,1 & $4.411,8$ & 2726,0 & 1751,0 & 0,87 & 2,52 \\
\hline $\mathrm{P} 2 / 1$ & $2.165,5$ & 161,5 & $6.137,0$ & 2338,0 & 1699,0 & 0,93 & 3,60 \\
\hline $\mathrm{P} 2 / 2$ & $2.350,3$ & 146,3 & $5.559,4$ & 2240,0 & 1921,0 & 1,05 & 2,88 \\
\hline $\mathrm{P} 3 / 1$ & $2.681,8$ & 131,8 & $5.008,4$ & 3066,0 & 2833,0 & 0,87 & 1,77 \\
\hline
\end{tabular}

Os valores das relações $F_{\exp } / F_{\text {teo }}$, são praticamente iguais a unidade, tendo, a relação de COLLINS, uma excelente previsão para os valores experimentais.

As relações $M_{\text {exp }} / M_{\text {teo }}$, também ficaram acima da unidade, concordando com os valores obtidos utilizando a relação proposta por LIMA, sugerindo, assim, que algum problema poderia ter ocorrido com o sistema de ensaio.

Como resumo apresenta-se a tabela 6.11, onde são apresentadas as relações entre os valores teóricos e os experimentais, bem como os valores médios

TABELA 6.11- Análise dos esforços resistentes para as relações tensão $x$ deformação proposta LIMA (1997 e COLLINS et al. (1993)

\begin{tabular}{|c|c|c|c|c|c|c|c|c|}
\hline \multirow{3}{*}{ Modelo } & \multicolumn{2}{|c|}{$\begin{array}{c}\text { LIMA (1997) } \\
\text { Força última }\end{array}$} & \multicolumn{2}{c|}{$\begin{array}{c}\text { LIMA (1997) } \\
\mathbf{8 0} \text { força última }\end{array}$} & \multicolumn{2}{c|}{$\begin{array}{c}\text { COLLINS et al. (1993) } \\
\text { força última }\end{array}$} & \multicolumn{2}{c|}{$\begin{array}{c}\text { COLLINS et al. (1993) } \\
\mathbf{8 0 \%} \text { força última }\end{array}$} \\
\cline { 2 - 9 } & $\begin{array}{c}\mathbf{F}_{\text {exp }} / \\
\mathbf{F}_{\text {teo }}\end{array}$ & $\begin{array}{c}\mathbf{M}_{\text {exp }} / \\
\mathbf{M}_{\text {teo }}\end{array}$ & $\begin{array}{c}\mathbf{F}_{\text {exp }} / \\
\mathbf{F}_{\text {teo }}\end{array}$ & $\begin{array}{c}\mathbf{M}_{\text {exp }} / \\
\mathbf{M}_{\text {teo }}\end{array}$ & $\begin{array}{c}\mathbf{F}_{\text {exp }} / \\
\mathbf{F}_{\text {teo }}\end{array}$ & $\begin{array}{c}\mathbf{M}_{\text {exp }} / \\
\mathbf{M}_{\text {teo }}\end{array}$ & $\begin{array}{c}\mathbf{F}_{\text {exp }} / \\
\mathbf{F}_{\text {teo }}\end{array}$ & $\begin{array}{c}\mathbf{M}_{\text {exp }} / \\
\mathbf{M}_{\text {teo }}\end{array}$ \\
\hline $\mathrm{P} 1 / 1 \mathrm{R}$ & 0,89 & 2,60 & 1,04 & 2,17 & 0,98 & 1,28 & 0,91 & 2,04 \\
\hline $\mathrm{P} 1 / 2$ & 1,00 & 2,58 & 0,95 & 2,21 & 1,04 & 2,53 & 1,04 & 1,92 \\
\hline $\mathrm{P} 1 / 3$ & 0,98 & 2,18 & 0,86 & 2,50 & 1,19 & 1,19 & 0,87 & 2,52 \\
\hline $\mathrm{P} 2 / 1$ & 0,93 & 3,35 & 0,87 & 3,72 & 0,99 & 4,28 & 0,93 & 3,60 \\
\hline $\mathrm{P} 2 / 2$ & 0,97 & 3,24 & 0,95 & 3,08 & 1,02 & 2,70 & 1,05 & 2,88 \\
\hline P3/1 & 0,87 & 2,62 & 0,84 & 1,88 & 0,98 & 2,72 & 0,87 & 1,77 \\
\hline \multirow{2}{*}{ Média } & 0,94 & 2,76 & 0,92 & 2,59 & 1,03 & 2,45 & 0,95 & 2,45 \\
\hline
\end{tabular}

Percebe-se na tabela 6.11 , que os valores obtidos utilizando a relação tensão x deformação proposta por COLLINS, apresentou resultados mais próximos dos experimentais do que aqueles calculados com a relação proposta por LIMA, tanto para esforços normais quanto para momentos 
fletores. No entanto, as duas propostas apresentam excelente precisão para as forças normais.

Com relação à diferença para os momentos fletores, pode-se tomar alguns aspectos sobre as excentricidades e o momento fletor efetivamente atuante:

Devido a aplicação de duas forças independentes, pode estar ocorrendo a ação de um momento fletor contrário ao aplicado pelas forças excêntricas relativo ao aparecimento de excentricidades acidentais. Este momento fletor é resultante do produto da força aplicada no eixo longitudinal do modelo com uma provável excentricidade acidental que se dava do lado contrário ao da aplicação da força excêntrica. Como a força aplicada no eixo longitudinal era de grande intensidade, bastava uma pequena excentricidade acidental para gerar um momento fletor de intensidade considerável na seção central do modelo. A coerência dessas excentricidades acidentais é razoável de se admitir, pois pode ser proveniente do posicionamento das barras da armadura, posicionamento do modelo no pórtico de ensaio, colocação dos aparelhos de apoio, entre outros. Como exemplo pode-se tomar os modelos P1/2, P2/2 e P3/1, e adota-se valor para excentricidade acidental $\left(e_{\text {acid }}\right)$ de $1,2 \mathrm{~cm}$, calculando-se os momentos fletores finais, obteve-se os valores indicados na tabela 6.12.

TABELA 6.12 - Correção do momento fletor experimental, proveniente de excentricidade acidental, relação de Collins, para a ação última

\begin{tabular}{|c|c|c|c|c|c|c|c|c|}
\hline Modelo & $\begin{array}{c}\mathbf{F}_{\text {long.cent }} \\
\mathbf{k N}\end{array}$ & $\begin{array}{c}F_{\text {exp, exc }} \\
\text { kN }\end{array}$ & $\begin{array}{c}F_{\text {exp, cent }} \\
\text { kN }\end{array}$ & $\begin{array}{c}\mathbf{F}_{\text {long.cent }} \mathbf{X} \\
\mathbf{e}_{\text {acid. }}\end{array}$ & $\begin{array}{l}F_{\text {exp. exc. }} \\
\mathbf{X} \mathbf{e}_{\text {geom. }}\end{array}$ & $\begin{array}{l}M_{\text {exp. resul. }} \\
\text { kN.cm }\end{array}$ & $\begin{array}{c}\mathrm{M}_{\text {teo }} \\
\text { kN.cm }\end{array}$ & $\begin{array}{c}\mathbf{M}_{\exp } / \\
\mathbf{M}_{\text {teo }}\end{array}$ \\
\hline $\mathrm{P} 1 / 2$ & $2.700,0$ & 125,8 & $2.825,8$ & $-3.240,0$ & $4.780,4$ & $1.540,4$ & 1888,0 & 0,82 \\
\hline P2/2 & $2.749,0$ & 153,2 & $2.902,2$ & $-3.298,0$ & $5.821,6$ & $2.522,8$ & 2158,0 & 1,17 \\
\hline $\mathrm{P} 3 / 1$ & $3.150,0$ & 157,6 & $3.307,6$ & $-3.780,0$ & $5.988,8$ & $2.208,8$ & 2196,0 & 1,00 \\
\hline \multicolumn{8}{|c|}{ Média } & 0.99 \\
\hline
\end{tabular}

$>$ O aparelho de apoio, que funciona pelo princípio da deformabilidade do neoprene confinado, pode ter ocasionado uma rigidez ao aparelho de apoio podendo esta não ser desprezível. Com isto pode ter havido uma restrição suficiente- 
mente grande para alterar o valor do momento supostamente aplicado. Além disso, talvez fosse preciso verificar se o centro de rotação não sai fora do centro geométrico do aparelho de apoio.

Isso mostra que os problemas do ensaio podem ter sido: colocação da força centrada no eixo longitudinal do modelo; saber qual o valor aproximado da excentricidade que a força longitudinal está submetida; ter maior conhecimento do funcionamento do aparelho de apoio utilizado.

6.4.2.3- Relação tensão x deformação proposta pelo Código Modelo - MC90 CEB-FIP (1991)

O CEB-FIB (1991) sugere para relação tensão x deformação de CAR um diagrama parábolo-retângulo, cujas expressões, vistas no capítulo 3, são:

$$
\begin{gathered}
\sigma_{c d}=0,85 f_{c d}\left[2 \cdot\left(\frac{\varepsilon_{c}}{\varepsilon_{c 1}}\right)-\left(\frac{\varepsilon_{c}}{\varepsilon_{c 1}}\right)^{2}\right] \\
\varepsilon_{c 1}=0,002 \quad \text { e } \quad \varepsilon_{c u}=0,0035 \cdot\left(\frac{50}{f_{c k}}\right) \quad(\mathrm{MPa})
\end{gathered}
$$

As análises dos esforços resistentes para a força última são mostradas na tabela 6.13 .

TABELA 6.13 - Análise dos esforços resistentes para a relação tensão x deformação sugerida pelo MC90 CEB-FIP (1991), para a ação última

\begin{tabular}{|c|c|c|c|c|c|c|c|}
\hline Modelo & $\begin{array}{c}\mathbf{F}_{\text {exp, cent }} \\
\mathbf{k N}\end{array}$ & $\begin{array}{c}\mathbf{F}_{\text {exp, exc }} \\
\mathbf{k N}\end{array}$ & $\begin{array}{c}\mathbf{M}_{\text {exp }} \\
\mathbf{k N . c m}\end{array}$ & $\begin{array}{c}\mathbf{F}_{\text {teo }} \\
\mathbf{k N}\end{array}$ & $\begin{array}{c}\mathbf{M}_{\text {teo }} \\
\mathbf{k N . c m}\end{array}$ & $\begin{array}{c}\mathbf{F}_{\text {exp }} / \\
\mathbf{F}_{\text {teo }}\end{array}$ & $\begin{array}{c}\mathbf{M}_{\text {exp }} / \\
\mathbf{M}_{\text {teo }}\end{array}$ \\
\hline $\mathrm{P} 1 / 1 \mathrm{R}$ & $3.157,0$ & 156,0 & $5.928,0$ & $1.543,0$ & $4.314,0$ & 2,05 & 1,37 \\
\hline $\mathrm{P} 1 / 2$ & $2.825,8$ & 125,8 & $4.780,4$ & $1.995,0$ & $4.311,0$ & 1,42 & 1,11 \\
\hline $\mathrm{P} 1 / 3$ & $2.967,8$ & 117,8 & $4.476,4$ & $1.795,0$ & $4.252,0$ & 1,65 & 1,05 \\
\hline $\mathrm{P} 2 / 1$ & $2.788,9$ & 189,9 & $7.216,2$ & $1.832,0$ & $4.626,0$ & 1,52 & 1,56 \\
\hline $\mathrm{P} 3 / 1$ & $2.902,2$ & 153,2 & $5.821,6$ & $2.063,0$ & $4.635,0$ & 1,41 & 1,26 \\
\hline
\end{tabular}

Analisando a tabela 6.13, pode-se perceber que os valores das relações $F_{\text {exp }} / F_{\text {teo }}$, estão abaixo dos valores experimentais encontrados. Como essa relação é adotada para cálculo, pode-se considerá-la a favor da segurança, mas com pouca precisão. 
Com relação aos momentos fletores $M_{\text {exp }} / M_{\text {teo }}$, são também conservativas, ficando abaixo dos valores experimentais encontrados. No entanto, esta análise não leva em conta a excentricidade acidental detectada nos ensaios, podendo essas relações terem valores menores.

\subsubsection{Relação tensão x deformação proposta pelo ACI 318 - M89}

O diagrama retangular de tensões assumido pelo $\mathrm{ACl}$, é definido por dois parâmetros $\alpha_{1}$ e $\beta_{1}$, como mostra a figura 3.6, no capítulo 3. O parâmetro $\alpha_{1}$ é assumido para um valor constante de 0,85 . O parâmetro $\beta_{1}$ é igual a 0,85 para resistência do concreto até $30 \mathrm{MPa}$, e é reduzido continuamente a uma taxa de 0,08 , para cada $10 \mathrm{MPa}$ que excede $30 \mathrm{MPa}$. $\mathrm{O}$ parâmetro $\beta_{1}$ não pode ser menor que 0,65 .

A análise dos esforços resistentes para a força última é mostrada na tabela 6.14.

O diagrama simplificado sugerido pelo $\mathrm{ACI} 318$, apresenta valores para os esforços normais, abaixo dos encontrados experimentalmente, como também para os momentos fletores. Mas, devido à sua simplicidade, tais valores podem ser considerados muito bons para utilizar em escritórios de projetos estruturais. Ressalva deve ser feita com relação aos momentos fletores, que apresentam valores muito abaixo dos obtidos experimentalmente. No entanto, essa análise não levou em consideração a provável excentricidade acidental encontrada nos modelos, podendo-se assim tornar essas relações bem menores.

TABELA 6.14- Análise dos esforços resistentes para a relação tensão $x$ deformação sugerida pelo ACI 318 - M89, para a ação última

\begin{tabular}{|c|c|c|c|c|c|c|c|}
\hline Modelo & $\begin{array}{c}\mathbf{F}_{\text {exp, cent }} \\
\mathbf{k N}\end{array}$ & $\begin{array}{c}\mathbf{F}_{\text {exp, exc }} \mathbf{k N} \\
\text { kN }\end{array}$ & $\begin{array}{c}\mathbf{M}_{\text {exp }} \\
\mathbf{k N . c m}\end{array}$ & $\begin{array}{c}\mathbf{F}_{\text {teo }} \\
\mathbf{k N}\end{array}$ & $\begin{array}{c}\mathbf{M}_{\text {teo }} \\
\mathbf{k N . c m}\end{array}$ & $\begin{array}{c}\mathbf{F}_{\text {exp }} / \\
\mathbf{F}_{\text {teo }}\end{array}$ & $\begin{array}{c}\mathbf{M}_{\text {exp }} / \\
\mathbf{M}_{\text {teo }}\end{array}$ \\
\hline $\mathrm{P} 1 / 1 \mathrm{R}$ & $3.157,0$ & 156,0 & $5.928,0$ & $1.989,0$ & 969,6 & 1,59 & 6,11 \\
\hline $\mathrm{P} 1 / 3$ & $2.825,8$ & 125,8 & $4.780,4$ & $1.917,1$ & 934,6 & 1,47 & 5,11 \\
\hline $\mathrm{P} 2 / 1$ & $2.967,8$ & 117,8 & $4.476,4$ & $1.848,5$ & 901,2 & 1,61 & 4,97 \\
\hline $\mathrm{P} 2 / 2$ & $2.902,2$ & 189,9 & $7.216,2$ & $2.015,3$ & 982,5 & 1,38 & 7,34 \\
\hline $\mathrm{P} 3 / 1$ & $3.307,6$ & 153,2 & $5.821,6$ & $2.005,1$ & 977,5 & 1,45 & 5,96 \\
\hline
\end{tabular}




\subsubsection{5- Relação tensão x deformação proposta por DINIZ}

DINIZ apud VASCONCELOS (1998) propõe um diagrama retangular que foi descrito no capítulo 3 desta dissertação.

As análises dos esforços resistentes para as forças últimas são mostradas na tabela 6.15 .

TABELA 6.15- Análise dos esforços resistentes para a relação tensão x deformação proposta por DINIZ, para a ação última

\begin{tabular}{|c|c|c|c|c|c|c|c|}
\hline Modelo & $\begin{array}{c}\mathbf{F}_{\text {exp, cent }} \\
\text { kN }\end{array}$ & $\begin{array}{c}F_{\text {exp, exc }} \\
\text { KN }\end{array}$ & $\begin{array}{c}M_{\exp } \\
\text { kN.cm }\end{array}$ & $\begin{array}{l}F_{\text {teo }} \\
\text { kN }\end{array}$ & $\begin{array}{c}\mathbf{M}_{\text {teo }} \\
\text { kN.cm }\end{array}$ & $\begin{array}{l}F_{\text {exp }} / \\
F_{\text {teo }}\end{array}$ & $\begin{array}{c}\mathbf{M}_{\exp } / \\
\mathbf{M}_{\text {teo }}\end{array}$ \\
\hline $\mathrm{P} 1 / 1 \mathrm{R}$ & $3.157,0$ & 156,0 & $5.928,0$ & $2.079,4$ & $1.185,2$ & 1,22 & 4,42 \\
\hline P1/2 & $2.825,8$ & 125,8 & $4.780,4$ & $2.004,2$ & $1.142,4$ & 1,12 & 3,56 \\
\hline $\mathrm{P} 1 / 3$ & $2.967,8$ & 117,8 & $4.476,4$ & $1.932,5$ & $1.101,5$ & 1,22 & 4,01 \\
\hline $\mathrm{P} 2 / 1$ & $2.788,9$ & 189,9 & $7.216,2$ & $2.106,9$ & $1.200,9$ & 1,03 & 5,11 \\
\hline $\mathrm{P} 2 / 2$ & $2.902,2$ & 153,2 & $5.821,6$ & $2.096,2$ & $1.194,9$ & 1,12 & 4,65 \\
\hline $\mathrm{P} 3 / 1$ & $3.307,6$ & 157,6 & $5.988,8$ & $2.044,8$ & $1.165,5$ & 1,31 & 4,30 \\
\hline
\end{tabular}

Analisando a tabela 6.15 pode-se perceber que os valores das relações $F_{\text {exp }} / F_{\text {teo }}$ e $M_{\text {exp }} / M_{\text {teo }}$, apresentaram resultados muito bons, levando em conta a sua simplicidade. Tais valores se mostraram mais preciso que os apresentados pelo $\mathrm{ACl}$, aparentando boa precisão para uso em projetos estruturais em CAR.

Com relação aos momentos fletores estarem bem abaixo dos experimentais, deve-se as mesmas explicações do item anterior.

\section{5- Ductilidade}

No tocante à ductilidade, observou-se que para a taxa de armadura longitudinal utilizada na série $1,2,26 \%(8 \phi 12,5)$, a variação da taxa de armadura transversal de 1,58\%, 0,79\% e 0,53\%, não resultou em perda considerável da capacidade resistente da seção do pilar. Esta variação, através do aumento do espaçamento entre os estribos, causou diferentes forma de ruptura do modelo. Para as taxas de 1,58\% e 0,79\%, a ruptura foi não brusca, com destacamento do cobrimento de concreto, enquanto que, para a menor taxa, a ruptura foi muito frágil, com ruína por ruptura súbita do concreto da seção central do pilar. 
Para a série 2, onde utilizou-se uma taxa de armadura longitudinal menor, $1,26 \%(8 \phi 12,5)$, obteve-se para a taxa de armadura transversal de 0,79\%, uma ruptura frágil com ruptura da seção central do pilar. Para a taxa de $1,58 \%$, a ruptura foi pouco dúctil com destacamento do cobrimento de concreto.

Isso mostra que a ductilidade é função das taxas de armadura longitudinal e transversal, onde, para a taxa longitudinal de $2,26 \%$, série 1 , foi suficiente uma taxa transversal de 0,79\%, e quando baixou-se a taxa longitudinal para 1,26\%, série 2, esta taxa transversal não foi suficiente, sendo necessário uma maior de 1,58\%.

\section{6- Considerações Finais}

Um ponto interessante na análise dos gráficos força $x$ deformação, se deu com relação as mudança na inclinação da curva quando a força alcançava em torno de $55 \%$ da força de ruptura. Este fato pode ser proveniente do início do destacamento do cobrimento de concreto que envolvia a armadura, ocasionando uma acomodação da estrutura.

Este ponto pode também marcar a transição do regime elástico para o elastoplástico do concreto. Onde era caracterizado por fissuração do concreto e as hipóteses da elasticidade não eram mais válidas.

Em se tratando das relações tensão $x$ deformação analisadas, as propostas por LIMA (1997) e COLLINS et al. (1993) descreveram precisamente 0 valores das tensões para CAR. Os diagrama de tensões propostos pelo ACI 318 e por DINIZ (1997), podem ser considerados convenientes, pela sua simplicidade e boa precisão dos valores, e é recomendado para cálculos práticos como em projetos estruturais em CAR.

As diferenças para o momento fletor experimental, se deram pois 0 sistema de ensaio adotado, não deve ter apresentado uma forma de centrar, com maior precisão, a força aplicada no eixo longitudinal dos modelos, ocasionando o aparecimento de excentricidade acidental não prevista. 
A análise da variação das taxas de armadura, mostrou que a ductilidade da seção transversal é função das taxas de armadura transversal e longitudinal, mas é necessário maior número de ensaios para se chegar a conclusões mais precisas a respeito disto. 


\section{7}

CONCLUSÃO

Este trabalho é continuidade de estudo experimental de pilares de CAD submetidos a compressão excêntrica, em desenvolvimento no Departamento de Engenharia de Estruturas da EESC-USP.

As resistências à compressão dos concretos utilizados nos pilares, ficaram acima do pretendido, que era de $80 \mathrm{MPa}$. Mas isso não comprometeu os objetivos da pesquisa, pois a diferença entre as características mecânicas dos concretos de resistências entre 80MPa e 90MPa são mínimas.

$\mathrm{Na}$ análise das características mecânicas do concreto, observou-se que as expressões propostas na literatura, prevêem satisfatoriamente os valores para a resistência à tração do concreto, e para o módulo de deformação longitudinal. Para a resistência à tração, a expressão proposta por CARRASQUILLO et al. (1981), apresentou melhor precisão em comparação com os valores experimentais obtidos. Em se tratando do módulo de deformação longitudinal, a expressão proposta pelo $\mathrm{ACl} 318$ (1994), foi a que apresentou melhor proximidade com os valores experimentais.

A análise dos resultados obtidos nos ensaios dos modelos experimentais, submetidos à compressão excêntrica, foi feita em duas etapas do ensaio: na etapa onde ocorria a última força, quando foram considerados os colapsos, e para uma ação relativa a $80 \%$ da ação da força última, onde a estrutura estava em serviço.

Os diagramas que relacionaram as forças aplicadas com as deformações dos pilares, apresentaram, de maneira geral, resultados coerentes com os esperados em ensaios deste tipo. 
Os efeitos da flexão oblíqua, provavelmente não foram sentidos nos ensaios, devido à proximidade dos pontos onde se fazia a leitura das deformações longitudinais. Para isso, seria necessário instrumentar as barras da armadura longitudinal localizadas nas extremidades da seção do pilar, tendo assim, as prováveis diferenças de deformações e uma situação mais real do que estava acontecendo na seção.

As deformações últimas de compressão do concreto, na face mais comprimida do pilar, variaram entre $2,3 \%$ e $3 \%$, tendo média de $2,59 \%$. Estes resultados confirmam a alteração proposta para o diagrama de domínios de deformação, quando se trata de concreto de alta resistência.

Um ponto interessante na análise dos gráficos força $x$ deformação, foi com relação às mudanças na inclinação da curva, quando a força alcançava em torno de $55 \%$ da força de ruptura. Este fato pode ser proveniente do início do destacamento do cobrimento de concreto que envolveria a armadura, ocasionando uma acomodação da estrutura.

A análise da variação das taxas de armadura, mostrou que a ductilidade da seção transversal é função das taxas de armadura transversal e longitudinal, mas é necessário um maior número de ensaios para se chegar a conclusões mais precisas a respeito disto.

$\mathrm{Na}$ análise dos esforços resistentes, observou-se que as relações $F_{\text {exp }}$ / $F_{\text {teo }}$ são praticamente iguais à unidade, tanto para a relação tensão $x$ deformação proposta por LIMA (1997), quanto para a proposta por COLLINS et al. (1993).

As relações $M_{\text {exp }} / M_{\text {teo }}$, ficaram acima da unidade. Devido a esse fato, pôde-se supor algumas justificativas:

$>$ a excentricidade geométrica, que era responsável pelos momentos experimentais atuantes nas seções transversais de meia altura dos pilares, não ocorreram na sua integridade, podendo existir também excentricidades acidentais que geravam momentos contrários ao aplicado pelas forças excêntricas;

$>$ aparelho de apoio, que funciona pelo princípio da deformabilidade do neoprene confinado, pode ter ocasionado uma rigidez não 
desprezível. Com isto pode ter havido uma restrição suficientemente grande para alterar o valor do momento supostamente aplicado. Além disso, talvez fosse preciso verificar se o centro de rotação não sai fora do centro geométrico do aparelho de apoio.

Observou-se também que os valores obtidos utilizando a relação tensão x deformação proposta por COLLINS, apresentaram resultados mais próximos do experimental do que a relação proposta por LIMA, tanto para esforços normais quanto para momentos fletores. No entanto, as duas propostas apresentam excelente precisão para os esforços normais.

As grandes diferenças para o momento experimental, deram-se devido ao sistema de ensaio adotado, o qual não apresentou uma forma de centrar, com maior precisão, a força aplicada no eixo longitudinal dos modelos, ocasionando 0 aparecimento de excentricidade acidental desconhecida.

Para as relações tensão $\mathrm{x}$ deformação analisadas, as propostas por LIMA (1997) e COLLINS et al. (1993) descreveram precisamente os valores das tensões para CAR. Os diagramas de tensões propostos pelo ACl 318 (1994) e por DINIZ (1997), podem ser considerados convenientes, pela sua simplicidade e boa precisão dos valores, e são recomendados para cálculos práticos, como em projetos estruturais em CAR.

O trabalho proporcionou a todos os envolvidos maiores conhecimentos sobre o assunto, envolvendo o sistema de ensaio adotado, bem como o comportamento desse tipo de estrutura com relação às deformações e esforços resistentes.

\section{Sugestões para Continuidade da Pesquisa}

Como continuidade da pesquisa, pode-se sugerir melhorar o sistema de ensaio, ou a forma de se aplicar o momento experimental, pois esse objetivo não foi alcançado nesta pesquisa.

Podem-se realizar ensaios de pilares sob compressão excêntrica, com duas classes de resistências do concreto, uma de resistência usual e outra de alta resistência, para se poder comparar as diferenças entre os 
resultados obtidos com as classes de concreto, partindo das mesmas condições de ensaio.

Para fins de ductilização dos pilares na ruptura, pode-se estudar o efeito da fibra adicionada ao concreto, mantendo-se a taxa de armadura transversal em níveis normalmente utilizados para concreto de resistência usual.

Pode-se também utilizar outras configurações de estribos, que possam ser utilizadas comumente na prática, e avaliar seu comportamento com relação àductilização do pilar. 


\section{8}

\section{REFERÊNCIAS BIBLIOGRÁFICAS E BIBLIOGRAFIA COMPLEMENTAR}

\section{1- Referências Bibliográficas}

AGOSTINI, L. R. S. (1992). Pilares de concreto de alta resistência. São Paulo. Tese (doutorado) - Escola Politécnica, Universidade de São Paulo.

ALMEIDA, I. R. de (1990). Betões de alta resistência e durabilidade: composição e características. Lisboa 740p. Tese (doutorado) Universidade Técnica de Lisboa.

AMARAL, C. K. (1988). Microssílica em concretos e argamassas de alta resistência. In: REUNIÃO ANUAL DO IBRACON, 30., Rio de Janeiro, 1988, Anais. v. 1, p. 67-80.

AMERICAN CONCRETE INSTITUTE. Committee 363R (1992). State of the art report on high strength concrete. Detroit, 55p.

- Committee 318R (1994). Building code requirements for reinforced concrete. Detroit.

AMERICAN SOCIETY FOR TESTING AND MATERIALS (1993). Standard Specifications for Silica Fume for Use in Hydraulic-Cement and Mortar. ASTM C 1240-93, Philadelphia.

ASSOCIAÇÃO BRASILEIRA DE NORMAS TÉCNICAS. (1987). NBR 7217 Agregado: determinação da composição granulométrica. Rio de Janeiro. . (1980) NBR 6118 - Projeto e execução de obras de concreto armado. Rio de Janeiro. . (1980) NBR 5739 - Ensaio de compressão de corpos-de-prova cilíndricos de concreto. Rio de Janeiro. 
(1987) NBR 9776 - Agregados: determinação da massa específica de agregados miúdos por meio do Frasco de Chapman. Rio de Janeiro.

. (1984) NBR 6474 - Cimento portland e outros materiais em pó determinação da massa específica. Rio de Janeiro.

(1982) NBR 7222 - Argamassa e concretos - determinação da resistência à tração por compressão diametral de corpos-de-prova cilíndricos. Rio de Janeiro.

(1994) NBR 12142 - Concreto - determinação de resistência à tração na flexão em corpos-de-prova prismáticos. Rio de Janeiro.

AZIZINAMINI, A.; KEBRAEI, M. (1996). Flexural capacity of high strength concrete columns under eccentric loading. In: INTERNACIONAL SYMPOSIUM ON UTILIZATION OF HIGH STRENGTH/HIGH PERFORMANCE CONCRETE, 4. Paris, may, p.863-871, Proceedings.

CARINO, N.J.; CLIFTON, J.R. (1991). High - performance concrete: research needs to enhance its use. Concrete International, v.13, n.9, p.70-76.

CARRASQUILLO, P. M.; NILSON, A. H.; SLATE, F. O. (1981). Properties of high strength concrete subject to short-term loads. ACI Materials journal, p.171-181, May-June.

CEB (1991). CEB-FIP model code 1990. Bulletin d'Information, n.203-205, July.

CEB (1990). Working Group on High-strength Concrete (1990), High strength concrete- state of the art report. CEB Bulletin dlnformation, n.197, ago.

CEB (1993). Advanced studies on structural concrete. Bulletin dlnformation, n.221, p.108-124. mar.

Cimento Hoje abcp (1998). Informativo da ABCP - Associação Brasileira de Cimento Portland, Ano II № 19 Dezembro de 1998.

CIVIL ENGINEERING RESEARCH FOUNDATION.(1993). High-performance construction materials and systems: an essential program for America and its infrastructure. Washington, CERF/ASCE. Technical Report 935011 
COLLINS, P.M.; MITCHELL, D.; MACGREGOR, J. (1993). Structural Design Consideration for High-Strength Concrete. Concrete International, p. 2734, May.

CORBIOLI, N. (1997). Desempenho medido na Prática. Revista de tecnologia da construção - Téchne. São Paulo, n.29, p.24-29, jul-ago.

CUSSON, D.; PAULTRE, P. (1994). High-strength concrete columns confined by rectangular ties. Journal of structural engineering, ASCE, v.120, n.3, p.783-804, mar.

DAL MOLIN, D. C. (1995). Contribuição ao estudo das propriedades mecânicas dos concretos de alta resistência com e sem adição de sílica ativa. São Paulo. 286P. Tese (doutorado) - Escola Politécnica, Universidade de São Paulo.

DE LARRARD, F.; MALIER, Y. (1989). Propriétés constructives des betons à trés hautes performances: de la micro à la macroestruture. Annales de L'Institut Technique du Batiment et des Travaux Publics, Série: Beton 268, n.479, p.77-109, dec.

DUCATTI, V. A. (1993). Concreto de elevado desempenho - estudo de aderência com a armadura. São Paulo. 374P. Tese (doutorado) - Escola Politécnica, Universidade de São Paulo.

FUSCO, P. B. (1995) Técnicas de armar as estruturas de concreto, São Paulo, Pini.

GIONGO, J. S.; LIMA, F. B.; TAKEYA, T.(1996). Análise experimental de pilares de concreto armado de alto desempenho solicitados a compressão simples e flexão normal composta. São Carlos. Escola de Engenharia de São Carlos - USP (Relatório de Auxílio à Pesquisa apresentado à FAPESP - Processo 95/2458-4 ).

GIONGO, J. S.; GUIMARÃES, A. E. P.; TAKEYA, T.(1998). Análise experimental de pilares de concreto armado de alto desempenho com adição de fibras. São Carlos. Escola de Engenharia de São Carlos - USP (Relatório de Auxílio à Pesquisa apresentado à FAPESP - Processo 97/00932-6). 
GONZALEZ-ISABEL (1993). Hormigon de alta resistência, Madrid, INTEMAC.

HERRMANN, E.; CAMERATO, C. R. (1988). Estudo e aplicação de concreto de alta resistência com microssílica no Brasil. In: REUNIÃO ANUAL DO IBRACON, 30., Rio de Janeiro, 1988. Anais. v. 1, p. 81-93

IBRAHIM, H. H. H.;MAC GREGOR, J. G. (1996). Tests of eccentrically loaded high-strength concrete columns. ACI Structural journal. v. 93, n. 5, Sep.-Oct.

LEITE, M. F. (1994). The Suarez Trade Building in Salvador, Brazil In: OUR WORLD IN CONCRETE \& STRUCTURES, 19. Singapore, 24-26, aug. Anais.

LEITE, M. F.; MIRANDA, M. (1997). Estruturas Criativas, Newsletter da Leite e Miranda Engenheiros Associados, Ltda., Salvador - BA. v2.1, mar.

LEONHARDT, F. \& MONNING, E. (1978). Construções de concreto, v. 1. Rio de Janeiro. Interciência.

LIMA, F.B. (1997). Pilares de concreto de alto desempenho: fundamentos e experimentação. São Carlos. Escola de Engenharia de São Carlos USP. (Tese de doutorado)

LLOYD, N. A.; RAGAN, B. V. (1996). Studies on high-strength concrete columns under eccentric compression. ACI Structural journal. v. 93, n. 6, nov.-dec.

MEHTA, P. K.; MONTEIRO, P. J. M. (1994). Concreto: estrutura, propriedade e materiais. São Paulo, Pini, 573p.

MEHTA, P. K.; AITCIN, P. C. (1990). Microstructural basis of selection of materials and mix proportions for high strength concrete. In: INTERNATIONAL SYMPOSIUM ON APPLICATIONS OF HIGH STRENGTH CONCRETE, 2. Berkeley, p.265-286, Procedings.

MORAES, M. F. (1990). Algumas propriedades mecânicas do concreto com microssílca. São Paulo. Dissertação (mestrado). Escola Politécnica, Universidade de São Paulo.

NEVILLE, A. M. (1997). Propriedades do concreto. São Paulo, Pini. 
NEVILLE, A. M; BROOKS, J. J. (1987). Concrete Technology. England: Longman Scientific \& Technical, 439p.

NS 3473 E (1992). Concrete structures: design rules. 4 ed. Oslo, Norway, nov.

PEREIRA NETO, P. M. (1994). O efeito do agregado graúdo em algumas propriedades do concreto de alta resistência com microssílica. São Paulo. 173p. Dissertação (mestrado) - Escola Politécnica, Universidade de São Paulo.

PINTO JUNIOR, N. O. (1992). Flexão de vigas de concreto de alta resistência. São Paulo. Tese (doutorado) - Escola Politécnica, Universidade de São Paulo.

ROCHA, S. (1997). Desempenho medido na Prática. Revista de tecnologia da construção - Téchne. São Paulo, n.29, p.14-22, jul-ago.

SHAH, S. P.; AHMAD, S. H. (1994). High performance concrete and applications. London, Edward Arnold, 402 p.

SILVA FILHO, A. F. (1996). Emprego de concreto de alto desempenho na Bahia um relatório histórico: início-estágio atual-perspectivas. In: INTERNATIONAL CONGRESS ON HIGH-PERFORMANCE CONCRETE, AND PERFORMANCE AND QUALITY OF CONCRETE STRUCTURES, Florianópolis, 05-07, jun. 1996.

SOUSA, M. (1997). As Torres Prateadas. Revista de tecnologia da construção - Téchne. São Paulo, n.30, p.50-53, set-out.

VASCONCElOS, A. C. (1994). O papa do concreto. Revista Construção, Ed. Pini, n. 2402, fev.

VASCONCELOS, A. C. (1998). Concreto de alto desempenho - CAD. I Material divulgado na Palestra "A Prática de Projetos Estruturais Usando concreto de Alto Desempenho" e "Pontos Relevantes no Congresso da FIP/98 em Amsterdam - Holanda" ministrada no Departamento de Estruturas - EESC - USP, em 16/09/1998.

WEBB, J. (1993). High - strength concrete: economics, design and ductility. Concrete International, v.15, n.1, p.27-32. 


\section{2- Bibliografia Complementar}

AITCIN, P. C.; LAPLANTE, P.; BEDARD, C. (1985). Development and experimental use of a $90 \mathrm{MPa}(13,000$ psi) field concrete. In: RUSSEL, H. G., ed. Detriot, ACl. p.51-70 (SP-87)

AMARAL FILHO, E. M. (1993). Concreto de alta resistência. São Paulo. Associação Brasileira de Cimento Portland. 75p.

AMARAL FILHO, E. M. (1993). Recuperações e aplicações em estruturas de concreto de alto desempenho. São Paulo. Associação Brasileira de Cimento Portland. 73p.

ASSOCIAÇÃO BRASILEIRA DE NORMAS TÉCNICAS. (1983) NBR 7211 Agregados para concreto. Rio de Janeiro.

. (1982) NBR 7223 - Concreto determinação da consistência pelo abatimento de tronco de cone. Rio de Janeiro.

. (1983) NBR 7809 - Agregado graúdo - determinação do índice de forma pelo método do paquímetro. Rio de Janeiro.

. (1986) NBR 5736 - Cimento Portland Pozolânico. Rio de Janeiro.

(1988) NBR 6153 - Produtos metálicos - ensaio de dobramento semi-guiado. Rio de Janeiro.

(1992) NBR 6152 - Materiais metálicos - Determinação das propriedades mecânicas à tração. Rio de Janeiro.

. (1992) NBR 8953 - Concreto para fins estruturais: classificação por grupos de resistências. Rio de Janeiro.

. (1994) NBR 5738 - Moldagem e cura de corpos-de-prova cilíndricos ou prismáticos de concreto. Rio de Janeiro.

. (1996) NBR 7480 - Barras e fios de aço destinados a armadura para concreto armado. Rio de Janeiro.

ATTARD, M. M.; FOSTER, S. J. (1996). Static ductility of high strength concrete columns under eccentric loading. In: INTERNATIONAL SYMPOSIUM ON UTILIZATION OF HIGH-STRENGTH/HIGHPERFORMANCE CONCRETE, 4. Paris, may, p.863-871, Proceedings. 
AZIZINAMINI, A.; KUSKA, S.; BRUNGARDT, P.; HATFIELD, E. (1994).

Seismic behavior of square high-strength concrete columns. ACI

Structural Journal, p. 336-345.

BUCHAS, J.; BUCHAS, F. (1993). Uso y perspectivas de los hap (hormigones de alta performance) en estructuras en nuestra region. In: JORNADAS SUDAMERICANAS DE INGENIERIA ESTRUCTURAL, 26., Montevideo, Uruguay, 15-19 nov. 1993. Memorias v.4, p. 149-162

CLAESON, C.; GYLLTOFT, K.; GRAUERS, M. (1996). Experiments and numerical analyses of reinforced high strength concrete columns. In: INTERNATIONAL SYMPOSIUM ON UTILIZATION OF HIGHSTRENGTH/HIGH-PERFORMANCE CONCRETE, 4. Paris, may, p.797806, Procedings.

COLACO, J. P. (1985). 75-Story Texas commerce plaza, Houston - the use of high-strength concrete. In: RUSSEL, H. G., ed. Detriot, ACI. p.1-8 (SP87)

DAL MOLIN, D. C.; WOLF, J. (1991). Viabilidade técnico-econômica da utilização de concretos de alta resistência em edifícios altos. In: CICLO DE PALESTRAS SOBRE NOVAS TENDÊNCIAS DE AUMENTO DA RESISTÊNCIA DO CONCRETO, CB-18, ABNT, Porto Alegre, abr.

DINIZ, S. M. C.; FRANGOPOL, D. M. (1997). Strength and ductility simulation of high-strength concrete columns. Journal of structural engineering, ASCE, v.123, n.10, p.1365-1374, oct.

FAFITIS, A.; SHAH, S. P. (1985). Lateral reinforcement for high-strength concrete columns. In: RUSSEL, H. G., ed. Detriot, ACI. p.213-232 (SP87)

FERNANDES, G. B. (1992). Cisalhamento de vigas de concreto de alta resistência. São Paulo. Tese (doutorado) - Escola Politécnica, Universidade de São Paulo.

FUSCO, P. B. (1986). Estruturas de Concreto: solicitações normais, estados limites últimos, teoria e aplicações. Rio de Janeiro, Guanabara Dois. 
GOMES NETO, D. P. (1998). Dosagem de microconcretos leves de alto desempenho para a produção de pré-fabricados de pequena espessura: estudo de caso. São Carlos. Escola de Engenharia de São Carlos - USP. (Dissertação de Mestrado)

HELENE, P. R. L.; TERZIAN, P. (1992). Manual de dosagem e controle do concreto, São Paulo, Pini, 349p.

IBRAHIM, H. H. H.;MAC GREGOR, J. G. (1996). Flexural behavior of laterally reinforced high-strength concrete sections. ACl Structural journal. v. 93, n. 6, nov.-dec.

IBRAHIM, H. H. H.;MAC GREGOR, J. G. (1997). Modification of the ACI rectangular stress block for high-strength concrete. ACI Structural journal. v. 94, n. 1, jan.feb.

KÖNIG, K.; SIMSCH, G. (1996). Failure mechanism and load-deformation behavior of high-strength concrete columns with confining reinforcement. In: INTERNATIONAL SYMPOSIUM ON UTILIZATION OF HIGHSTRENGTH CONCRETE, 4. Paris, may, p.777-786, Proceedings.

MODESTO DOS SANTOS, L. (1981). Cálculo de concreto armado. São Paulo.

MODESTO DOS SANTOS, L. (1994). Sub-rotinas básicas do dimensionamento de concreto de armado. São Paulo.

MORENO JUNIOR, A. L. (1996). Cisalhamento em vigas de concreto de alta resistência submetidas à flexo-compressão. São Paulo. Tese (doutorado) - Escola Politécnica, Universidade de São Paulo.

NILSON, A. H. (1985). Design implications of current research on highstrength concrete. In: RUSSEL, H. G., ed. Detriot, ACl. p.85-118 (SP-87)

NILSON, A. H. (1990). Concreto de alta resistência - desempenho como material e comportamento estrutural. $30^{\circ}$ REIBRAC, Rio de Janeiro, Brasil.

OLIVEIRA, F. R. M. (1993). Comportamento estrutural de colunas utilizando concreto armado de alto desempenho In: JORNADAS SUDAMERICANAS DE INGENIERIA ESTRUCTURAL, 26., Montevideo, Uruguay, 15-19 nov. 1993. Memorias v.3, p. 489-500 
PACIOS, A.; GETTU, R.; SHAH, S. P. (1992). Utilización del hormigón de alta resistencia en EE. UU. Cemento-hormigón, Barcelona, n.709, p.1118-1135, ago.

PAIVA, N. M. B. (1994). Pilares de concreto de alta resistência com seção transversal retangular solicitados à compressão simples. Campinas. Dissertação (mestrado) - Faculdade de Engenharia Civil, Universidade Estadual de Campinas.

PEREIRA NETO, P. M.; DJANIKIAN, J.G. (1995). Algumas características do concreto de alta resistência com microssílica. São Paulo, EPUSP, 13p. (BT/PCC/143).

SHAH, S.P. (1996). Special HPCs: fiber-reinforced HPC, ultra-high strength concrete. In: Fourth International Symposium on the UTILIZATION OF HIGH STRENGTH/ HIGH PERFORMANCE CONCRETE. Paris, France, 29-31 May. Proceedings vol.1. p. 75-81.

SHEIKH, S. A.; YEH, C. C. (1986). Flexural behavior of confined concrete columns. ACI Structural journal, Detroit, p.389-404, may-june.

SHEIKH, S. A.; SHAH, D. V.; KHOURY, S. S. (1994). Confinement of highstrength concrete columns. ACl Structural journal, Detroit, v.91, n.1, p.100-111, jan-feb.

TARTUCE, R.; GIOVANNETTI, E. (1990). Princípios básicos sobre concreto de cimento portland. São Paulo, Ibracon/pini. 107p.

TARTUCE, R. (1989). Dosagem experimental do concreto. São Paulo. Ibracon/pini. 115p.

XIE, J.; ELWI, A. E.; MAC GREGOR, J. G. (1997). Performance of highstrength concrete tied columns - a parametric study. ACI Structural journal. v. 94, n. 2, mar.-apr. 


\section{APÊNDICE}

Estão apresentados todos os gráficos montados a partir dos resultados obtidos nos ensaios realizados. De cada pilar ensaiado foram feitos os gráficos na seguinte ordem: força em função das deformações da armadura longitudinal; força em função das deformações longitudinais no concreto; força $x$ deformação das armaduras transversais; força em função das deformações transversais no concreto; força $x$ deformação do pilar; força $\mathrm{x}$ deslocamentos do pilar. 


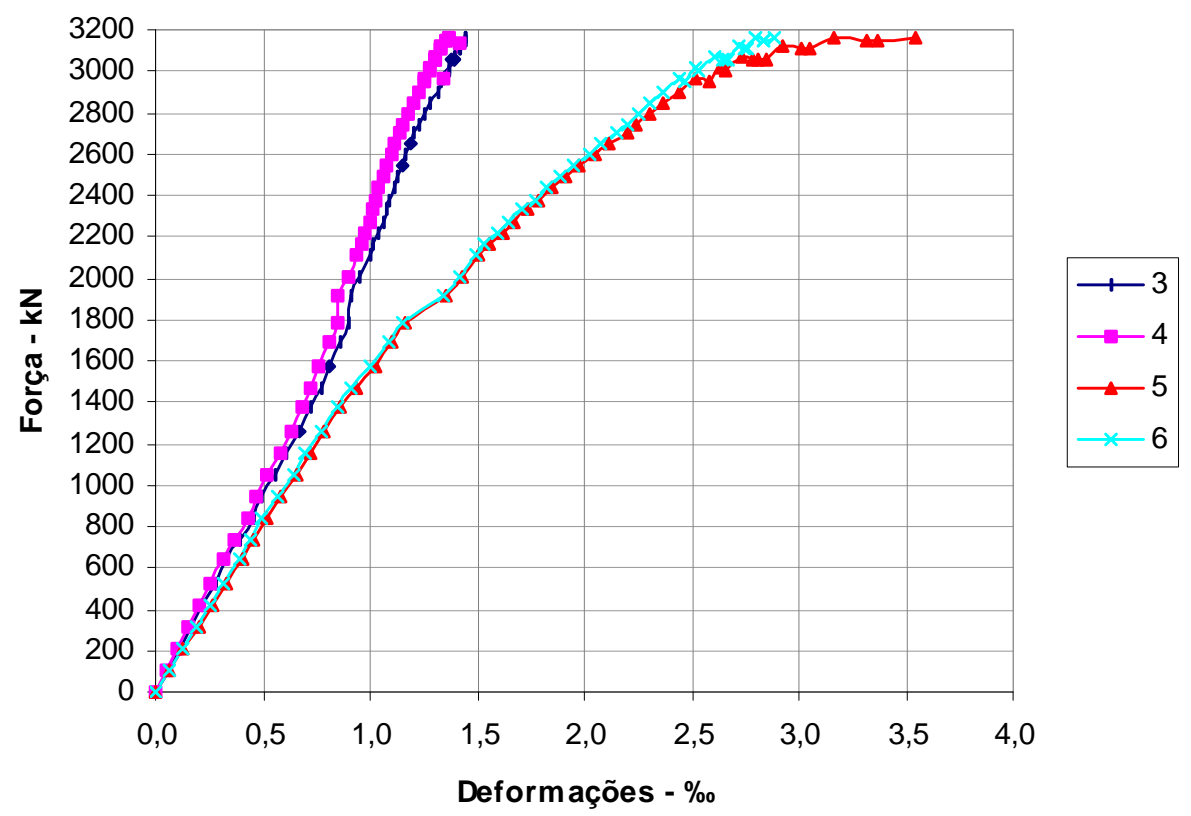

Diagrama força $\mathrm{x}$ deformação da armadura longitudinal

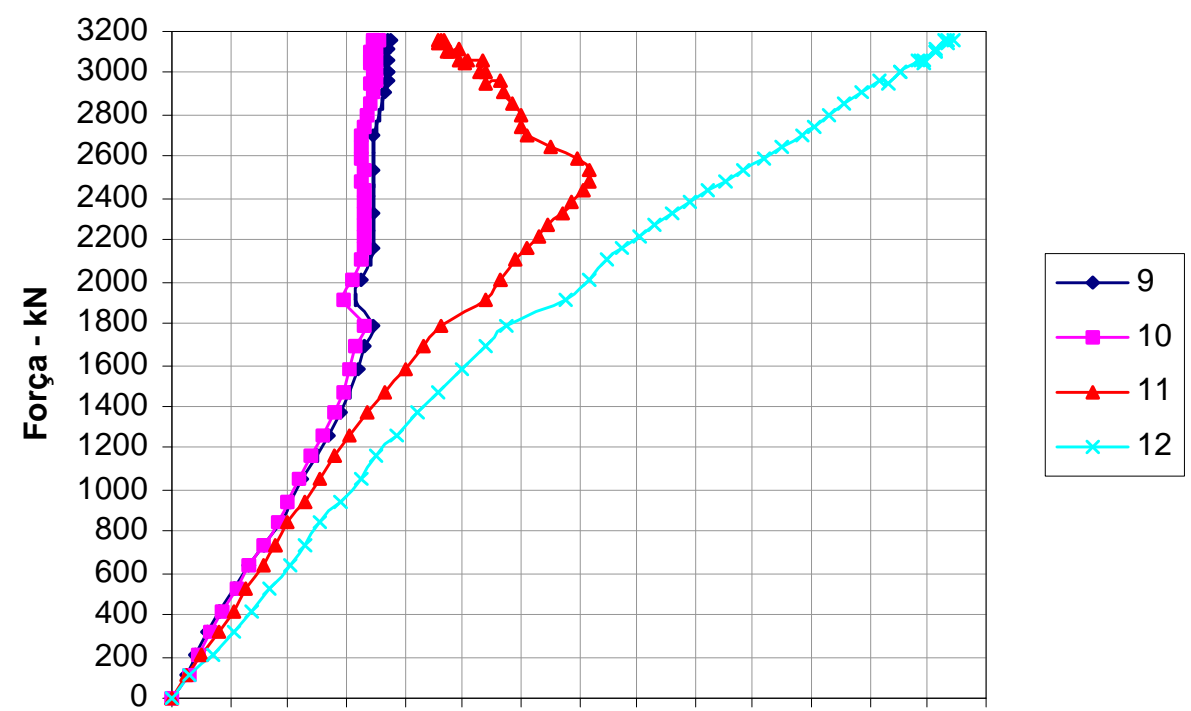

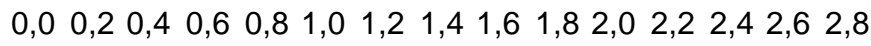

Deformações -\%。

Diagrama força $x$ deformação longitudinal do concreto 


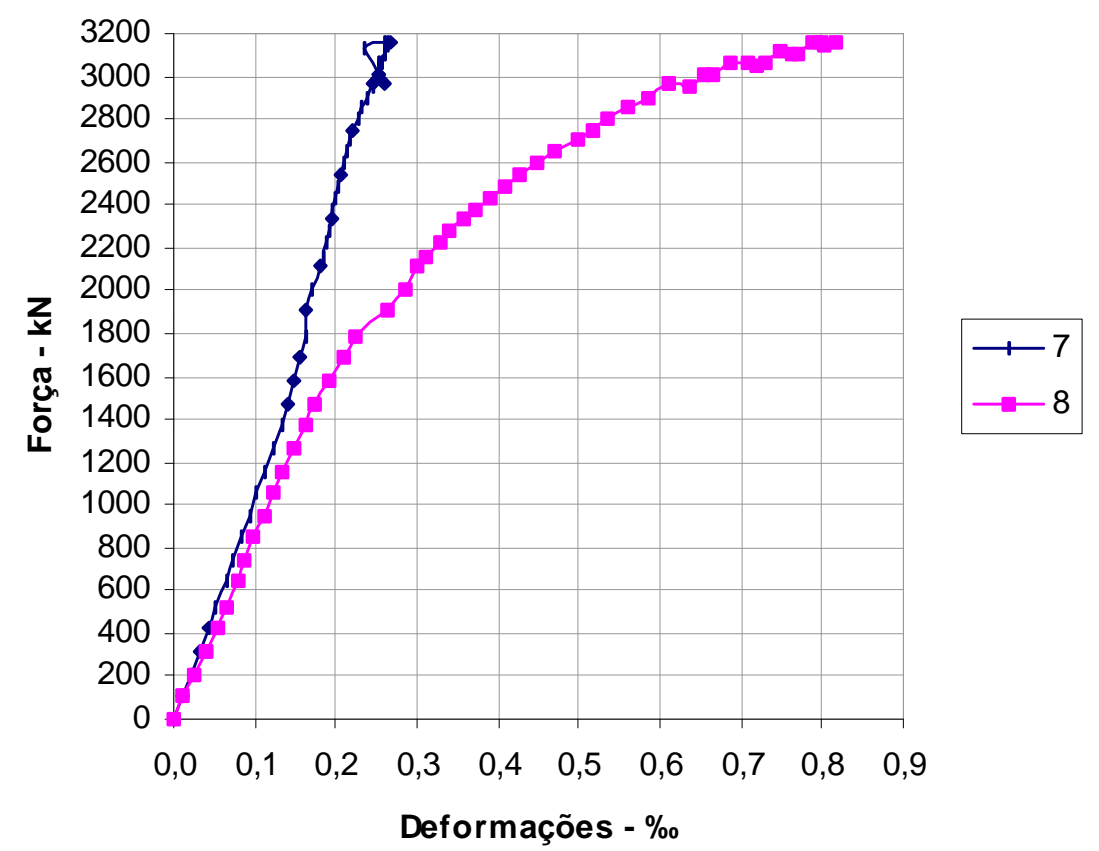

Diagrama força $x$ deformação na armadura transversal

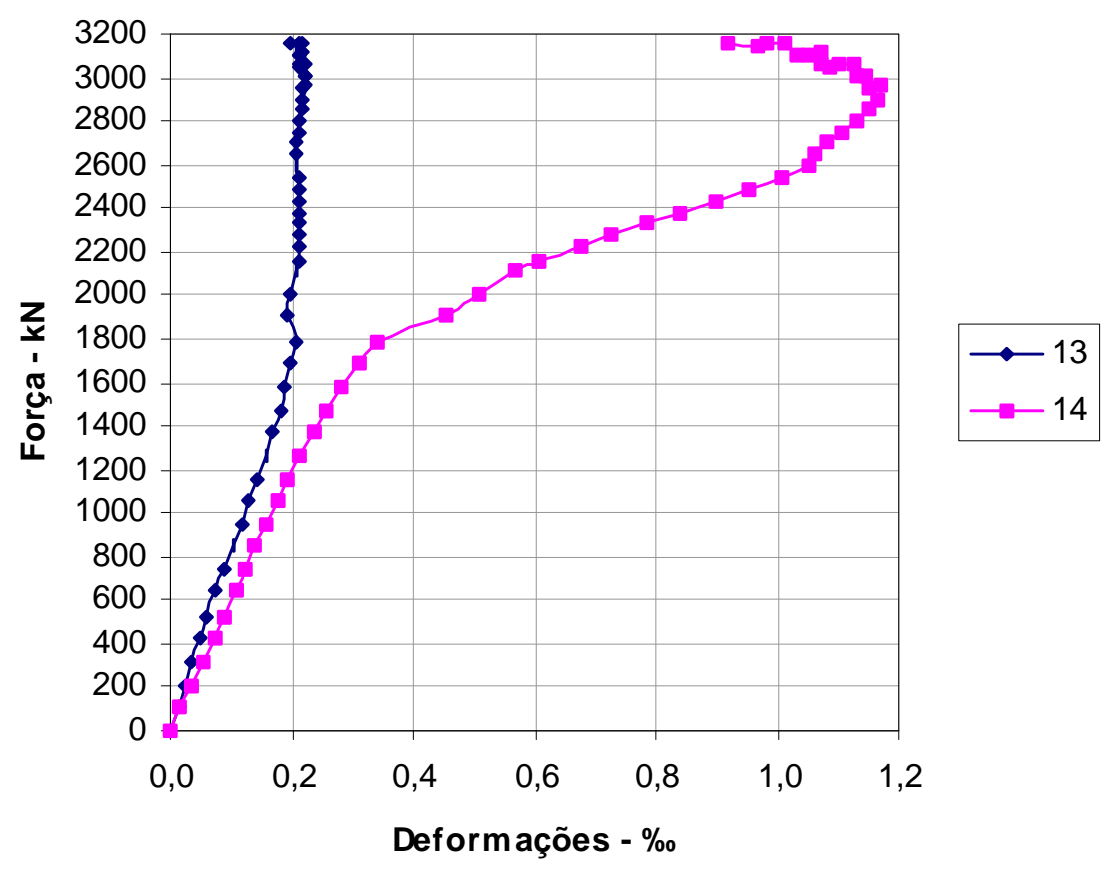

Diagrama força $x$ deformação transversal do concreto 


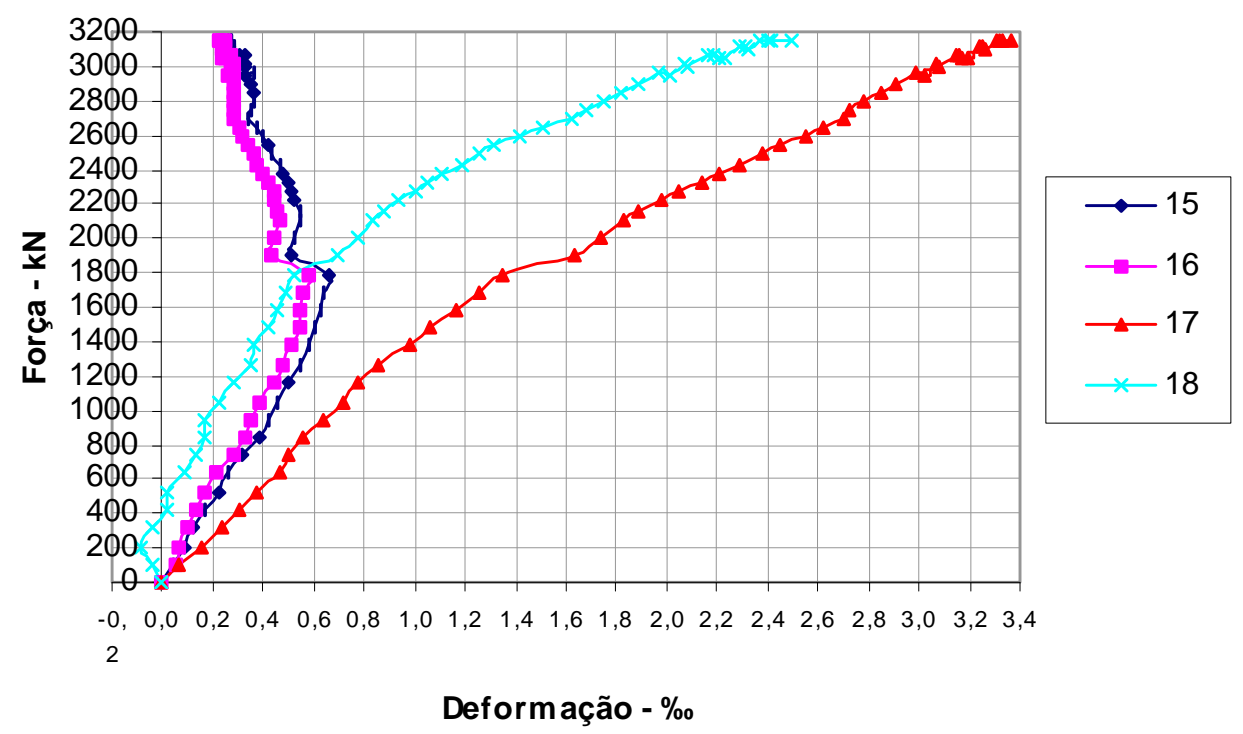

Diagrama força $\mathrm{x}$ deformação do pilar

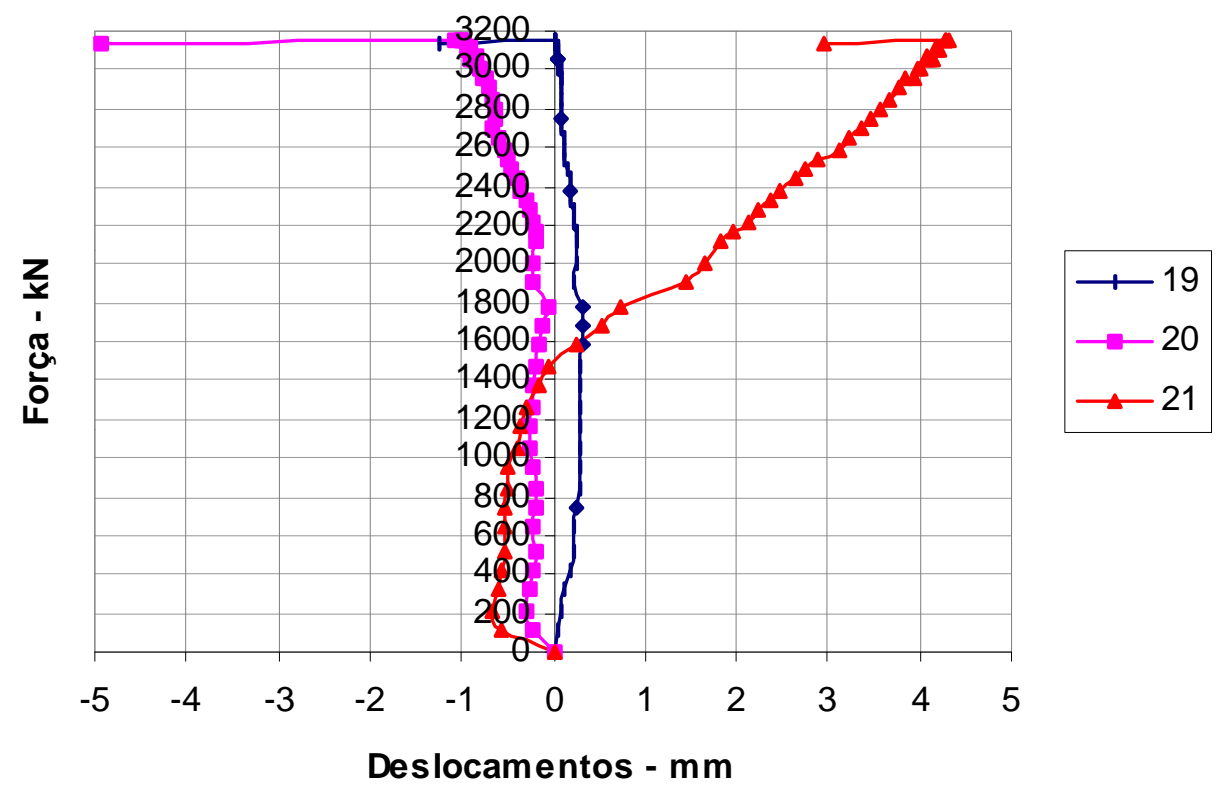

Diagrama força $x$ deslocamentos do pilar 


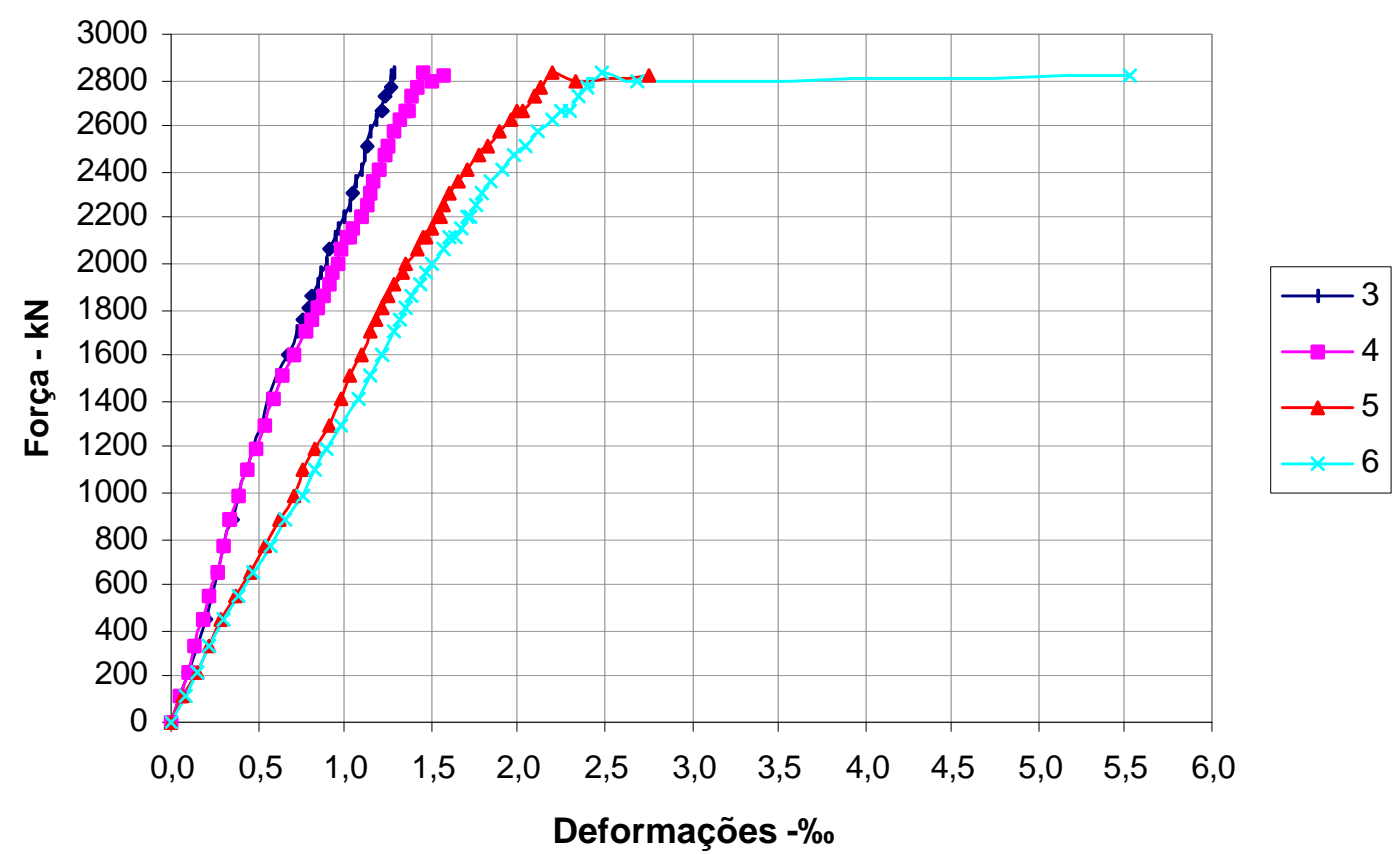

Diagrama força $x$ deformação da armadura longitudinal

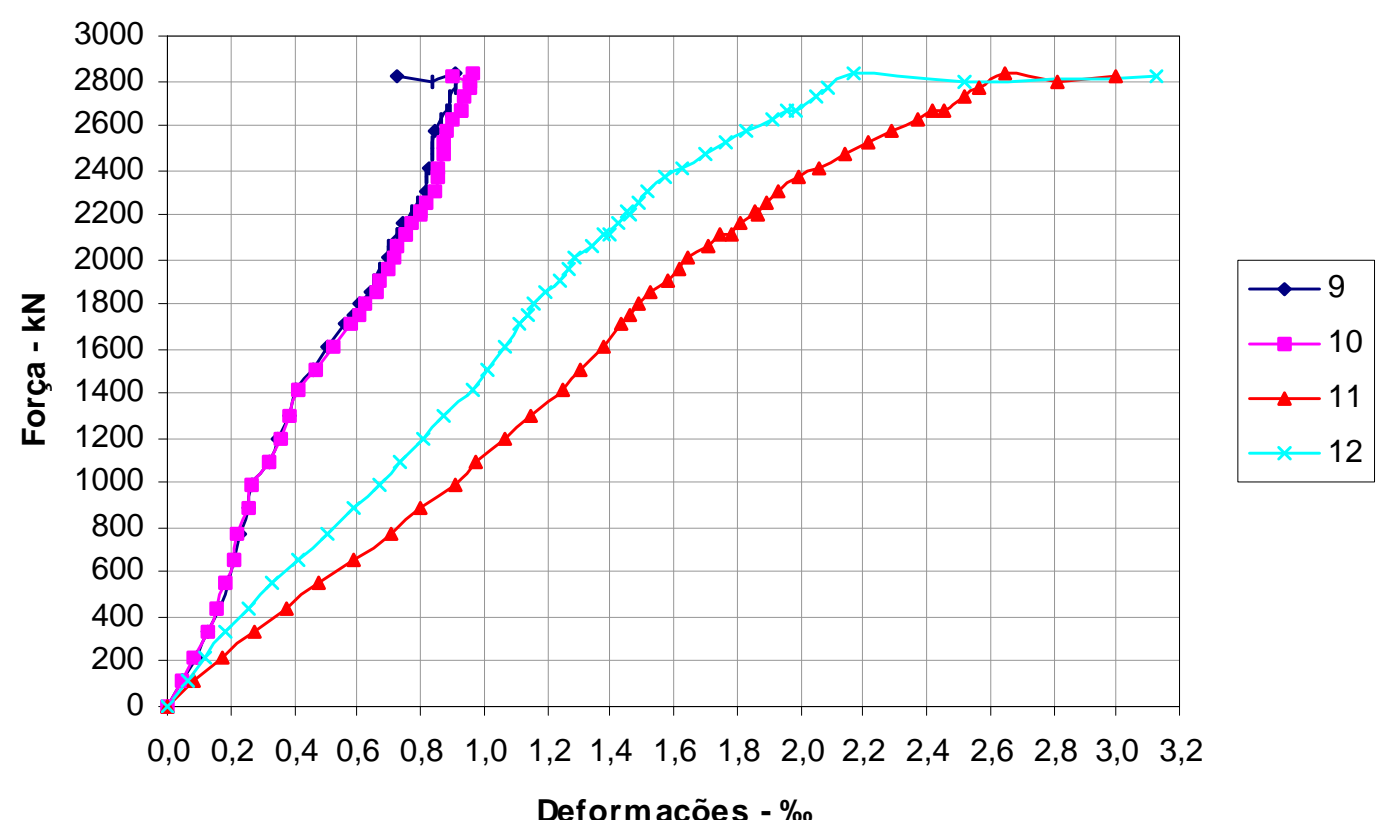

Diagrama força $x$ deformação longitudinal do concreto 


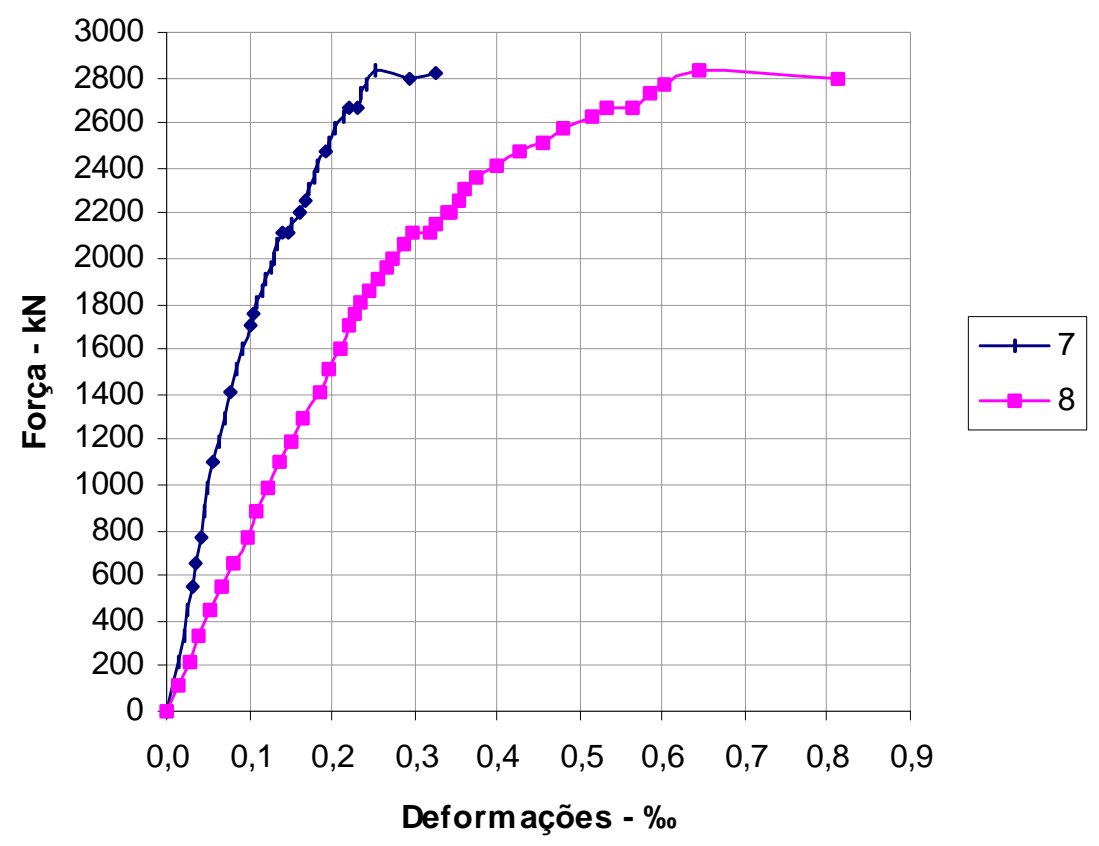

Diagrama força $x$ deformação na armadura transversal

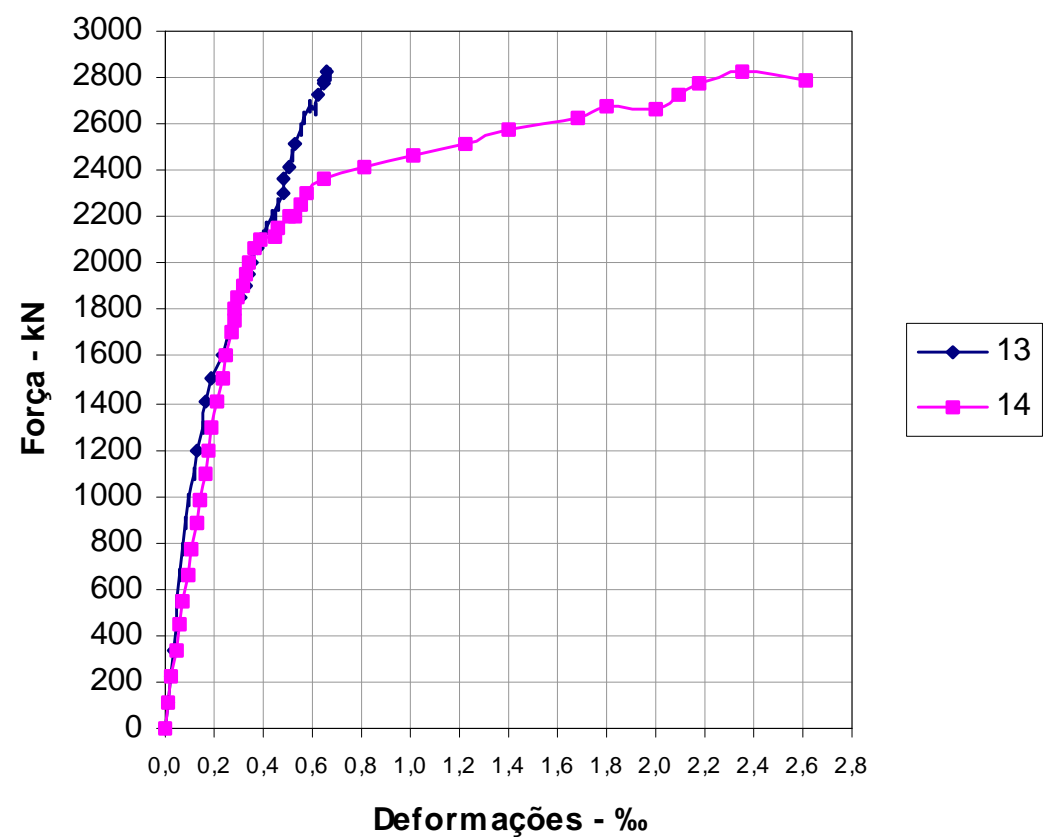

Diagrama força $x$ deformação transversal do concreto 


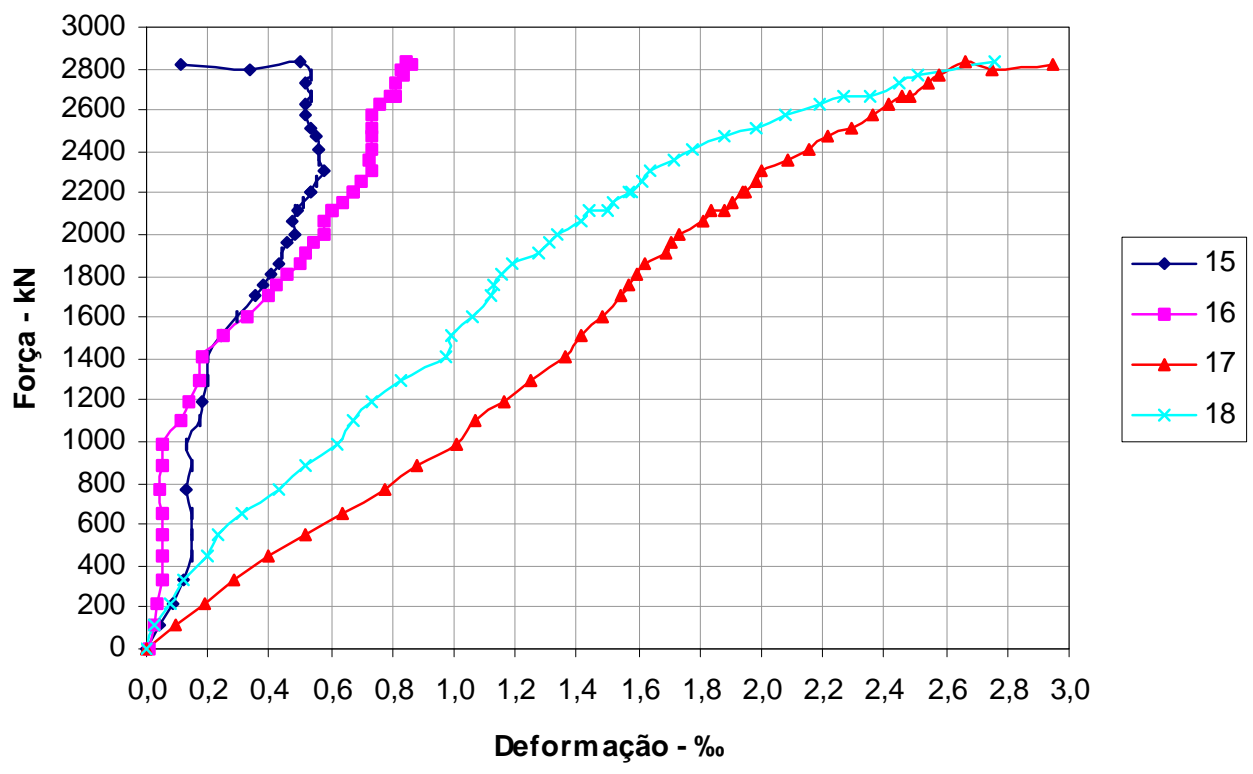

Diagrama força $\mathrm{x}$ deformação do pilar
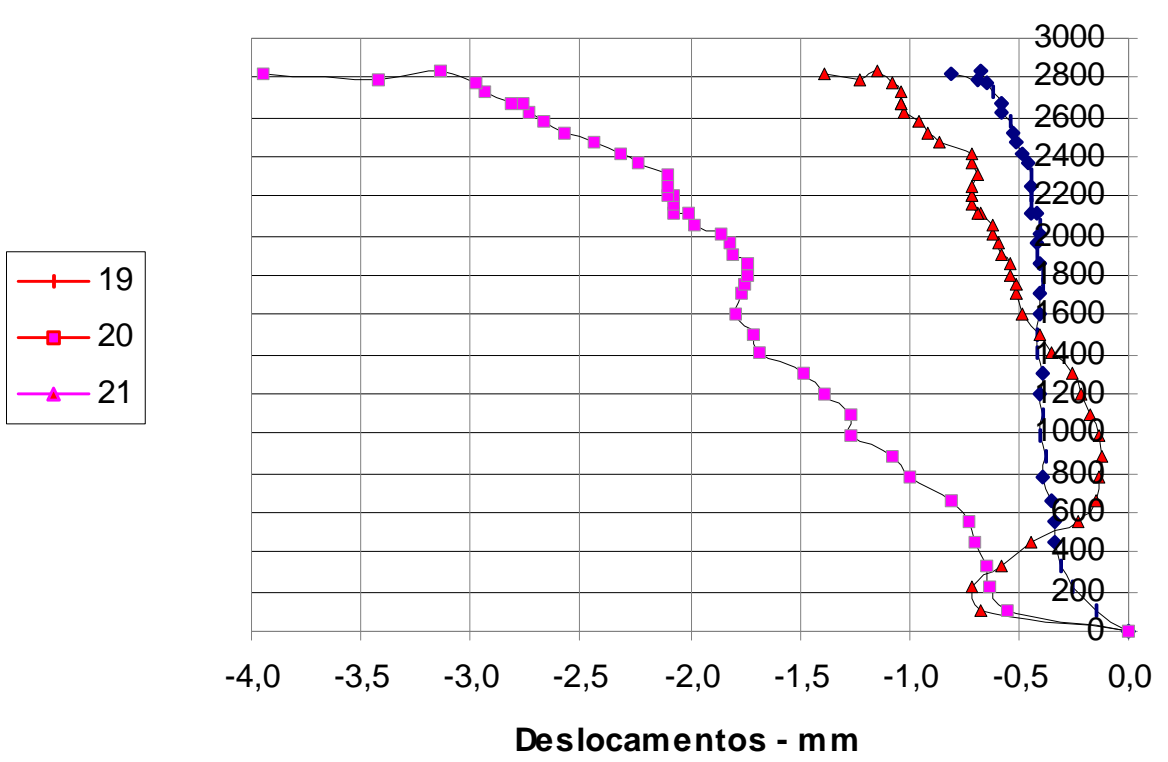

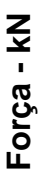

Diagrama força $\mathrm{x}$ deslocamentos do pilar 


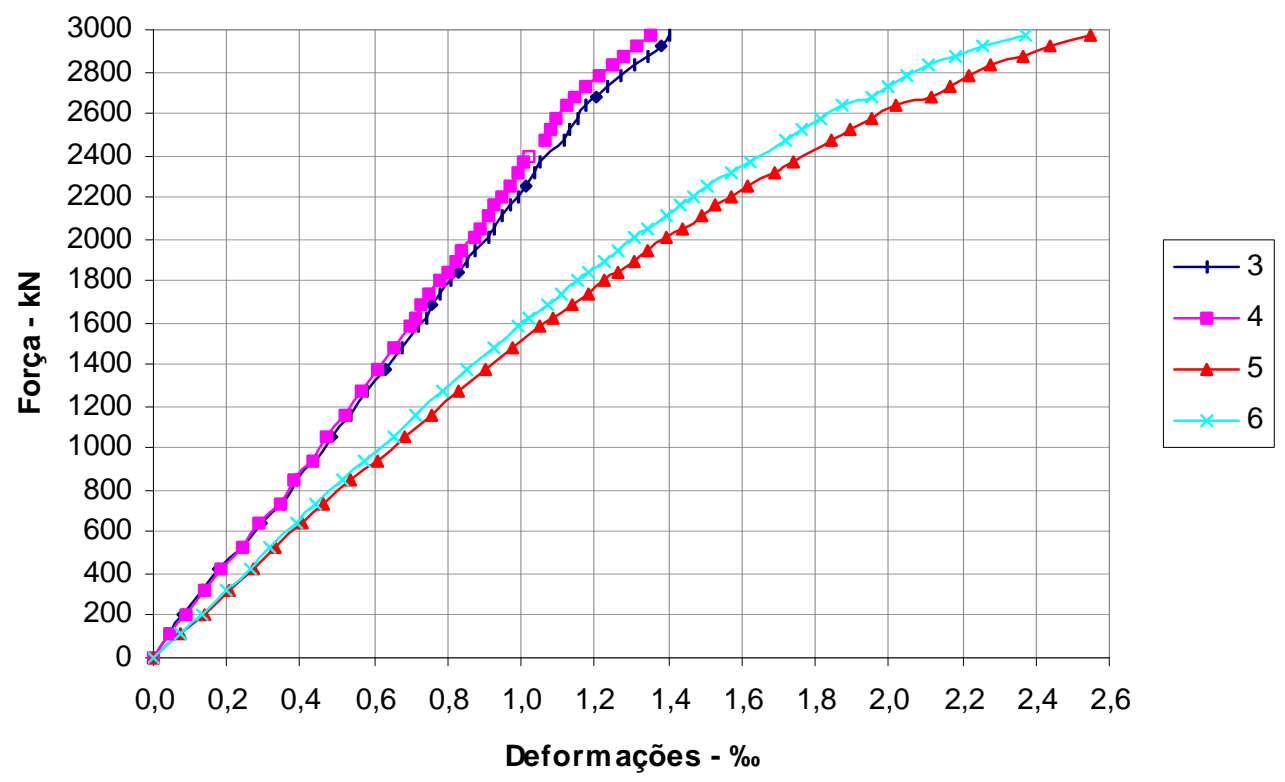

Diagrama força $\mathrm{x}$ deformação da armadura longitudinal

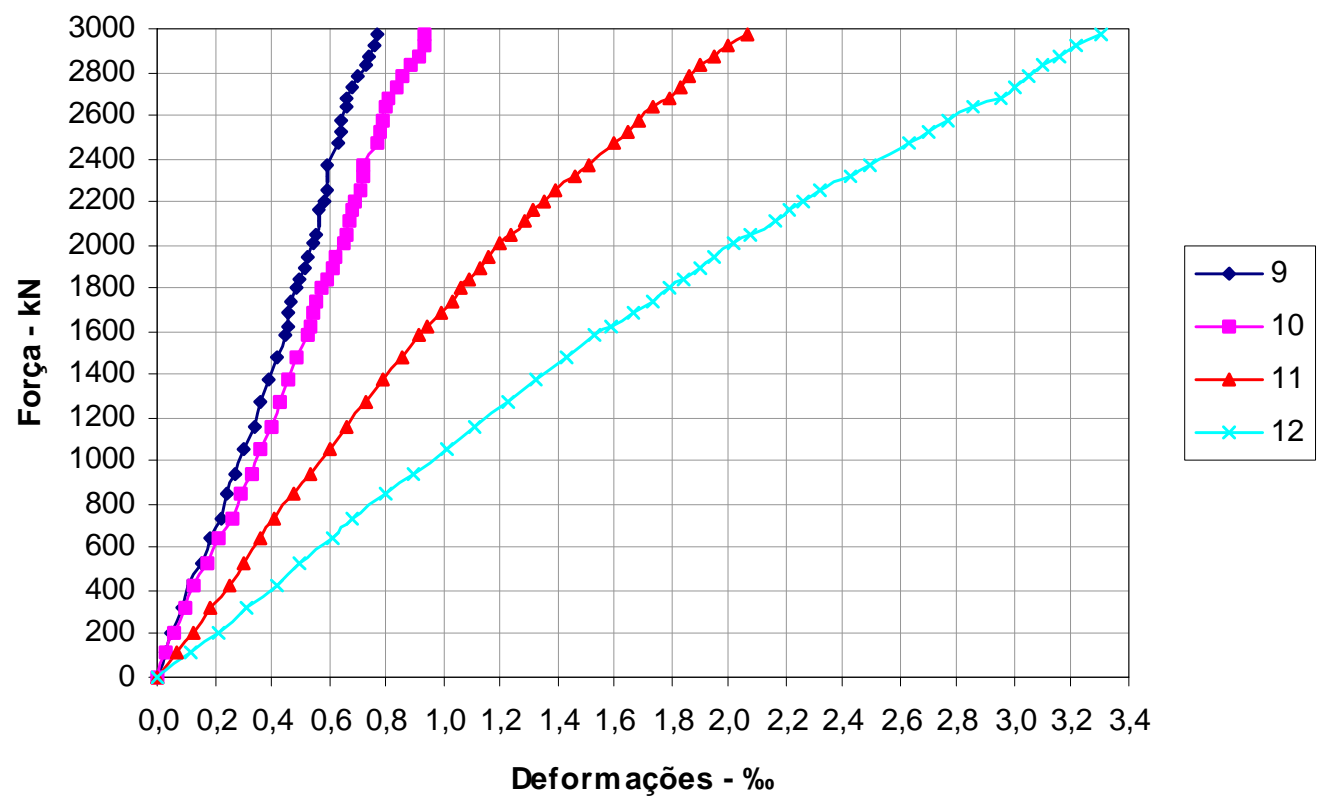

Diagrama força $\mathbf{x}$ deformação longitudinal do concreto 


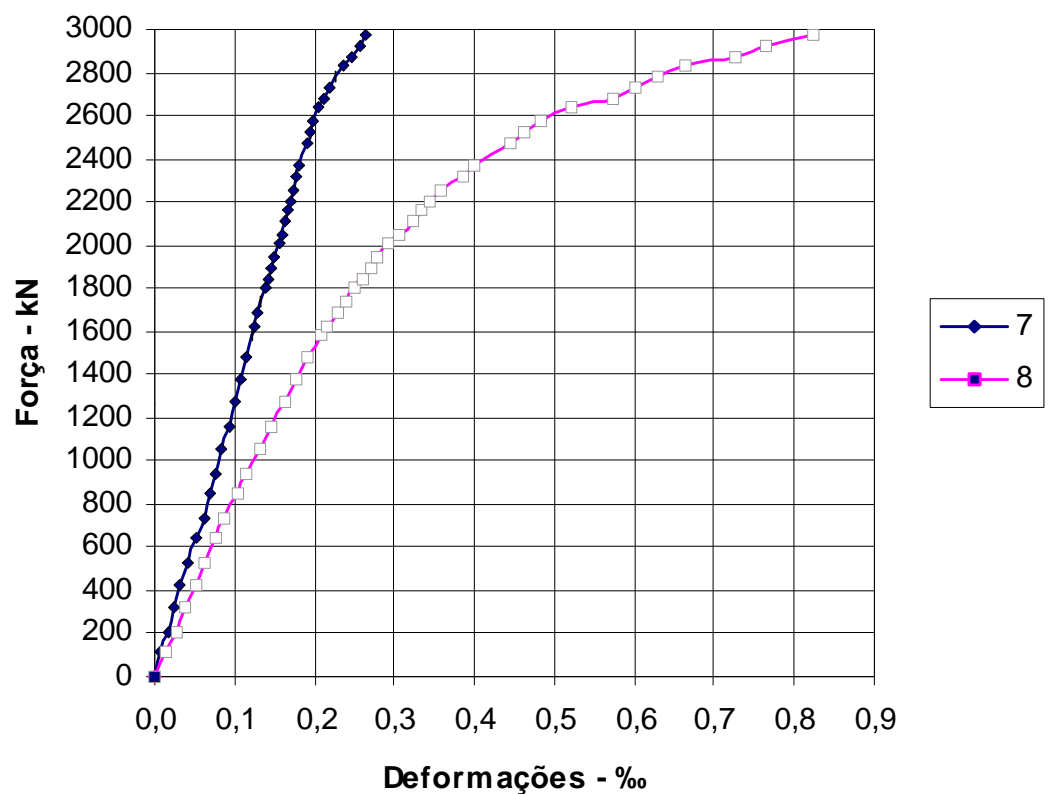

Diagrama força $x$ deformação na armadura transversal

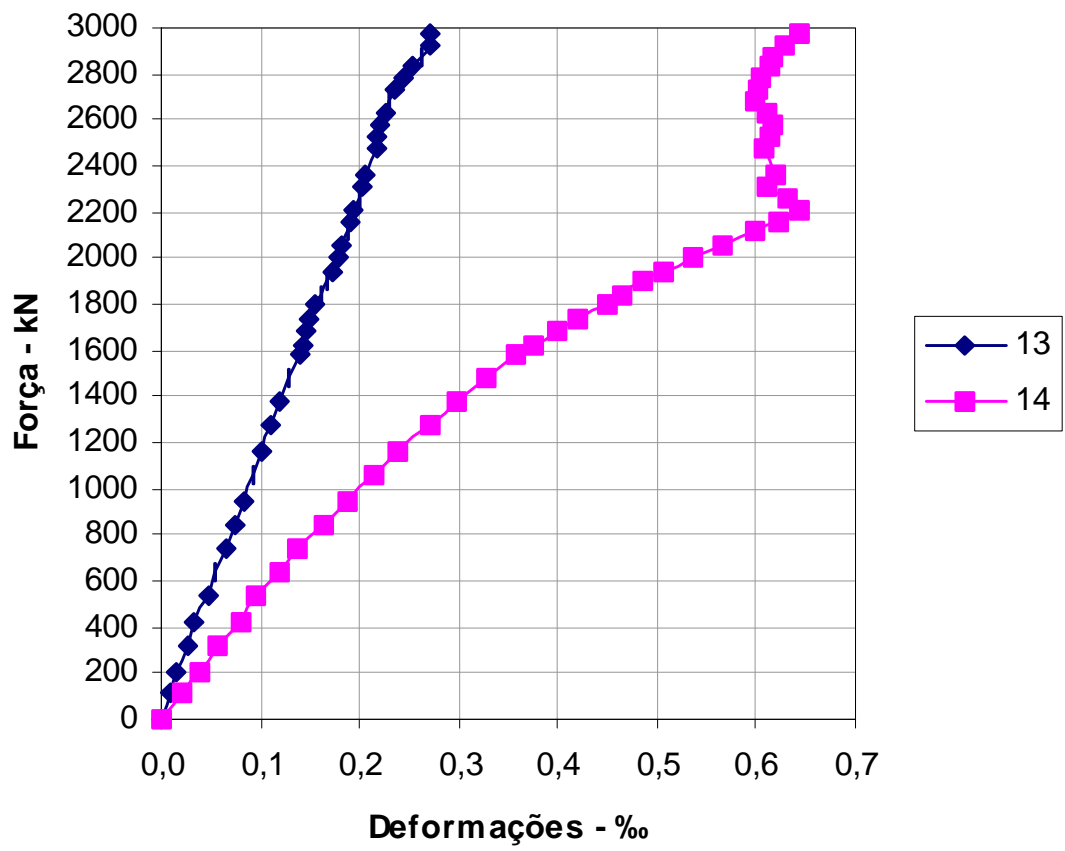

Diagrama força $x$ deformação transversal do concreto 


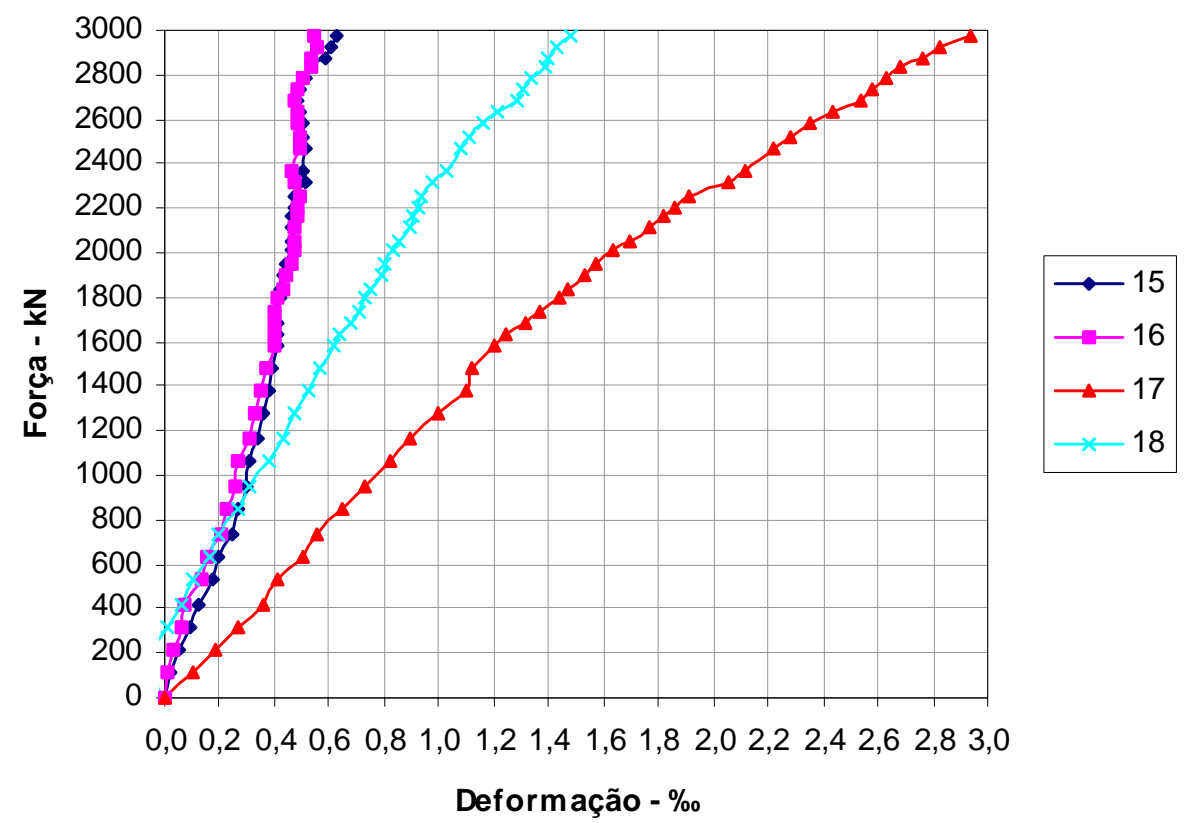

Diagrama força $\mathrm{x}$ deformação do pilar

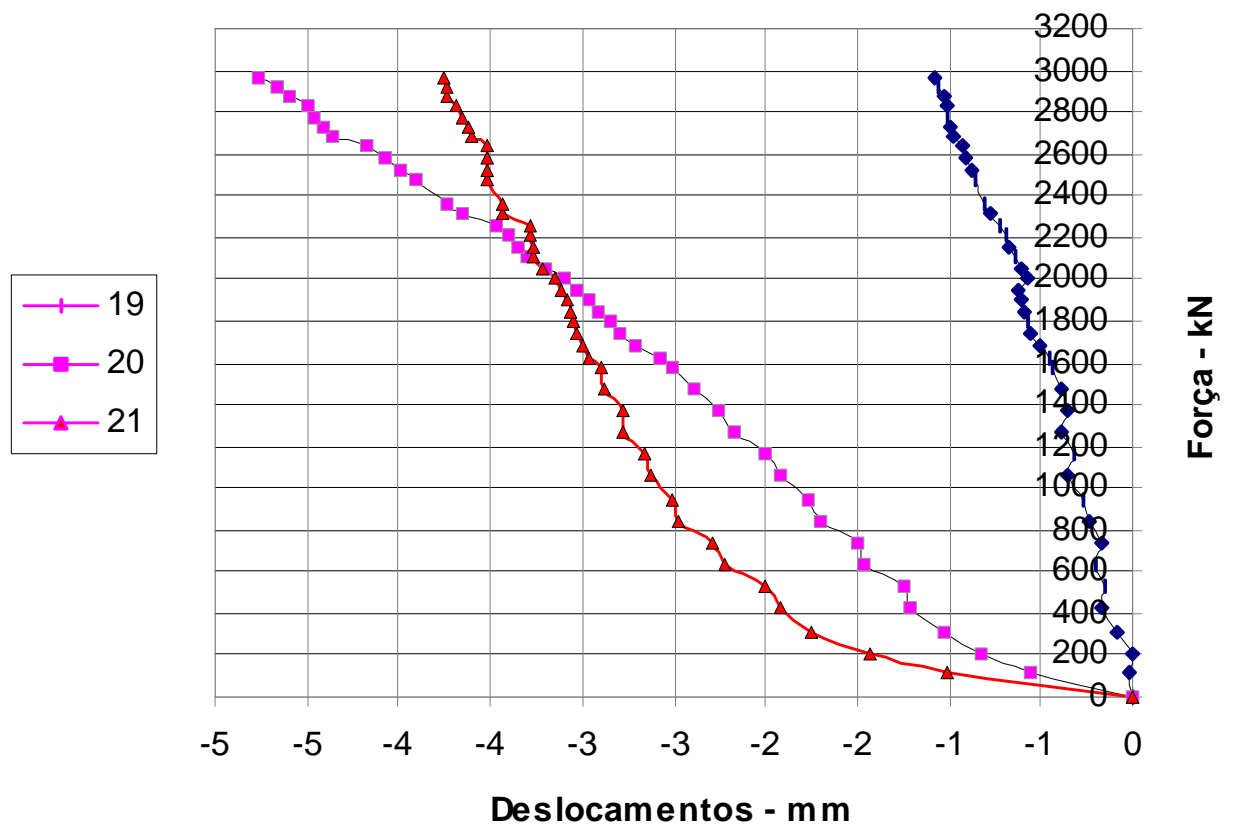

Diagrama força $\mathrm{x}$ deslocamentos do pilar 


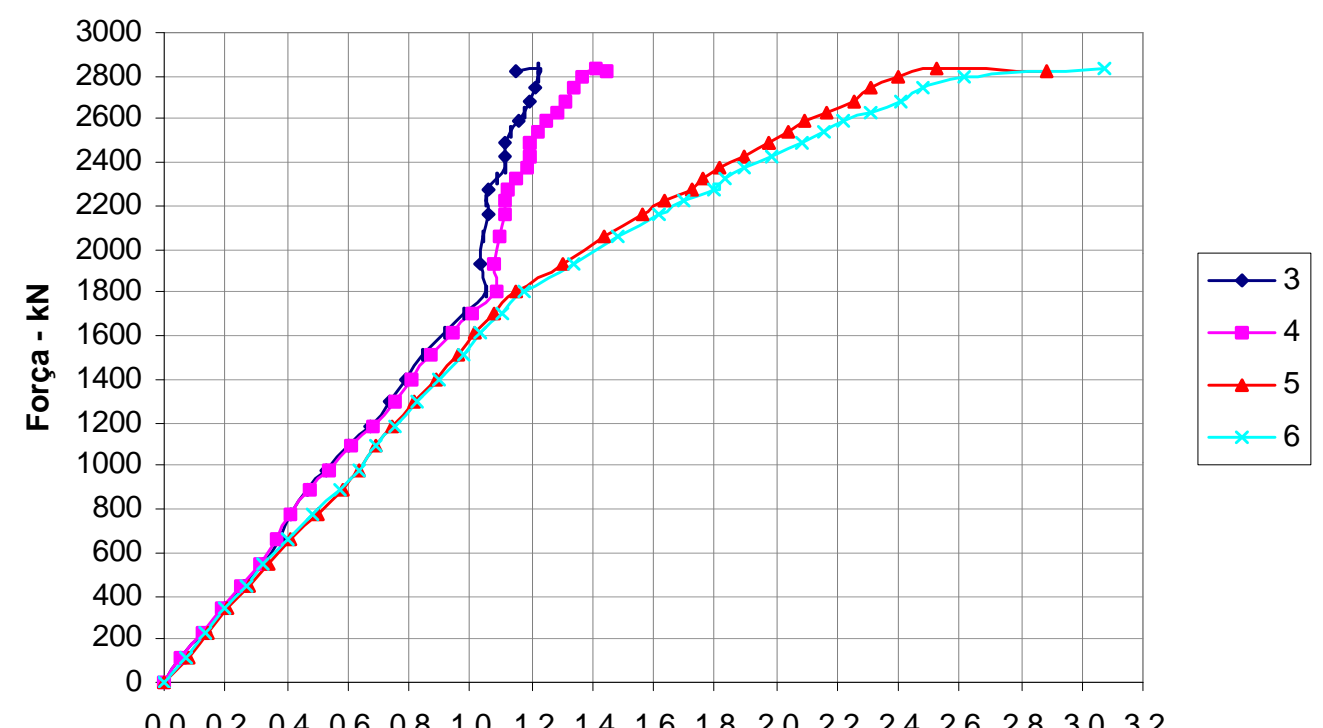

Deformações - \%。

Diagrama força $x$ deformação da armadura longitudinal

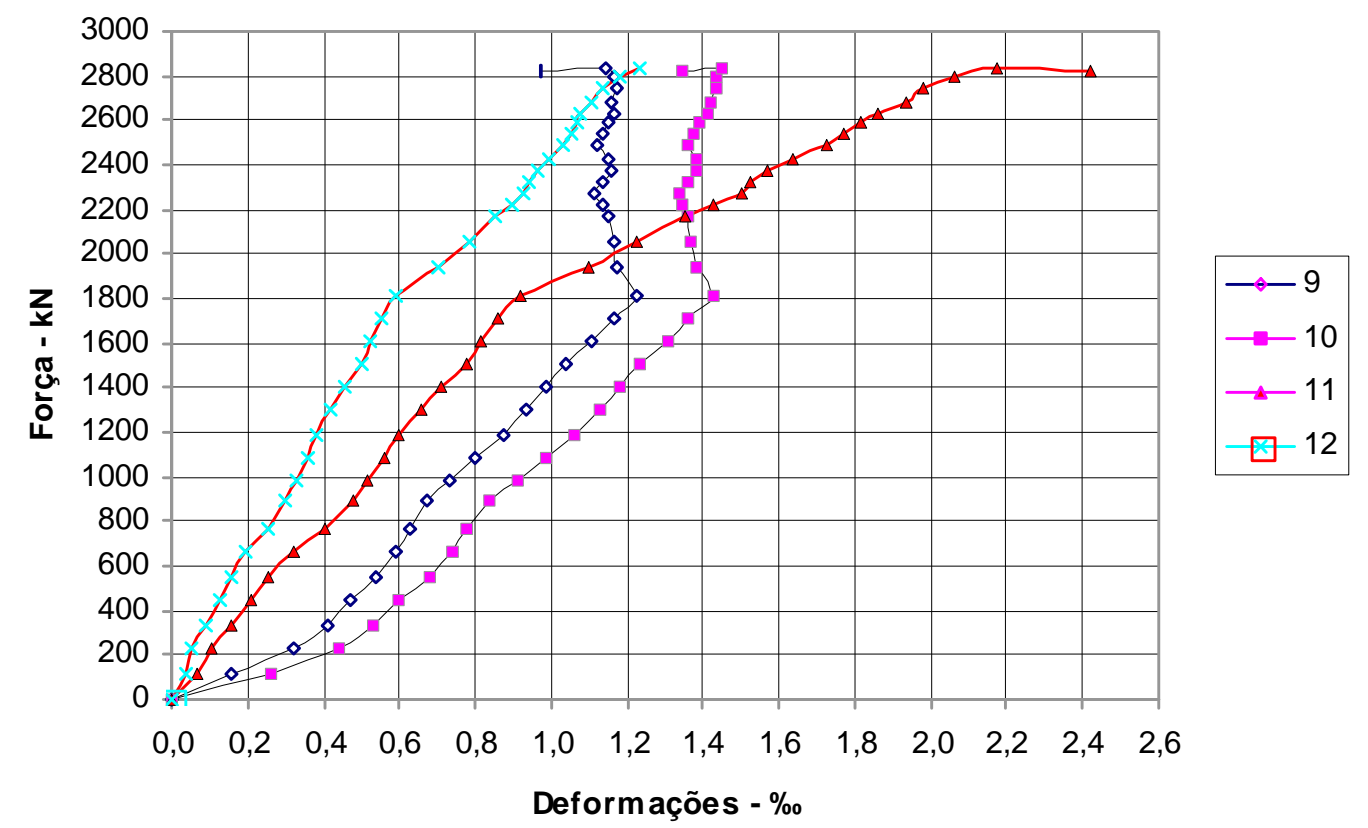

Diagrama força $x$ deformação longitudinal do concreto 


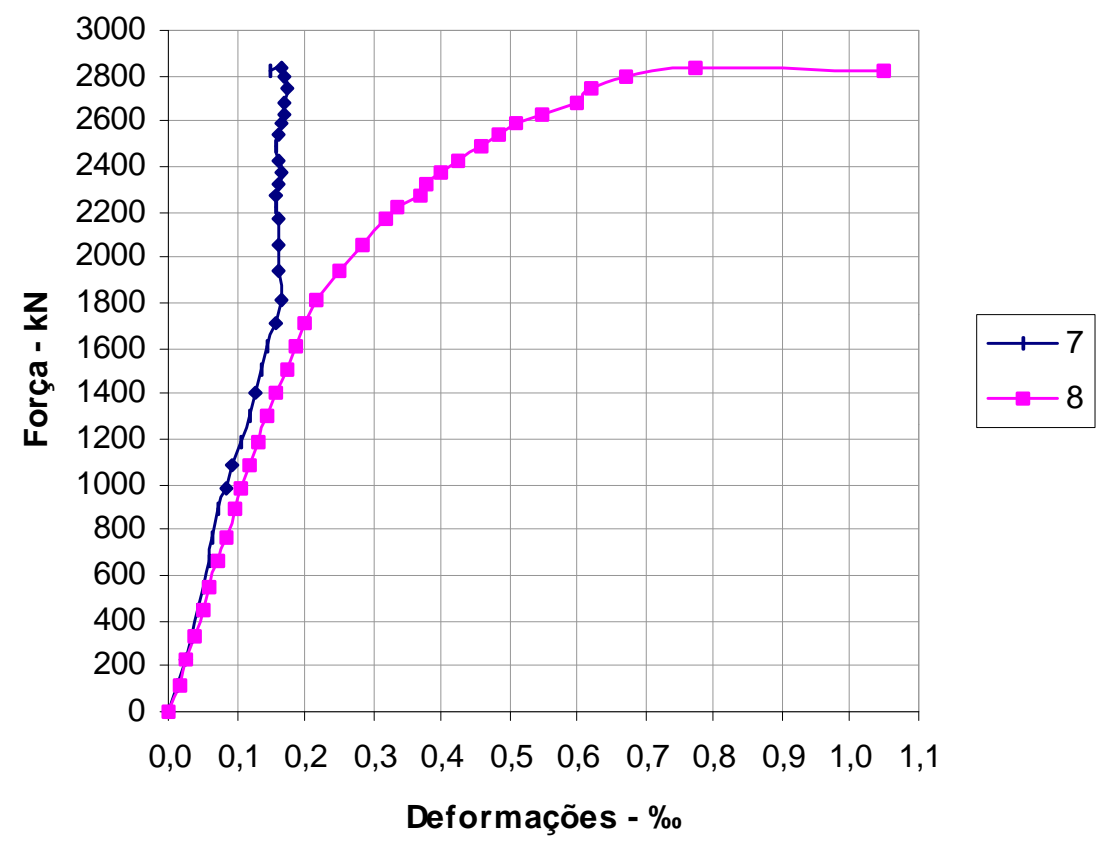

Diagrama força $x$ deformação na armadura transversal

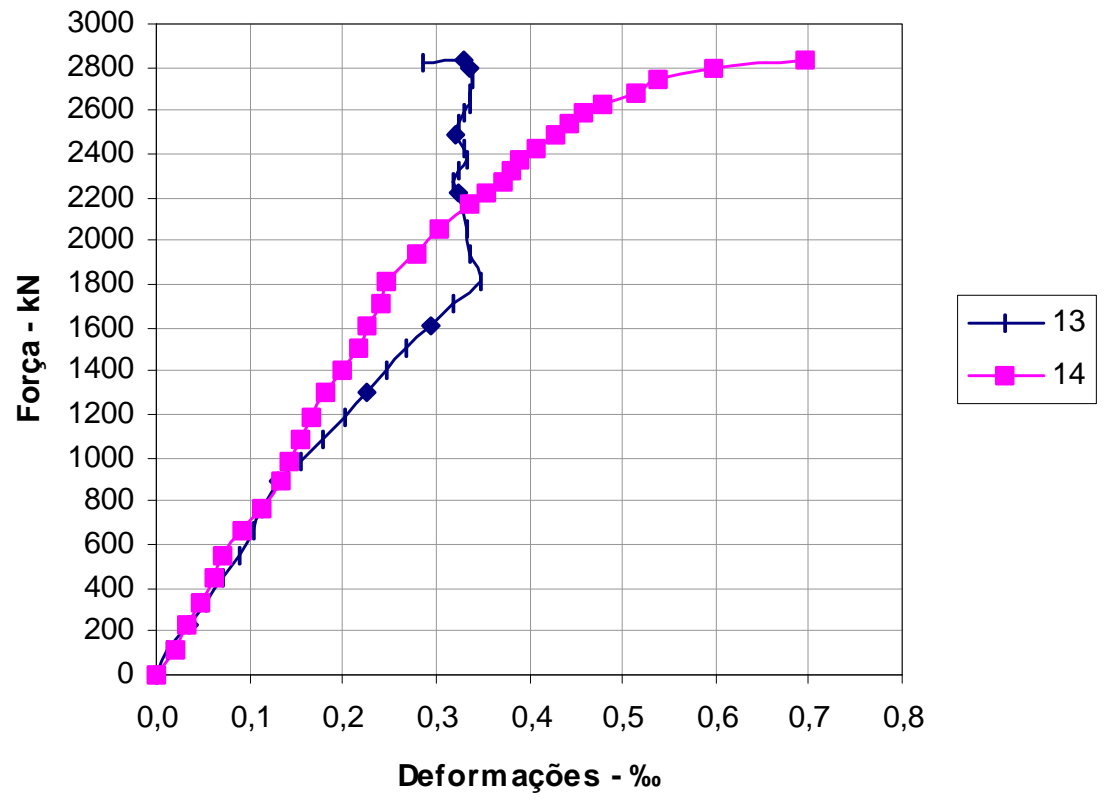

Diagrama força $x$ deformação transversal do concreto 


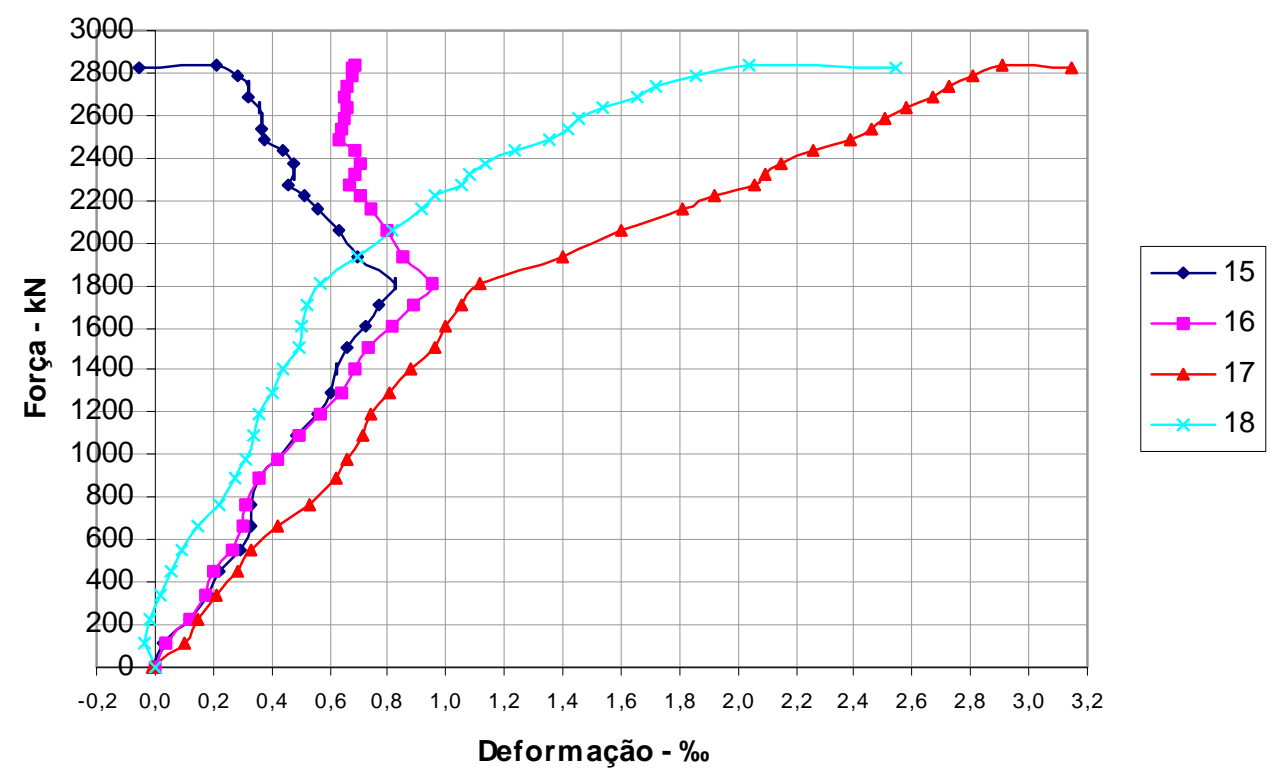

Diagrama força $x$ deformação do pilar

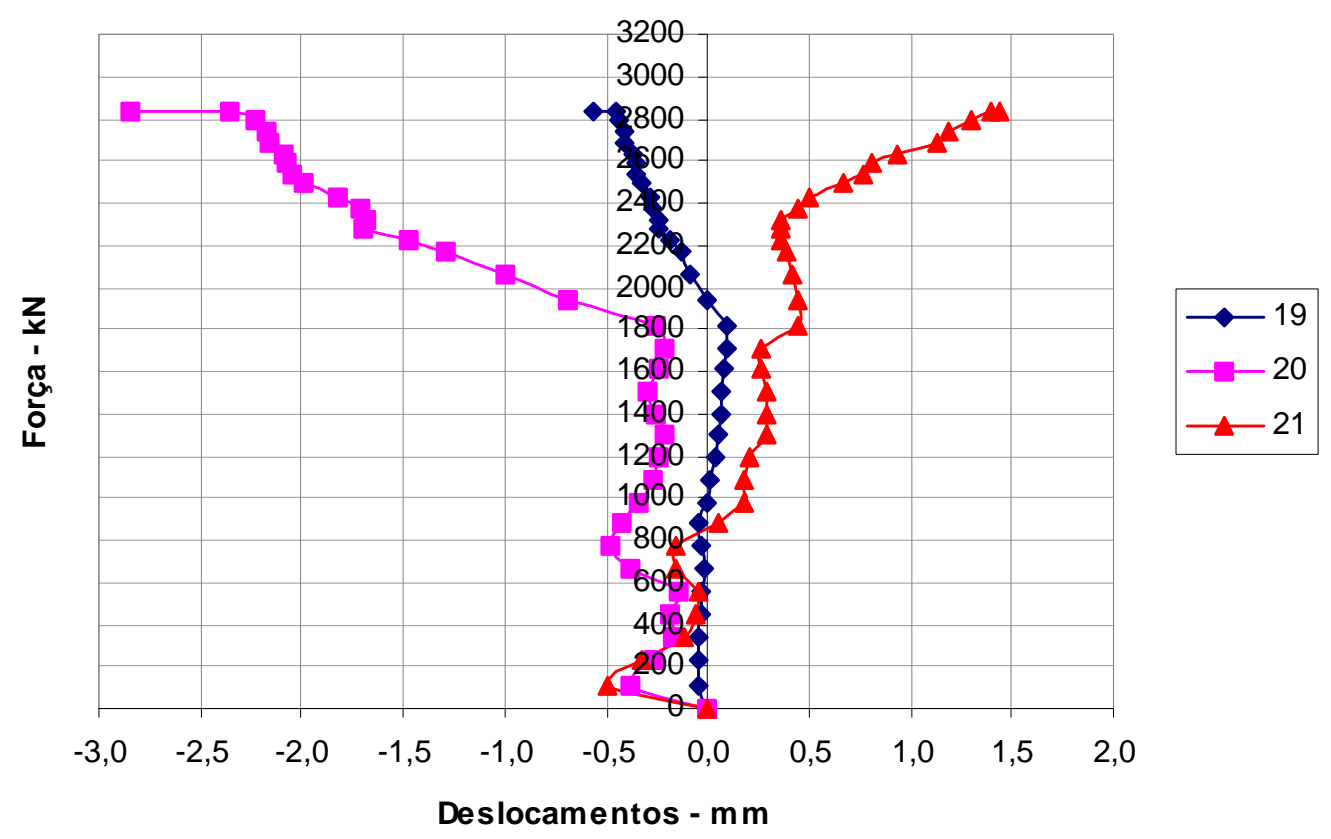

Diagrama força $\mathrm{x}$ deslocamentos do pilar 


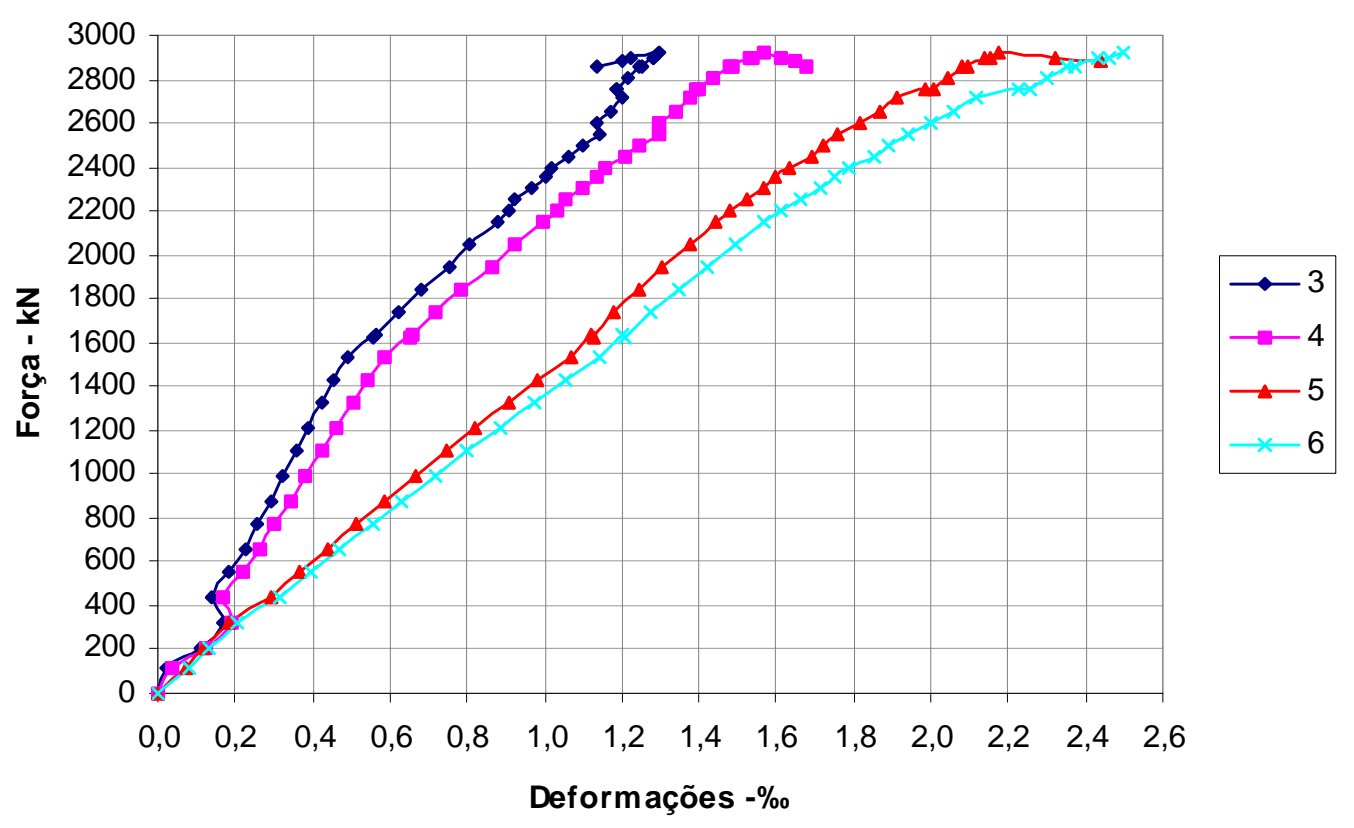

Diagrama força $\mathrm{x}$ deformação da armadura longitudinal

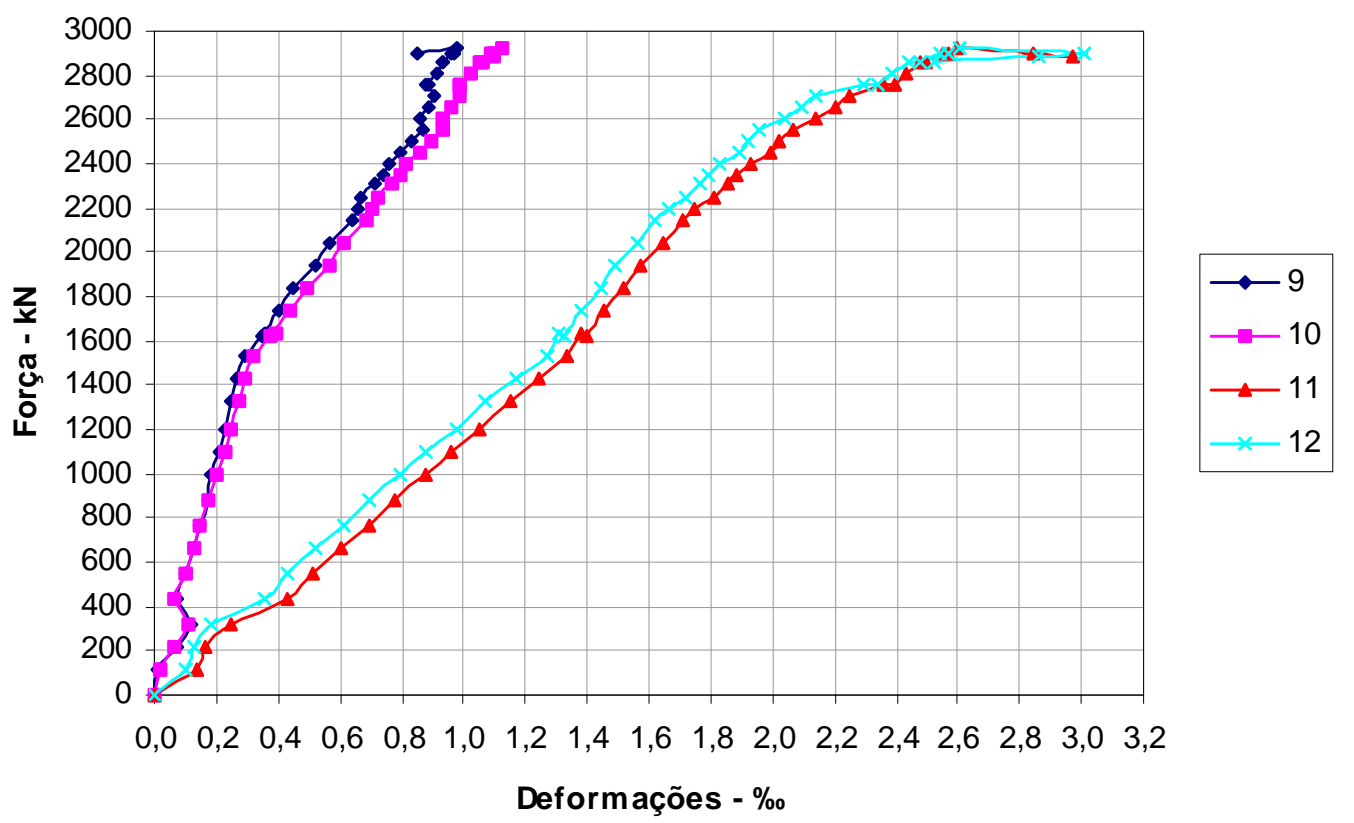

Diagrama força $x$ deformação longitudinal do concreto 


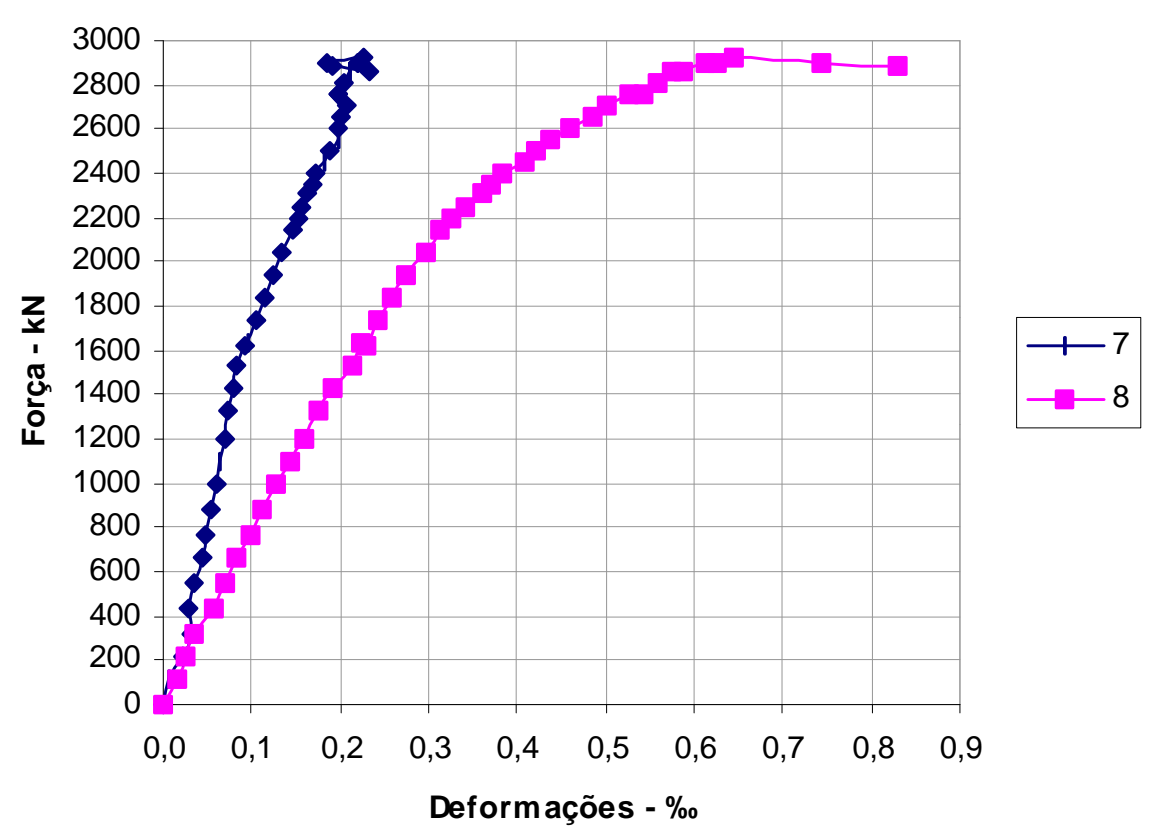

Diagrama força $x$ deformação na armadura transversal

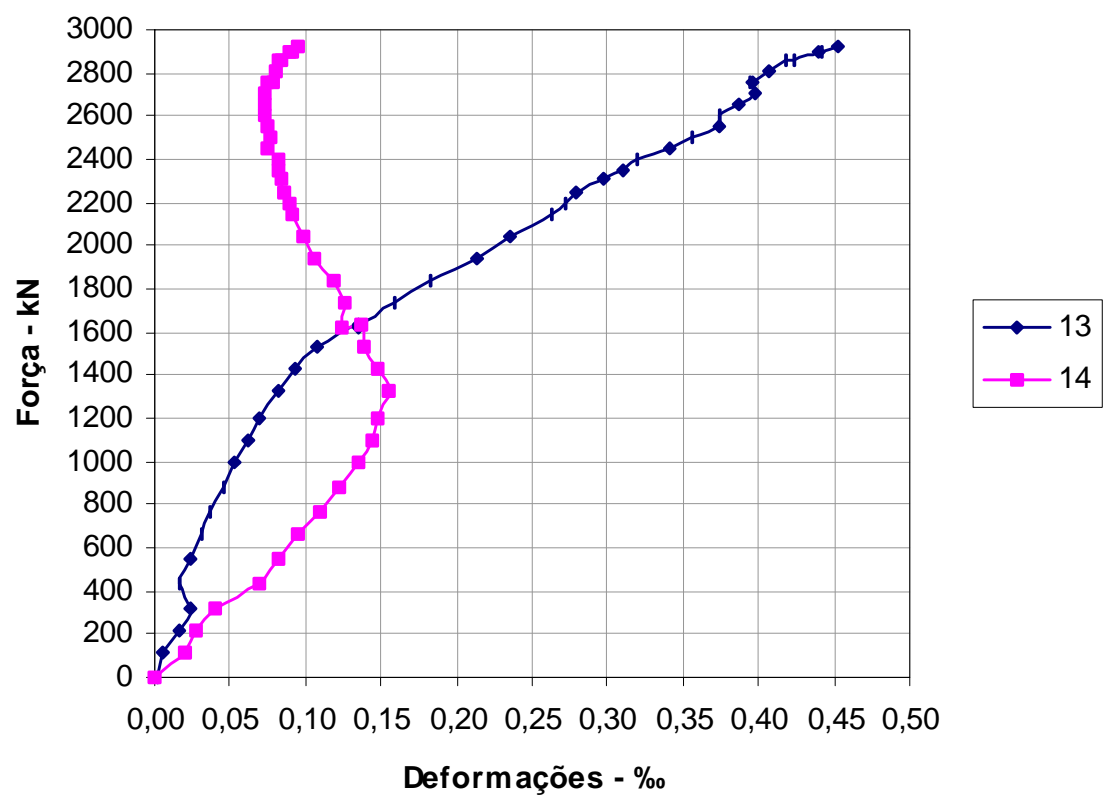

Diagrama força $x$ deformação transversal do concreto 


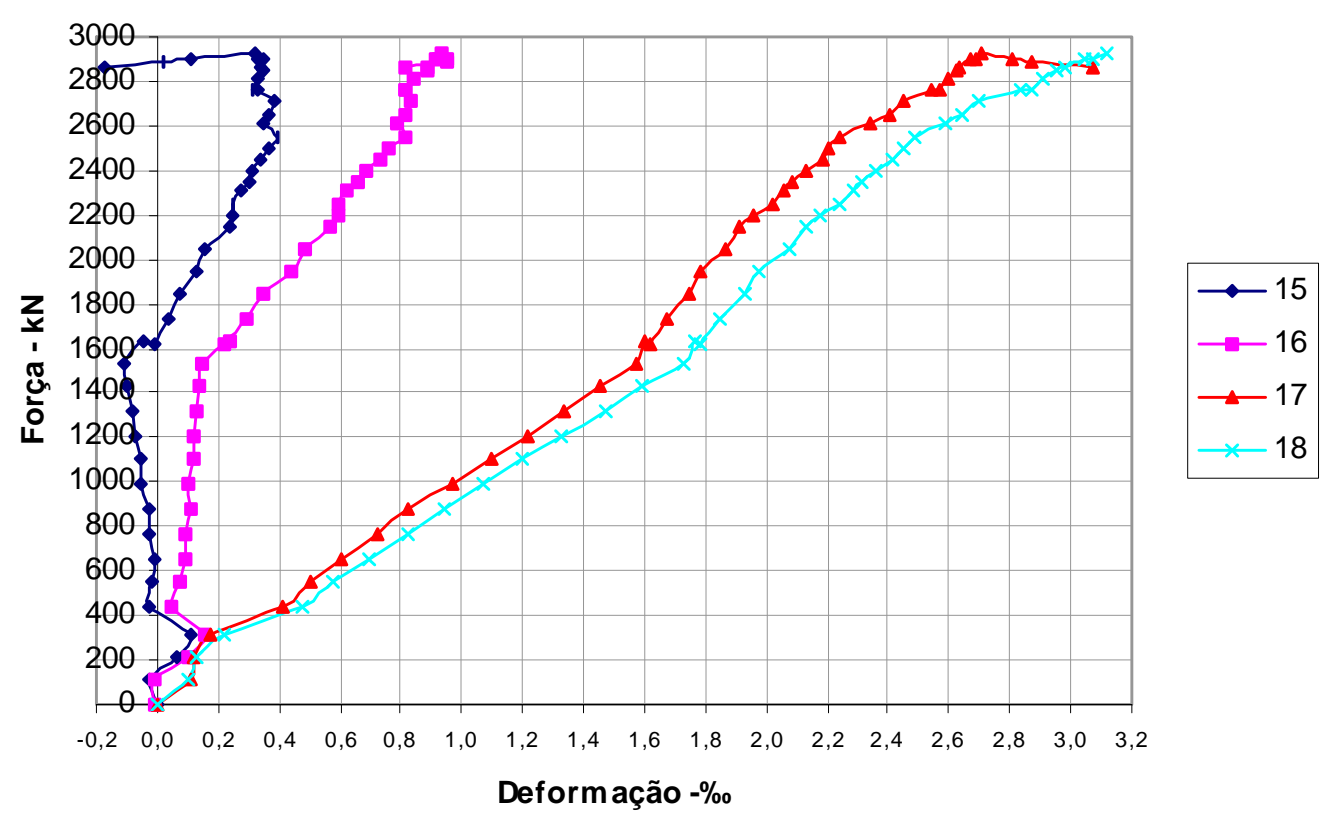

Diagrama força $\mathrm{x}$ deformação do pilar

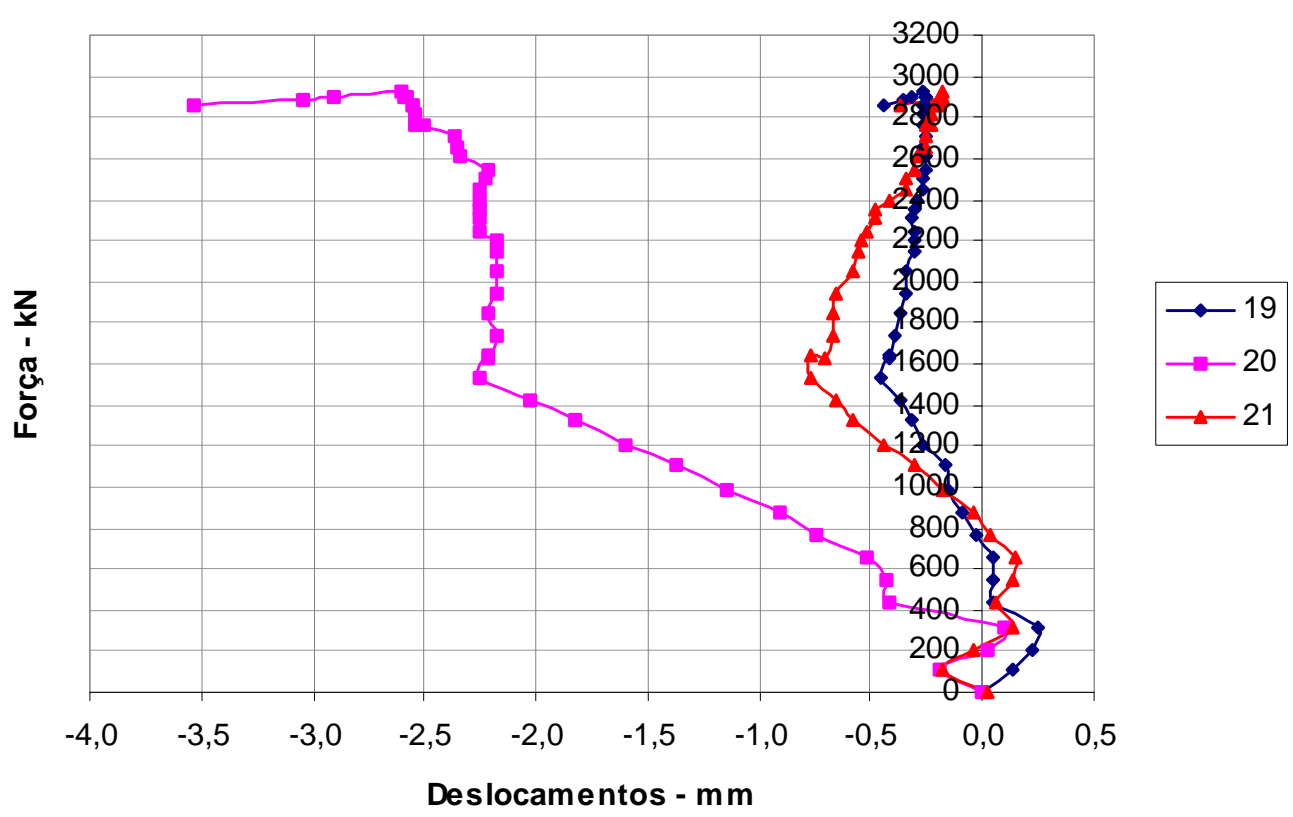

Diagrama força $\mathrm{x}$ deslocamentos do pilar 


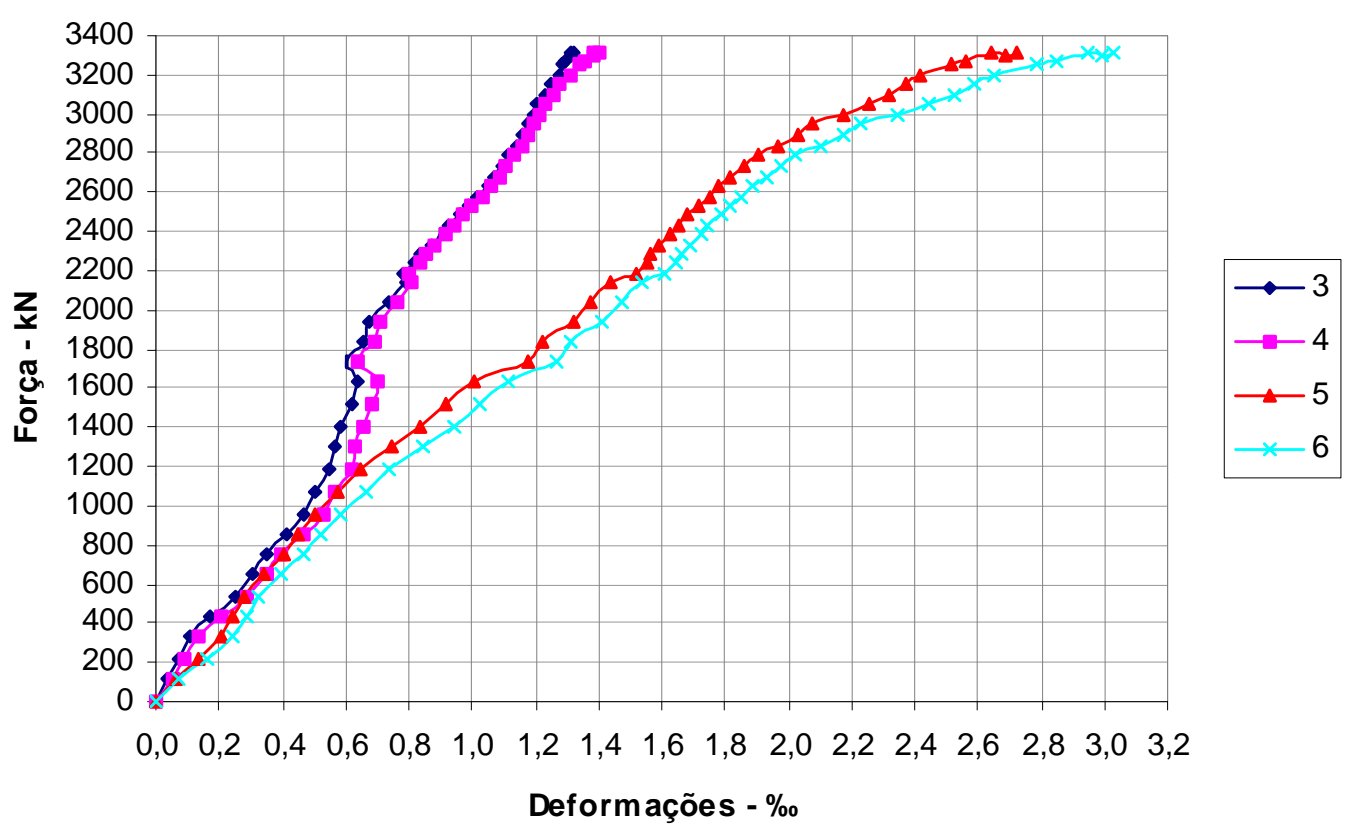

Diagrama força $x$ deformação da armadura longitudinal

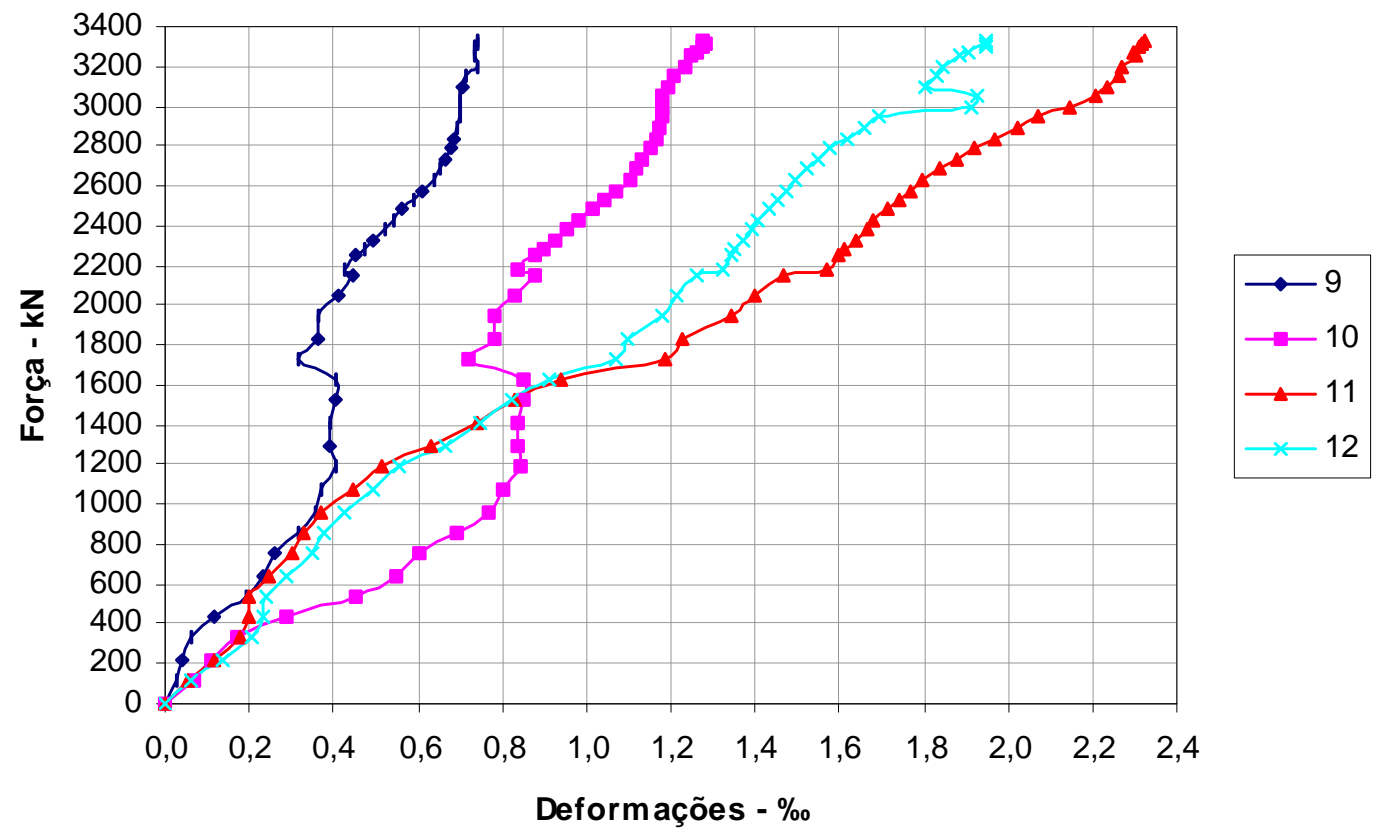

Diagrama força $x$ deformação longitudinal do concreto 


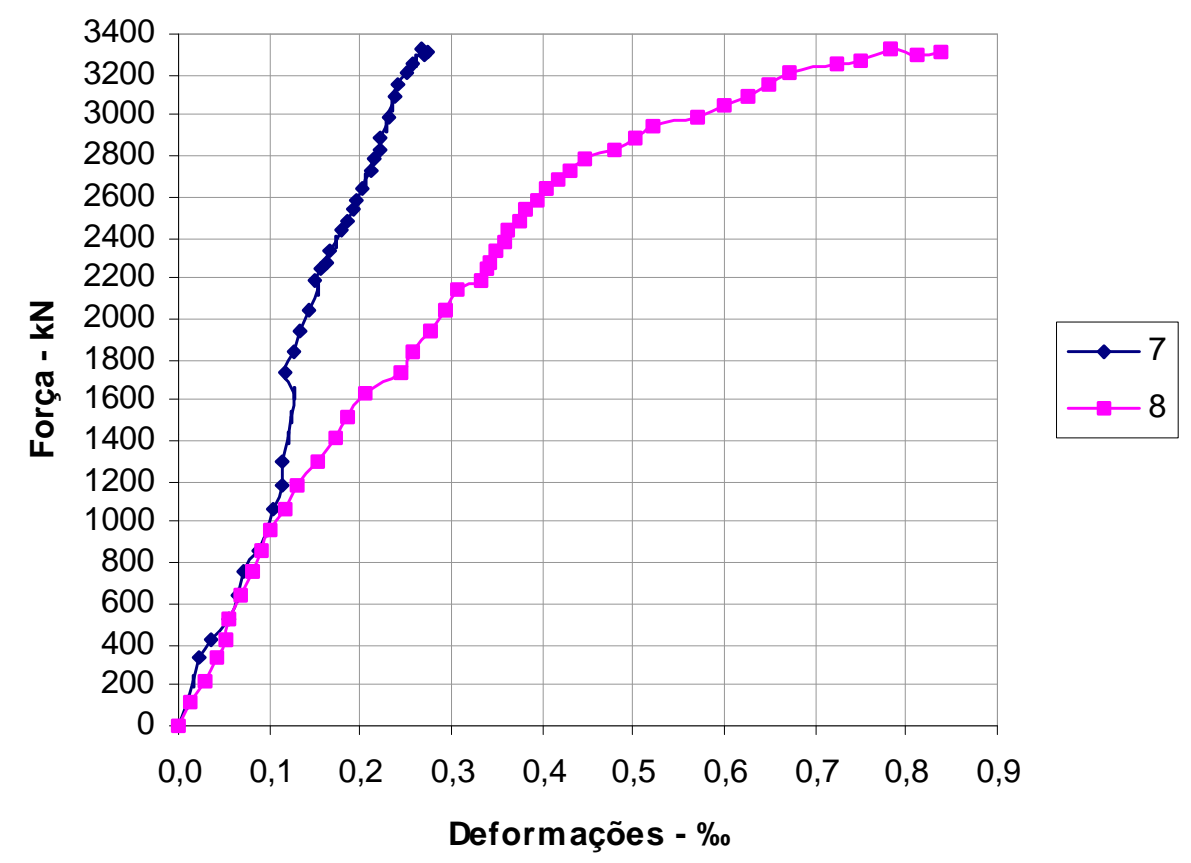

Diagrama força $x$ deformação na armadura transversal

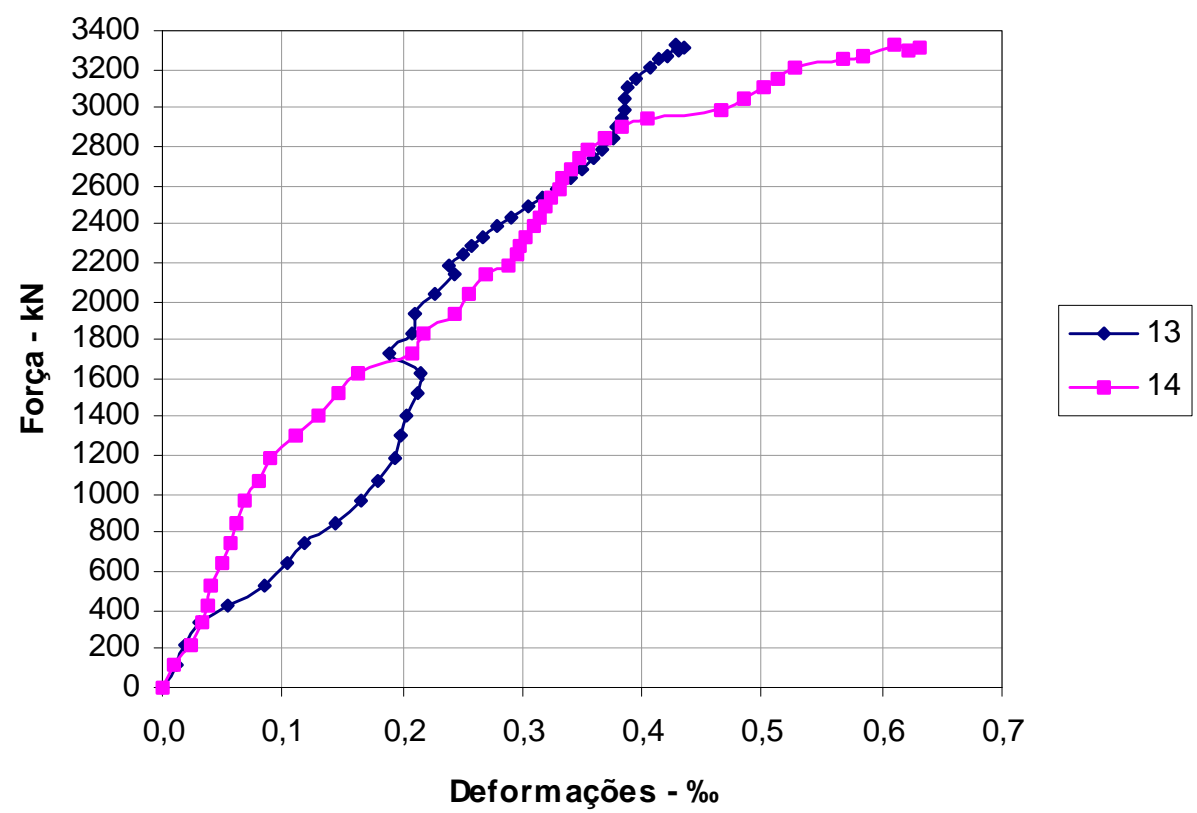

Diagrama força $x$ deformação transversal do concreto 


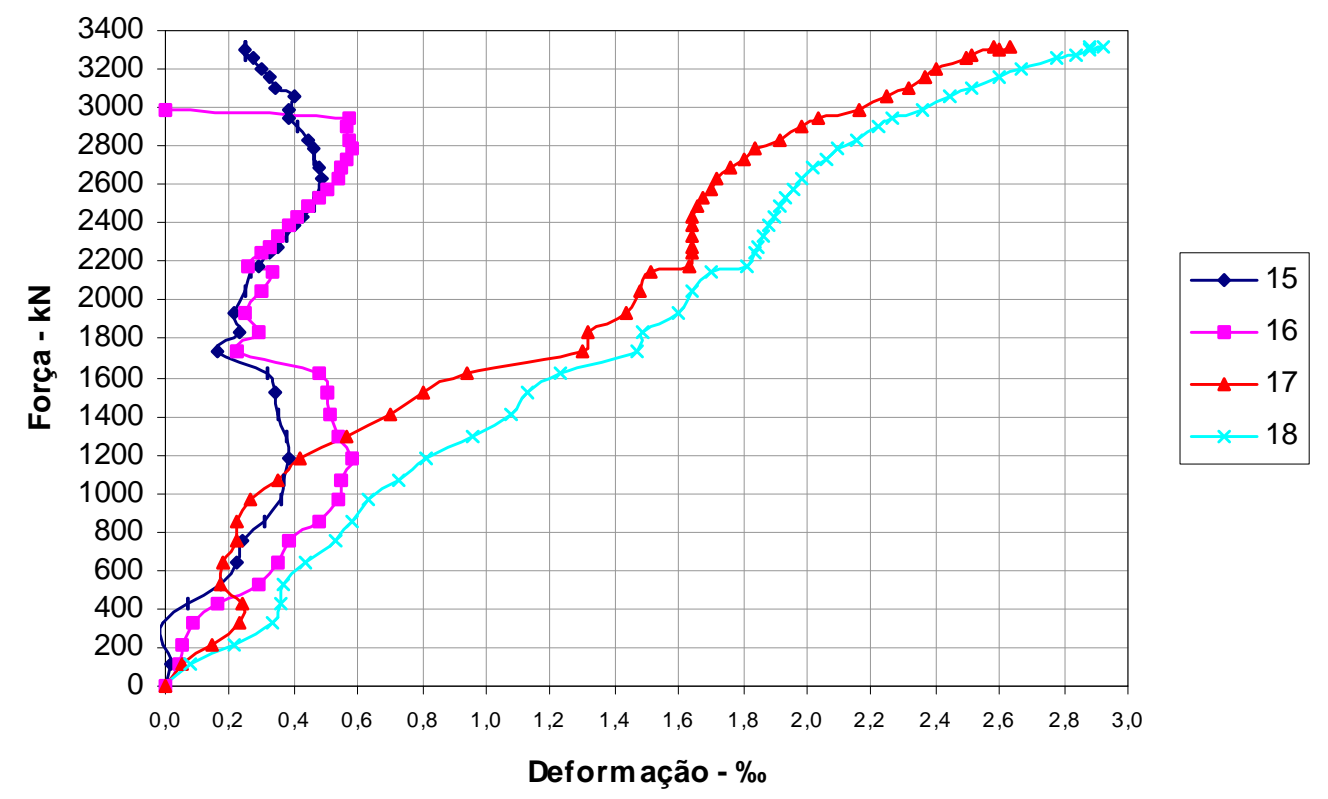

Diagrama força $\mathrm{x}$ deformação do pilar

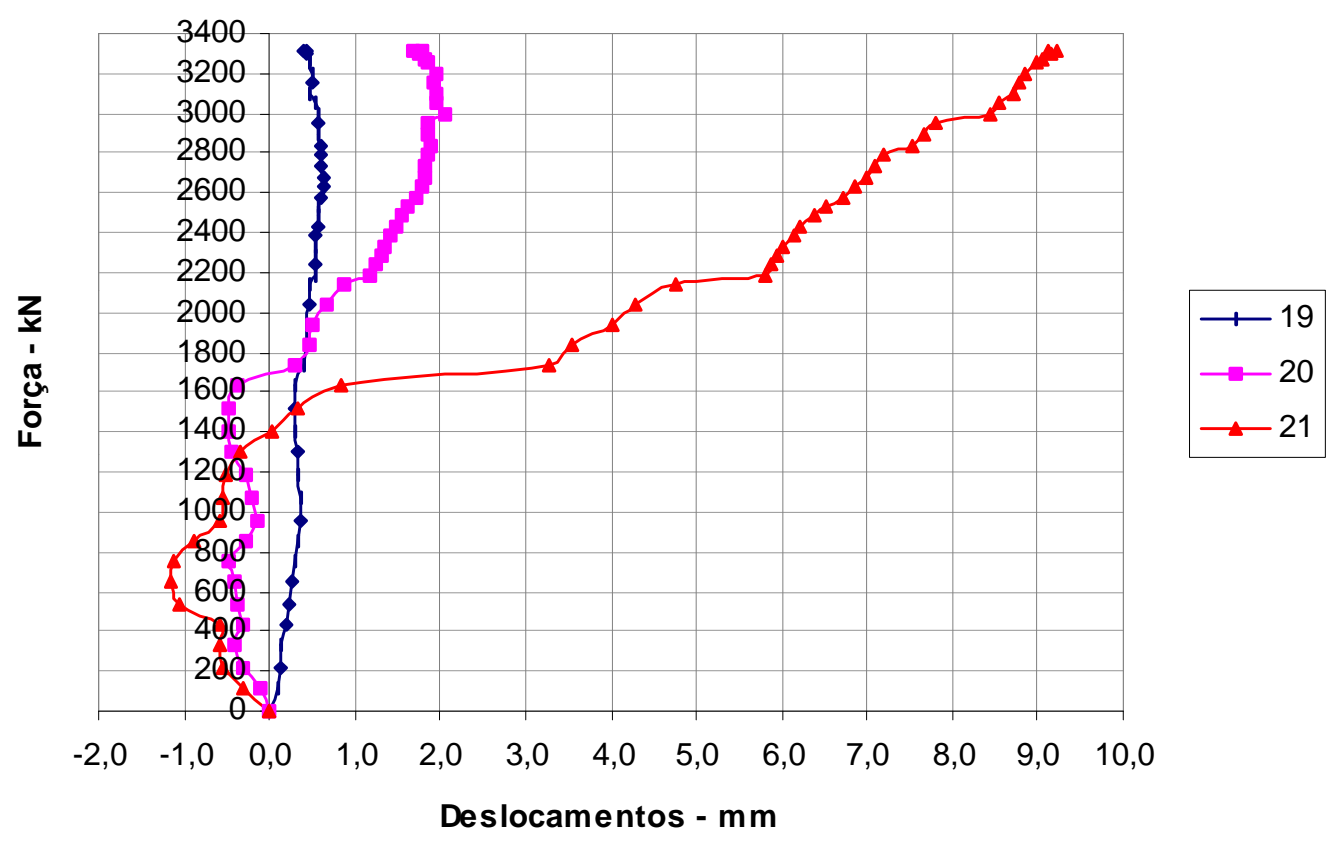

Diagrama força $\mathrm{x}$ deslocamentos do pilar 